\title{
Green politics in Latin American cities : sustainable transport agendas
}

Citation for published version (APA):

Cadena Gaitán, C. (2014). Green politics in Latin American cities : sustainable transport agendas.

[Doctoral Thesis, Maastricht University]. Maastricht University. https://doi.org/10.26481/dis.20141016cc

Document status and date:

Published: 01/01/2014

DOI:

$10.26481 /$ dis.20141016cc

Document Version:

Publisher's PDF, also known as Version of record

\section{Please check the document version of this publication:}

- A submitted manuscript is the version of the article upon submission and before peer-review. There can be important differences between the submitted version and the official published version of record.

People interested in the research are advised to contact the author for the final version of the publication, or visit the DOI to the publisher's website.

- The final author version and the galley proof are versions of the publication after peer review.

- The final published version features the final layout of the paper including the volume, issue and page numbers.

Link to publication

\footnotetext{
General rights rights.

- You may freely distribute the URL identifying the publication in the public portal. please follow below link for the End User Agreement:

www.umlib.nl/taverne-license

Take down policy

If you believe that this document breaches copyright please contact us at:

repository@maastrichtuniversity.nl

providing details and we will investigate your claim.
}

Copyright and moral rights for the publications made accessible in the public portal are retained by the authors and/or other copyright owners and it is a condition of accessing publications that users recognise and abide by the legal requirements associated with these

- Users may download and print one copy of any publication from the public portal for the purpose of private study or research.

- You may not further distribute the material or use it for any profit-making activity or commercial gain

If the publication is distributed under the terms of Article $25 \mathrm{fa}$ of the Dutch Copyright Act, indicated by the "Taverne" license above, 


\section{Green Politics in Latin American Cities}

Sustainable Transport Agendas

\section{DISSERTATION}

to obtain the degree of Doctor at

Maastricht University, on the authority of the Rector Magnificus Prof.

Dr. L. L. G. Soete

in accordance with the decision of the Board of Deans,

to be defended in public

on Thursday 16 October 2014, at $16.00 \mathrm{hrs}$

by

Carlos Cadena Gaitán 


\section{Promoter:}

Prof. Dr. Luc Soete

\section{Co-supervisors:}

Dr. María Josefina Figueroa. Copenhagen Business School, Copenhagen, Denmark

Dr. Juan Pablo Bocarejo. Faculty of Engineering, Universidad de los Andes, Bogotá, Colombia

\section{Assessment Committee:}

Prof. Dr. Graeme Evans (Chairperson)

Dr. Marie Thynell (School of Global Studies, University of Gothenburg)

Prof. Dr. Julio D Dávila (DPU Director, University College London)

Dr. Marc Dijk 


\section{Acknowledgments}

\section{The PhD Top-10}

Was it worth it? Would I embark on such a humongous and labyrinthine endeavour once again, if I had the chance? And, perhaps more importantly for you, dear reader: should you?

If I was to do it all over again, this is what I would do:

1. Before even thinking about my research question, I would select a city/village/metropolis where I feel certain that I could live a happy life, for at least four years.

- Maastricht (and The Netherlands), offered me a fantastic day-today living experience, which changed my perspectives about a number of ordinary activities. Totally recommended!

2. I would then explore the deepest depths of my creativity, for a way to provide my family, with an elevator summary of what it is that "doing a PhD" entails. If you do not do this, they will simply think you "do nothing, and just sit stoically in front of a computer for weeks in a row, without producing a single understandable output". They will worry; they will be baffled by the fact that you were always an outstanding student, and "now seem to be completely lost in life".

- Gracias madre por animarme a hacer el doctorado, y por apoyarme siempre que creí perder el impulso.

- Gracias Talla, Andrés, Yolanda, Alfonso, Lalis, Ciro, Héctor, Elvia, Martha Escobar, Carmenza por estar pendiente de mí durante estos años de aventuras académicas.

- Entrego para siempre este esfuerzo a mis adorados Danis y Pedris; espero que les sirva de inspiración para pedalear sin mirar hacia atrás.

- Ofrezco estos modestos esfuerzos a mis nuevos sobrinos: DaniRi, Alejo, Nico y Santi. ¡Que sea una bienvenida positiva para todos!

3. While starting the research project, I would first clearly define supervisors that I admire. If you do not admire them, you can feel free to assume that sooner or later during the $\mathrm{PhD}$ process, you will be tempted to "break-up". 
- Thanks Luc, for making each of our meetings valuable; thank you for helping in giving a structure to my spirited dreams.

- Thanks Mindel for pushing me hard when it was necessary; thank you for offering me your trust. It was a true pleasure sharing so many GPAC challenges (and accomplishments) with you.

- Gracias doctora Mariajo, gracias doctor Juan Pablo por tantas horas de correcciones; gracias por regalarme semejente paciencia sin límites.

4. When faced with the dilemma whether to go out for fieldwork, there is only one answer: do it! Since this might be one of the times, during which one would probably need much more "human help", than ever before, I would compose a solid list of local talents that can connect you with the right people; I would not be afraid to knock on the door of wellrenowned local figures, because at the end, most of them will actually help you.

- Gracias a David Escobar y José Fernando Ángel por abrirme las puertas de una Medellín, que en ese momento era inalcanzable para mí.

- Gracias a Sergio Restrepo, Felipe Targa, Javier Ramírez, Rafael Nanclares, Javier Castañeda, Sergio Bustamante, Jorge Pérez Jaramillo, Alejandro González, Diego Reyes, Carlos Andrés Pérez y Juan Pablo Ospina por aceptar responder todas y cada una de mis preguntas (por correo, celular, twitter y en persona), así fueran redundantes y a veces -lo admito- hasta molestas.

- Agradezco también el tiempo y la energía de David y Pati, Alfredo Hidalgo, Ale Costa Nascimento, Iván de la Lanza, Ariel Kogan, Jesús Acero, Lina López, Alexander Nizhelski, Tomás Molina y demás "bicicletos" de Medellín.

5. Anticipating the intermittent academic embitterment, so unique of the $\mathrm{PhD}$ adventure, I would make a good effort to consolidate a solid support group that will keep you going.

- Gracias Franco, gracias Howard for permanently being willing to share an honest drink with me; thanks for making me feel confident that I can always trust you. I also appreciate the fact that you read the first draft of this dissertation to provide valuable feedback.

- Thanks to all those friends who were 'forced' to hear my thoughts about the seemingly eternal process of composing a PhD dissertation: Lisa, Jennifer, Jose Sánchez, Josy, Irina, Karla, 
Guney, Luciana, Sonja, Katie, Ozge, Renée, Omar, Ale, Nordine, Hasse, Eduardo, Ayo, Raquel, Clovis, Daniel, Rafa, Corinne, Derek, Silvia, Camilo, Richard, Bernard, Shuan, Eze, Camillo, Yulia, Laura Torvinen, Paula, Julieta y Agus, Saba, and many more kind souls.

- Thanks Susan, Eveline, Janneke, Danny, Ad, Herman, Mieke, Eric, Wilma, Marc, for teching me how to break the bureaucratic obstacles sprouting invariably in my way.

- Thanks Eddy, Chris, Franziska, Lutz, Theo, Sebas Dellepiane, Joe, Kati Kriz, Carlos Pardo for offering bright ideas at the right times.

6. Similarly, in order to convince oneself that this puzzle might actually have a solution (somewhere), I would not loose track of those friends who have gone through the same process, and who have already succeeded.

- Thanks Victor, Denisa, Metka, Lila, Treena, Maha, Zina, Henry, Diego Escobar, Luis Bernardo Mejía for your valuable example.

7. Since all the books, articles and papers that you will consume might entice you to generate pragmatic actions targeted at real changes, I would plant and organically fertilize a network of friends, who trust that 'crazy' ideas are the only avenue towards great ideas.

- Gracias a mis amigos de locuras urbanas: Kathy, Julia, Sara, Laura A, Laura B, Laura F, Jime, Maira, Hélène, Juli, JuanMa, Richard, Luis, Santi O, Santi M, Juanpa, Jose, David, JuanS, Florian, y muchos más, por ayudarme a creer que no somos los únicos loquitos.

8. In order to write a $\mathrm{PhD}$, you might need a computer. If you are lucky enough to get an office, I would make sure this place allows for minimizing all possible distractions as much as possible. In the smartphone era, accomplishing this depends directly on having good office mates.

- My office mates were spectacular: Giorgio, François, Samy, Andrés, igracias!

9. At times, one would think humans need distractions away from books and computers. If I was to do this all over again, I would find interesting friends somewhere away from the host city/village/metropolis, so that I can 'disconnect' for a tiny bit.

- Merci Ghita et Jacques; merci Yves et Ghislain pour l'énergie positive, la bonne nourriture et les vins délicieux que nous avons partagé. 
- Gracias Montoya, Vallenatólogo, Vallenatero por abrirme las puertas del sabor.

- Gracias Juanpa Barrientos y Gabo por ofrecerme los mejores ejemplos positivos de gente que ama lo que hace, y que por tanto es capaz de hacerlo mucho mejor que los demás.

- Thanks Lau, Andi, Jais, Rolf, Hans K for supporting my best European extracurricular activities during these 5 years.

10. If I were to do a $\mathrm{PhD}$ all over again, I would focus on finding people whose lifestyle I want to replicate; whose accomplishments I admire. People who have the gift of offering happiness with their smiles, and honest mindfulness with their words.

- Gracias a mi Taz, a Tarzán y a Laurens por inspirarme a perseguir felicidad, y sobretodo, por haberme regalado el perfecto complemento para mis locuras, durante estos años de doctorado.

So, with no further ado, allow me to answer the question: yes! I would do it again, and you should too ;) 


\section{Table of Contents}

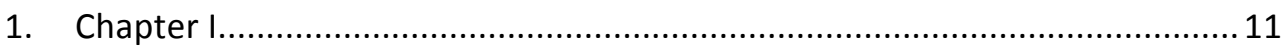

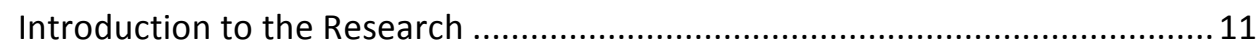

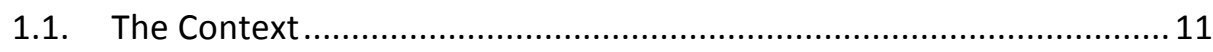

1.2. The Problem Tackled................................................................... 12

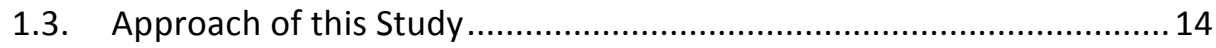

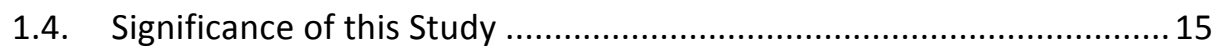

1.5. Structure of this Dissertation ........................................................ 16

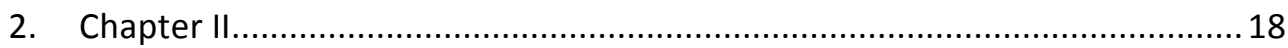

Literature Review and Theoretical Context............................................... 18

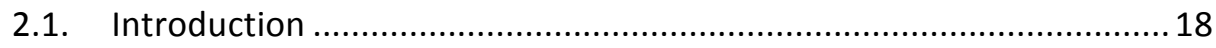

2.2. Cities Matter ................................................................. 18

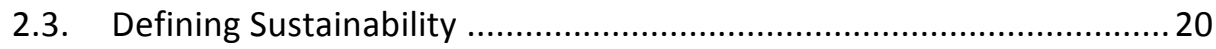

2.4. Structural Conditions frame Urban Sustainability............................. 23

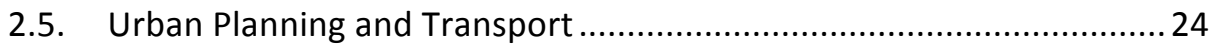

2.6. The Changes in Urban Transport Paradigms ..................................... 26

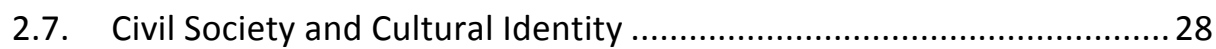

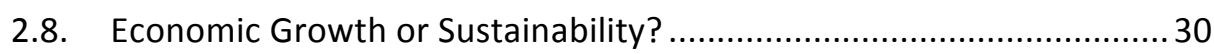

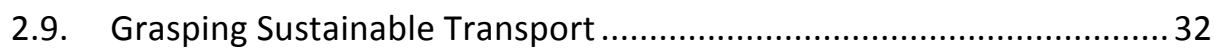

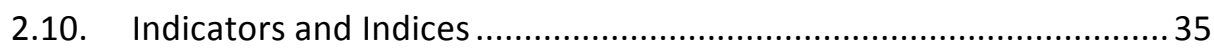

2.11. Governance in Metropolitan Areas ....................................... 38

2.12. Institutionalism in the Urban Context .................................... 46

2.13. The Case for Latin America ....................................................... 49

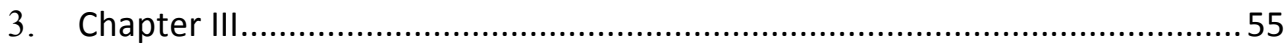

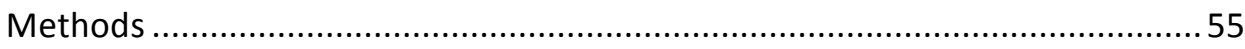




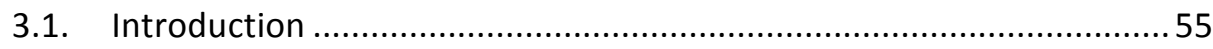

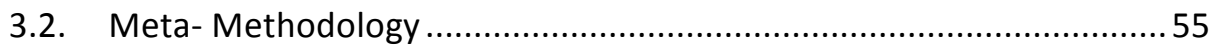

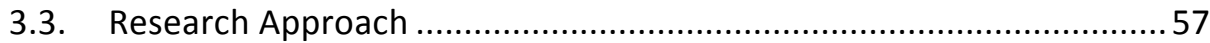

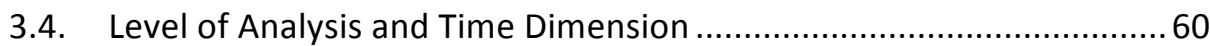

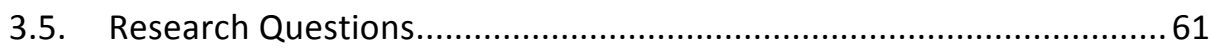

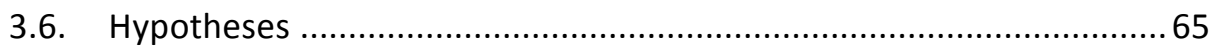

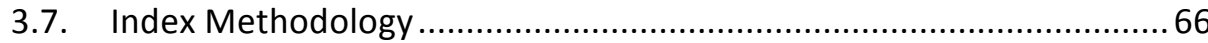

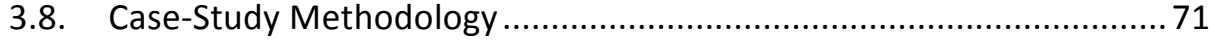

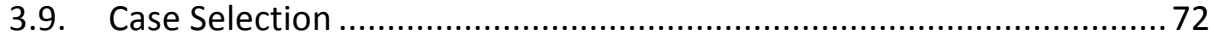

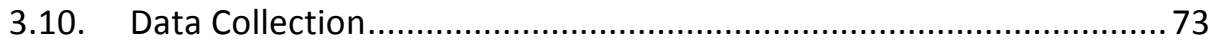

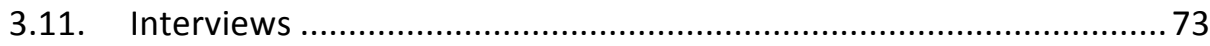

3.12. Data Coding and Analysis.............................................................

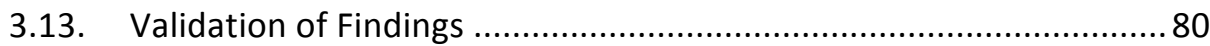

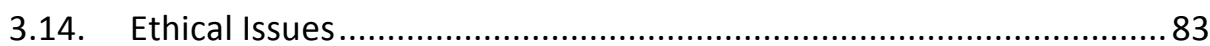

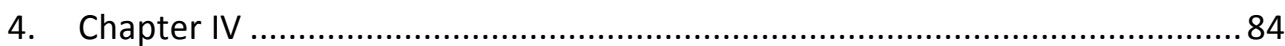

Patterns of Transport Sustainability in Latin American Cities .......................... 84

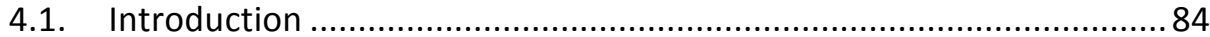

4.2. Urban Transport in Latin America Today ............................................. 85

4.3. Representation of Dependent and Explanatory Variables....................88

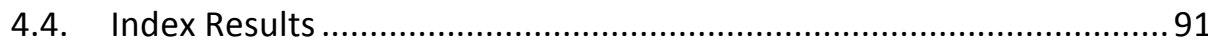

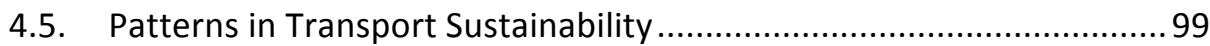

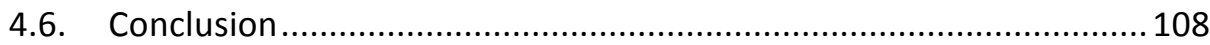

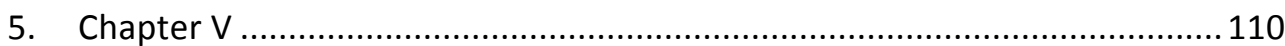

Political Complexities of Transport Sustainability in Latin America ................. 110

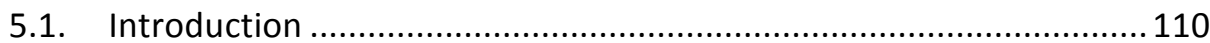

5.2. Representation of Dependent and Explanatory Variables..................110

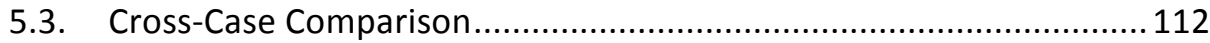


5.4. Transport Sustainability Trends

5.5. Political and Institutional Complexities................................... 114

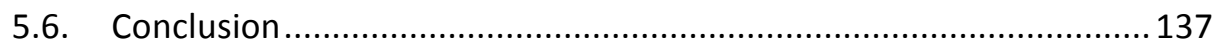

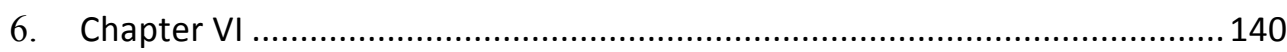

Determinants of Transport Sustainability in Curitiba, Guadalajara and Medellín

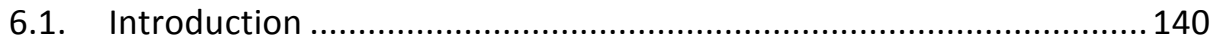

6.2. Representation of Dependent and Explanatory Variables................. 140

6.3. Cross-Case Comparison.......................................................... 143

6.4. Central Themes for Hypothesis 1 .............................................. 143

6.5. Central Theme for Hypothesis 2 - Metropolitan Coordination .......... 163

6.6. Central Theme for Hypothesis 3 - Previous Decisions ...................... 171

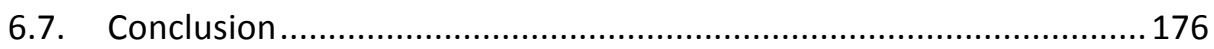

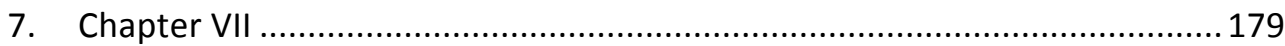

A Convergence to Transport Sustainability in Latin American Cities................ 179

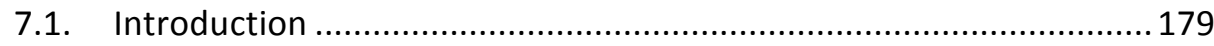

7.2. Representation of Dependent and Explanatory Variables.................179

7.3. Cross-Case Comparison........................................................ 181

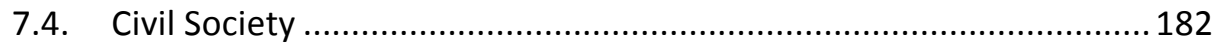

7.5. Corporate Interests ............................................................. 186

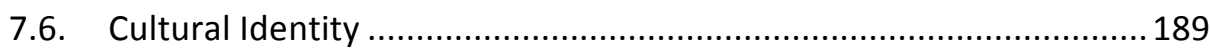

7.7. Overall Relationship between Transport Sustainability Levels and its

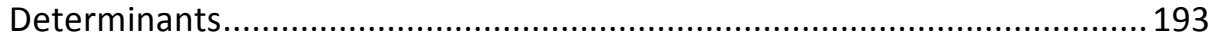

7.8. Theoretical Compilation .......................................................... 198

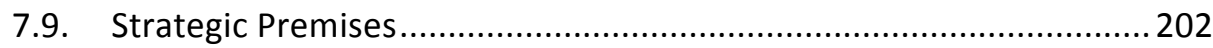

7.10. A Convergence for Transport Sustainability ...............................204

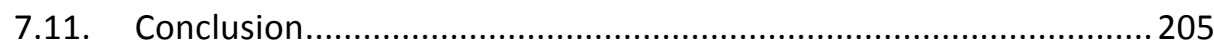

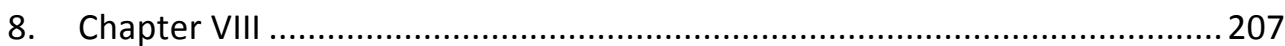


8.1. Background and Motivation for the Research ..................................207

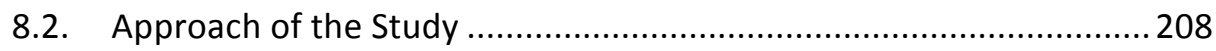

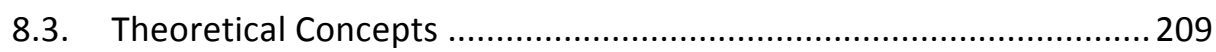

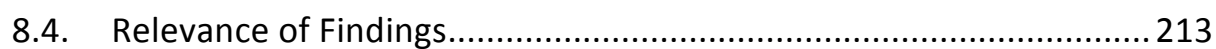

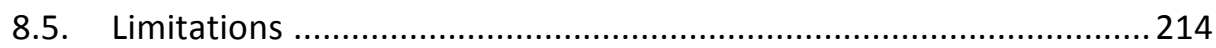

8.6. Opportunities for Further Research ............................................... 215

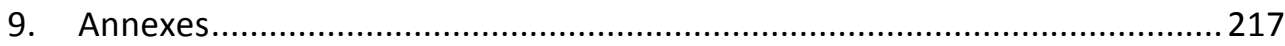

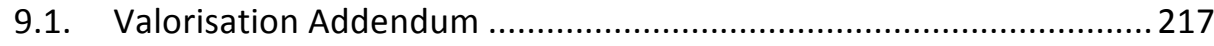

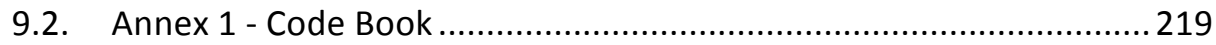

9.3. Annex 2 - Full list of key informants interviewed.................................225

9.4. Annex 3 - Example of coded interview...............................................231

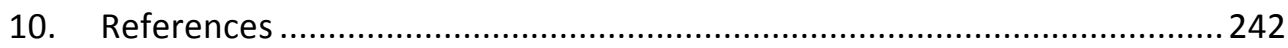

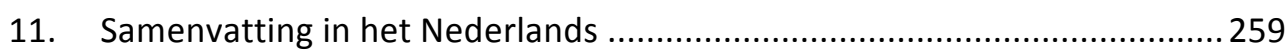

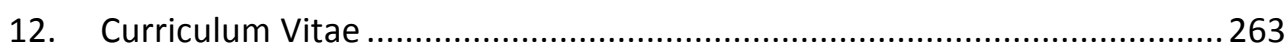

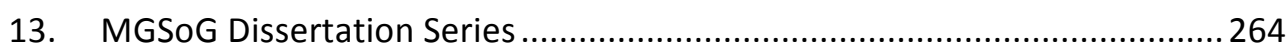




\section{Chapter I}

\section{Introduction to the Research}

"This is the dichotomy of the city: its potential to brutalize, and its potential to civilize" - Richard Rogers

\subsection{The Context}

This is a study about cities, their transport systems, and the politics behind these structures. More specifically, this dissertation is concerned with Latin American cities ${ }^{1}$, urban transport -analyzed from a sustainability perspective-, and metropolitan governance. This research contributes with a unique in-depth analysis of the transport sustainability context for Curitiba, Guadalajara, and Medellín.

The urban population in our world is growing rapidly. The rate of urban demographic growth in some developing world regions also takes place in an often chaotic and disorderly way. In fact, a vast proportion of this urban growth is concentrated in informal settlements characterized by precarious living conditions and difficult accessibility to employment opportunities; hence, posing immense challenges to local, regional and national governments. According to the United Nations Population Fund, the world is undergoing the largest wave of urban growth in history (UNFPA 2007), and calls for urgent actions to be taken in guaranteeing more sustainable rates of urbanization. For example, in the last sixty years, between 1951 and 2011, the global urban population enlarged almost five times (UNHABITAT 2011), sparking worries about the capacity of our cities to plan accordingly, so as to assimilate these new urban dwellers and allow for their increased well-being.

Urbanization and the agglomeration of populations in central places create economies of scale (Henderson 2003; Nakamura 1985; Moomaw 1988). People may access resources easier, produce cheaper goods, and trade more effectively. Similarly, they can actively participate in societal life, exercise their political rights and duties, and share similar urban spaces with others.

${ }^{1}$ All mentions of the word city actually refer to the full metropolitan area of that city (unless otherwise noted explicitly). 
Urbanization has the power to re-position cities as the "fundamental places where social and political life takes place, knowledge is created and shared, and various forms of creativity and art are developed" (UNHABITAT 2010, pg. 3).

The exponential growth of urban populations is being accompanied by unprecedented destruction of urban ecosystems and an indiscriminate use of finite natural resources, resulting in manifest environmental catastrophes in urban areas. With $50 \%$ of the world's population already living in cities, these not only generate the majority of global greenhouse gases, but also use over two-thirds of the world's energy; an estimated 7,900 Million tons of oil equivalent (mtoe) in 2006 (KPMG, 2010). By 2030, according to the International Energy Agency (OECD/IEA 2008), cities will account for $87 \%$ of the energy consumption in the United States, $75 \%$ in Western Europe, and $80 \%$ in Australia and New Zealand. However, the largest increase in energy use is expected in cities in developing countries, where the fastest urban growth is expected.

Similarly, it has been forecasted that by 2030 all developing regions, including Asia and Africa, will have more people living in urban than rural areas (UNHABITAT 2010). Latin America is according to the United Nations Population Division, the most urbanized region in the developing world, with $81 \%$ of its population living in cities and, it is expected that this figure will rise further by 2030 reaching $86 \%$, on a par with Western Europe (Economist Intelligence Unit 2010). If the population of the South doubles from 2 to 4 billion people by 2030, this means we would need to find resources, finance, and provide adequate habitable land equivalent each year, to 5 cities of an equivalent size to that of Mexico City, with its twenty million inhabitants in 2010.

\subsection{The Problem Tackled}

One specific area to tackle when studying urban sustainability concerns transport systems. These, not only are inherently tied to the urban levels of environmental pollution and congestion, but also deal with the vital structure that allows citizens to mobilize, and thus, fulfill their social and economic needs. 
Car dependency is one of the key phenomena to consider. It implies that cities where cars are the predominant transport mode, deny their citizens freedom of choice about the way they live and move around the city, generating a cultural trait, which Newman \& Kenworthy (1989) have described as a sort of addiction to cars. Unfortunately, this car-dependency generates serious social, environmental and economic damages. A vast number of studies show that transportation currently consumes more than half of global liquid fossil fuels; consumes between $20 \%$ and $50 \%$ of total urban energy consumption; emits nearly a quarter of the world's energy related $\mathrm{CO} 2$; and generates more than 80 per cent of the air pollution in cities in developing countries (UNEP 2011; ITDP \& Gehl Architects 2010; B. Lefèvre 2010).

These conditions have generated "a growing consensus on the need for more sustainable patterns of transport" (UNEP 2011, p.380). Sustainable transport refers to an urban system that supports (1) environmental sustainability through the protection of the global climate, ecosystems, public health and natural resources; (2) economic sustainability through an affordable, fair and efficient transport that promotes a sustainable competitive economy as well as balanced regional development and the creation of decent jobs, and; (3) social sustainability by allowing the basic access and development needs of individuals, companies and society to be met safely and in a manner consistent with human and ecosystem health, while promoting poverty reduction and equity within and between successive generations (UNEP 2011).

Transport not only empowers citizens to have access to jobs, education, and entertainment, but it is now conspicuous that adequate urban mobility systems are a prerequisite for cities to become more sustainable. Since urban transport systems can be plagued with negative externalities (i.e. environmental pollution, congestion, high mortality rates, social exclusion), it is often the case that the urban poor end up being deprived from certain economic and social benefits of urban mobility such as equal access to employment and housing opportunities, and in general the fundamental right to the city (UNHABITAT 2010). 


\subsection{Approach of this Study}

The core objective of the research is to identify the institutional and political factors that determine variations in transport sustainability outcomes across metropolitan areas in Latin America. The project is guided by this research question:

Under which political and institutional conditions is sustainability of urban transport facilitated in Latin American metropolitan areas?

Under this context, the dependent variable is represented by the "Sustainability of urban transport", as defined by the UNEP (2011). This variable is operationalized via the index composed in Chapter IV, and maintains three separate dimensions of sustainability: environmental, economic, and social.

The approach of this study is composed of a two-tiered research analysis consisting of an initial empirical characterization of the urban transport systems in sixteen Latin American cities, and a comparative case-study analysis for three key cities. The initial characterization takes the form of a Green Transport Index and is used for selecting the cases in the second phase of the research, where limited generalizations about role of political and institutional conditions on transport sustainability, are generated. The study is designed so that both tiers complement each other.

The study has an inductive nature. Possible explanatory variables are solely proposed as tools to frame the themes in which the cross-case comparisons will focus. Similarly, I acquiesce that while making use of this study design, some hypotheses will arise during the research process, as such, no initial hypotheses are offered, but instead three guiding assumptions are presented:

\section{Political conditions and financial conditions are crucial for increasing levels of urban transport sustainability. 2. Well defined and sustained intergovernmental arrangements for transport policy and planning in Latin American cities could influence transport sustainability at the metropolitan scale.}


This dissertation exhibits an explanatory nature rooted in an evidence-based research approach. Both the index and the case study results prove to be highly policy relevant for actors in the region. With the former, I aim at establishing a recurring exercise, ultimately serving as a benchmark, and concomitantly providing incentives for political actors in the region to pursue more sustainable transport policies. With the latter, I contribute in identifying crosscutting conditions affecting the levels of transport sustainability in the studied cities.

\subsection{Significance of this Study}

The past two decades have seen a significant upsurge in discussions about what sustainable transport implies. Today, we have sufficient academic agreement about the specific goals and policies necessary for transitioning into the low carbon, clean and safe mobility systems, that are vital for sustainable development in developing countries (Figueroa et al. 2013). However, the actual advances on the ground continue to be modest; especially for developing world cities.

Seemingly, the disconnection between theory and practice can be partly explained by the role of politics. In Latin America, for instance, policymaking is often marked by a disconnection between political rhetoric and policy action; leading to notable plans and proposals that frequently do not materialize (IADB 2006). Furthermore, in most Latin American cities, government functions across multiple geographical scales. Even though certain planning issues require coordination at the metropolitan scale, the actual result is a direct consequence of the traditional political dynamics of the region. Instead of optimizing coordination channels, for producing and implementing public policies, the interlocking connection, coordination, and aggregation of public action at the metropolitan level are chaotic, fragmented, dispersed, contradictory, and frequently redundant (Paiva 2003).

Moving towards sustainability requires solid urban governance. Apart from the obvious need for appropriate technology and funds, it is precisely sound 
governance, correct planning, and strong implementation capabilities that become crucial in attaining urban sustainability (UN-HABITAT 2002). This dissertation focuses on governance at a metropolitan scale and the contributions that governance towards higher transport sustainability can achieve; referring specifically to the patterns of rule and public service delivery within the geographical boundaries of a full metropolitan area.

These trends pose worrying prospects to the urban sustainability of Latin America, as the region struggles with additional challenges in terms of poverty, public finances, and violence, amongst others. According to UNHABITAT (2012), the cities in Latin America and the Caribbean are the most unequal cities in the world. Moreover, through its Emerging and Sustainable Cities Initiative, the IADB (2012) regards that even after the broad wave of decentralization during the 1990s, most cities in the region have limited fiscal space to accommodate necessary investments in sustainability. Likewise, the UNDP (2013), claims that "most countries in the region have homicide rates which are much higher than for other regions and which are considered to be at epidemic levels by the World Health Organization" (UNDP 2013, p.III).

Hence, I have chosen to concentrate my research efforts in this region, intending to generate a debate about needed government action, in a sector and region, not commonly included in global scenario studies. This study, thus, intends to produce a highly policy relevant output.

\subsection{Structure of this Dissertation}

Chapter two presents the theoretical framework for this dissertation. It reviews current developments in regards to urban sustainability, sustainable transport and metropolitan governance. It highlights critical perspectives and previous contributions to the connections between metropolitan governance and transport sustainability, with a particular focus to Latin America, and the social and cultural contexts of some key cities.

Chapter three presents the detail of the research design and describes the way in which the combination of quantitative and qualitative methods were selected and used in this dissertation. The Green Transport Index is used to quantitatively measure how each city is currently performing (both in terms of quantity and quality). Furthermore, a qualitative approach composed by a case study informed by key expert interviews composes the backbone of the 
project. The remaining chapters follow the methodological conditions described in this chapter.

Chapter four examines the findings of the Green Transport Index, and discusses patterns within the broad trends towards sustainability in transport systems of selected Latin American cities. The current section constructs the key operationalization for the dependent variable: sustainability of urban transport. This depiction is also used as the base for comparing and contrasting the levels of engagement of each city with the principles of sustainability in transport.

Chapter five maps the key themes framing transport sustainability, resulting from the cross-case comparison in the selected cities. The influence of the identified themes is explained in the context of each city's conditions, as drawn from the interview data, which later allows for the exploration of specific variables drawn from the initial assumptions.

Chapter six discusses the determinants to the variation in transport sustainability outcomes for the selected set of cities. The analysis is based on the gathered data and supported by the concepts derived from the governance and sustainability discourses, which have guided the organization and classification of the data.

Chapter seven probes the influence of various factors not originally included in the guiding assumptions of this research, yet, often cited by key informants. The extent to which these factors affect the conclusions from the previous chapter, is used as a final input for the conclusions of the research.

Chapter eight provides a discussion of the lessons learned, the contribution and limitations of this research, and is followed by a list of references and the annex. 


\section{Chapter II}

\section{Literature Review and Theoretical Context}

"The difficulty lies not so much in developing new ideas as in escaping from the old ones" -John Maynard Keynes.

\subsection{Introduction}

This chapter comprises a review of current developments in regards to urban sustainability, sustainable transport and metropolitan governance, which sets the framework for this dissertation. The initial section presents evidence of the contemporary urban challenges, and the rationale for sustainable transport as a major theme in the literature. This is followed by a discussion of what metropolitan governance entails, including a review of the key concepts used in the literature. Thirdly, the institutional background of the study is highlighted, in the perspective of the various strands of the theory. Finally, the concluding section focuses the study in the context of the Latin American region, pointing out the main theoretical assumptions on which the study is constructed.

\subsection{Cities Matter}

This century has seen the consolidation of a global network of cities in becoming the primary scenario for crucial human interaction. Some cities have become such crucial nodes in the global economic system, that they have become part of their own scale; as 'global cities' (Sassen 2001). Global cities compete directly with each other to attract financial and scientific activity, while 'second' 2 and 'third' cities shift their focus away from their nation, to compete globally.

Cities - like organisms - need vast resources to survive, generating dependencies to providers, and waste in different forms and quantities. Although 'primate cities' continue to exhibit unique characteristics, second

2 For an insight into characteristics of a 'second-city', see: (Newton 1976). 
cities are growing rapidly, to the point that new unforeseen challenges arise. In explaining the concept of 'primate city, Jefferson (1989), reminds us that:

"Once a city is larger than any other in its country, this mere fact gives it an impetus to grow that cannot affect any other city, and it draws away from all of them in character as well as in size. It is the best market for all exceptional products. It becomes the primate city". (Jefferson 1989, p.227)

Notwithstanding the differences in population, both primate, and large second cities all over the world are facing similar challenges. These 'urban organisms' have grown into vastly complex structures, which trace their current situation to a chain of decisions previously taken by numerous actors; as such, the implementation of sustainability reaches its highest weight and success, precisely at the city-level. Nevertheless, contemporary cities suffer from "the somewhat arbitrary political units that typically define urban areas" (Zegras 2005a, p.20). One can rarely know where the exact limits of cities are, as these legal boundaries rarely match the actual geographical limits. For the purpose of this research, urban areas are described according to the guidelines set forth by the United Nations Department of Economic and Social Affairs: "because of national differences in the characteristics that distinguish urban from rural areas, the distinction between the urban and the rural population is not yet amenable to a single definition that would be applicable to all countries" (UNDESA 2013). While traditional definitions for urban areas in the developing world are built around the concepts of ways of life and standards of living, in the industrialized world, this distinction has become blurred, and substituted by an issue of degree of concentration of population (UNDESA 2013).

Moreover, in studying sustainability, it is crucial to note that ecosystems hardly ever match administrative entities of government (Gustavson et al. 1999), and as such, data collection, analysis, and policy implementation are negatively affected. However, this thesis aims at grasping the best possible representation of metropolitan areas in Latin America, aiming to reflect the actual realities for the full context of these cities. 


\subsection{Defining Sustainability}

An issue of great concern when studying urban sustainability deals with its definition. Although there is no consensus on how to define sustainability (Alberti 1996; Litman 2013; Joumard \& Gudmundsson 2010), its modern theoretical origins can be traced back to the United Nations Brundtland report. Sustainable development was introduced as a concept then, and defined as "development that meets the needs of the present without compromising the ability of future generations to meet their own needs" (WCED 1987; p. 5).

However, there is active discussion concerning the previous moments during which 'sustainable development' and 'sustainability' had been used. The environmental movement of the 1970's delivered a crucial event with the UN Conference on the Human Environment in Stockholm (1972), whose final declaration although not having included explicitly the term "sustainability" did include several provisions that many now consider to be crucial within sustainability ${ }^{3}$. That same year saw the publication of a key report to the Club of Rome, by Meadows et al. (1972), and perhaps more crucially, twenty years later, the 1992 Conference on Environment and Development in Rio de Janeiro marked the inauguration of the official global movement around the concept of 'sustainability'.

Thus, sustainability can be defined in a number of ways, while framed under the idea of sustainable development. Richard Rogers summarizes sustainability proficiently, by arguing that the core of this concept is "the redefining of wealth to include natural capital: clean air, fresh water, an effective ozone layer, a clean sea, fertile land, and the abundant diversity of species $[\ldots]$. The ultimate aim of sustainable economic development, is to leave to future generations a stock of natural capital that equals or ideally exceeds our own inheritance" (Rogers 1997, p.5). Other more operational definitions have been proposed, such as that by Neumayer (2003), which is

3 Selected principles from the Stockholm Declaration (1972) include for example: (1) Natural resources must be safeguarded; (2) The Earth's capacity to produce renewable resources must be maintained; (3) Non-renewable resources must be shared and not exhausted; (4) Pollution must not exceed the environment's capacity to clean itself.

* Numbers do not correspond to the original order in the Declaration. To read the full declaration, please see (UNEP 1972) 
highly oriented towards a purely economist perspective in analyzing total values of capital, Neumayer suggests a definition for sustainability as the ability to "maintain the capacity to provide non-declining well being over time".

In regards to the concept of 'sustainable mobility', there is also an open debate regarding its definition. According to Litman, "the term sustainable transport came into use as a logical follow-on from sustainable development, and is used to describe modes of transport, and systems of transport planning, which are consistent with wider concerns of sustainability. There are many definitions of the sustainable transport, and of the related terms sustainable transportation and sustainable mobility" (Litman 2010).

For the purpose of this dissertation, the definition by the UNEP on 'green transport' has been chosen. The 'green transport' concept was coined by the United Nations Environment Programme, referring explicitly to an urban system that supports (1) environmental sustainability through the protection of the global climate, ecosystems, public health and natural resources; (2) economic sustainability through an affordable, fair and efficient transport system that promotes a sustainable competitive economy as well as balanced regional development and the creation of decent jobs, and; (3) social sustainability by allowing the basic access and development needs of individuals, companies and society to be met safely and in a manner consistent with human and ecosystem health, while promoting poverty reduction and equity within and between successive generations (UNEP 2011).

Some other well-known definitions include those of the World Bank in 1996 and the OECD in 2002. The World Bank's definition reflects a rather economic-oriented focus, by highlighting the efficient use and proper maintenance of assets; the consideration of external effects; and the broad distribution of transport benefits (World Bank 1996). On the other hand, the OECD definition takes a heavily biased environmental stance, by highlighting the need to meet transport access needs without endangering public health or ecosystems in a way consistent with no net decline in the stock of renewable and non-renewable resources (OECD 2002). And more recently, Hull defines sustainable transport, in similar terms to those of the UNEP, "a transport system that: allows the basic access needs and development of individuals, companies and societies to be met safely and in 
a manner consistent with human and ecosystem health, and promotes equity within and between generations; is affordable, operates efficiently, offers choice of transport mode, and supports a vibrant economy, and regional development; and limits emissions and waste within the planet's ability to absorb them, uses renewable resources at or below their rates of generation, and, uses non-renewable resources at or below the rates of development of renewable substitutes and minimizes the use of land and the generation of noise" (Hull 2008, p.95).

\section{Figure II-1: Sustainable Transport Goals}

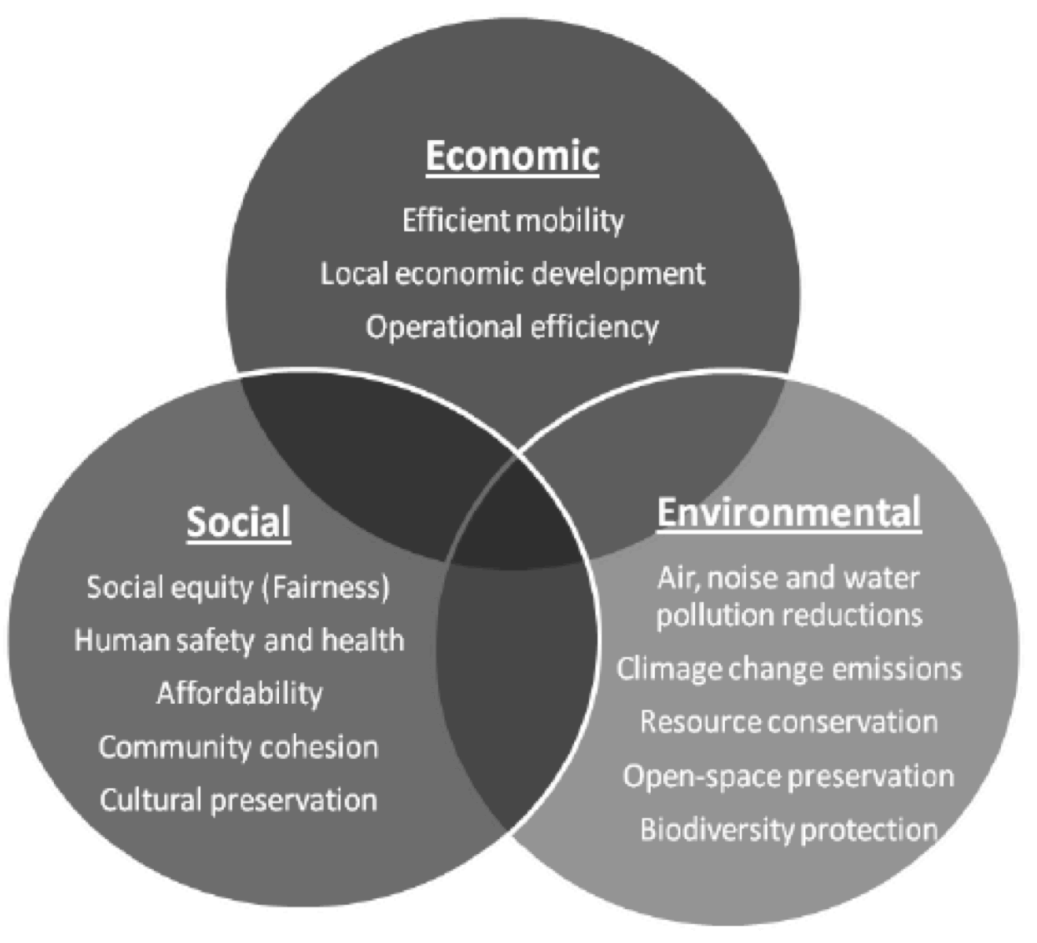

Source: Litman (2013)

Notwithstanding the lack of agreement in defining the concept, all these definitions refer to the same basic dynamic that motivates the realization of this dissertation: contemporary urban transport patterns generate dangerous externalities -air pollution, traffic safety, sprawling urban development 
patterns, automobile dependence, etc. (Zegras 2005a, p.24) - that insinuate the urgent need for a 'different system'. One that, in a very general way, promotes the reduction of private vehicle use, and facilitates the increased access of the population to public transportation, walking and cycling. A system that guarantees the right balance between the three critical dimensions of sustainability, while aiming at contributing with various transport goals, as shown in Figure II-1.

The implication is that assessing (or intending to assess) sustainable mobility might always suffer from the same ethereal nature of the sustainability concept; a similar lack of technical research clarity like the intangible studies aiming at defining sustainability.

\subsection{Structural Conditions frame Urban Sustainability}

Cities follow different sustainability trajectories. This could depend on seemingly cursory conditions such as average urban temperatures, or topography; yet, it could also be related to levels of economic development or population density. However, a key idea to consider when comparing sustainability trajectories refers to the 'timing'. That is, the history of the city greatly influences its current level of sustainability (KPMG 2010).

Current theory suggests that present urban policies are pre-determined by previous decisions, which implies high costs for changing the system (Thelen 1999; Schafer \& Victor 2000; Mahoney 2000). Ignoring the fact that early urban transport development patterns constrain possible future choices limits the understanding of the context of decision-making. Furthermore, when initial decisions 'lock-in', the choice of future transport modes becomes constrained by path-dependency (Schafer 2000).

Technological advances also play a role in influencing transport sustainability. New transport technologies have the potential to promote cleaner, lower carbon transport systems. In evaluating the potential of strategic niche management as a transition tool, Kemp et al. (1998) identify various barriers that impede a shift towards more sustainable transport technologies; "creating path dependencies too early by focusing on a specific technology may lead to a mismatch between emerging application conditions and the chosen new technology" (Kemp et al. 1998, p.187). 
Being a policy area that depends highly on building and capital expenditures, urban transport systems seem to be especially hard to reform, as major changes in the status quo pose lofty costs to various vested interests. This research is developed with a particular focus on the intertemporal relation between past and present policies in order to describe an accurate picture of urban governance, in the context of chosen trajectories, contingent events, and the way in which this has influenced transport sustainability. As Thelen reminds us: "once a path is taken, then it can become 'locked-in', as all the relevant actors adjust their strategies to accommodate the prevailing pattern" (Thelen 1999, p.385).

\subsection{Urban Planning and Transport}

The way cities are designed and/or built reflects the specific sets of values of the people inhabiting them at any given time. Different cities have been designed in different ways, hoping to achieve the preferred outcomes, central to that specific society and culture, and facing the specific economic, technological, and social changes taking place in cities (A. Jacobs \& Appleyard 1987).

Different ways of thinking about growing cities has influenced urban transport development patterns. Le Corbusier, and other founding members of the Congrès Internationaux d'Architecture Moderne (CIAM), developed the concepts of "Functional City", to emphasize an urban planning paradigm focused on efficiency, simplicity in design, and separation of urban uses (Gold 1998). Their goals included the belief that social order could be influenced by the built space, and thus, would aim at impacting "form" via designing "function" (Zegras 2005a). The "Garden City" movement initiated by Sir Ebenezer Howard also proposed settlement building as a reaction to what were then clear threats of the industrialization of urban centres (A. Jacobs \& Appleyard 1987). This emphasis resulted in a pattern of highly car-dependent separated urban uses, with suburban areas sprawling around traditional city centres, and great highways projected as a transport solution (Filion 1999).

A different planning paradigm started to flourish after key critiques of the consequences brought about by post-war planning (i.e. Jacobs 1961; Mumford 1961; Goodman 1971). Inspired by the perceived negative consequences of the modernist, top-down, expert based approach (i.e. 
addiction to the car, isolated and disconnected suburbia, low quality of life in traditional city centres), a wave advocating for participatory planning aimed at placing well-being and quality of life in the first line of priorities. Some general resulting forms of these propositions entail the historic preservation of urban areas, mixed uses, buildings and built environment at a human scale (Harvey 1987; Norcliffe et al. 1996).

Nevertheless, visions of urban planning continue to be profoundly influenced by modernism and expert-based planning in many cities around the developing world, "Le Corbusier-inspired high-rise developments, supported by US-type urban freeways, have prevailed and become symbols of economic virility and "progress" (Dotson 2011, p.28). This is not entirely surprising for Latin America, as highlighted by UN-Habitat (2009): "A central observation in this report is that in many parts of the world, planning systems are in place that have been imposed or borrowed from elsewhere. In some cases, these 'foreign' ideas have not changed significantly since the time they were imported" (UN-HABITAT 2009, p. 50). Perhaps, the best example for this influence of foreign ideas in local planning is the case of Brasilia; a planned new city, which influenced by Le Corbusier's ideas, accorded priority to motorized vehicular traffic under Lucio Costa's master plan (UN-HABITAT 2009, p.53)

The current panorama for Latin America could be understood as a reflection of the different urban development patterns followed by various regions after the Second World War. While European cities embarked on a full reconstruction period and North American cities began suburbanizing following the official housing incentives provided by the welfare state of the time, cities in Latin America only continued to expand in an informal way, as a result -primarily- of the exponential demographic growth of the urban population, and the incapacity of public authorities to provide appropriate housing solutions (Ramírez Ríos 2011). During this period, vast migratory waves from the rural areas to the urban centres took place, motivated by stronger industrialization within city cores (UNAL 2012). However, due to the lack of appropriate regulatory frameworks, and systematic policies to guide such urban growth, urban expansion for the region started to reflect what will be the most characteristic feature of city planning in Latin America: disorganized growth (Massiris Cabeza 2012).

The particularities of urban development in the Latin American region pose direct mobility challenges for its cities. Former mayor of Bogotá, Enrique 
Peñalosa, summarizes it in this way: "population growth, and all that comes with a higher income per capita [...] will make Latin American cities double or triple their built up area over the next 50 years [...] How will mobility be solved in these giant cities?" (Peñalosa 2013, p.19).

\subsection{The Changes in Urban Transport Paradigms}

A path-dependent behaviour also seems to be valid for transport planning, where concrete paradigms have long ruled developments and institutions. Proponents of urban sustainable transport have extensively addressed the difficulties in achieving sustainability (Banister 1998; Gakenheimer 2004). Moving towards sustainability in transport not only implies a paradigmatic change in the way societies understand their mobility, but also requires important technical and political steps.

Various paradigms for managing societal mobility needs are tied to specific transport planning approaches. Since the second half of the 20th century, the dominant paradigm in urban transport planning has been one of maximizing personal mobility (Cervero 2001). This approach focused on auto-mobility and became known as 'predict and provide'. It is centred on providing the needed infrastructure according to the predictions spurned by mobility growth models.

Challenges to this planning approach arised in the 1990's, pointing at the evidence that "road construction generates induced demand for road travel" (Vigar 2001; p. 427) and a growing awareness of the negative effects of increased car travel on social and environmental conditions. This emerging approach, known as the 'predict and prevent' approach, called for avoiding predicted mobility by discouraging the use of the car, while promoting alternative means of transport (Goodwin 1991; Owens 1995). However, advocating for such transition might not consider certain dynamics of contemporary urban life, since "it ignores the degree to which the wellbeing of households and the viability of companies have become dependent on rapid and cheap mobility" (Bertolini 2009). The challenge presented by this dilemma then, concerns the reconciliation between vital mobility and its inherent negative social and environmental effects, considering the high costs already generated by previous decisions on transport system development. 
In parallel, accessibility is also an important concept to consider when grasping the various contemporary transport approaches. Accessibility, understood as the ease of reaching any area of activity using a specific transport system (Dalvi \& Martin 1976), becomes a key concept under this vision. Transitioning towards a sustainable mobility paradigm implies changing the focus towards accessibility as the most important factor in urban mobility (Pardo 2005), and generates a new list of transport planning objectives addressing various sustainability goals (see Figure II-2). These goals are taken into consideration to develop the Green Transport Index introduced in Chapter IV.

A greater emphasis on accessibility also produces important symbolic considerations:

"Replacing auto-mobility planning with accessibility planning means that social considerations take precedence over individualistic ones. It also recognizes what cities are about first and foremost people and places, not movement. Efficient, well-managed cities minimize the need to travel, enabling residents to spend time more productively than fighting traffic" (Cervero 2001, p.421).

Table II-1: Sustainable Transport Goals and Objectives

\begin{tabular}{|c|c|c|c|c|c|c|c|c|}
\hline \multirow[b]{2}{*}{ Sustainability Goals } & \multicolumn{8}{|c|}{ Transport Planning Objectives } \\
\hline & 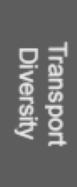 & 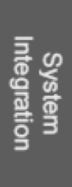 & 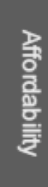 & 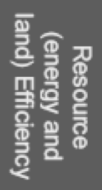 & 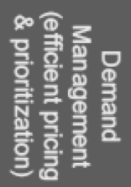 & 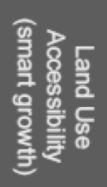 & 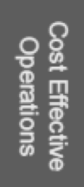 & 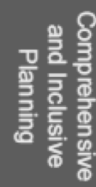 \\
\hline Economic productivity & $\checkmark$ & $\checkmark$ & & $\checkmark$ & $\checkmark$ & $\checkmark$ & $\checkmark$ & \\
\hline Economic development & $\checkmark$ & $\checkmark$ & $\checkmark$ & $\checkmark$ & $\checkmark$ & $\checkmark$ & & $\checkmark$ \\
\hline Energy efficiency & $\checkmark$ & $\checkmark$ & & $\checkmark$ & $\checkmark$ & $\checkmark$ & & \\
\hline Affordability & $\checkmark$ & $\checkmark$ & $\checkmark$ & $\checkmark$ & $\checkmark$ & $\checkmark$ & & \\
\hline Operational efficiency & & & & & $\checkmark$ & & $\checkmark$ & $\checkmark$ \\
\hline Equity / Fairness & $\checkmark$ & $\checkmark$ & $\checkmark$ & & $\checkmark$ & $\checkmark$ & & \\
\hline Safety, security and health & $\checkmark$ & $\checkmark$ & $\checkmark$ & $\checkmark$ & $\checkmark$ & $\checkmark$ & & $\checkmark$ \\
\hline Community development & $\checkmark$ & $\checkmark$ & $\checkmark$ & $\checkmark$ & $\checkmark$ & $\checkmark$ & & $\checkmark$ \\
\hline Heritage protection & $\checkmark$ & & & $\checkmark$ & $\checkmark$ & $\checkmark$ & & $\checkmark$ \\
\hline Climate stability & $\checkmark$ & $\checkmark$ & $\checkmark$ & $\checkmark$ & $\checkmark$ & $\checkmark$ & & \\
\hline Air pollution prevention & $\checkmark$ & $\checkmark$ & $\checkmark$ & $\checkmark$ & $\checkmark$ & $\checkmark$ & & \\
\hline Noise prevention & $\checkmark$ & & & $\checkmark$ & & & & \\
\hline Water pollution & $\checkmark$ & $\checkmark$ & $\checkmark$ & $\checkmark$ & $\checkmark$ & $\checkmark$ & & $\checkmark$ \\
\hline Openspace preservation & $\checkmark$ & $\checkmark$ & $\checkmark$ & & $\checkmark$ & $\checkmark$ & & $\checkmark$ \\
\hline Good planning & & & & & & & & $\checkmark$ \\
\hline Efficient Pricing & & & & $\checkmark$ & $\checkmark$ & & $\checkmark$ & \\
\hline
\end{tabular}


Accessibility, thus, serves as a complement to the principal assets of a good transport system: speed and reduced travel times (Bocarejo S. \& Oviedo H. 2012). This becomes crucial for example, when addressing activity-based measures in developing world cities, where accessibility could have a direct impact on well-being by determining the ease of reaching destinations; such is the case for Bogotá, where "the capacity of individuals to travel in the poorest segment of the population, is reduced to less than 1.5 trips per day" (Bocarejo S. \& Oviedo H. 2012, p.1), a low value compared to the average trips per day in Chicago (3.99), London (2.81), and Tokyo (2.86) (CAF 2011, p.288).

Promoting sustainable mobility in developing regions ends up competing with economic growth. As income levels rise significantly in some of these regions, economic development continues to be the main priority for policy makers. As such, policies that promote public transport, while restraining private individual transport, often do not sell well (Banister et al. 2011). Furthermore, as local governments in developing countries strive to provide affordable rapid and cheap mobility to their citizens, it is clear that "the increase of personal travel and mass motorization that results from regional economic development trends closely relates to the intensification of unsustainable environmental, climate and energy security trends" (Figueroa \& Ribeiro 2013, p.4).

\subsection{Civil Society and Cultural Identity}

Civil society can have an important influence over public policies. This may come via direct pressure towards a specific objective, via indirect lobby before various actors in regards to certain ideas, or due to the influence of electoral dynamics that define the role of political and institutional actors. This concept of citizen participation has been widely studied in different contexts, with Arnstein's (1969) "Ladder of Citizen Participation" being one of the primary contributions. Although she argues that the idea of citizen participation "is a little like eating spinach: no one is against it in principle because it is good for you" (Arnstein 1969, p.216), she also makes a strong case for the high incentives for manipulation, which are inherent to local political decision making processes where citizen power is at stake.

The interest in this issue has been growing steadily during the last decades. As Roberts (2004) describes in her study of public deliberation, "the latter part of the $20^{\text {th }}$ century saw a shift toward greater direct citizen participation 
[a trend which] is expected to grow" (Roberts 2004, p.315). By using the Ladder of Citizen Participation, Arnstein (1969) is able to depict how citizens move from non-participation to active participation, while progressing through degrees of tokenism and degrees of citizen power. In this regard, high levels of citizen power may be understood as a surrogate for direct citizen participation, which is "viewed with scepticism and even wariness" (Roberts 2004, p.316).

Notwithstanding the importance of citizen power, the purpose of this dissertation is not to explore how decision making power is achieved through citizen participation, but rather to understand to what extent have decision makers in the studied cities, acted upon the stimuli received from citizens, when advancing the urban transport systems. Therefore, the role of culture, cultural perceptions, and social norms also become crucial. As put by Enrique Peñalosa when explaining the urban design goals for Latin America cities: "Since our reality is different, the city model that we need is also different to that which is predominant in advanced cities" (Peñalosa 2003, p.2). Among the main characteristics of these cities (as compared to those in the developed world), he includes:

1. Extreme poverty problems.

2. Higher rates of population growth.

3. Higher population densities.

4. More acute inequality and exclusion problems.

5. Low levels of motorization.

6. Generally, weather patterns without extreme colds.

7. Generally, closer familiar and communitarian links.

Fundamentally, cultural identities and the power of symbols within societies must be considered. Even though there might exist plenty of information reaching the various socioeconomic strata of societies, with messages about the negative consequences of highly motorized urban development models, the perception of the car as a 'symbol' might be enough to alter individual decisions. In studying types of travellers and their attitudes, Jensen (1999) finds that most people recognize the car "as a symbol of a number of things" (Jensen 1999, p.27). This might be freedom and independence, but could also be closely related to power and status. Similarly in studying the motives for car use, Steg (2005) finds that "car use not only fulfils instrumental functions, but also important symbolic and affective functions"(Steg 2005, p.147). 


\subsection{Economic Growth or Sustainability?}

Economic growth and urban sustainability should not be considered to be contradictory. In fact, the economic effects of transport are always two-fold: (1) increasing economic development causes more traffic, accidents and pollution, while (2) the mobility of people and goods is a precondition for greater productivity (Joumard \& Gudmundsson 2010).

Recent studies suggest that green transport would in fact generate exceptional economic returns for cities (i.e. UNEP 2011; Hammer et al. 2011; VNG uitgeverij 2000; Weisbrod \& Reno 2009). Thus, the potential of the 'sustainable mobility' paradigm resides in the fact that it proposes a solution to the paradox between mobility and its negative effects, by pursuing three lines: (1) meeting the mobility requirements of economic players, (2) ensuring social equity and road safety, and (3) limiting consumption of resources.

This green transport strategy means cities would have to refurbish their urban transport structure, to the point that they can offer their citizens high quality systems, where as many trips as possible use low-carbon or noncarbon intensive modes. According to some estimates, such a change would bring about a global cumulative of "seven million more green jobs in cities only on the operators' side of the supply chain, [assuming] that public transport labour productivity keeps increasing by about 1\% per year" (UITP 2011, pg. 1).

Moreover, there might not be a need for further investment in order to achieve this structural change. With "a reallocation of just 0.16 per cent of global GDP in support of public transport infrastructure and efficiency improvements to road vehicles would reduce the volume of road vehicles by around one-third by 2050. It would diminish the use of oil-based fuel by up to one-third and promote strong and sustainable employment in the sector" (UNEP, 2011 379). The relationship between availability of funds and the pursuit of various urban transport trajectories is a key focus of this research, assessing the extent to which key decisions are justified locally in terms of fund availability.

These costs to society also are significant if we were to continue along unsustainable paths. For instance, societal costs related to pollution, traffic accidents and congestion, can add up to more than 10 per cent of a country's 
GDP, and are likely to grow, primarily because of the expected growth of the global vehicle fleet (UNEP 2011). Finally, if we use conservative estimates to provide value for human lives, and price each of these at U\$ 1.4 million, then savings from urban traffic fatalities could amount up to U\$250 billion per year (UITP 2011), globally.

Institutional coordination plays a key role in reconciling these goals. Solid institutions are one of several prerequisites for the implementation of multiobjective, multi-actor and integrated policy interventions (May et al. 2012; Wittneben et al. 2009). Moreover, when considering conditions that facilitate strategic decisions to avoid lock-ins in terms of urban transport infrastructure, institutional coordination (both between public and private sectors) stands out as an important component (Figueroa et al. 2013).

The public institutions and private stakeholder's interest in sustainable transport has been growing steadily in Latin America. As is the case of other growing economies, in Latin America mass motorization is posing challenges to the region's weak institutions and available infrastructure (Figueroa \& Ribeiro 2013). The region is home to the well-known successes of Curitiba, Bogotá, and others during previous decades, in implementing Bus Rapid Transit systems.

In developing countries, income level trends are often tightly related to motorization levels. Some authors argue as economies grow, there is a specific income threshold at which people move into cars; Ohmae set this threshold at USD 5000 in his studies of Asian cities during the 1990's, for example (Ohmae 1996). Many others, have also provided empirical evidence to conclude that in developing world cities, "rising incomes are the major driving force for car ownership" (Mohamad \& Kiggundu 2007, p.1). In exploring the connection, between GDP and $\mathrm{CO}_{2}$ emissions from transport, (Millard-Ball \& Schipper 2011) provide evidence of a positive correlation between GDP per capita and transport emissions per capita, for OECD countries (see Figure II-3). On the other hand, as indicated by Kenworthy (2011), "whilst it appears that rising incomes push naturally in the direction of the car, it is clear [...] that there is no real inevitability about that trajectory, as demonstrated by the positive outcomes in many Western European and high-income Asian cities" (J. Kenworthy 2011, p.109). 
Figure II-2: Relationship between GDP and transport $\mathrm{CO}_{2}$ emissions highlighting OECD countries

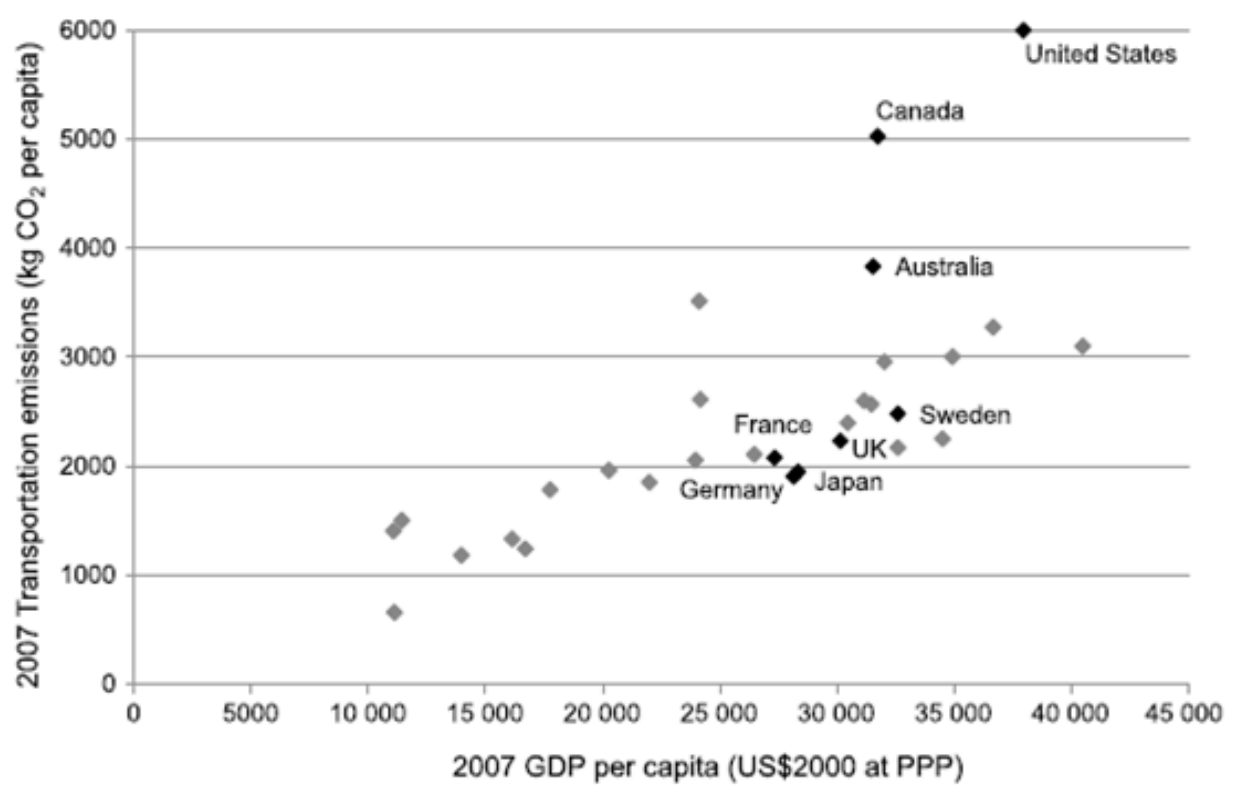

Source: Millard-Ball \& Schipper (2011), p.360

Furthermore, there are economic benefits brought about by the car industry (i.e. taxes, provision of inputs, direct and indirect jobs, etc.), which could result in strong links with the cities that house them. Wright (2004) forecasts that the global car fleet will grow from 1 billion in 2007 to 2.6 billion in 2030 , with most of the growth happening in the countries of the South. As such, the situation in Latin America merits detailed analysis.

\subsection{Grasping Sustainable Transport}

Transport is a key element to analyze when engaging urban sustainability (Banister 2008; B. Lefèvre 2010; Whitelegg 2007; Litman 1999). It is responsible for $28 \%$ of the total final energy demand, and greenhouse gas (GHG) emission generation (IEA 2012). In terms of energy, for example, transport is responsible for approximately one quarter of the total global demand, with almost three-quarters of this, used solely for road passenger 
and goods movement (OECD/IEA 2008). Moreover, higher motorization levels in developing world regions increase the importance of transport as a component of urban sustainability. According to UN-HABITAT (2013), amongst developing regions of the world, Latin America has the highest number of both motor vehicles and passenger cars, as a proportion to population (see Figure II-4).

Table II-2: Global stock of motor vehicles and passenger cars 2010

\begin{tabular}{|c|c|c|c|c|c|c|c|}
\hline & \multicolumn{3}{|c|}{$\begin{array}{l}\text { Motor } \\
\text { Vehicles }\end{array}$} & \multicolumn{3}{|c|}{$\begin{array}{l}\text { Passenger } \\
\text { cars }\end{array}$} & \multirow{2}{*}{$\begin{array}{l}\text { Passenger } \\
\text { cars } \\
\text { As \% of all } \\
\text { motor } \\
\text { vehicles }\end{array}$} \\
\hline & $\begin{array}{c}\text { Total } \\
\text { number }\end{array}$ & $\begin{array}{l}\text { Per } 1000 \\
\text { populatio } \\
n \\
\text { (millions) }\end{array}$ & $\begin{array}{l}\% \text { of } \\
\text { total }\end{array}$ & $\begin{array}{c}\text { Total } \\
\text { number }\end{array}$ & $\begin{array}{l}\text { Per } 1000 \\
\text { population } \\
\text { (millions) }\end{array}$ & $\begin{array}{l}\% \text { of } \\
\text { total }\end{array}$ & \\
\hline TOTAL & 1047 & 159 & 100 & 825 & 125 & 100 & 79 \\
\hline $\begin{array}{l}\text { Developed } \\
\text { countries }\end{array}$ & 604 & 656 & 58 & 492 & 535 & 60 & 81 \\
\hline $\begin{array}{l}\text { Transitional } \\
\text { countries }\end{array}$ & 98 & 303 & 9 & 83 & 259 & 10 & 85 \\
\hline $\begin{array}{l}\text { Developing } \\
\text { countries }\end{array}$ & 345 & 64 & 33 & 249 & 47 & 30 & 72 \\
\hline -Africa & 35 & 40 & 3 & 26 & 29 & 3 & 74 \\
\hline $\begin{array}{l}\text {-Asia and } \\
\text { Pacific }\end{array}$ & 213 & 54 & 20 & 150 & 38 & 18 & 70 \\
\hline $\begin{array}{l}\text {-Latin } \\
\text { American } \\
\text { and the } \\
\text { Caribbean }\end{array}$ & 96 & 180 & 9 & 73 & 137 & 9 & 76 \\
\hline
\end{tabular}

While some regions have developed highly fossil fuel dependant transport systems, others are still on the verge of initiating vast motorization trends for the majority of their population. In the United States and Canada, for instance, two-thirds of oil consumed, is used for transportation (mainly cars), which accounts to a massive figure of approximately 850 million gallons of crude oil per day (Owen 2010). On the other hand, developing countries in Asia and Latin America, where individual motorized travel was kept at a low due to past economic conditions, are now in the midst of fast transitions from non-motorized and public transport modes, to the car (Banister et al. 2011; Figueroa et al. 2013; Schafer 2011). Some forecasts by the World Business Council on Sustainable Development (WBCSD 2004) project growth in passenger transport activity for Latin America as the second-highest in the world, only after China itself, with an average annual 
rate of increase of almost 3\% (measured in terms of average passenger kilometres travelled) (see Figure II-4).

Figure II-3: Personal Transport Activity by Region (Forecasts to 2030 and 2050)

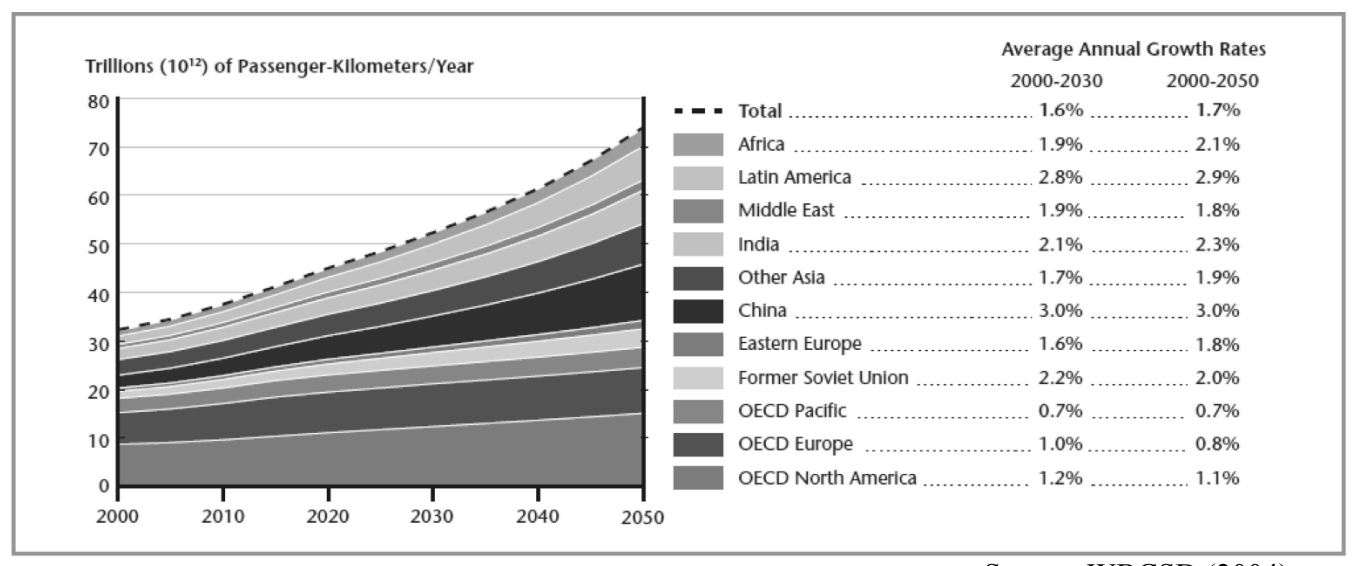

Source: WBCSD (2004)

Moving towards sustainability requires solid urban governance. A key message after the first UN-Habitat World Urban Forum in Nairobi, called for the improvement of local governance capacities, to support urban sustainable planning: "the most immediate and fundamental bottlenecks to sustainable urbanisation are not the lack of technology, funding or international agreements (although these are important) but rather the lack of local planning, management and implementation capacities and sound urban governance" (UN-HABITAT 2002). With regards to transport, for instance, cities (and their governments) occupy a key position. Cities house large populations and businesses, generating a great deal of mobility, and are therefore major emitters of greenhouse gasses. This immediately implies that these have unique opportunities to develop - and lead - appropriate policies that can significantly reduce the environmental impact of their transport systems (KPMG 2010).

There are some clear cut propositions about the specific goals and policies necessary for transitioning into the low carbon, clean and safe mobility systems, that are necessary for sustainable development in developing countries (Figueroa et al. 2013). Furthermore, there is growing consensus on the need for a proper mix of policies that generates a true paradigm shift towards greater sustainability in transport planning (Litman 1999; Litman 2009; Banister 2008). 
These policies should target specific categorical goals within the sustainability dimensions of: economic development, urban development and equity, health and environmental protection, GHG emissions, and energy security ${ }^{4}$. Furthermore, to allow for an understanding of how different urban transport systems perform, in comparison to each other, we need some sort of measurement tool. One possibility is resorting to indicators, which are often necessary, since full models to describe interactions between transport activity and impacts on sustainability are often not available or not practical (Joumard \& Gudmundsson 2010).

\subsection{Indicators and Indices}

A plethora of indicators has been proposed and used to assess transport. An excellent work summarizing these possibilities and the ways in which different indicators might be used is Joumard \& Gudmundsson's 2010 piece, Indicators of environmental sustainability in transport, where they harmonize previous knowledge on environmental impact indicators, with a focus on transport. Nevertheless, it is pertinent to state that the diversity in objectives, goals and rhetoric is immense. For those initiatives specifically targeted to measuring sustainable transport, Zegras (2005) reminds us that there simply is:

“(1) an overwhelming number of indicators derived, and (2) a failure to make clear the links between the proposed metrics and the goals/objectives. The multiple indicator initiatives and numerous indicators thereby derived- represent ambitious efforts to provide a comprehensive picture of sustainable transportation" (Zegras 2005a, p.33)

Several initiatives do propose interesting lessons. From the purely business sector oriented end of the spectrum, the World Business Council for Sustainable Development (agglomerating some of the largest car manufacturers and oil producers of the world, amongst other corporate power), has conducted a project on sustainable transport since the early 2000's; the 'Sustainable Mobility Project". For the 2004 version of their report, an interesting combination of indicators focused on tangibles, was

4 For a detailed review of these goals, dimensions, and policies, please see:(Figueroa et al. 2013; Santos et al. 2010). 
offered. This approach to measuring sustainable mobility has also been taken up by other researchers (see Figure II-6).

Table II-3: Sustainable Mobility Project Indicators

\author{
1. Accessibility \\ 2. Financial outlay required of users \\ 3. Travel time \\ 4. Reliability \\ 5. Safety \\ 6. Security \\ 7. Greenhouse gas emissions (GHGs) \\ 8. Impact on the environment and on public well-being \\ 9. Resource use \\ 10. Equity Implications \\ 11. Impact on public revenues and expenditures \\ 12. Prospective rate of return to private business
}

On the other hand, works stemming from more socially advocating organizations stress the direct consequences on quality of life for citizens, as related to transport externalities. Litman (2013) summarizes these possibilities in detail in Figure II-7.

Similarly to the indicator variety and disagreement in regards to sustainable transport indicators, the efforts on sustainable transport index development have also been varied. Notable initiatives for sustainable transport index creation include those by Black (2000), through which he proposes initial characterizations for what such an index should include; Gouvea-Campos et al. (2009), through which they propose a procedure to evaluate sustainable mobility in urban areas and apply it to Belo Horizonte; and also, the wellmarketed studies by Siemens and the Economist Intelligence Unit in 2009 and 2010, through which they produce indices for urban sustainability in Europe and Latin America. Although these works do not focus only on transport, they do include short sections specifically dedicated to rating key cities of each region, according to their performance in 'green transport'. All of these indices are composed using a variety of indicators, uniquely chosen for each particular project. 
Table II-4: Key Sustainable Transport Goals, Objectives and Indicators

\begin{tabular}{|c|c|c|}
\hline Sustainability Goals & Objectives & Performance Indicators \\
\hline \multicolumn{3}{|l|}{ 1. Economic } \\
\hline $\begin{array}{l}\text { Economic } \\
\text { productivity }\end{array}$ & $\begin{array}{l}\text { Transport system efficiency } \\
\text { Transport system integration } \\
\text { Maximization of accessibility } \\
\text { Efficient pricing and incentives }\end{array}$ & $\begin{array}{l}\text { Per capita GDP } \\
\text { Portion of budget devoted to transport } \\
\text { Per capita congestion delay } \\
\text { Efficient pricing (road, parking, insurance, fuel, } \\
\text { etc.) } \\
\text { Efficient priorization of facilities }\end{array}$ \\
\hline $\begin{array}{l}\text { Economic } \\
\text { development }\end{array}$ & Economic and business development & $\begin{array}{l}\text { Access to education and employment } \\
\text { opportunities } \\
\text { Support for local industries }\end{array}$ \\
\hline Energy efficiency & $\begin{array}{l}\text { Minimization of energy costs, } \\
\text { particularly petroleum imports }\end{array}$ & $\begin{array}{l}\text { Per capita transport energy consumption } \\
\text { Per capita use of imported fuels }\end{array}$ \\
\hline Affordability & $\begin{array}{l}\text { All residents can afford access to } \\
\text { basic (essential) services and } \\
\text { activities }\end{array}$ & $\begin{array}{l}\text { Availability and quality of affordable modes } \\
\text { (walking, cycling, ridesharing and public } \\
\text { transport) } \\
\text { Portion of low-income households that spend } \\
\text { more than } 20 \% \text { of budgets on transport }\end{array}$ \\
\hline $\begin{array}{l}\text { Efficient transport } \\
\text { operations }\end{array}$ & $\begin{array}{l}\text { Efficient operations and asset } \\
\text { management maximizes cost } \\
\text { efficiency }\end{array}$ & $\begin{array}{l}\text { Performance audit results } \\
\text { Service delivery unit costs compared with peers } \\
\text { Service quality }\end{array}$ \\
\hline \multicolumn{3}{|l|}{ 2. Social } \\
\hline Equity/fairness & $\begin{array}{l}\text { Transport system accommodates all } \\
\text { users, including those with } \\
\text { disabilities, low incomes, and other } \\
\text { constraints }\end{array}$ & $\begin{array}{l}\text { Transport system diversity } \\
\text { Portion of destinations accessible by people } \\
\text { with disabilities and low incomes }\end{array}$ \\
\hline $\begin{array}{l}\text { Safety, security and } \\
\text { health }\end{array}$ & $\begin{array}{l}\text { Minimization of risk of crashes and } \\
\text { assaults, and support of physical } \\
\text { fitness }\end{array}$ & $\begin{array}{l}\text { Per capita traffic casualty (injury and death) } \\
\text { rates. } \\
\text { Traveller assault (crime) rates } \\
\text { Human exposure to harmful pollutants } \\
\text { Portion of travel by walking and cycling }\end{array}$ \\
\hline $\begin{array}{l}\text { Community } \\
\text { development }\end{array}$ & $\begin{array}{l}\text { Help create inclusive and attractive } \\
\text { communities } \\
\text { Support community cohesion }\end{array}$ & $\begin{array}{l}\text { Land use mix } \\
\text { Walkability and bikeability } \\
\text { Quality of road and street environments }\end{array}$ \\
\hline $\begin{array}{l}\text { Cultural heritage } \\
\text { preservation }\end{array}$ & $\begin{array}{l}\text { Respect and protect cultural heritage } \\
\text { Support cultural activities }\end{array}$ & $\begin{array}{l}\text { Preservation of cultural resources and traditions } \\
\text { Responsiveness to traditional communities }\end{array}$ \\
\hline \multicolumn{3}{|l|}{ 3. Environmental } \\
\hline Climate stability & $\begin{array}{l}\text { Reduce global warming emissions } \\
\text { Mitigate climate change impacts }\end{array}$ & $\begin{array}{l}\text { Per capita emissions of greenhouse gases }\left(\mathrm{CO}_{2} \text {, }\right. \\
\mathrm{FCSs}, \mathrm{CH}_{4} \text {, etc.) }\end{array}$ \\
\hline $\begin{array}{l}\text { Prevent air } \\
\text { pollution }\end{array}$ & $\begin{array}{l}\text { Reduce air pollution emissions } \\
\text { Reduce exposure to harmful } \\
\text { pollutants }\end{array}$ & $\begin{array}{l}\text { Per capita emissions (PM, VOCs, NOx, CO, etc.) } \\
\text { Air quality standards and management plans }\end{array}$ \\
\hline $\begin{array}{l}\text { Prevent noise } \\
\text { pollution }\end{array}$ & Minimization of traffic noise exposure & Traffic noise levels \\
\hline $\begin{array}{l}\text { Protect water } \\
\text { quality }\end{array}$ & $\begin{array}{l}\text { Minimization of water pollution } \\
\text { Minimization of impervious surface } \\
\text { area }\end{array}$ & $\begin{array}{l}\text { Per capita fuel consumption } \\
\text { Management of used oil, leaks and storm water } \\
\text { Per capita impervious surface area }\end{array}$ \\
\hline $\begin{array}{l}\text { Open space and } \\
\text { biodiversity } \\
\text { protection }\end{array}$ & $\begin{array}{l}\text { Minimization of transport facility land } \\
\text { use } \\
\text { Encourage more compact } \\
\text { development } \\
\text { Preserve high quality habitat }\end{array}$ & $\begin{array}{l}\text { Per capita land devoted to transport facilities } \\
\text { Support for smart growth development } \\
\text { Policies to protect high value farmlands and } \\
\text { habitat }\end{array}$ \\
\hline
\end{tabular}


Table II-4: Key Sustainable Transport Goals, Objectives and Indicators (continued)

\section{Good Governance and Planning}

Integrated, Clearly defined planning process

comprehensive and Integrated and comprehensive

inclusive planning analysis

Strong citizen engagement Portion of population engaged in planning

Lease-cost planning (most beneficial

solutions are selected and funded)

Clearly defined goals, objectives and indicators

Availability of planning information and

documents

decisions

Range of objectives, impacts and options

considered

Transport funds can be spent on alternative

modes and demand management if most

beneficial overall

Source: Litman (2013)

\subsection{Governance in Metropolitan Areas}

\subsubsection{Governance}

The word governance has a long history of existence, but a shorter history of practical application. Its inclusion in the mainstream vocabulary is a striking development in the analysis of politics and policy-making during the last decade (Hajer \& Wagenaar 2003). Bevir (2009) reminds us that the word was already used by the medieval poet Geoffrey Chaucer, in referring to the activity of ruling 'house and land'. However, this concept was for long simply related to the idea of the procedural element in conducting governmental issues.

More recently, however, a greater interest in the term and its applicability to different contexts aroused from the neoliberal reforms of the public sector in the 1980s. Governance started moving towards a new meaning, of a governmental model that is quite opposed to the very hierarchical models of before; this, in an attempt to make it more efficient, and reminiscent of the private sector.

This new way of governing would make a distinction between making policy decisions and delivering the services than emanate from public decisions. Osborne and Gaebler (1992) refer to this distinction in terms of steering and rowing; where steering concerns the policy making decisions, which ought to be central to an efficient form of governance; and where rowing concerns the public service delivery, which ought to be optimized by transforming it in line with private sector values. 
This new government idea stimulates additional propositions, generally meaning that a broad platform of networks, markets, and organizations are created around the state, generating dependencies amongst each other, and thus neutralizing the ability of the state to command others effectively (Bevir 2009). The new perspective is thus characterized by greater levels of interaction and cooperation between key players involved in public decisions (which in this sense, could be considered as a mélange of private and public frames).

Apart from the use of the governance concept to describe the changes in the role of the state after such reforms, the concept can also be used to describe "any pattern of rule that arises either when the state is dependent upon others or when the state plays little or no role" (Bevir 2009, p.3). This new 'pattern of rule' can be understood as the governing process in its entirety, as it involves rules and regulations, and societal interactions among all the above-mentioned actors. Moreover, it allows the academic exploration of the specific practices of coordination, construction, and implementation of policies experimented by governments.

In this context, a public service such as urban transport depends highly on the patterns of rule that are specific to local scenarios. It is an issue that increasingly needs to be tackled from a metropolitan perspective due to high levels of urbanization, and other recent urban trends. Cities all over the world face the challenge of adjusting the process by which their own citizens collectively solve their problems and meet society's needs (OECD 2000), to ensure satisfactory metropolitan public service delivery. Based on this definition, and for the context of Latin American cities, governance involves all social actors beyond public authorities, and two additional components: the process of decision-making and the process by which decisions are implemented (or not implemented) (UN-ESCAP 2005).

\subsubsection{Good Governance}

Even though there is no agreed definition of good governance, each organization concerned with it, often creates its own meaning for the concept (Bevir 2009). Good governance could be understood as optimal decision-making and implementation processes, in a territory within a democratic system. Thus, according to the UN, these processes characterised themselves for having certain qualities. They are participatory, 
consensus oriented, accountable, transparent, responsive, effective and efficient, equitable and inclusive and follow the rule of law (UN-ESCAP 2005).

Nevertheless, the concept still generates animated debates due to its frequent association to economic development and relationships with international donors. As the term was initially introduced during the 1990's as a novel lending requirement by the World Bank, it also generated the idea of what opposite, "bad governance" practices meant: corruption, wastefulness, incompetence, etc. (Bevir 2009).

Moreover, its close association with economic development (due to its noticeable relationship with international aid and assistance programs), contributed to that stark contrast between the strengths of the western world, and the weaknesses (and ills) of the global south. In the light of what Easterly (2007) calls The White Man's Burden this debate suggests that while international donors expect to improve governance in Africa, Asia and Latin America, their proposition suggests the idea that the specific ills of "bad governance" are unique to these regions of the world (Bevir 2009).

For the purpose of this dissertation, however, good governance translates into sound capacity of all social actors to make adequate metropolitan public decisions, which could be assessed according to its legitimacy from a threefold dimension (Lefévre 2005). First, the political legitimacy consists on the power and legal support given to metropolitan decisions. It involves planning and systematic decision-making on relevant responsibilities aligning the functional territory with the administrative territory. Therefore, cities join efforts creating metropolitan structures in some cases managed by elected officials. Second, the functional legitimacy evokes the amount of resources permitting decisions implementation. Commonly, functional legitimacy requires technical, personal and financial resources. Third, the social legitimacy refers to the level of identity, ownership and interactions of social actors within the metropolitan territory. Social legitimacy could be promoted for instance by mobility systems, cultural or sport events, civil society, labour and businessmen unions action. The level of legitimacy of the metropolitan governance becomes a political factor, which determines transport sustainability. 


\subsubsection{Theoretical Settings for Governance}

Whatever the particular understanding of ruling patterns chosen for describing governance, its meaning will also vary according to the specific theoretical context in which it is used. While rational choice theory procures for the explanation of actions in terms of utility-maximizing rationality, the approach catered by advocates of the new institutionalism aims at explaining individual actions via the analysis of specific institutional settings (Procopiuck 2011).

Social constructivism, on the other hand, proposes an evaluation of individual actions based on the specific meanings of patterns. Beliefs, ideas and meanings particular to mental constructs in each culture, become vital inputs to understanding patterns of rule, and as such, assuming that "people act on beliefs, ideas, or meanings - whether conscious or not - we can explain their actions properly only if we grasp the relevant meanings " (Bevir 2009, p.21).

Aligning with constructivism proposes a fundamental idea that knowledge is not discovered directly from the world, by collecting specific facts. On the contrary, knowledge is understood as a social construction derived from a rich interaction of social and cultural traditions (Berger \& Luckmann 2011). In this sense, scientific contributions admit a range of mental constructs that explain specific actions and experiences, a stark contrast to the fundamental tenets of positivism.

These different views of meanings reflect an understanding of the different ways to understand individuals, and their decisions. Such an approach presents a provocative platform to assess the contemporary patterns of rule within urban transport systems in Latin America. A constructivist approach in this context, allows for the establishment of a bottom-up approach to explore -directly with those key actors involved- how meanings were created, sustained, contested and transformed by the activities of those individuals composing local power networks (Bevir 2009). Evidently, these approach to governance in the particular setting of metropolitan areas in Latin America, favours the assessment of tradition, discourse and culture as inputs allowing for specific actions to be taken. 


\subsubsection{Regional and Local Governance}

Regional governance is frequently used in connection to the new dynamics prompted by the rise of the European Union, and other similar bodies. As such, these new regimes insinuate the need for changes in the patterns of rule, as national governments see their autonomy eroded in some dimensions of policy (John 2001). It is different from the top-down concept of regionalization, as this intends to establish additional levels of government within one single national entity. It is pertinent here to introduce local governance, as an idea that refers more specifically to "those levels of government and administration below the central or national state" (Bevir 2009), and includes many of the actors that are key when assessing certain public services, such as urban transport.

At the local level, network structures involving a variety of organizations are frequent. Thus, public, private, and non-governmental entities often join in cooperating across multiple contexts and jurisdictional borders (Procopiuck 2011). As such, the specific interactions in terms of the contractual relationships or simply the socio-cultural connections of trust, become key aspects to analyze when understanding the specific institutional arrangements that occur.

When grasping 'new local governance' then, the nature of institutional relationships matters. These 'new' relationships differ greatly from those that are born out of following a "rules of the market" paradigm. Instead, a continuous and dynamic negotiation between actors and across levels is natural, adding interest to the particularities of local patterns of rule. Similarly, these interactions are more reminiscent of open, collaborative networks, rather than the stiff, and formal institutional interactions, so common of traditional local government functioning. The question that remains unanswered, although is not directly explored in this thesis, concerns whether traditional local government has now moved towards local governance dynamics, and to what extent this influences public service delivery decisions that have an influence at the metropolitan level.

\subsubsection{Metropolitan Governance and Multilevel Governance}


When assessing governance at the metropolitan level, it is crucial to concomitantly regard the concept of metropolitan government as a complementary one. While metropolitan governance refers to the patterns of rule and public service delivery within the geographical boundaries of a conurbation, metropolitan government is directly related to the structure and functions of a governmental entity at the metropolitan scale (Sharpe 1995). Metropolitan governance has been proposed as a concept that includes other forms of public action, which differ from those based on the government side alone, and that become necessary ingredients for the success of metropolitan government experiments (C. Lefèvre 1998).

A metropolitan government has previously been defined in terms of territory; that is, at the metropolitan scale (Paiva 2003). In this context, although the metropolitan level of public service provision is not presented as an additional layer of government per se, it is implied as the entity that could better serve the full metropolitan territory in terms of metro-scale utility provision and planning (Sharpe 1995), as it is well accepted that the functional dynamics of most cities often extend beyond the administrative boundaries of its territory (Brenner 1999; C. Lefèvre 1998; Paiva 2003). However, previous studies suggest that governments at the metropolitan scale are difficult to implement and have less continuity than central or local forms of government. In this regard, legal, historical, and political types of bottlenecks are identified as the main constraints to the consolidation of metropolitan governments (Lefèvre, 1998; Sharpe, 1995).

The possibility to secure full functional and administrative coverage of a metropolitan territory has positive implications for cities. From the very beginnings of the modernist revolution in urban planning, economic and social relationships have moved away from a basic interdependency with city centres, to operate on wider geographical scales. As such, not only planning and service delivery must consider these parallel interdependencies with alternative urban production and housing centres, but also labour dynamics become a vital measure of the full metropolitan territory. If public service delivery is fulfilled satisfactorily, and the metropolitan labour market is addressed holistically, the competitive position of a city may improve in a globally integrated system (Simon 1993).

Public policy decisions in cities are exposed to an extensive selection of problems, whose resolution depends directly on the coordination between actors at different institutional levels. In order to understand these multi- 
level relationships, and their policy consequences, it is crucial to analyze two overarching ideas, as Procopiuck (2011) reminds us: (1) how these institutions are organized; and (2) how their agents act strategically in society in order to obtain resources and competencies that can be applied towards public policies in the long run.

Multilevel governance also proposes an avenue to better understand the interactions between actors across various levels of government. A crucial component to keep in mind is that these policy actors can be positioned both vertically and horizontally:

\begin{abstract}
"So, multilevel governance may involve well defined vertical power relationships between the central state and its constituent, subordinate, local entities. But, likewise, it may involve complex interactions that occur among various state and non-state actors on various levels of government. Indeed, multilevel governance often crosses horizontal as well as vertical levels. It is not constrained by traditional jurisdictional boundaries" (Bevir 2009, p.134).
\end{abstract}

The implications of multi-level governance arrangements in metropolitan areas are varied. Allowing for the participation of a diverse set of public and private actors in the policy making process could lead to better targeted decisions at the metropolitan scale. Although local government structures vary per country, one can generally identify two powerful government structures affecting the functioning of urban patterns of rule: the national scale, corresponding with central government (be it unitary, federal, etc), and the local scale, corresponding with the specific local variation of a municipal government.

Moreover, the possibility of escaping, from the duopoly controlled by the local and national governments could imply a solution to what Sharpe (1996) calls the "first and most obvious problem of a metropolitan area at the organizational level", that it is "squeezed between two probably hostile forces" (Sharpe 1996, p.22). On the other hand however, depending highly on multilevel governance schemes might pose challenges as well. As the responsibilities for specific policy decisions are now spread across multiple actors at multiple levels, this might result in weaker public accountability links. If citizens cannot clearly identify who is responsible for specific outcomes, then they cannot hold specific policy actors accountable. 
Assuming that metropolitan coordination is best practised by an entity that performs at the full metropolitan scale, subsidiarity becomes another key public management principle to consider. According to Bermann (1994), the concept can be traced back to twentieth-century Catholic social philosophy, which claimed subsidiarity requires that:

"Smaller social units...not be deprived of the possibility and the means for realizing that of which they are capable and larger units...restrict their activities to spheres which surpass the powers and abilities of the smaller units" (Bermann 1994, p.6).

As such, the possible creation of metropolitan scale entities faces an issue of conflicting sovereignty. Local government entities find little incentives to give up their political power to assign resources and decide government expenditure, while allowing other levels of government to centralize tasks that are in their hands.

The autonomy of local governments is also supported by public choice principles. Allowing municipalities (or smaller governmental units) to compete with each other in attracting citizens and enterprises to their territory, public services are thought to improve; what has come to be called "voting with the feet" (Tiebout 1956).

Transport is one of the key urban services that depends on metropolitan coordination and governance (Sager 2005). Origins and destinations for urban routes are rarely determined by the invisible borders of neighbouring municipalities or the competencies of government scales. Nevertheless, the existence of a unique administrative entity in charge of all transport modes in a metropolitan area, is the preferred mode of transport coordination (Monzón 2005). In reviewing fast-rising motorization, Kenworthy (2011) notes that "many of the problems of urban transport development in lowerincome cities can also be traced to systems of governance and 'communities of interest' that do not necessarily push in the direction of sound planning that benefits the majority of people in the city" (J. Kenworthy 2011, p.109).

The question that rests then is under which conditions can metropolitan areas set-up metropolitan governance arrangements that allow for more effective improvements towards urban sustainability in transport. A question that needs to be addressed from the assumption that as Lefévre (2005) says, there cannot exist two powers for one single territory. 
For the purpose of this dissertation, an emphasis is made on the latter. Exploring the determinants of urban sustainable transport from the perspective of metropolitan governance makes sense, as it allows us to delve into the particularities of coordination issues, intergovernmental arrangements, and other particular dynamics of metropolitan level patterns of rule, thus contributing to this quest for the mechanisms behind the various city outcomes in transport sustainability.

\subsection{Institutionalism in the Urban Context}

\subsubsection{Theoretical Strands}

Classic institutionalism was focused on the study of formal institutions. With a focus on norms and values, organizations were valued as avenues for control and were seen to be mostly managed following strict economic principles (March \& Olsen 1989). With the advent of new institutionalism, as a partial answer to the rational choice theory, informal norms and symbols become crucial in analyzing the ways in which institutional settings and individuals affect each other (Bevir 2009).

Within this new dimension, the most common varieties of the institutional theory comprise: rational choice institutionalism, sociological institutionalism, and historical institutionalism (Hall \& Taylor 1996). Although essentially allowing for the study of the same institutional phenomena, these competing factions propose different avenues to answering the same questions.

Rational choice institutionalism is deeply rooted in individualism. Proposing thus, that actors are always calculating their actions in terms of the maximization of their satisfaction, and thus, can influence the form of institutions, so that these serve the specific interests of people, as their preferences change (Torfing 2001).

Sociological institutionalism, on the other hand, tends to define institutions in a broader sense, including symbols and moral patterns that guide human actions, apart from rules and formal procedures (Adcock et al. 2007; J. W. 
Meyer \& Rowan 1977). As such, cultural and informal perspectives gain a strong influence in the analysis of organizations.

Within historical institutionalism, institutions are conceived as the procedures, routines, norms, formal, and informal conventions that are ultimately attached to organizational structures (Hall \& Taylor 1996). Institutions are thus associated to organizations but also to rules and other conventions, while much lesser emphasis is made on the micro-level particularities of individual behaviour (Bevir 2009).

Moving from rational choice institutionalism to historical institutionalism implies the abandonment of the perfect rationality assumptions. Thus, the imperceptions of the former, could now be understood as contributions within a model of the latter. Moreover, based on the interactions between institutions (formal and informal procedures, routines and rules), and the specific political strategies grasped, this variety of institutional theory allows for the understanding of those processes forming particular governance regimes in particular contexts (Procopiuck 2011).

Historical institutionalism also awards agency to a broader spectrum of groups and behaviours, hence admitting the potential from various actors and informal dynamics to affect the political arenas. This includes elites and the state, but also non-traditional actors such as bus drivers or social activists; their interactions with institutions promote a dynamic approach to studying history.

This dissertation takes a more cultural approach of historical institutionalism as a base for analyzing urban transport sustainability. As opposed to a calculus approach, this project assumes that "institutions provide familiar patterns that individuals rely on in their attempt to attain satisfactory outcomes"(Bevir 2009, p.113). It is thus an approach in which human actors are accepted both as agents and objectives of historical changes (Thelen 1999).

\subsubsection{Path Dependency}

When explaining changes in institutions, historical institutionalism proposes the concepts of 'critical junctures' and path dependency. These unintentional consequences suggest that although institutions generally 
mend their own development, at key times the path is altered, when crucial decisions are made (Bevir 2009).

A path dependence model considers the specific historical development conditions of each context, and as such rejects the idea that the same strategic action will generate the same results in different contexts (Procopiuck 2011). Conversely, the variety of results will be much closer related to the consequences of the interactions between various powerful policy actors (Hall \& Taylor 1996).

Institutional innovation also occupies a central position when studying path dependency. Often, the forces related to the successful creation of an institution are quite similar to those forces needed for long-term institutional survival. Institutions as "rules of the game" are difficult and costly to establish; hence, once established, institutions may be an important source of path dependency in their own right" North (1990).

Some theorists claim that innovation is "path dependent". Fagerberg et al. (2009) explain that "choices made in the past influence innovation today, and contemporary innovation activity will similarly leave its imprint on the opportunity set facing future entrepreneurs. Thus, "history matters" (Fagerberg et al. 2009, p.4). In explaining innovation as a cumulative phenomenon, building from existing innovation, this idea is in line with that by Schumpeter (1934) arguing that innovation should be distinguished from invention, which in turn is defined as the creation of new ideas (Schumpeter 1934)

Even though the term is widely used in the recent literature on economics and social sciences, 'path dependence' is often used without careful elaboration (Pierson 2000). Some clarification is offered by Mahoney (2000), when he argues that:

"Path dependence characterizes specifically those historical sequences in which contingent events set into motion institutional patterns or event chains that have deterministic properties. The identification of path dependence therefore involves both tracing a given outcome back to a particular set of historical events, and showing how these events are themselves contingent occurrences that cannot be explained on the basis of prior historical conditions" (Mahoney 2000, p.507). 
As it relates to urban policy-making, path dependence can provide a rigorous framework for understanding specific patterns of timing. Theory suggests that present urban policies are pre-determined by previous decisions, which implies high reversal costs for making major changes to the system (Thelen 1999; Schafer \& Victor 2000; Mahoney 2000). Large consequences may result from contingent events, which in turn once introduced, can be almost impossible to reverse, even if they are relatively small (Pierson 2000). For urban studies then, it is key to consider that a "sequence must meet two criteria to qualify as path dependency: a point of departure, a trigger which is contingent and which itself is not determined by laws or more general trends; and, a series of successive events $-\mathrm{A}, \mathrm{B}, \mathrm{C}$, D- with proven and explicable causal links" (Pflieger et al. 2009, p.1423).

Urban transport is a policy area that depends highly on building and capital expenditures. Thus, it can be particularly hard to reform, as major changes in the status quo mean pronounced costs to various vested interests. Ignoring the fact that early choices in urban transport constrain possible future choices has limitations in understanding the context of metropolitan decision-making. When high political and/or financial reversal costs 'lockin' initial decisions, the choice of future transport modes becomes constrained by path-dependency (Schafer 2000).

\subsection{The Case for Latin America}

Latin America as a region is composed of more than half a billion inhabitants with dozens of nations exhibiting a vast variety of racial backgrounds and diverging economic histories. Moreover, it also has "the most unbalanced distribution of resources of all regions in the world" (Hoffman \& Centeno 2003, p.363), an issue that permeates most contemporary discussions about Latin America.

A crucial historical period for Latin America's recent development is related to the Import Substitution Industrialization (ISI) economic model. Under this model of "inward-looking growth" started around the 30's and 40's, great urban industrialization generated an extraordinary redistribution of the rural to urban population (Lattes 1995). In detailing the various consequences that the ISI model had on Latin American cities, Portes \& Roberts (2005) highlight the fact that a "growing population put upward 
pressure on land and housing markets, leading to prices that bore no relation to wages in either formal industry or informal services" (Portes \& Roberts 2005 , p.44). Informal settlements sprouted along urban peripheries in what became known as 'shantytowns", built precariously but with simple traits resembling the traditional villages and ways of life of the rural areas (Jaramillo 2012). At the same time, however, the "elites and middle classes also abandoned the city center, relocating to increasingly remote suburban areas"(Portes \& Roberts 2005, p.45), thus starting to follow a traditional North American city suburbanization dynamic.

More momentous changes came with the dismantling of the ISI model during the late 70's and 80's. Giving way to a model based on open markets, privatization, and a reduced role of the central state in directing the economy (Lattes 1995), which had significant consequences for urban societies in the region. As the process of decentralization moved ahead, increasing unemployment prompted a decline of the formal working class, and a rise of inequality as economic benefits accrue to a minority of the population (Portes \& Roberts 2005; Salinas \& Wormald 2003). By the $21^{\text {st }}$ century, Latin America was already, by far, the most unequal region in the world (Portes \& Hoffman 2003), with the top 5\% of the region's income ladder receiving twice the share of their OECD counterparts while the bottom receiving half of what their OECD counterparts receive (Hoffman \& Centeno 2003, p.365).

Latin American cities today continue to bare a strong legacy in their urban form, from the prevalent economic models of the $20^{\text {th }}$ Century. Several challenges continue to be shared across the region: "urban spaces are used without formal organization, degradation of natural resources, pollution and biodiversity destruction, disparities in regional development, among others" Massiris Cabeza 2012, p.29). Although fast urbanization and motorization could pose additional challenges to the region, cities offer the best opportunity to improve income levels and quality of life in Latin America (Rojas 2005). An opportunity for research contributions in this matter opens when considering that cities in this region exhibit particular characteristics that merit an analysis in their own context. As Monzón highlights in his study of urban transport in Latin America: "probably the greatest errors are produced when policies that have been successful in certain conditions and contexts are applied in different situations" (Monzón 2005, p.409).

\footnotetext{
${ }^{5}$ Also known as tugurios, favelas, villas in Spanish and Portuguese.
} 
Cities in this region rarely exhibit government institutions dedicated to planning that cover the full metropolitan scale (Massiris Cabeza 2012). On the other hand, however, the service provision challenges posed by rapid urbanization trends in the region, require better metropolitan-wide planning approaches (Economist Intelligence Unit 2010). This lack of governmental entities covering the full metropolitan scale is made worse by weak coordination and institutional collaboration in urban planning (Paiva 2003).

The resulting fragmentation poses a significant challenge for institutional coordination efforts. In order to generate public policies at the local city level, governments often have to coordinate efforts with regional, national and/or international institutions (Sager 2005). Thus, coordination capabilities turn out to be important attributes in designing and implementing metropolitan-wide policies for certain urban services like transport, air quality, waste collection, sanitation, and others.

Efforts at institutional coordination are thus frequent contributions to metropolitan governance. These efforts take the form of various arrangements with different results. Walker (1987) and Mitchell-Weaver et al. (2000) offer measurement scales to grasp the various magnitudes of intergovernmental coordination at the metropolitan level. The scale chosen for this dissertation describes the various arrangements, with different magnitudes of coordination, which are possible within metropolitan patterns of rule (see Figure II-8). The sections titled "hardest" comprise city-county wide consolidation (as one-tier consolidation); broad federal structure (as two-tier restructuring); and full-fledged metropolitan-wide structures (as three-tier reform).

Latin American metropolitan areas have interesting conditions framing local policy making. One of the most notable characteristics of the recent evolution in public administration for Latin America has been decentralization of public functions (Rojas 2005). Aiming at improving competitiveness and economic growth, national governments are increasingly transferring responsibilities to the sub national levels of government. However, this initiative has encountered significant obstacles from the lack of efficient intergovernmental relationships across levels of governments, both vertically and horizontally (Willis et al. 1999; Rojas 2005). According to Paiva (2003), Latin America is an interesting region to assess metropolitan governance developments: "in many of [Latin America's] cities, government functions on multiple geographical scales. 
Table II-5: Types of Intergovernmental Coordination in Metropolitan Governance

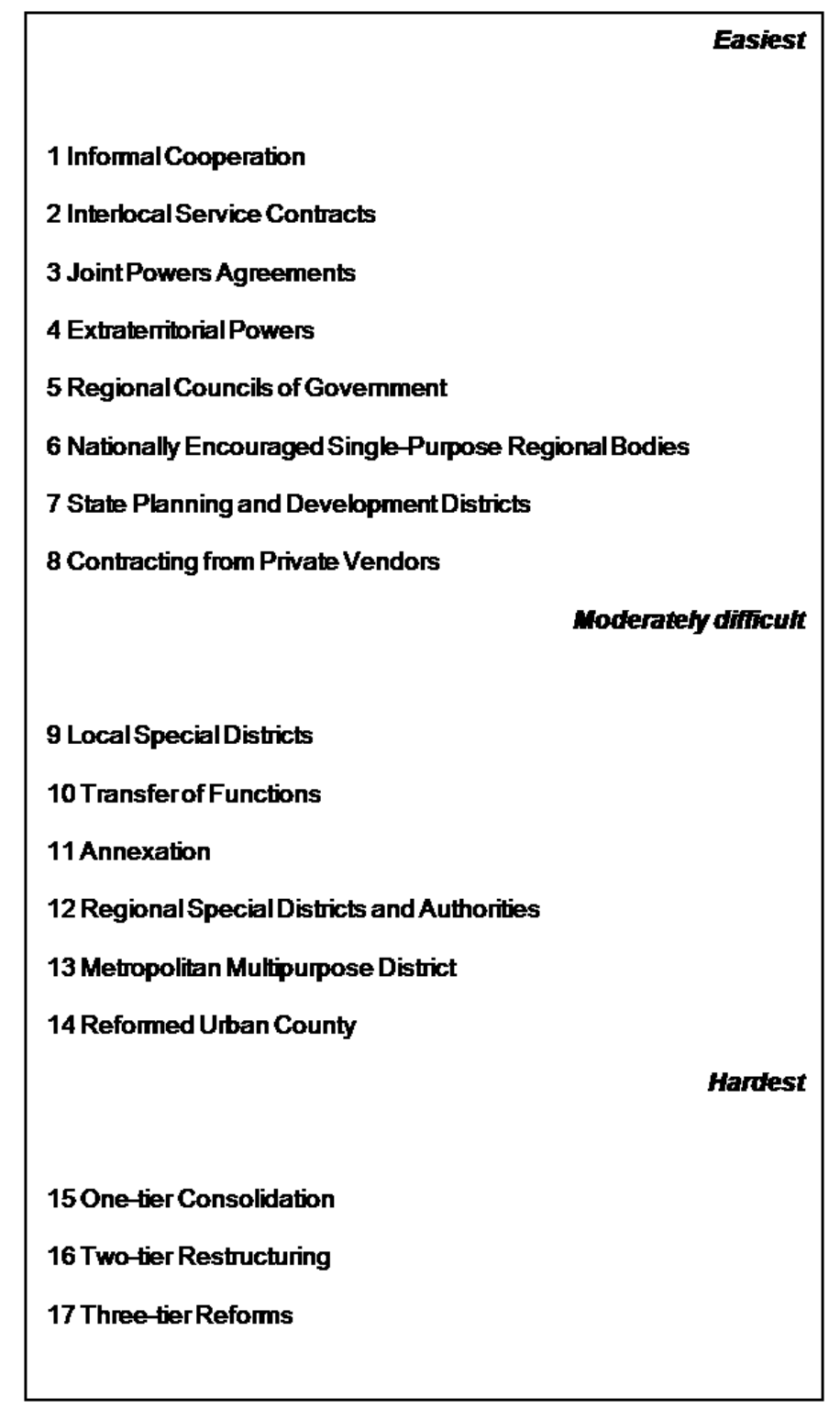

Source: Adapted from Mitchell-Weaver et al. (2000) and the original by Walker (1987).

The interlocking connection, coordination, and aggregation of public action are a chaotic, fragmented, dispersed, contradictory, and on occasion redundant. This deplorable situation is rarely translated into a public political issue, although the major problems of the city are directly related to 
the questions of scale. These may concern geographical scale, metropolitan scale, or economy of scale" (Paiva 2003, p.18).

Current conditions in the region make advanced tiers of coordination difficult and costly. Various nations in the region have seen major waves of decentralization and re-territorialisation since the 1990's (Boisier 1997; Willis et al. 1999), which have empowered local governments with greater competencies and autonomy of functions. However, excessive decentralization is also regarded as dangerous. As Lefévre (2005) remarks, when municipalities acquire too much autonomy and self-control, they can fall in "institutional racism", thus curtailing intergovernmental coordination.

The standard set-up now for Latin America, usually makes local governments subordinate to other levels of government, with less powers and responsibilities, while key decisions about powers and finances get taken at other levels (John 2006). In fact, according to Rojas (2005), only $15 \%$ of the government expenditures are controlled by local authorities, a stark contrast to the average for industrialized nations of 35\% (Rojas 2005, p.45).

Furthermore, for specific issues related to certain urban services, such as transport, isolated local planning can generate even challenges for the region. For example, to have separate transport companies serving different groups that inhabit the same functional metropolitan unit, would only bring inefficiencies. In this sense, metropolitan arrangements seem to make much more sense.

Policy making is the other great institutional challenge for a region that still lags behind in transport sustainability. Nevertheless, many Latin American cities often lack the institutional capacity to design, implement, and enforce policies within highly dynamic sectors, such as urban transport. In this region, for instance, policy-making is often marked by a disconnection between political rhetoric and policy action; leading to notable plans and proposals that frequently do not materialize (IADB 2006).

Policy action needs to be given greater importance in the context of Latin American cultural dynamics. As Cook \& Wagenaar explain, when critiquing the traditional approach to policy analysis, traditional assessments of political processes give major weight to theoretical outputs, without considering the actual actions that support these arguments (Cook \& 
Wagenaar 2003). Considering action as a fundamental component of metropolitan policy analysis guarantees greater precision for my study.

Against this backdrop then, this dissertation is developed as a contribution to similar studies on urban transport sustainability and metropolitan governance, yet, with a particular focus to Latin America, and the specific social and cultural contexts of some key cities. Metropolitan coordination, metropolitan scale planning dynamics, and metropolitan-wide policymaking are regarded as issues of utmost importance in this analysis. 


\section{Chapter III}

\section{Methods}

"Not everything that can be counted counts, and not everything that counts can be counted" -William Bruce Cameron

\subsection{Introduction}

This chapter describes the research design and methods chosen for this dissertation. It has been constructed based on the concepts of sustainable transport and metropolitan governance, composing the theoretical framework previously shared, as it aims to fill some of the gaps still found in the literature. The project is mostly based on a qualitative approach around a comparative case study backbone; furthermore, this approach is complemented by an empirical characterization of the sustainability of transport systems in the chosen cities, and according to the selected indicators to measure this. Ultimately, the objective has been to generate knowledge regarding the political determinants that lead to higher levels of sustainability in transport in Latin American cities ${ }^{6}$.

\subsection{Meta- Methodology}

The possibility of any chosen method for generating valid knowledge depends on the initial alignment with the more profound philosophical questions structuring any research. Hence, it has been crucial to define solid ontological and epistemological bases from the very first steps of the study, so as to guarantee a consequential process in generating valid knowledge. As Bevir reminds us, "only when we know what kinds of knowledge and explanation are apt for political science can we intelligently decide what methods are best suited for producing them" (Bevir 2008, p.48).

6 The concept of sustainable transport, as well as the measurement scales that I have defined for this study are described in detail in Chapter 2. 
Throughout this dissertation, Denzin \& Lincoln's (1994) definition of qualitative research is used as the main characterization for the method of inquiry:

"Qualitative research is an interdisciplinary, transdisciplinary, and sometimes counterdisciplinary field. It crosscuts the humanities and the social and physical sciences. Qualitative research is many things at the same time. It is multiparadigmatic in focus. Its practitioners are sensitive to the value of the multimethod approach. They are committed to the naturalistic perspective, and to the interpretive understanding of human experience. At the same time the field is inherently political and shaped by multiple ethical and political positions. Qualitative research embraces two tensions at the same time. On the one hand it is drawn to a broad, interpretive, postmodern, feminist, and critical sensibility. On the other hand, it is drawn to more narrowly defined positivist, postpositivist, humanistic, and naturalistic conceptions of human experience and its analysis" (Denzin \& Lincoln 1994, p.3).

In terms of broad theoretical paradigms, this study aligns closely with the constructivist paradigm, reflecting an understanding of a subjective and multiple reality (SAUTU et al. 2005). This, within a context that proposes a continuum between positivism and constructivism, as converse possibilities for adopting ontological assumptions about the nature of reality (Procopiuck 2011).

This research intends not to construct parsimonious rules, but rather, to find specific patterns for specific periods in the reality of the studied cities. This dissertation is informed by a belief in scientists' capacities to construct knowledge from the realities analyzed, rather than just discovering it. Furthermore, a crucial ontological principle refers, precisely, to the nature of reality. Only the natural sciences fulfil the requirements for attaining fully objective realities (Haig 1995); thus, in the process of this dissertation, it is more plausible to identify limited generalizations pertaining the determinants to sustainability of transport in the studied cities, than general laws that apply for the whole Latin American region at any point in time; as Gerring (2012) describes it, limited generalizations may have vast implications for subsequent developments, "in explaining $\mathrm{X}$, one may also, by extension, be explaining other phenomena. Second, each of these events 
may be regarded as a case study of a more general phenomenon..." (John Gerring 2012, p.62).

The specific researcher-object of study relationship is a crucial epistemological question. The constructivist approach adopted in this thesis calls for an active immersion of the researcher within the investigated context, because the actual interaction between the researcher and the object of study is accepted as a valid contribution to the study, and stimulates mutual influence (SAUTU et al. 2005). Moreover, this research is distanced in this way, from a purely positivist paradigm, advocating for the complete separation between researcher and object of study, as a pre-requisite for attaining objective knowledge.

Due to their very own nature, epistemological assumptions are ontologically charged. As the "study of the nature of knowledge and justification" (Moser 2005, p.3), epistemology deals with attaining legitimacy for research conclusions, particularly while focusing on: "(1) the defining components [of knowledge], (2) the substantive conditions or sources, and (3) the limits of knowledge and justification" (Moser 2005, p.3). In describing our acquired knowledge, one additional temporal characteristic must be accounted for: this research deals with urban sustainability and political decision-making processes that are in constant evolution. As such, the results of these are directly characterized by the human interactions that define them, and which I see as unfeasible to fully determine objectively.

\subsection{Research Approach}

This dissertation has an explanatory nature rooted in an evidence-based research approach. By establishing an empirical characterization of the urban transport sustainability levels, and complementing it with a qualitative analysis of the specific transport developments for three cities, hypotheses are generated, as inputs for theory construction. This project uses a casestudy approach not for theory testing, but rather for the generation of conjectures that can reflect the real happenings in the practical contexts of the studied cities. This approach is justified, as Gerring (2007) puts it, because "social science research involves a quest for new theories as well as a testing of existing theories; it is comprised of both "conjectures" and "refutations". Regrettably, social science methodology has focused almost exclusively on the latter. The conjectural element of social science is usually 
dismissed as a matter of guesswork, inspiration, or luck - a leap of faith, and hence a poor subject for methodological reflection" (John Gerring 2007, p.39)

The choice of evidence-based research as a guiding approach is justified by the nature of the phenomena analyzed. There is no clarity on the political and institutional conditions that have facilitated (or curtailed) sustainability of transport in Latin American cities, even though there has been a clear interest in the issue for some years (CAF 2011). By starting from collecting first-hand evidence on the conditions of these cities, and iteratively assessing the ideas prompted from this evidence with the actual practitioners and experts involved in the processes, contributions between political conditions and urban transport sustainability are generated.

In identifying these conjectures, this dissertation follows a structured framework influenced by the less structured power of 'intellectual love', which Einstein describes, as cited by Popper: "there is no such thing as a logical method of having new ideas, or a logical reconstruction of this process $[\ldots]$ every discovery contains 'an irrational element', or a creative intuition', in Berson's sense. In a similar way Einstein speaks of 'the search for those universal laws...from which a picture of the world can be obtained by pure deduction. There is no logical path', he says, 'leading to these...laws. They can only be reached by intuition, based upon something like an intellectual love ('einfühlung') of the objects of experience"' (Popper 2002, p.8).

Previous studies have taken similar approaches. In analyzing atypical public sector performance in dysfunctional environments, Abah (2012) highlights that "using this method successfully requires both a deep immersion in the evidence (couple with practitioner experience of what works), and an iterative approach to theory building that views theory from multiple perspectives" (Abah 2012, p.20).

This research does not start from a 'blank sheet'. Instead, the starting point comprises a review of literature to formulate initial questions and assumptions. The overall framework of this dissertation is based on the "Evidence Based Model" proposed by (Gray 2004), as shown in Figure III1. 
Figure III-1: Overall Methodological Framework

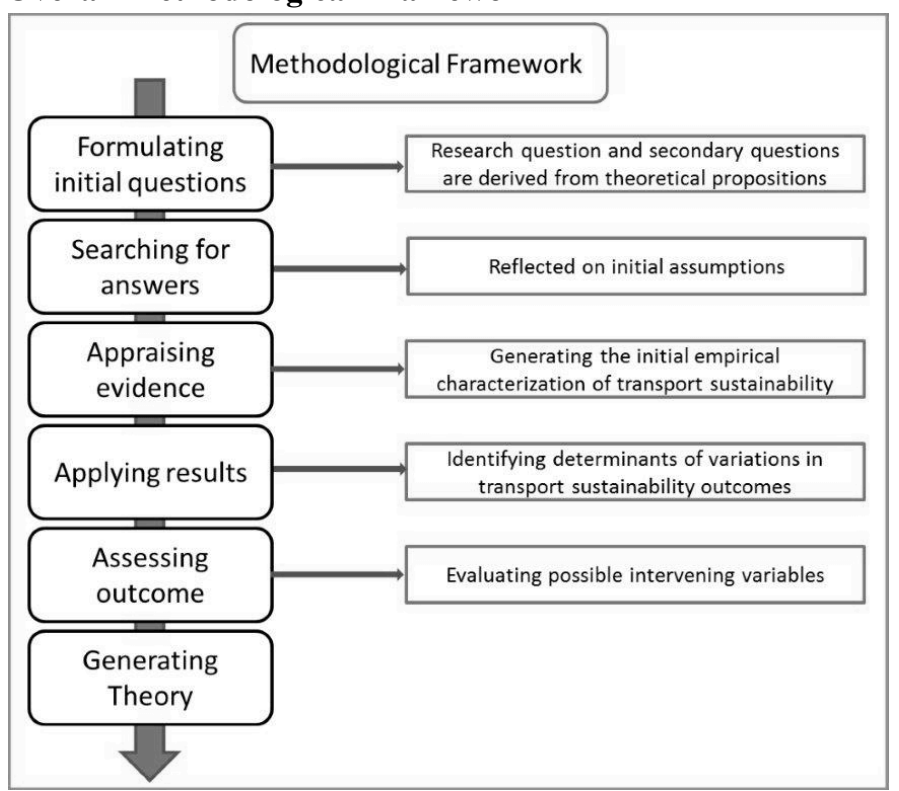

Source: own elaboration based on Gray (2004).

Moreover, this framework is combined with an inductive research strategy operationalized through a comparative case study approach. This choice is an important one, as Blaikie states: "the choice of research strategy, or a combination of them, constitutes the second most important research design decision. The reason for this is that I believe knowledge can only be advanced in the social sciences by using one or more of these research strategies" (Blaikie 2010, p.24). The inductive strategy allows the collection of data that then is used to derive conjectures using an inductive logic (Blaikie 2010). On the other hand, the comparative case study approach strengthens the robustness of findings, because "investigating an issue in more than one context is often better than basing results on just one case" (Blumberg et al. 2008, p.376).

Furthermore, some components of an abductive theory are borrowed into the general research strategy. Due to the interest in understanding the motivations for crucial actors in implementing certain policies in the sustainable transport arena, it is convenient for this project to "develop 
concepts and theory in conjunction with data collection" (Blaikie 2010, p.253), during the final interview phases.

This overall approach aims at mapping the complexities of the institutional and political factors behind the transport sustainability outcomes of the studied cities. This approach has been designed to (a) seek explanations for the variation in outcomes; and (b) determine if the empirical facts meet the theoretical expectations. Ultimately, the cross-case comparison for sustainable transport allows to deeply "dig into the details of how phenomena come about and develop insights [...] that current theories cannot accommodate" (Geddes 1990, p.149, emphasis added).

\subsection{Level of Analysis and Time Dimension}

Selecting an appropriate level of analysis is a crucial decision while designing a comparative study. Landman (2008) suggests a distinction between macro and micro levels; focused at the national level, and subnational levels, correspondingly. In this respect, this study takes a caseoriented approach at the sub-national level, with the unit of analysis being the city (full metropolitan area). Due to the social constructivist perspective of this study, an emphasis is places on the role of individual activity, cultural and social behaviours, as well as their implications on the public policy processes related to urban transport. Nevertheless, this study is focused on urban transport systems, and the way in which these influence the composition of cities. Landman (2008) highlights the consequences that a rigid selection of a level of analysis might bring, when referring to the "structure-agency" problem: "micro-analysts believe that the world of politics is shaped by the actions of "structureless agents"" (Landman 2008, p.19). As such, the data collection, data analysis and report writing stages of this dissertation are interrelated, and firmly grounded on the understanding that all key informants are also influenced by the structure provided by each city, and its institutions.

All efforts have been made to avoid confusion in the level of analysis throughout the study. Doing so, could lead to committing aggregate (ecological or individualist) fallacies Lor (2014). Ecological fallacies refer to inferences made about individuals on the basis of data about larger units; while individualistic fallacies refer to inferences made about a higher level of measurement from analyzing data at a lower level. In the case of this 
research, for example, the interaction between the individual level decisions by policy makers, and the structures of the local planning institutions, could be measured at a different level than what the sustainability of urban transport (the dependent variable) is measured. As such, precautions are taken to avoid mixing levels of analysis.

This study is mainly a historical one. Historical studies "deal with social events or phenomena in the past, and are very different in character to those that can collect data about and from people in the present" (Blaikie 2010, p.229). Interviews are based on specific situations that have taken place during the last twenty years in the studied cities. However, findings about the past are also connected with the actual situation in the present, and allow for critical contingent events from moments outside of this range to be considered within the analysis.

\subsection{Research Questions}

The core objective of this research project is to identify the institutional and political factors that determine variations in transport sustainability outcomes across metropolitan areas of Latin America. Even though "there is no universally accepted definition of sustainability, sustainable development, or sustainable transport" (Litman 2007; p. 10), for the purposes of this study the following definition is adopted, based on the UNEP (2011) definition of green transport:

Green transport promotes (1) environmental sustainability through the protection of the global climate, ecosystems, public health and natural resources; (2) economic sustainability through an affordable, fair and efficient transport that promotes a sustainable competitive economy as well as balanced regional development and the creation of decent jobs, and; (3) social sustainability by allowing the basic access and development needs of individuals, companies and society to be met safely and in a manner consistent with human and ecosystem health, while promoting poverty reduction and equity within and between successive generations (UNEP 2011). 


\subsubsection{Main Research Question}

Under which political and institutional conditions is sustainability of urban transport facilitated in Latin American metropolitan areas?

In order to appraise the true sustainability of the transport systems, this study begins by providing an empirical characterization of the level of sustainability in transport for sixteen metropolitan areas through a set of sustainability indicators. This empirical characterization is used as the base for examining the policies that are connected to these outcomes.

Ultimately, the political and institutional determinants of these implemented policies are mapped and contrasted across the studied metropolitan areas. For clarification purposes, implementation is defined separately for those policies that are construction intensive, and those that are not. For the former, implementation is understood as the moment when the facility is opened to service for the public. This is the case for roads, metro systems, bike lanes, and other facilities that need to be built. For the latter, implementation is understood as the moment when the regulation becomes legally binding for the public. This is the case for taxes on fuel, transit restrictions, one-waying streets, and other regulations that can be put into place in shorter timeframes. By accounting only for services that are available to the public, and regulations that are legally binding, I intend to correct for policies and plans that are decided on, but never fully implemented.

\subsubsection{Secondary Questions}

To answer the central research question, these additional issues are examined:

- Which are the patterns in sustainability trends characterizing the urban transport systems in Latin America? How do these systems compare against each other in terms of sustainability?

- How do transport policies become decided upon and implemented in metropolitan areas? What is the role of metropolitan governance in influencing urban transport sustainability?

- Which urban policies determine variations in transport sustainability outcomes? Which other factors determine these outcomes? 
- How relevant are previous policy decisions in explaining present transport policy decisions?

- How do institutional and political factors explain the variation in the implementation of sustainable transport policies across metropolitan areas?

\subsubsection{Dependent Variable: Sustainability of urban transport}

The dependent variable has been defined along three separate dimensions: environmental, economic, and social. By separating them, possible tradeoffs between these dimensions are accounted for. One might encounter, for instance, that some conurbations rank very high in social sustainability, yet very low in environmental sustainability, which provokes different repercussions for the overall assessment of its sustainability.

These dimensions are operationalized via 33 indicators adapted from lists compiled by Alberti 1996; Nicolas, Pochet et al. 2003; Litman 2007, and; CAF 2009. The CAF Mobility Database provides data for these indicators for the year 2009. The construction of the indicators and the index is described in detail below in this chapter.

\subsubsection{Explanatory Variables}

The mechanisms of four explanatory variables on the implementation of sustainable transport policies are explored in this dissertation. These explanatory variables have been adapted for the context of Latin America from general lists proposed by Gakenheimer (2004; p.169) and Sperling $(2002 ; \text { p. } 25)^{7}$. However, these potential explanatory variables are only used as focus points during the case study comparison, to identify the key crosscase themes, and then, the strategic premises leading to a final theory for the dissertation.

\section{Degree of centralization of authority in metropolitan governance: \\ Refers to the strength of a local government to implement policies}

${ }^{7}$ However, the author is aware that other factors could prove to be important at later stages of the research. 
autonomously. Local governments acting in highly centralized systems can find it hard to implement certain policies that are not supported by higher levels of government.

2. Institutional coordination: Refers to the interaction and collaboration levels of the various institutions involved in deciding upon, and implementing sustainable transport policies. This variable is measured following the intergovernmental co-ordination and policy collaboration scales suggested by Walker (1987); and Mitchell-Weaver et al.( 2000), and focuses on two types of decisions:

a. Land-use decisions: Some of these decisions include zoning, and preservation of specific corridors for future transport related use.

b. Public transport decisions: Some of these decisions include the location of metro stations, the routes for inter-municipal buses, and the prices for tickets.

3. Interactions between political players: Refers to the planners, mayors, city council members, presidents, ministers, governors, and organized interest groups involved in deciding for and implementing sustainable transport policies. Each actor will strategically influence the policy process according to his or her own specific interests. This project is started by assuming that some of this political interaction might include:

a. Character and weight of political leader(s): Characterizes political leaders on the basis of their political ideology, and the size of their coalition in the city council. Stronger political leaders could be more successful in breaking path dependencies and leading institutional change.

b. Political player conflict: Addresses the nature of the discussions between the political actors involved in the policy process. Previous and/or unrelated political conflicts could disturb, reframe, or determine the implementation of sustainable transport policies.

c. Technical-Political conflict: Addresses the nature of the technical discussions around sustainable transport policies between transport planners and politicians. Although serving different responsibilities, the interaction between these groups defines the agenda for sustainable transport policies.

d. Strength of organized interest groups: Addresses the ability of these groups to affect policy. Organized interest groups are 
understood as "collective non-state actors participating in governance [by influencing public policy making]" (Hassel 2010; p. 4, own emphasis), and as such, they often play important roles in defining plans, and framing discussions. This variable is characterized according to the typology of organized interests proposed by (Scharpf 1997) ${ }^{8}$.

4. Type of initial stimulus: Refers to the financial, political, or social factor(s) sparking the revision or introduction of key policies. Common ones are ordinary revision of public policies, crises (such as a hike in oil prices), and an election of a political leader on a specific policy change agenda, which gives him or her a strong mandate for policy change (Bratzel 1997). Different initial stimuli can spark sequences of events, with different impacts on path dependencies.

\subsection{Hypotheses}

Initial hypotheses can be tentative answers to research questions, but can also guide the process of theory construction (Blaikie 2011). For this dissertation, guiding assumptions are used as a base for constructing an evidence-based theory. In this type of studies, hypotheses will often emerge from the evidence arising out of the completed study (Abah 2012).

Since hypotheses are not tested in this research, they are not explicitly offered initially. Blaikie (2011) explains the importance of using solid hypotheses for some research projects, "however, not all research questions, or all research projects, require hypotheses. They are particularly relevant to 'why' questions and perhaps to some 'how' questions, but they are not relevant to 'what' questions. In addition, hypotheses are only relevant when research is about theory testing, and they are not relevant when the concern is with theory development. The latter may use many tentative hypotheses in the trial and error process of developing theoretical ideas to account for the data at hand, but these cannot be formulated at the research design stage" (Blaikie 2010, p.27).

Although the final hypotheses of this study may arise during the process of the research, these guiding assumptions are offered:

8 Please refer to appendix 5 for an insight into this typology. 
Guiding assumption \#1: Political conditions are equally important to financial conditions in increasing levels of urban transport sustainability. Guiding assumption \#2: Some institutional conditions in Latin American cities result in higher levels of sustainability in transport.

Guiding assumption \#3: Previously taken decisions determine the major public policies implemented in urban transport in Latin American cities.

\subsection{Index Methodology}

An empirical description of the current state of transport sustainability has been developed for sixteen large $e^{9}$ metropolitan areas in Latin America, by means of an index. This mix of metropolitan areas represents the diversity of realities in the continent, and facilitates an understanding of the general trends in urban transport sustainability for Latin America.

The Green Transport Index (GTI) scores sixteen cities ${ }^{10}$ from nine Latin American countries, across three baskets -environmental sustainability, social sustainability, and economic sustainability- using 33 indicators. The choice of indicators was grounded on the corresponding literature, and significantly constrained by the availability of data in Latin America, as has been described in Chapter IV. All of these, aim at quantitatively measuring how each city is currently performing (both in terms of quantity and quality). Thus, qualitative assessments of cities' aspirations or proposals are not included, as it is assumed for this dissertation, that Latin American policy-making is often marked by a disconnection between political rhetoric and policy action; leading to notable plans and proposals that frequently do not materialize.

However, this thesis is built upon a theoretical understanding that empirical characterizations, such as the GTI, can in fact be used to impact positively the sustainability levels of transport in cities. Moreover, the right set-up for this research projects can generate greater interactions between the economic, social, and environmental dimensions of sustainability, with the less discussed political and institutional dimensions affecting ultimate levels of urban sustainability. This interaction can be recognized in the basic

\footnotetext{
${ }^{9}$ More than one million inhabitants by 2009.

${ }^{10}$ For general descriptions of the chosen cities, please consult the annex.
} 
model proposed by (Zegras et al. 2004) in Figure III-2. Raw data is used to compose an index, which aims to generate policy relevant conclusions, in a particular field of sustainable development, for a particular region of the world.

Figure III-2: The Information Hierarchy through the Sustainable Indicator Prism
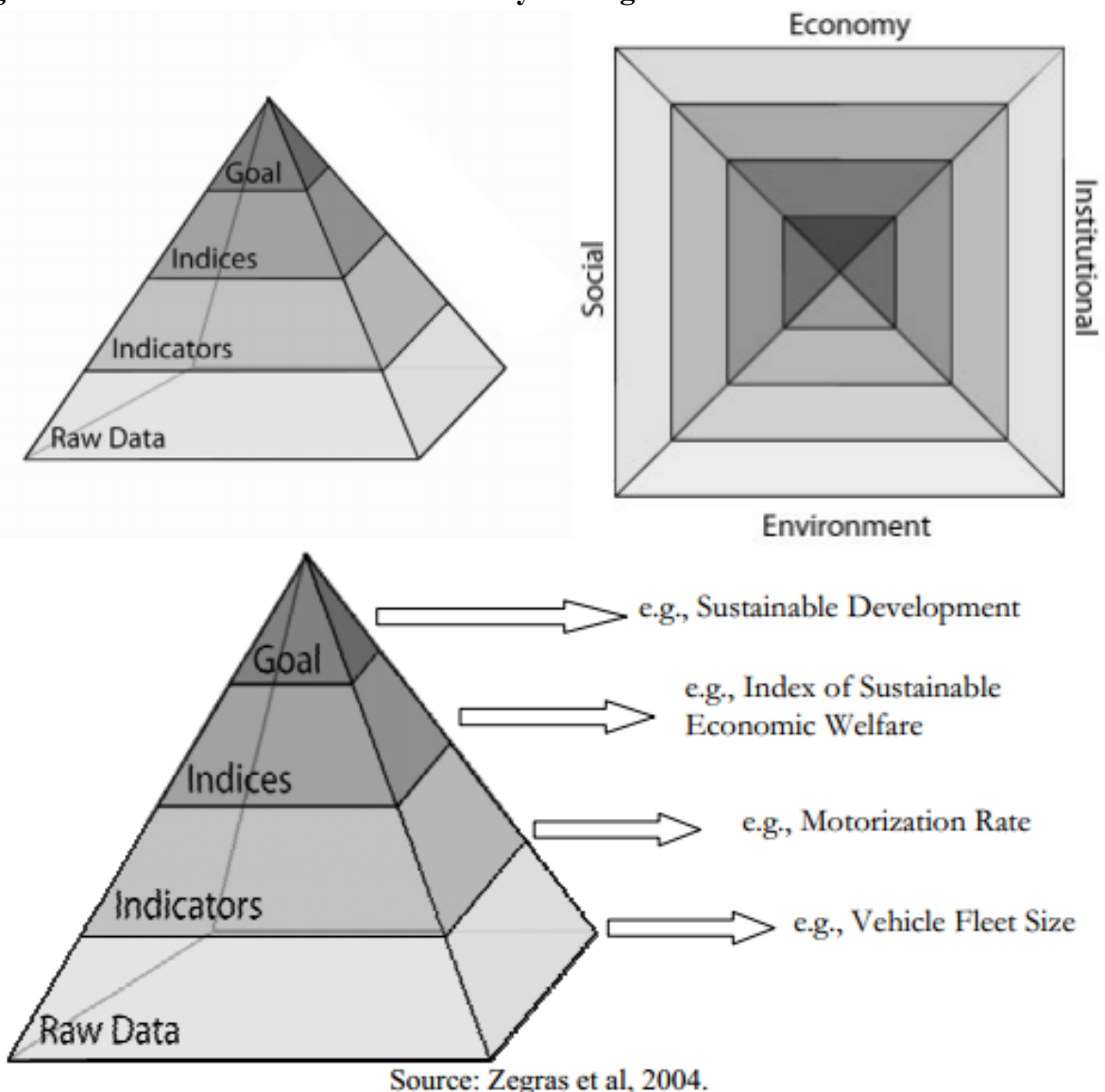

Source: Zegras et al, 2004.

Apart from using this ranking as a measurement tool, this dissertation also aims at providing a powerful decision support tool ${ }^{11}$ for planners, decisionmakers and activists in Latin America. The index showcases variations on sustainability outcomes for the studied cities - hence serving as a

\footnotetext{
${ }^{11}$ For an insight into the use-categories for sustainable transport composite indicators, please refer to the work of Joumard \& Gudmundsson 2010.
} 
measurement tool - but concomitantly stimulates policy action for the relevant actors, due primarily to its nested structure. The final ranking is composed by linearly aggregating all normalized scores in the underlying indicators.

The sub-indicators are firstly aggregated for each basket, creating three separate scores for each category. By maintaining these sub-indices separate, it is understood that a deficit in one indicator may be compensated by a surplus in another (within the same basket); nonetheless, it is expected that this can simultaneously help to discern the political trade-offs faced by policymakers when deciding on projects and policies.

Most of the indicators and structural variables considered in the GTI reflect data from 2009. Nevertheless, some data actually correspond to earlier measurement years, as it takes at least two years for it to be collected, analyzed and published. When some specific figures were impossible to collect, estimates from national measures of central tendency were produced. The environmental basket reflected some of these gaps, as local governments in the region often fail in recording a number of these measures. Clearly, for some of these cities, quantifications of $\mathrm{CO} 2$ emissions could actually be solely estimates of fossil fuel consumption (Parlow 2011, p.40), for example.

All final individual indicators receive equal weighting in the index, thus implying that all are deemed to be equally important in promoting transport sustainability, under the context of the definition used in this dissertation, the applicable literature, and the strategic goal of serving as a decision support tool for relevant local actors. However, the final choice of indicators reflects a heavy emphasis on the social aspects of green transport, as described in the aforementioned definition. This might be regarded as providing a heavier weight to the social basket; nonetheless, this decision aims at creating a healthy indicator mix of what sustainable transport systems should look like in the context of Latin American cities. Hence, even though each basket is also rebased onto a scale of 0 to 10 , the final index does not aggregate the three previously aggregated scores for the baskets, but uses instead a fresh 33-indicator linear aggregation.

In order to make data points comparable across cities and to further build the aggregate scores, all qualitative indicators were normalized using a min$\max$ technique. A [0 - 10] range has been used, by subtracting the minimum 
value from the value to be normalized, and then dividing by the range of the indicator values, thus, following a basic technique suggested by the OECD (2008):

\section{Standard Min-Max Normalization}

$$
I_{q c}^{t}=\frac{x_{q c}^{t}-\min _{c}\left(x_{q}^{t_{0}}\right)}{\max _{c}\left(x_{q}^{t_{0}}\right)-\min _{c}\left(x_{q}^{t_{0}}\right)}
$$

The indicators ${ }^{12}$ chosen to compose the GTI are not intended to become an exhaustive nor ideal list for analyzing sustainable transport wherever. In fact, this dissertation is built on the premise that "highly complex, illdefined or contested phenomena (like 'sustainable transport') are particularly at risk of generating indicators that misguide or legitimize rather than inform actions" (Joumard \& Gudmundsson 2010, p.35). As such, the focus has been placed on selecting valid indicators for measuring the current transport trends, strongly considering the particularities of the Latin American context. Moreover, a strategic decision was taken from the beginning of the project, to concentrate on indicators measuring phenomena that may actually be improved by public policy in the short to medium term. It is crucial thus, to understand what the role of indicators is in an average transportation planning process, and how these could be used to target the accomplishment of actual measurable impacts on sustainability, while framed in the context of metropolitan scales. In visually communicating this, the key theoretical propositions by Zegras (2005) have been followed, as shown in Figure III-3.

The structure of indicators proposed in this dissertation can be used to evaluate changes in transport sustainability through time for this region. If it becomes possible to collect data from the same sources used, at regular intervals, it would then be valuable to update the index and track progress. It is precisely this trait that some authors consider vital when deciding for sustainable transport indicators. Lee (2003), for example, proposes good transport indicators to be regularly updated performance measures that help transport planners and managers to take into account the full range of

\footnotetext{
${ }^{12}$ The list of indicators and their description is presented in Chapter 4 of this dissertation.
} 
economic, social and environmental impacts of their decisions (Lee et al. 2003).

Figure III-3: The Role of Indicators in the Transportation Planning Process

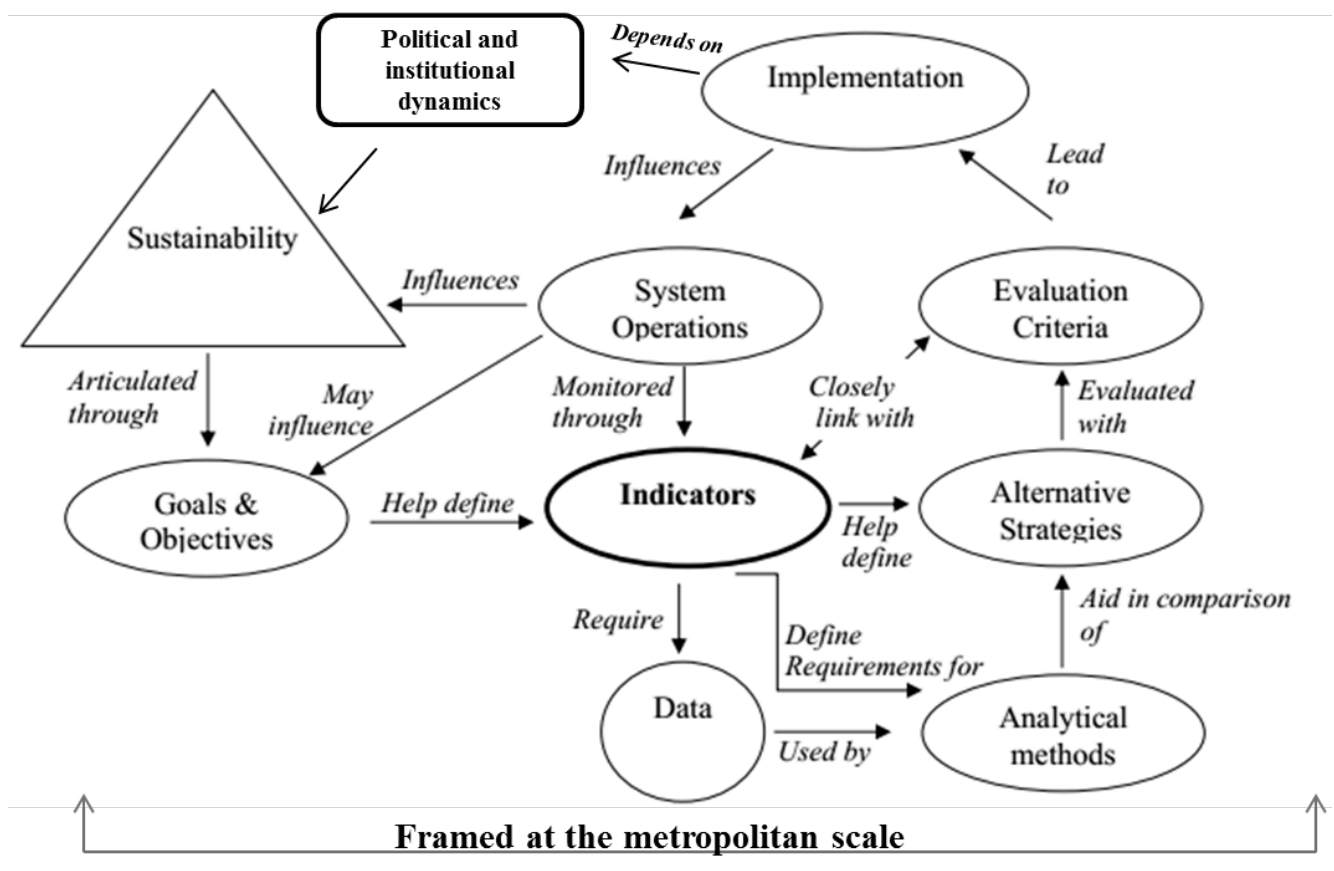

Adapted from Zegras (2005) and Meyer \& Miller (2001)

With a growing awareness of the urgent need to promote more sustainable patterns of transport in Latin America, it has now become "still more important to be able to measure and assess the sustainability of present and future transport trends and policies within the global concept of sustainability" (Joumard \& Gudmundsson 2010, p.19). The Green Transport Index has two-fold objectives; it aims at providing an empirical characterization of the current trends in transport sustainability for Latin American cities, while offering incentives for mobilizations in favour of more sustainable policies. This dissertation intends to affect this arena, as "cities, particularly in the coming years, will require tailor-made policies that are designed to achieve optimal and sustainable results in a costeffective manner" (KPMG 2010, p.2). By capturing objective and measurable outcomes across environmental, social, and economic aspects of transport sustainability, these empirical characterizations allow for 
comparisons in the sustainability performance of cities, and set the base for tracing measurable paths towards improved sustainable mobility.

The separate baskets reflect the complexity of sustainability. The environmental impact of a transport system is clearly important, but this does not reflect whether it is an affordable system for all, or whether it is widely accessible, for example. Hence, for the purpose of this dissertation, these three dimensions of sustainability are considered as equally important, and thus presented separately as sub-indices.

\subsection{Case-Study Methodology}

The results of the initial empirical characterization suggest the need for a deeper exploration into urban transport sustainability levels in Latin American cities, and the relationship to the political processes framing long term urban policies. This approach is valid as it aims to inspect a contemporary phenomenon in its real life context, considering that the boundaries between the phenomenon and the context are not clearly evident (Yin 2009, p.18). For the purpose of this research, the phenomenon refers to the level of transport sustainability, and the context refers to the structural similarities between the studied cities.

The case study methodology is selected to analyze the three cases. This approach implies that "each case is considered as a whole, taking into account the total configuration or constellation of factors and conditions" (Ragin 1987, p.20). Moreover, the chosen methodology emphasizes a shift away from the positivist model of explanation, as described by Gerring (2007). Although this author recognizes that "most methodologists still view case study research design with "extreme circumspection", he suggests a need for more case study research, and a promotion of its understanding: "although much of what we know about the empirical world has been generated by case studies and case studies continue to constitute a large proportion of work generated by the social science disciplines, the case study method is poorly understood" (Gerring 2007, p.93).

It is clear that numerous cities in the region are actively finding ways to promote their urban sustainability and mitigate green house gas emissions (WWF 2010). The case study is useful to provide evidence about the political conditions that have allowed some of the cities to advance much more than other conurbations sharing similar structural characteristics. This 
refers to political, institutional, an governance issues; experts acquiesce that "governance issues for urban transportation [...] require more extensive analysis" (EMBARQ 2010, p.33), one which would find appropriate complement in a case study methodology. As such, accepting the full value of case studies as a methodology that "allows the researcher to explore a situation in depth, looking at such issues as linkages and causality" (W. Naumes \& M. J. Naumes 2006, p.15), the specific intention with this strategy is to map the complexities of the political factors behind their transport sustainability outcomes, using the chosen cases as descriptions of real events, written from the perspective of an objective observer. Even though the author approaches this dissertation with preconceived notions concerning the topic of sustainable transport, from the start it becomes clear that a well-developed systematic case-study methodology "contain no greater bias toward verification of the researcher's preconceived notions than other methods of inquiry" (B. Flyvbjerg 2006, p.237).

\subsection{Case Selection}

The results of the GTI are used as direct input for informing a case selection process. In order to guarantee theoretical relevance, the results from the GTI are complemented with the broader theoretical context for the final selection. In order to represent "the full range of values characterizing $\mathrm{X}, \mathrm{Y}$, or some particular X/Y relationship" (Seawright 2008, p.300), one city from each of the overall performance bands in the GTI has been chosen: top, average and poor. Conversely, in order to minimize variation for the set of structural variables discussed above, and assure that the chosen cities in fact share similar structural characteristics, the variation in structural conditions has been minimized, by selecting three cities with similar population, area, GDP per capita, and population density.

As such, the selected set of cases comprises: Curitiba (Brazil), Guadalajara (Mexico), and Medellín (Colombia). Medellín and Guadalajara are the prototypical second-city cases, constantly in the shadow of the primate cities, and mega-capitals, Bogotá and Ciudad de México, correspondingly. Curitiba, the top scorer in the GTI and eternal urban sustainability leader in the region does not fit as the de jure second-city of Brazil, but considering the enormity of this country's large cities, it certainly enjoys "second-city status", being the capital city of the powerful state of Paraná. 


\subsection{Data Collection}

A variety of data sources have been used throughout the process of writing this dissertation. The urban mobility database published by CAF in 2009, has served as the backbone for the development of the Green Transport Index. Moreover, these indicators on urban mobility have been complemented with data from publications by the Economist Intelligence Unit, the Inter-American Development Bank, and most importantly, pertinent local governmental departments, when available. All of these official sources are open to the public, and properly referenced at the end of this dissertation.

The collection of the necessary data for the case studies was collected via fieldwork in the three chosen metropolitan areas, using semi-structured interviews. The main body of this data consists of a total of 56 key informant interviews, amounting to a total of 210 pages of text of transcribed interviews.

\subsection{Interviews}

The in-depth semi-structured interviews allow an examination of the motivations and roles of the stakeholders in deciding on, and implementing specific transportation policies. In the context of an evidence-based model, these interviews also served as a validation mechanism for the initial findings on the level of transport sustainability during the first empirical characterization of Curitiba, Guadalajara and Medellín.

The researcher spent at least one month in each of the cities, during which, the face-to-face semi-structured interviews with key informants were performed. All interviews were done personally by the author, and were planned to last one full hour. However, some of the interviews had to be cut short, due to agenda issues on the side of the interviewee, while some others ended up going above the 1-hour mark, as the conversation naturally overextended itself. Interviews were recorded, and summaries for the most pertinent sections were transcribed in either Spanish or Portuguese, and complemented with field notes after the interviews. The result of the initial empirical characterization was shared with all interviewees; thus, allowing for their knowledge about the way in which their city is compared to the other analyzed cities. 
A summary of the interviews is presented in Table III-1, where the major weakness of the sample is highlighted; the lack of a proportional representation by both genders within the group of key informants. Even though all efforts were made to secure a large number of female key informants, this was not possible in any of the studied cities. Nevertheless, I was able to confirm throughout the process of the sampling, that this is an accurate representation of the male/female ratio within the fields targeted. It might be related to a cultural heritage in the region, indirectly determining the number of females working in fields related to transport planning, or it could also be related to the average age groups of those sampled. However, this issue is left opened to be explored at another future opportunity. The full names, affiliations, dates and places for each interview are described in the annex.

Table III-1: Key Informants in Curitiba, Guadalajara and Medellín

\begin{tabular}{|c|c|c|c|}
\hline City & Country & $\begin{array}{c}\text { Number of } \\
\text { interviews }\end{array}$ & $\begin{array}{c}\text { Male/Female } \\
\text { ratio }\end{array}$ \\
\hline Curitiba & Brazil & 19 & $13 / 6$ \\
\hline Guadalajara & Mexico & 20 & $17 / 3$ \\
\hline Medellín & Colombia & 17 & $15 / 2$ \\
\hline
\end{tabular}

In order to specifically target the mechanisms behind different outcomes related to the dependent variable, all interviews followed a functional interview guide, compiled from the list of explanatory variables initially inspired by the literature. The same functional interview guide was used with all 56 respondents across the three countries. It comprised a list of 14 open-ended questions developed in parallel with the initial literature review phase of the research (see Table III-2). Moreover, this list was later on rephrased, so as to guarantee the "sayability" and "clarity" of all questions during the interactions with the key informants (Gillham 2005, p.21).

These key informants include politicians, public servants, members of the city councils, owners and managers of the private transport providing companies, leaders of advocacy organizations in the urban transport field, and business leaders; an emphasis was also placed on impartial observers to the policy process, such as academics, who seldom have political legacies to defend. Stakeholders were mapped ex-ante, so as to target the administrative positions that are most relevant, and to have appropriate back-ups for 
interviewees that become unavailable at the last minute. All interviewees were recruited personally by the author, via email or telephone.

Table III-2: Standard Interview Guide Used

Interviewguide used in interviews (translated to English)

1. Is there a formal and broadly shared definition of sustainable mobility from the local administration?

2. Is there an integral strategy to improve the sustainability of transport? since when?

3. Which is the most recent flagship major project in transport for the city?

4. What type of negotiations took place between the city and other entities to allow for the (recent flagship transport project) to be approved?

5. Could you describe the political environment at the moment of the creation of the project (recent flagship transport project)?

6. Which political/social entities supported the creation of the project (recent flagship transport project)? Which ones opposed it?

7. Did the political parties pressure to influence the project (recent flagship transport project)?

8. Did the organized economic groups pressure to influence the project (recent flagship transport project)?

9. Did the international financial organisms influence the creation of the project (recent flagship transport project)?

10. How much institutional coordination has been necessary to allow these projects to implemented (i.e. with other levels of government

1. In which issues is greater coordination needed?

1. Land uses?

2. Decisions directly related to public transport?

3. Financial decisions?

11. To what extent would you say that the level of sustainability of the transport system in the city depends on the financial capacity of the associated institutions?

1. Financial capacity of the city?

2. Access to financial resources from the global system?

12. To what extent would you say that the level of sustainability of the transport system in the city depends on the political interactions amongst the different players?

13. Which factors would be most important in this respect? (Naming a few: human characteristics of the mayor, term of office? Weight of the City Council? Weigh of other technical institutions? Weight of interest groups? Type of initial stimulus?

14. To what extent would you say that the level of sustainability of the transport system in the city depends on the support/pressure by the citizens or not-for-profit pressure groups?

After initial local contacts in the city, snowball sampling was used to identify key additional informants. As the selection of key informants was purposive rather than random, the data do not allow for any statistically representative generalization. Furthermore, although all possible efforts were made to confirm times and dates for all interviewees before travelling 
to the country, that was often not the case. As such, additional contacts were made locally to secure the right mix of key informants willing to perform the interview. Even though all respondents were clearly informed that the interviews were voluntary, there was no need to go through an Institutional Review Board (or related) process with any of the respondents. On the other hand, however, they were all given the chance to answer anonymously some (or all) of the questions, if they found it convenient.

The collected data also accounts for the specific contexts and social interactions characterizing the timing during which the interviews were tendered. As Blaikie (2010) states:

\begin{abstract}
"Just as with structured interviews, any form of qualitative interview keeps the social researcher removed from the natural setting; individual behaviour and social interaction will be reported rather than observed. However, the qualitative interview, particularly the in-depth variety, can get close to the social actors' meanings and interpretations, to their accounts of the social interaction in which they have been involved. Interviewing, in combination with reasonably extensive observation of actual social situations, provides a useful alternative to participant observation" (Blaikie 2010, p.234).
\end{abstract}

The data compiled through these interviews was complemented by an analysis of pertinent legislation, records from city council sessions, local budget proposals and forecasts, strategic development plans, and other relevant documents describing the social, economic and political context of the moments in time when specific events took place, affecting the status quo of the urban transport sector. All possible efforts were made to sum up final reports from the interviews with full objectivity; nevertheless, the author is aware that "no form of representation, writing, or reporting is innocent. All forms are loaded with the researchers' interests and intentions" (Kvale \& Brinkmann 2009, p.282).

\title{
3.12.Data Coding and Analysis
}

Systematizing the collected data before its analysis was a crucial step of this process. Apart from facilitating the description of the data, transforming it into consistent and comparable data is a prerequisite for any analysis and 
theory generation initiatives. A data-driven coding approach has been selected to systematically conceptualize statements. Moreover, content analysis has been chosen as the method for analysing the gathered data. This process was supported by the use of the Atlas.ti (C) software.

As pointed out by Creswell (2013), the phases of the data collection and analysis process vary according to the specific method of analysis selected. In general, data collection, data analysis and report writing are interrelated. According to this author, the process can be characterized as a "data analysis spiral" in which "the researcher engages in the process of moving in analytic circles rather than using a fixed linear approach" (Creswell 2013, p.182).

For this research, two principal stages were followed for coding, as per suggested by Blaikie (2010): First, an open coding stage during which all compiled data was classified across categories and sub-categories; apart from breaking down the data, this process also aimed at comparing, conceptualizing, and categorizing the full qualitative data package. An additional advantage of generating these categories is that it "makes it possible to quantify how often specific themes are addressed in the text, and the frequency of themes can be compared and correlated with other measures" (Kvale \& Brinkmann 2009, p.203).

Secondly, a stage of axial coding was performed, intending to re-organize the data puzzle back into a solid state, following the central lines of thought of the research objective, in regards to sustainable mobility. It is not only valid, but also important to filter back these categories and sub-categories using the researchers own paradigm, as Blaikie explains: "axial coding is done by using a 'coding paradigm' which involves thinking about possible causal conditions, contexts, intervening conditions, action/interaction strategies used to respond to a phenomenon in its context, and the possible consequences of action/interaction not occurring" (Blaikie 2010, p.239). The full code book designed after these two stages can be found as an annex to this dissertation.

In terms of the magnitude for retaining the integrity of the phenomena analyzed, it is important to mention that this study followed a low stance compatible with an abductive approach. Thus, intending to derive concepts and meaning from the lay language, and not necessarily to impose the 
authors' own. This decision provides a key distinction with the particularities of the Grounded Theory approach, as Blaikie (2010) explains:

"In its purest form, the abductive research strategy involves a low stance because it develops technical concepts and theoretical propositions from accounts provided in lay language. Technical concepts generated in this way are designed to be more abstract and generalizable that is possible with lay concepts. Grounded theory, on the other hand, is much more a process of the research 'inventing' and imposing concepts on the date; it adopts a high stance. ...grounded theory is not strictly an abductive research strategy" (Blaikie 2010, p.241)

Content analysis is a basic approach to data analysis in the tradition of qualitative research (Neuendorf 2002). It allows for linking gathered data with concepts derived from the existent literature regarding the phenomena of interest. In the case of this research content analysis is used for the systematic analysis of the data gathered through key informant interviews on the urban transport arena, from Curitiba, Guadalajara and Medellin. While the analysis is based on the gathered data, the process is supported by the concepts derived from the governance and sustainability discourses which also guide the organization and classification of the data.

This approach follows the strategy of relying on the theoretical propositions to guide the full process, as proposed by Yin (2009). As such, the same theoretical propositions that led to the development of this case study (and the initial hypotheses, research question, and literature review) remain at the heart of the data collection and data analysis stages. Initial theoretical propositions are also considered as an input for the interaction with the interviewees, so as to generate new ideas about the political determinants of transport sustainability in Latin American cities. In doing so, this dissertation follows the roadmap proposed by Eisenhardt (1989) for building theories from case study research (see Table III-3): "the theory-building process relies on past literature and empirical observation or experience as well as on the insight of the theorist to build incrementally more powerful theories" (Eisenhardt 1989, p.548). 
Table III-3: Process of Building Theory from Case Study Research

\begin{tabular}{|c|c|c|}
\hline Step & Activity & Reason \\
\hline Getting Started & $\begin{array}{ll}\text { - } & \text { Definition of research question } \\
\text { - } & \text { Possibly a priori constructs } \\
\text { - } & \text { Neither theory nor hypotheses }\end{array}$ & $\begin{array}{l}\text { - } \quad \text { Focuses efforts } \\
\text { - } \quad \text { Provides better grounding of } \\
\text { construct measures } \\
\text { - } \quad \text { Retains theoretical flexibility }\end{array}$ \\
\hline Selecting Cases & $\begin{array}{ll}\text { - } & \text { Specified population } \\
\text { - Theoretical, not random, } \\
\text { sampling }\end{array}$ & $\begin{array}{l}\text { - } \begin{array}{l}\text { Constrains extraneous variation and } \\
\text { sharpens external validity }\end{array} \\
\text { - Focuses efforts on theoretically useful } \\
\text { cases - i.e. those that replicate or } \\
\text { extend theory by filling conceptual } \\
\text { categories }\end{array}$ \\
\hline $\begin{array}{l}\text { Crafting } \\
\text { Instruments and } \\
\text { Protocols }\end{array}$ & $\begin{array}{l}\text { - Multiple data collection } \\
\text { methods } \\
\text { Qualitative and quantitative } \\
\text { data combined } \\
\text { - } \quad \text { Multiple investigators } \\
\end{array}$ & $\begin{array}{l}\text { - } \quad \text { Strengthens grounding of theory by } \\
\text { triangulation of evidence } \\
\text { - } \quad \text { Synergistic view of evidence } \\
\text { - Fosters divergent perspectives and } \\
\text { strengthens grounding }\end{array}$ \\
\hline Entering the Field & $\begin{array}{ll} & \text { Overlap data collection and } \\
\text { analysis, including field notes } \\
\text { - } & \text { Flexible and opportunistic data } \\
\text { collection methods }\end{array}$ & $\begin{array}{l}\text { - } \quad \text { Speeds analyses and reveals helpful } \\
\text { adjustments to data collection } \\
\text { - Allows investigators to take } \\
\text { advantage of emergent themes and } \\
\text { unique case features }\end{array}$ \\
\hline Analysing Data & $\begin{array}{l}\text { - } \quad \text { Within-case analysis } \\
\text { - Cross-case pattern search using } \\
\text { divergent techniques }\end{array}$ & $\begin{array}{ll}- & \text { Gains familiarity with data and } \\
\text { preliminary theory generation } \\
\text { - } \\
\text { Forces investigators to look beyond } \\
\text { initial impressions and see evidence } \\
\text { through multiple lenses }\end{array}$ \\
\hline $\begin{array}{l}\text { Shaping } \\
\text { Hypotheses }\end{array}$ & $\begin{array}{l}\text { - Iterative tabulation of evidence } \\
\text { for each construct } \\
\text { - Replication, not sampling, logic } \\
\text { across cases } \\
\text { - Search evidence for "why" } \\
\text { behind relationships }\end{array}$ & $\begin{array}{l}\text { - Sharpens construct definition, } \\
\text { validity, and measurability } \\
\text { - Confirms, extends, and sharpens } \\
\text { theory } \\
\text { - Builds internal validity }\end{array}$ \\
\hline $\begin{array}{l}\text { Enfolding } \\
\text { Literature }\end{array}$ & $\begin{array}{l}\text { - } \quad \text { Comparison with conflicting } \\
\text { literature } \\
\text { - Comparison with similar } \\
\text { literature }\end{array}$ & $\begin{array}{l}\text { - Builds internal validity, raises } \\
\text { theoretical level, and sharpens } \\
\text { construct definitions } \\
\text { - Sharpens generalizability, improves } \\
\text { construct definition, and raises } \\
\text { theoretical level }\end{array}$ \\
\hline Reaching Closure & $\begin{array}{l}\text { - } \quad \text { Theoretical saturation when } \\
\text { possible }\end{array}$ & $\begin{array}{ll} & \text { Ends process when marginal } \\
\text { improvement becomes small }\end{array}$ \\
\hline
\end{tabular}

Source: Eisenhardt (1989), p. 533

In regards only to the data analysis process, this research follows the description by Creswell (2013, p 182), consisting of the following four steps:

1. Careful listening and transcription of the interviews. 
2. Preliminary reading of the transcribed material and preliminary familiarization with the material.

3. Organization, classification, coding and interpretation of the data into themes.

4. Representation of the findings.

Finally, the representation of the findings relies on extensive use of direct citations from the interviews, which aims at complementing the author's own conclusions. Moreover, specific citations correspond with specific ways in which key informants perceive that certain conditions have determined the current situation of the city, as characterized by the GTI. It must be noted that names are used in most quotations. Although all of them were explicitly informed about the purpose of the research, the way in which the data gathered would be used, and given the possibility to remain anonymous, no specific requests for confidentiality were received. As such, this research benefits from having quotes linked to their original source, as a complement to original conclusions. In summary, this approach "allows the data to speak", but links data with what is already known about the studied phenomenon.

This dissertation was designed to generate specific knowledge that can be used for increasing the levels of transport sustainability in applicable cities, be it through the academic additions that could have an impact at the local policy making scene, or via any other citizen and/or political channels that could convert this knowledge into pragmatic improvements. All in all, the contributions from this project must be framed by important strengths like "novelty, testability, and empirical validity, which arise from the intimate linkage with empirical evidence" (Eisenhardt 1989, p.548).

\subsection{Validation of Findings}

The trustworthiness, strength and transferability of the generated knowledge depends on its reliability and validity. Reliability is understood as the "consistency and trustworthiness of research findings. It is often treated in relation to the issue of whether a finding is reproducible at other times by other researchers" (Kvale \& Brinkmann 2009, p.241). Validity, on the other hand, refers to the "correctness and strength of an argument" (Kvale \& Brinkmann 2009, p.241). Moreover, it also insinuates the more philosophical question of what is truth. 
For this dissertation, reliability is guaranteed by minimizing all possible sources of inconsistency. Although it is possibility that some of the key informants could in fact provide different answers to the same questions, if received at another time, and by another person, the open-ended format of the interviews allowed for the use of leading questions in order to actively verify their statements on critical topics in situ. Moreover, the fact that only the author performed the interviews, interacted with the key informants, transcribed, coded, and categorized the data minimizes the risk that somebody else's subjectivity could permeate the interview findings. Likewise, this implies that all possible sources of reliability are solely the responsibility of the author.

Table III-4: Validation at Seven Stages

1. Thematizing: validity of an investigation rests upon the soundness of the theoretical presuppositions of a study and upon the logic of the derivations from theory to the research questions of the study.

2. Designing: validity of knowledge produced involves the adequacy of the design and the methods used for the subject matter and purpose of the study. From an ethical perspective a valid research design involves beneficence - producing knowledge beneficial to the human situation while minimising harmful consequences.

3. Interviewing: validity here pertains to the truth worthiness of the subject's reports and the quality of the interviewing, which should include a careful questioning to the meaning of what is said and a continual checking of the information obtained as validation in situ.

4. Transcribing: the question of what is valid translation from oral to written language is involved by the choice of linguistic style of the transcript.

5. Analyzing: this involves the question of whether the questions put to a text are valid and whether the logic of the interpretations made is sound.

6. Validating: this entails reflective judgement as to what forms of validation are relevant in a specific study and the application of the concrete procedures of validation, and a decision on what is the appropriate community for a dialogue on validity.

7. Reporting: This involves the question whether a given report gives a valid account of the main findings of a study, and also the question of the role of readers of the report in validating the results.

Source: Kvale \& Brinkmann (2009), p. 248

In regards to validity, the key question concerns, as Kvale \& Brinkmann (2009) put it, how to go beyond the extremes of a subjective relativism in interview research, where everything can mean everything, and an absolutist quest for the one and only true objective meaning. The approach in this 
research distributes the quest for validity transversally; hence, validation does not belong to a separate stage of the investigation, but permeates the entire research process. Kvale \& Brinkmann (2009) suggest a seven-step validation approach, which is followed throughout this dissertation in order to guarantee validity of the findings (see Table III-4).

Nonetheless, this dissertation also emphasizes the role of pragmatic validity, as insinuated by Flyvbjerg (2001) in his "phronetic social science" framework. This idea highlights the capacity of research to contribute successfully "to the ongoing social dialogue and praxis in society, rather than to generate ultimate, unequivocally verified knowledge" (Flyvbjerg 2001, p.139).

Triangulation as a complementary strategy can be used in different ways, for different research set-ups, in the case of this thesis it is used solely intending to build greater consistency out of the various messages communicated by the respondents. As Blaikie (2010) puts it, "this use of triangulation is consistent with the ontological and epistemological assumptions of at least some versions of the abductive research strategy" (Blaikie 2010, p.269).

From the very beginning, a clear assumption was made to take all comments by respondents, as true versions of the events being described. Nonetheless, most major topics were iteratively discussed with additional respondents, as often as it was possible. The main objective of this was not necessarily to check for false statements, but rather to guarantee the consistency of the context being sewed together by the parallel accounts of various key informants. This project was developed under the belief that "field research does require that the information gathered by the case writer be verified, in some form or another" (W. Naumes \& M. J. Naumes 2006, p.54).

Under no circumstance does this strategy intend to summarize the variety of views about the level of urban transport sustainability, to a single view. On the contrary, the triangulation of all those critical comments received by respondents is used to generate greater evidence for building a solid theory regarding the studied cases. Ultimately, the author is fully aware that although this approach might allow for the data to converge, it might also expose it as inconsistent or contradictory, in which case "the researcher must attempt to construct explanations for the data and about the data" (Mathison 1988, p.15). 
Ethical issues permeate the research project from start to end. These apply not only to the confidentiality of the information disclosed, but also to the ethical responsibility of verifying and reporting the gathered data. All interviewees were informed beforehand of the objectives of the research project, and the ways in which the data would be used. They were also given the option to remain anonymous, if need be. As previously mentioned, none of the key experts chose to take this option. On the other hand, at a more individual ethical level, this study intends to go beyond the scientific value of the knowledge sought and considers the way in which the results may improve the human condition, as suggested by Kvale \& Brinkmann (2009) under the thematizing principle. All efforts have been made to assure the highest ethical standards during the transcription, analysis, verification, and reporting stages of this process. 


\section{Chapter IV}

\section{Patterns of Transport Sustainability in Latin American Cities}

"Adding highway lanes to deal with traffic congestion is like loosening your belt to cure obesity" -Louis Mumford

\subsection{Introduction}

This chapter examines patterns within the broad trends towards sustainability in transport systems of selected Latin American cities. An empirical characterization of the sustainability levels for several urban transport systems in this region is provided. This depiction is also used as the base for comparing and contrasting the levels of engagement of each city with the principles of sustainability in transport. The characterization is performed by composing a ranking that rates transport sustainability as an aggregation of its three core dimensions: social, economic, and environmental. The ranking is presented as the 'Green Transport Index' (GTI) for Latin American Cities.

As discussed in Chapter II, for the purpose of this dissertation, the concept of 'Green Transport' ${ }^{13}$ has been adopted as the definition of transport sustainability. This concept was coined by the United Nations Environment Programme, referring explicitly to a system that supports (1) environmental sustainability through the protection of the global climate, ecosystems, public health and natural resources; (2) economic sustainability through an affordable, fair and efficient transport that promotes a sustainable competitive economy as well as balanced regional development and the creation of decent jobs, and; (3) social sustainability by allowing the basic access and development needs of individuals, companies and society to be met safely and in a manner consistent with human and ecosystem health, while promoting poverty reduction and equity within and between successive generations (UNEP 2011).

\footnotetext{
${ }^{13}$ Throughout the dissertation, I use the concepts of 'sustainable transport' and 'green transport' interchangeably.
} 
Building on this definition, the current section constructs the key operationalization for the dependent variable: sustainability of urban transport. Upon providing a measurable characterization for the dependent variable, the influence of the explanatory variables on it is assessed, hypotheses are proposed, and theory is refined.

\section{Figure IV-1: Studied Cities}

\section{Studied Cities}

- Guadalajara
León
- Sandad de México
- Caracas
- Medellín
Bogotá
- Lima
- Belo Horizonte
- Río de Janeiro
- Cũo Paulo
- Poritiba
- Santiago
- Montevideo
Buenos Aires

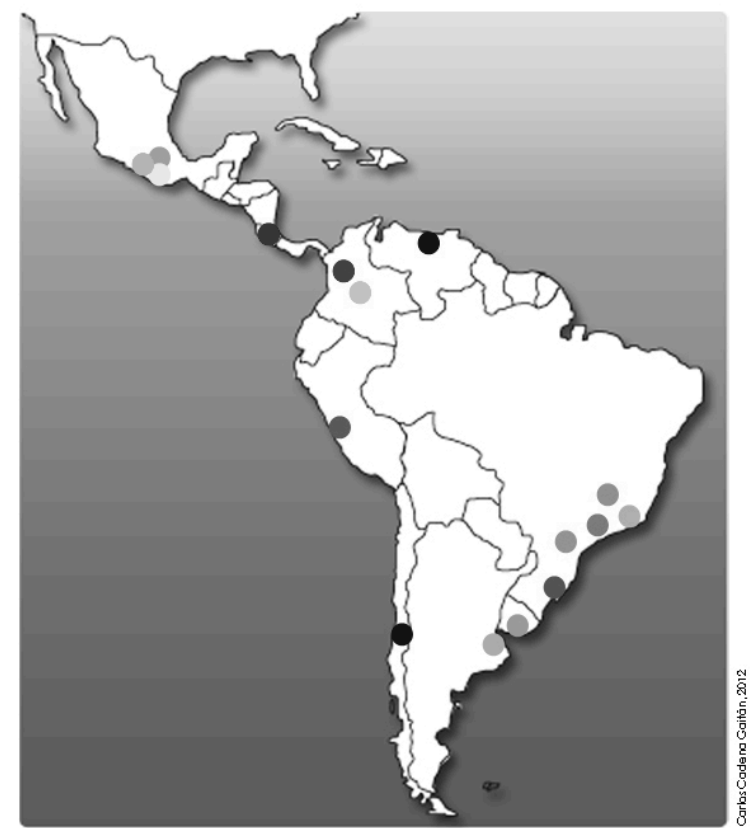

Source: own elaboration

This chapter presents an insight into the current characteristics of urban transport in the Latin American region. Secondly, it summarizes the rationale for the construction of the index to operationalize the dependent variable. Thirdly, it offers the results from the index. Finally, it outlines some initial considerations regarding the possible alternative explanations for this outcome, as proposed by the literature.

\subsection{Urban Transport in Latin America Today}

Sixteen cities representing a significant geographical, cultural, institutional, and demographical variety, of large cities in the region, have been selected. 
These cities span from León and Guadalajara in central México, all the way to Buenos Aires and Santiago in the south of the region, and include representation from nine countries (see Figure IV-1).

Table IV-1: List of Metropolitan Areas Included in the GTI

\begin{tabular}{|c|c|c|c|c|c|c|c|c|}
\hline City & $\begin{array}{c}\text { Total } \\
\text { popula } \\
\text { tion }\end{array}$ & Area & $\begin{array}{l}\text { GDP per } \\
\text { capita }\end{array}$ & $\begin{array}{c}\text { Populati } \\
\text { on } \\
\text { density }\end{array}$ & $\begin{array}{l}\text { Total } \\
\text { roads }\end{array}$ & $\begin{array}{c}\text { Road } \\
\text { deaths } \\
\text { per year }\end{array}$ & $\begin{array}{c}\text { Vehicle } \\
\text { s per } \\
\text { person }\end{array}$ & $\begin{array}{l}\text { Metro } \\
\text { system }\end{array}$ \\
\hline & & $\mathrm{km}^{2}$ & 2009 US\$ & $\begin{array}{c}\text { persons/ } \\
\text { km2 }\end{array}$ & $\mathrm{kms}$ & $\begin{array}{c}\text { Per } \\
100.000 \\
\text { inh }\end{array}$ & & \\
\hline $\begin{array}{c}\text { Belo } \\
\text { Horizonte }\end{array}$ & $\begin{array}{c}4,707,1 \\
34\end{array}$ & 603 & 6,267 & 7,812 & 11,370 & 3.8 & 0.39 & Yes \\
\hline Bogota & $\begin{array}{c}7,719,2 \\
97\end{array}$ & 523 & 8,411 & 14,755 & 7,749 & 7.0 & 0.15 & No \\
\hline $\begin{array}{c}\text { Buenos } \\
\text { Aires }\end{array}$ & $\begin{array}{c}13,156 \\
404\end{array}$ & 3,883 & 24,223 & 3,388 & 44,994 & 7.0 & 0.66 & Yes \\
\hline Caracas & $\begin{array}{c}3,135,3 \\
66\end{array}$ & 261 & 11,405 & 12,030 & 2,758 & 6.0 & 0.15 & Yes \\
\hline $\begin{array}{l}\text { Ciudad de } \\
\text { Mexico }\end{array}$ & $\begin{array}{c}19,239 \\
910\end{array}$ & 2,884 & 20,359 & 6,671 & 63,726 & 11.3 & 0.40 & Yes \\
\hline Curitiba & $\begin{array}{c}2,815,0 \\
36\end{array}$ & 425 & 10,797 & 6,624 & 6,677 & 2.7 & 0.50 & No \\
\hline $\begin{array}{c}\text { Guadalajar } \\
\mathbf{a}\end{array}$ & $\begin{array}{c}4,298,7 \\
15\end{array}$ & 544 & 9,409 & 7,896 & 11,045 & 16.1 & 0.37 & Yes \\
\hline Leon & $\begin{array}{c}1,265,0 \\
88\end{array}$ & 198 & 5,340 & 6,382 & 2,647 & 15.4 & 0.07 & No \\
\hline Lima & $\begin{array}{c}8,472,9 \\
35\end{array}$ & 735 & 4,873 & 11,528 & 12,439 & 6.3 & 0.14 & Yes \\
\hline Medellin & $\begin{array}{c}3,500,0 \\
00\end{array}$ & 382 & 5,548 & 9,162 & 2,055 & 9.7 & 0.07 & Yes \\
\hline $\begin{array}{c}\text { Montevide } \\
\text { o }\end{array}$ & $\begin{array}{c}1,273,9 \\
34\end{array}$ & 196 & 6,417 & 6,509 & 3,011 & 11.2 & 0.16 & No \\
\hline $\begin{array}{l}\text { Porto } \\
\text { Alegre }\end{array}$ & $\begin{array}{c}3,342,4 \\
62\end{array}$ & 434 & 12,082 & 7,702 & 9,903 & 4.8 & 0.38 & Yes \\
\hline $\begin{array}{c}\text { Rio de } \\
\text { Janeiro }\end{array}$ & $\begin{array}{c}10,631 \\
282\end{array}$ & 900 & 11,581 & 11,813 & 15,371 & 6.8 & 0.26 & Yes \\
\hline San Jose & $\begin{array}{c}1,157,8 \\
24\end{array}$ & 235 & 6,882 & 4,924 & 3,979 & 8.8 & 0.14 & No \\
\hline Santiago & $\begin{array}{c}5,975,2 \\
55\end{array}$ & 678 & 7,721 & 8,814 & 11,473 & 5.4 & 0.14 & Yes \\
\hline Sao Paulo & $\begin{array}{c}18,407 \\
976\end{array}$ & 2,209 & 15,090 & 8,333 & 38,419 & 8.5 & 0.44 & Yes \\
\hline
\end{tabular}

Source: Own elaboration using data from EIU 2010, América Economía 2010; CAF 2009. All values correspond to 2007 numbers, except for GDP. 
Although all of these conurbations are principal development poles in their corresponding countries, they exhibit a large variety of structural characteristics amongst themselves. In terms of population, for instance, these metropolitan areas range from the 1.2 million of San José (Costa Rica) to the 19.2 million of Mexico City (see Table IV-1).

Key characteristics of the recent development of the Latin American region concerns the high rates of urbanization, and the growth of a vast number of cities spread over metropolitan regions that traverse jurisdictional borders (Rojas 2005). With more than $75 \%$ of the population in the region currently living in cities, the challenges of the traditional mega cities (Mexico City, Sao Paulo, Buenos Aires) are now complemented by challenges posed by fast-growing large cities like Medellín, Belo Horizonte and Guayaquil. Furthermore, this region is home to approximately 140 cities with less than two million people (emerging cities) whose economies and populations are going through a phase of rapid growth (IADB 2012). Notwithstanding the size of the population, improved planning for urban sustainability becomes crucial for all of these cities in Latin America, as urbanization trends forecast continued rapid growth (see Table IV-2).

Table IV-2: Total Population and Share that is Urban, by Region

\begin{tabular}{|c|c|c|c|c|}
\hline \multirow[b]{2}{*}{ Region } & \multicolumn{2}{|c|}{2000} & \multicolumn{2}{|c|}{2030} \\
\hline & Population & Urban Share & Population & Urban Share \\
\hline & illion people & (percent) & (million peopl & ) (percent) \\
\hline Asia & 3,683 & 37 & 4,877 & 53 \\
\hline Africa & 784 & 38 & 1,406 & 55 \\
\hline Europe & 729 & 75 & 691 & 83 \\
\hline Latin America & 519 & 75 & 726 & 83 \\
\hline North America & 310 & 77 & 372 & 84 \\
\hline
\end{tabular}

Source: O’ Meara Sheehan (2001)

These urbanization changes bring about important impacts for urban transportation systems. Private motorization is one of the first consequences, and although it initially acts as a powerful urban development factor (allowing for greater personal mobility), it quickly evolves into chronic urban congestion, ultimately generating dangerous urban "diseconomies" (Monzón 2005). On the other hand, greater private motorization also has a negative impact in several environmental indicators, such as energy 
consumption. In Latin America, for example, it is forecasted that average annual growth of energy consumption from transport will continue to increase at a much faster rate than those of OECD countries, and the world average (see Figure IV-2).

Figure IV-2: Consumption of Energy in Transport, by Region (Forecasts to 2030 and 2050)

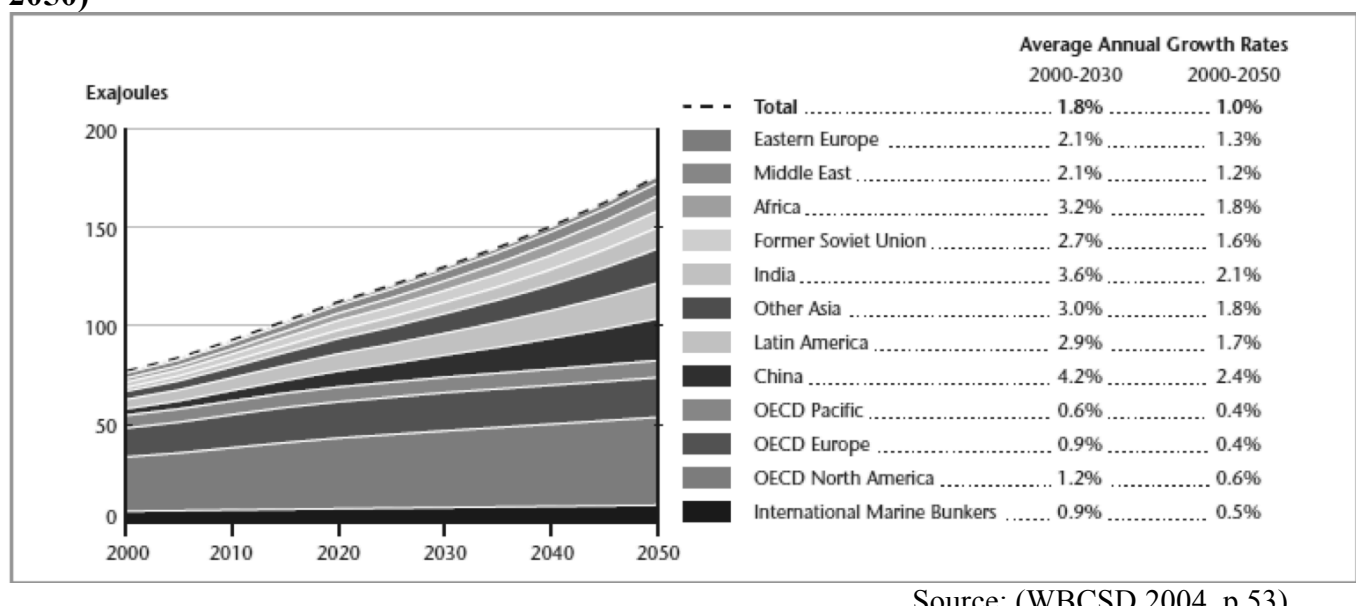

Source: (WBCSD 2004, p.53)

\subsection{Representation of Dependent and Explanatory Variables}

In order to appraise the levels of transport sustainability for selected cities in the region (the dependent variable), a Green Transport Index ${ }^{14}$ has been developed. Using this tool, the performance of sixteen cities from nine Latin American countries can be scored, across three broad baskets environmental sustainability, social sustainability, and economic sustainability.

Using the index, an empirical characterization of the current transport sustainability performance of each city, in a comparative fashion, is provided. Apart from a final ranking, separate rankings for each of the dimensions studied are also presented. By maintaining these sub-indices separate, it is acquiesced that a deficit in one indicator may be compensated by a surplus in another (within the same basket); nonetheless, this separation

14 Please note that details on the methodology for constructing the index have been provided in Chapter III. 
allows for a better understanding of the political trade-offs faced by policymakers when deciding on projects and policies.

Most of the indicators and structural variables considered reflect data from 2009. However, some data actually correspond to 2007, as it takes at least two years for it to be collected, analyzed and published. When some specific figures were impossible to collect, estimates from national measures of central tendency were produced. The data comes from a combination of sources, including the OMU database (CAF, 2009), the Latin American Green Cities Index (EIU, 2010), and official city sources, when available.

The indicators chosen to compose the GTI (see Table IV-3) are not intended to become an exhaustive nor ideal list for analyzing sustainable transport wherever. However, all efforts have been made to strategically select indicators that represent potential and actual impacts on transport sustainability as accurately as possible, so that the construction of a valid index was possible. The focus has been on selecting valid indicators for measuring the current transport trends, strongly considering the particularities of the Latin American political context, and understanding that "there is hardly one indicator able to represent equally well all aspects of sustainable transport" (Joumard \& Gudmundsson 2010, p.14). After reviewing lists of indicators suggested by Litman (2009) and Marsden, et al., (2005), this dissertation concentrates on those indicators rated as having the highest priority of usage according to the sustainability categories they represent.

It must be re-stated that the GTI shows cities' performance relative to each other, not in absolute terms; this produces the first vital conclusion for the region: all cities still have a long way to go before claiming advanced levels of sustainability in their urban transport systems. Finally, it is also crucial to mention that the influence of explanatory variables on the dependent variable is not tackled in this chapter.

Table IV- 3: List of Indicators Used in the GTI

\begin{tabular}{|l|l|l|l|}
\hline \multicolumn{1}{|c|}{ Category } & \multicolumn{1}{|c|}{ Indicator } & \multicolumn{1}{c|}{ Description } & \multicolumn{1}{c|}{ Source } \\
\hline Environmental & $\begin{array}{l}\text { CO Emissions in Tons - } \\
\text { Individual Transport }\end{array}$ & Per capita, per year & CAF, 2009; AMVA, 2009 \\
\hline Environmental & $\begin{array}{l}\text { NOx Emissions in Tons - } \\
\text { Individual Transport }\end{array}$ & Per capita, per year & CAF, 2009; AMVA, 2009 \\
\hline Environmental & $\begin{array}{l}\text { SO2 Emissions in Tons - } \\
\text { Individual Transport }\end{array}$ & Per capita, per year & CAF, 2009; AMVA, 2009 \\
\hline Environmental & $\begin{array}{l}\text { PM Emissions in Tons - } \\
\text { Individual Transport }\end{array}$ & Per capita, per year & CAF, 2009; AMVA, 2009 \\
\hline
\end{tabular}


Table IV-3: List of Indicators Used in the GTI (continued)

\begin{tabular}{|c|c|c|c|}
\hline Environmental & $\begin{array}{l}\text { CO2 Emissions in Tons - } \\
\text { Individual Transport }\end{array}$ & Per capita, per year & CAF, 2009; AMVA, 2009 \\
\hline Environmental & $\begin{array}{l}\text { CO Emissions in Tons - } \\
\text { Collective Transport }\end{array}$ & Per capita, per year & CAF, 2009; AMVA, 2009 \\
\hline Environmental & $\begin{array}{l}\text { NOx Emissions in Tons - } \\
\text { Collective Transport }\end{array}$ & Per capita, per year & CAF, 2009; AMVA, 2009 \\
\hline Environmental & $\begin{array}{l}\text { SO2 Emissions in Tons - } \\
\text { Collective Transport }\end{array}$ & Per capita, per year & CAF, 2009; AMVA, 2009 \\
\hline Environmental & $\begin{array}{l}\text { PM Emissions in Tons - } \\
\text { Collective Transport }\end{array}$ & Per capita, per year & CAF, 2009; AMVA, 2009 \\
\hline Environmental & $\begin{array}{l}\text { CO2 Emissions in Tons - } \\
\text { Collective Transport }\end{array}$ & Per capita, per year & CAF, 2009; AMVA, 2009 \\
\hline Environmental & $\begin{array}{l}\text { Energy Consumption - } \\
\text { Individual Transport }\end{array}$ & Equivalent Tons of Oil per capita, per day & CAF, 2009 \\
\hline Environmental & $\begin{array}{l}\text { Energy Consumption - } \\
\text { Collective Transport }\end{array}$ & Equivalent Tons of Oil per capita, per day & CAF, 2009 \\
\hline Social & $\begin{array}{l}\text { Daily Trips - Individual } \\
\text { Transport }\end{array}$ & Per capita & CAF, 2009; STT MDE, 2009 \\
\hline Social & $\begin{array}{l}\text { Daily Trips - Collective } \\
\text { Transport }\end{array}$ & Per capita & CAF, 2009; STT MDE, 2009 \\
\hline Social & Daily Trips - Walking & Per capita & CAF, 2009; STT MDE, 2009 \\
\hline Social & Daily Trips - Bicycle & Per capita & CAF, 2009; STT MDE, 2009 \\
\hline Social & Personal Mobility Index & $\begin{array}{l}\text { Number of daily trips per inhabitant } \\
\text { including all modes }\end{array}$ & CAF, 2009; STT MDE, 2009 \\
\hline Social & $\begin{array}{l}\text { Travel Time - Individual } \\
\text { Transport }\end{array}$ & $\begin{array}{l}\text { Average Minutes per Trip. Includes only } \\
\text { trips made by car, taxi, motorcycle }\end{array}$ & CAF, 2009; STT MDE, 2009 \\
\hline Social & $\begin{array}{l}\text { Travel Time - Collective } \\
\text { Transport }\end{array}$ & $\begin{array}{l}\text { Average Minutes per Trip. Includes only } \\
\text { trips made by bus }\end{array}$ & CAF, 2009; STT MDE, 2009 \\
\hline Social & Travel Time - Walking & Average Minutes per Trip. & CAF, 2009; STT MDE, 2009 \\
\hline Social & Mortality Index & $\begin{array}{l}\text { Yearly deaths in traffic accidents. Per } \\
\text { capita }\end{array}$ & CAF, 2009; STT MDE, 2009 \\
\hline Social & Mass Transport Network & $\begin{array}{l}\text { Total length of all train, tram, subway, bus } \\
\text { and other mass transport routes within the } \\
\text { city's boundaries; measured in } \mathrm{km} / \mathrm{km} 2 \text {. }\end{array}$ & $\begin{array}{l}\text { CAF, 2009; Economist } \\
\text { Intelligence Unit, } 2010\end{array}$ \\
\hline Social & $\begin{array}{l}\text { Superior Public } \\
\text { Transport Network }\end{array}$ & $\begin{array}{l}\text { Total length of all superior modes of } \\
\text { transport (lightrail, trolleybus, tram, } \\
\text { subway, and BRT) routes within the city's } \\
\text { boundaries; measured in } \mathrm{km} / \mathrm{km} 2 \text {. }\end{array}$ & $\begin{array}{l}\text { CAF, 2009; Economist } \\
\text { Intelligence Unit, } 2010\end{array}$ \\
\hline Social & $\begin{array}{l}\text { Priority for Public } \\
\text { Transport }\end{array}$ & $\begin{array}{l}\text { Kms w/ Priority Demarcation (simple } \\
\text { demarcation to separate lane) }\end{array}$ & CAF, 2009; STT MDE, 2009 \\
\hline Social & Priority for Pedestrians & Kms pedestrian only streets & CAF, 2009; STT MDE, 2009 \\
\hline Social & Priority for Cyclists & Kms of priority lanes for bicycles & CAF, 2009; STT MDE, 2009 \\
\hline Economic & $\begin{array}{l}\text { Stock of Cars and } \\
\text { Motorcycles }\end{array}$ & $\begin{array}{l}\text { Total stock of cars and motorcycles, with } \\
\text { half-weighting allocated to motorcycles; } \\
\text { measured in vehicles/person. }\end{array}$ & $\begin{array}{l}\text { CAF, 2009; Economist } \\
\text { Intelligence Unit, } 2010\end{array}$ \\
\hline Economic & Cost of Fuel & $\begin{array}{l}\text { Gas liters that can be bought with one } \\
\text { minimum wage }\end{array}$ & CAF, 2009; STT MDE, 2009 \\
\hline Economic & $\begin{array}{l}\text { Relative Cost Public } \\
\text { Transport }\end{array}$ & $\begin{array}{l}\text { Relative weight of } 50 \text { bus tickets on } \\
\text { minimum wage ( } 2007 \text { USD) }\end{array}$ & CAF, 2009; STT MDE, 2009 \\
\hline Economic & $\begin{array}{l}\text { Relative Cost of a Trip by } \\
\text { Car }\end{array}$ & $\begin{array}{l}\text { Cost of gas for a } 9 \mathrm{~km} \text { trip in } 2007 \text { USD: } \\
\left.\text { [(gas use coefficient }\{\text { lit } / \mathrm{km}\}^{*} 9 \mathrm{~km}\right)^{*} \text { (cost } \\
\text { of gas coefficient)] }\end{array}$ & CAF, 2009; STT MDE, 2009 \\
\hline Economic & $\begin{array}{l}\text { Relative Cost of a Trip by } \\
\text { Motorcycle }\end{array}$ & $\begin{array}{l}\text { Cost of gas for a } 9 \mathrm{~km} \text { trip in } 2007 \text { USD: } \\
\text { [(gas use coefficient }\left\{\text { lit/km\} }{ }^{*} 9 \mathrm{~km}\right)^{*} \text { (cost } \\
\text { of gas coefficient)] }\end{array}$ & CAF, 2009; STT MDE, 2009 \\
\hline Economic & $\begin{array}{l}\text { Relative Cost of a Trip by } \\
\text { Collective Transport }\end{array}$ & $\begin{array}{l}\text { Average of ticket price for } 9 \mathrm{~km} \text { trip in public } \\
\text { transport }\end{array}$ & CAF, 2009; STT MDE, 2009 \\
\hline Economic & $\begin{array}{l}\text { Investment in Superior } \\
\text { Public Transport }\end{array}$ & $\begin{array}{l}\text { Investment in superior public transport } \\
\text { modes as proportion of investment in roads } \\
\text { (2007 USD Millions) }\end{array}$ & $\begin{array}{l}\text { CAF, 2009; SOP MDE } \\
\text { 2011, MetroMDE } 2011 .\end{array}$ \\
\hline
\end{tabular}

Own calculations based on: CAF 92009); EIU,(2010); STT Medellín, Metro de Medellín, AMVA. 
This research explores sixteen major cities spanning the full extent of the Latin American region, which have been chosen hoping to represent a vigorous mix of Latin American urban regions, but essentially constrained by the availability of comparable data.

The selected theoretical and methodological frameworks noticeably value those transport policies and projects providing incentives against cardependent models, and in favour of collective transport and non-motorized transport. As such, findings suggest the existence of three broad groups of cities, which have been organized according to their performance in the final ranking: the top, average, and poor performers. Figure IV-3 exhibits the overall results of the final ranking, using green bars to represent the top performers, yellow bars for the average performers, and red bars for the poor performers. I observe a clear leadership from Curitiba, followed by Santiago and Rio de Janeiro.

The findings leave Brazilian cities in good standing, with all those studied ranking as top or average performers. Moreover, previous academic findings that have placed Curitiba as the regional leader in transport sustainability are confirmed. Led by former mayor Jaime Lerner, Curitiba is credited with inventing the "bus rapid transit" (BRT). Its promoters tout it as the perfect substitute for regular metro systems in cities with low transport budgets. Although these systems exhibit very high usage levels (i.e. 1,780 - 43,000 passengers/hour/direction), clearly comparable to some metro systems, their construction usually costs a fraction of that for an average metro (EMBARQ 2010). 


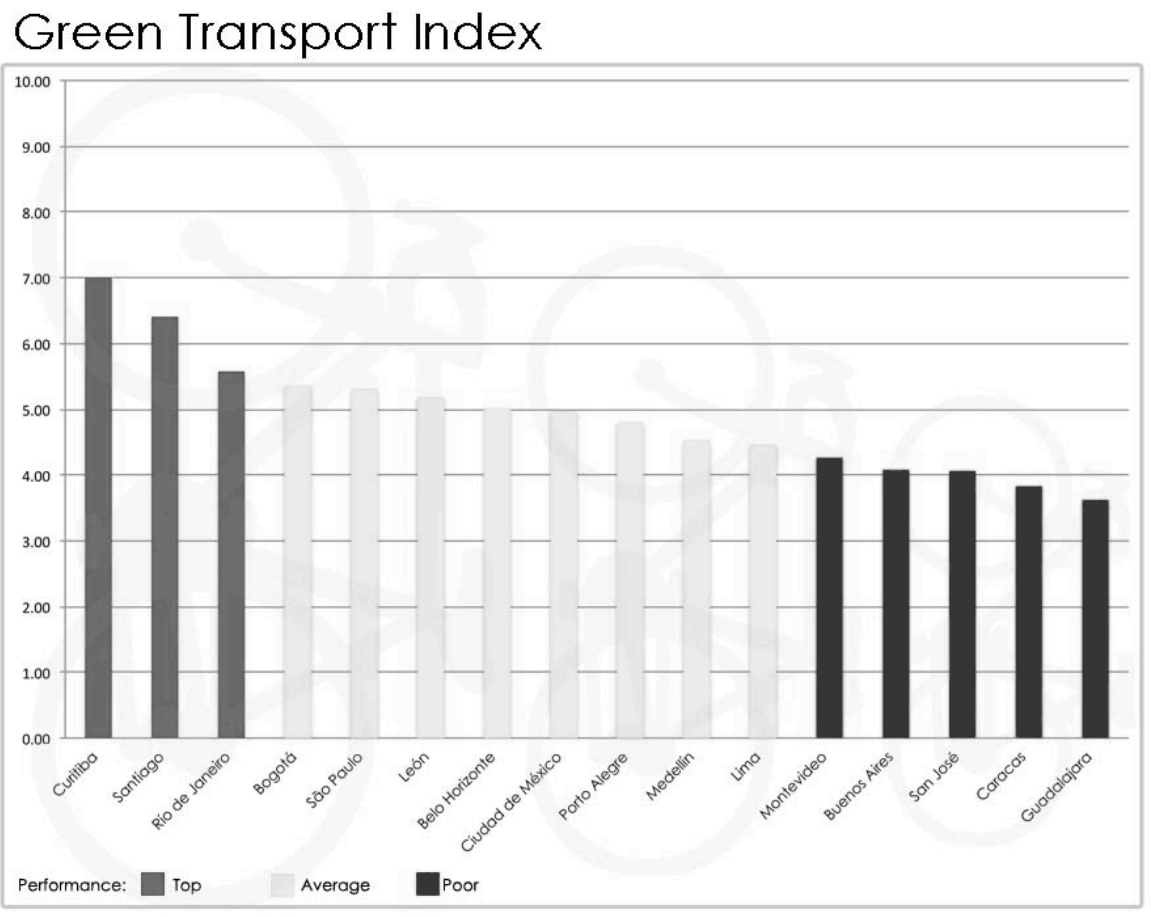

Own calculations based on: CAF (2009); EIU (2010); STT, MetroMed, and AMVA (2010).

Curitiba also boasts a vast network of pedestrian only streets and cycle paths, complementing master urban planning policies that use mass transport corridors as the central development urban areas, with high densities and mixed uses; thus, reducing long commuting times, and provide comfortable and economic alternatives to the private car (see Figure IV-4).

The second and third top performers also exhibit interesting transport system mixes. Santiago's position reflects recent specific actions against car-dependency. It continues to be the only city with congestion charging policies in place, having begun with the Costanera Norte expressway. The city's ranking reflects the grand effort to reform its transport system through Transantiago; a massive project that brought all bus operators under one organization, fully integrated with both the metro system and the novel BRT system. 
Figure IV-4: Public Transport as a Structure of Urban Development in Curitiba

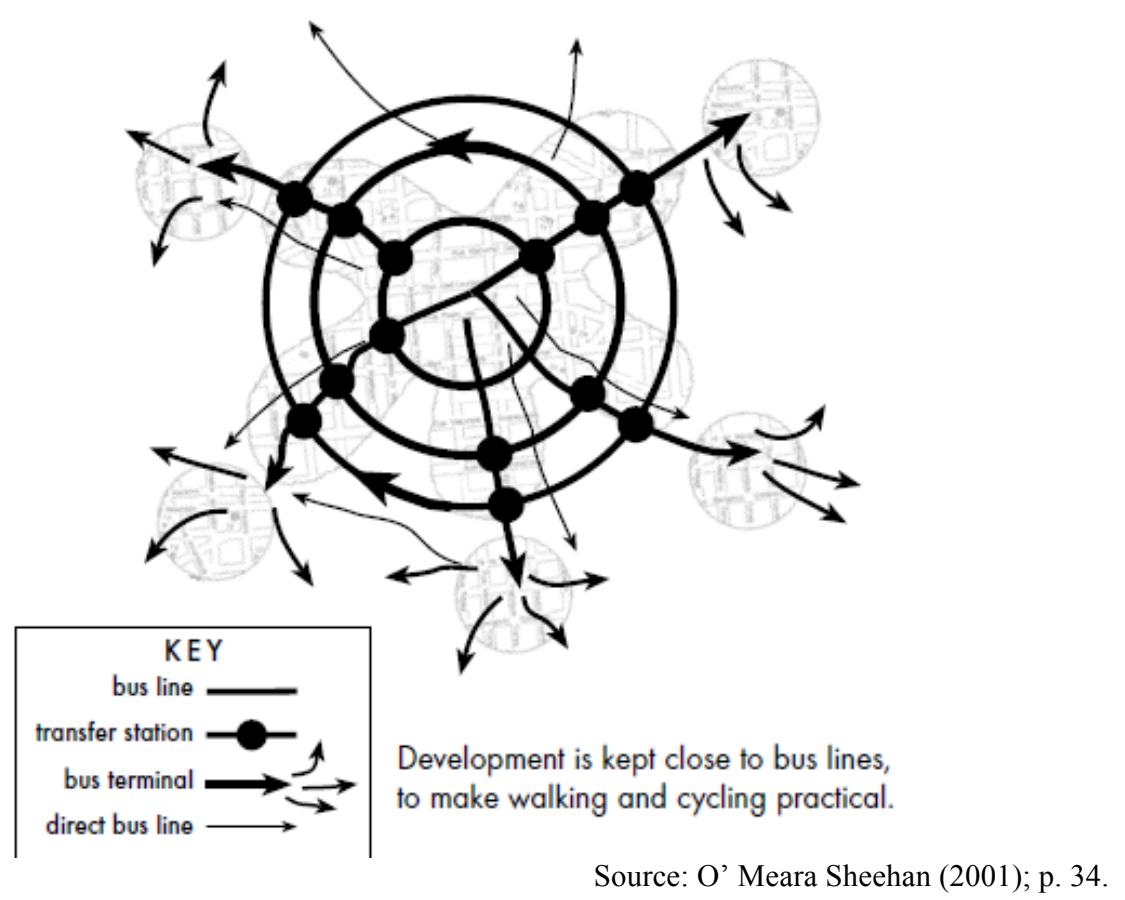

It is crucial to note that Chile's capital exhibits one of the smallest stocks of cars and motorcycles in the region, at just 0.14 vehicles per person (Economist Intelligence Unit 2010); significantly lower than the average for all analyzed cities of 0.28 . Similarly, Rio de Janeiro's strong standing in the ranking is partly due to its vast public transport system; the most expansive one from the studied cities (measured in proportion to city size). Apart from quality metro, bus, light rail, and water buses, the city offers a growing network of cycle paths; thus, providing alternatives to individual private motorized transport. Rio has a low ratio of cars and motorcycles per inhabitant, at only 0.26 (Economist Intelligence Unit 2010). This is both less than the average for all studied cities, and also the lowest ratio among the Brazilian cities analyzed.

The findings leave Guadalajara and Caracas at the bottom of the ranking. Although Guadalajara has an interesting multi-modal mass transport network (light rail and buses; the first line of the BRT was not included in the analyses yet), it suffers from price inconsistencies and a lack of system 
integration that results in increased costs to collective transport users. At the time of the measurements, Guadalajara had built zero kilometres of bike lanes, and pedestrian infrastructure continued to be deficient. Moreover, Guadalajara's performance in the ranking is affected by policies that have provided clear incentives to increase car dependence; amongst these, significant tax cuts for car owners, and large scale - yet citizen contested proposals for new urban highways. The situation in Caracas seemingly reflects the consequences of highly subsidized gas. Due to an ancient official national government policy, buying gas in Venezuela continues to be cheaper that buying water. According to the German Society for International Cooperation (GIZ), Venezuela has the cheapest gasoline prices in the world, at just 2,3 US cents per litre (GIZ 2013); as such, travelling by car is drastically cheaper than in any of the other studied cities.

Although Curitiba confirms its overall regional leadership, no city was found to lead (or occupy the last position in) all three baskets of transport sustainability; environmental, social and economic. Evidently, all cities have much to improve in specific components of their transport sustainability mix.

\subsubsection{Environmental Basket of Transport Sustainability}

Within this basket, this index aims to capture each city's contribution to global climate change; essentially, via measuring air pollution (both in terms of acidifying gases, and volatile organic compounds from transport), and the consumption of natural resources to power transport.

The top performers in this basket include Montevideo, the capital city of Uruguay, and Curitiba (see Figure IV-5). Montevideo profits from sitting on an estuary with a free connection to the open sea; which may help to disperse air pollution. Furthermore, the city government has established strict air quality codes and monitoring systems, highlighting their intention to reduce their overall contribution to climate change. However, this positive performance in the environmental basket for transport sustainability is not backed by equally superior performance in the remaining baskets.

In terms of air pollution, a focus is made on analyzing levels of carbon monoxide $(\mathrm{CO})$, nitrogen oxide $\left(\mathrm{NO}_{\mathrm{x}}\right)$, sulfur dioxide $\left(\mathrm{SO}_{2}\right)$, particulate matter $(\mathrm{PM})$, and carbon dioxide $\left(\mathrm{CO}_{2}\right)$ for both individual and collective 
transport. The index includes values in total tons per capita per year. Overall, Montevideo, Curitiba and Belo Horizonte exhibit the lowest emission of greenhouse gases (GHG) as compared to the remaining studied cities. In regards to energy consumption per capita, Montevideo once again scores highest, with the lowest scoring city located right across the River Plate; Buenos Aires. Although there is insufficient evidence to explain this phenomenon, and that is not the principal objective of this dissertation, such a sharp difference might be due to urban density. While Buenos Aires boasts an immense urbanized area of $3,883 \mathrm{~km} 2$, and a low population density of 3,389 inhabitants $/ \mathrm{km}$, Montevideo profits from a population density that is almost twice as large as that of its neighbour $(6,509 \mathrm{inh} / \mathrm{km})$, conveniently packed in a much smaller area $(196 \mathrm{~km} 2)$.

\subsubsection{Social Basket of Transport Sustainability}

The composition of this basket favours highly mobile societies with low dependence on the automobile (see Figure IV-6), as well as broad urban systems that offer affordable and equitable opportunities to mobilize about the city, via collective and/or non-motorized transport. Under this framework, Curitiba stands out as the overall undisputed leader, partly due to the large number of kilometres with priority for collective transport, bicycle lanes (second only to Bogotá's $300 \mathrm{~km}$ ), and leadership in kilometres for pedestrian only streets. Moreover, Curitiba exhibits the lowest proportion of deaths in traffic accidents, at only 2/100.000 inhabitants in 2007. 


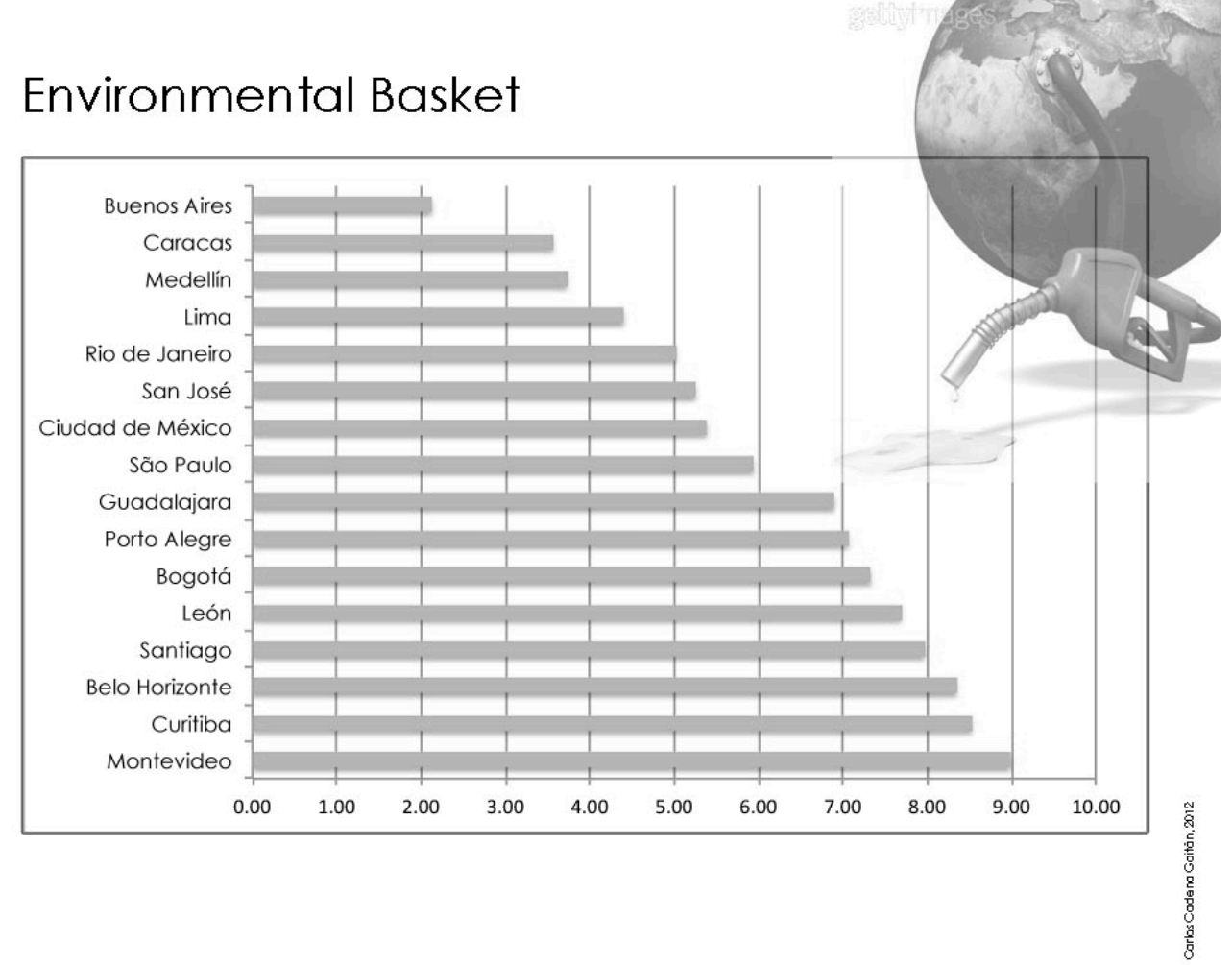

Own calculations based on: CAF (2009); EIU (2010); Secretaría de Tránsito y Transporte de Medellín, Metro de Medellín, Área Metropolitana del Valle de Aburrá.

In stark contrast, Guadalajara suffers greatly from what many consider to be transport's central public health concern; it showcases the highest proportion of deaths in traffic accidents, with 16/100.000 inhabitants for the same year. In terms of accessibility to jobs, education and entertainment, Santiago leads with an average of 3 daily trips per inhabitant; highly skewed towards collective and non-motorized transport modes. San José scores lowest in personal mobility, with only 1.2 daily trips per inhabitant in average, and Buenos Aires' daily trips by mode performance, leaves it as both the most-car dependant, and least bike-dependant city from the sample, with more than 13.000 total car trips per day, and less than 0.001 bike trips per capita per day, correspondingly. Regarding travel times, Montevideo 
and the Brazilian cities of Curitiba and Porto Alegre present similarly low average travel times - under 30 in average per trip -, while Bogotás performance reveals high levels of traffic and congestion, ranking lowest in this category, with 55 minutes in average per trip.

Figure IV-6: Social Basket Results

\section{Social Basket}

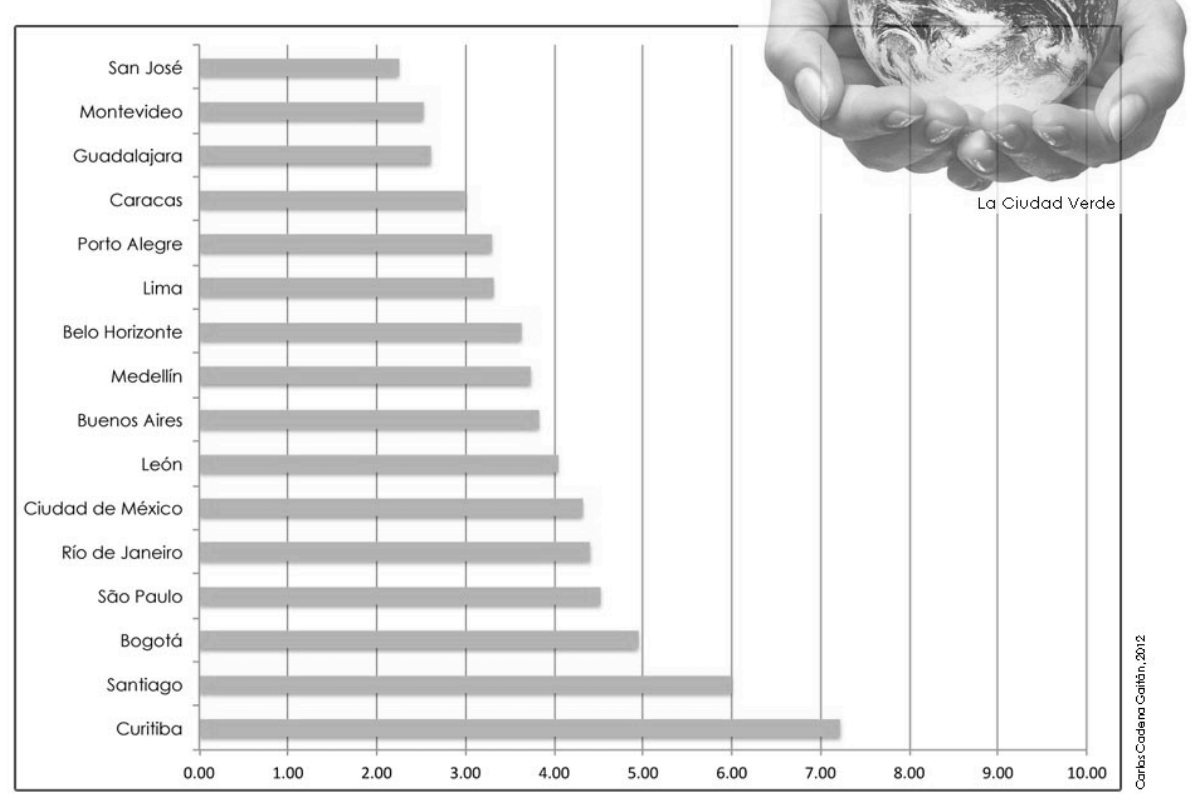

Own calculations based on: CAF (2009); EIU (2010); Secretaría de Tránsito y Transporte de Medellín, Metro de Medellín, Área Metropolitana del Valle de Aburrá.

Finally, as it refers to the availability of the collective transport networks, Rio de Janeiro ranks within the top tier (in relative terms to the other cities), exposing the most extensive network, and qualifying - a significant proportion of it - as superior modes of collective transport (i.e. metro, LRT, BRT). In this same context, Montevideo and Lima are severely castigated for depending highly on fossil fuels to power their transport system. Lima has more recently succeeded in revamping its decades old stalled metro project, yet this event is not accounted for in the data used in this dissertation. 


\subsubsection{Economic Basket of Transport Sustainability}

Within this last basket I intend to measure the costs of travel for users, the levels of car and motorcycle ownership, the costs of energy use, and the public prioritization of investment in superior modes of collective transport (see Figure IV-7). Rio de Janeiro tops this basket due to the positive combination of affordable travel in collective transport modes, the aboveaverage costs for car travel, and the significant public investments in superior modes of collective transport. For 2007, Rio de Janeiro invested U\$6,118 million in roads, while investing almost double of this (U\$12,800 million) in superior modes of collective transport (CAF 2009). In terms of private car and motorcycle numbers, and even though this is directly connected to average incomes, as previously discussed, the index results are indicative of a motorization trend. I find an average of 0.28 vehicles per person (with half-weighting allocated to motorcycles) for all the studied cities, this compares to the averages for global capitals such as New York (0.45), Tokyo (0.47), and Paris (0.44). Rio stands below the average for the GTI at 0.26 vehicles per person, while Buenos Aires ranks lowest with 0.66 vehicles per person. Curiously, this is one of the measures where Curitiba fails to hold an above average rating, with 0.50 vehicles per person.

It must be highlighted that the used data reflects the actual transport infrastructure in place by the start of 2008, and thus the associated sustainability levels at that point in time. Several important developments might have taken place since this date, yet difficulties in collecting appropriate and comparable data force an exclusion of the associated advances in sustainability. 


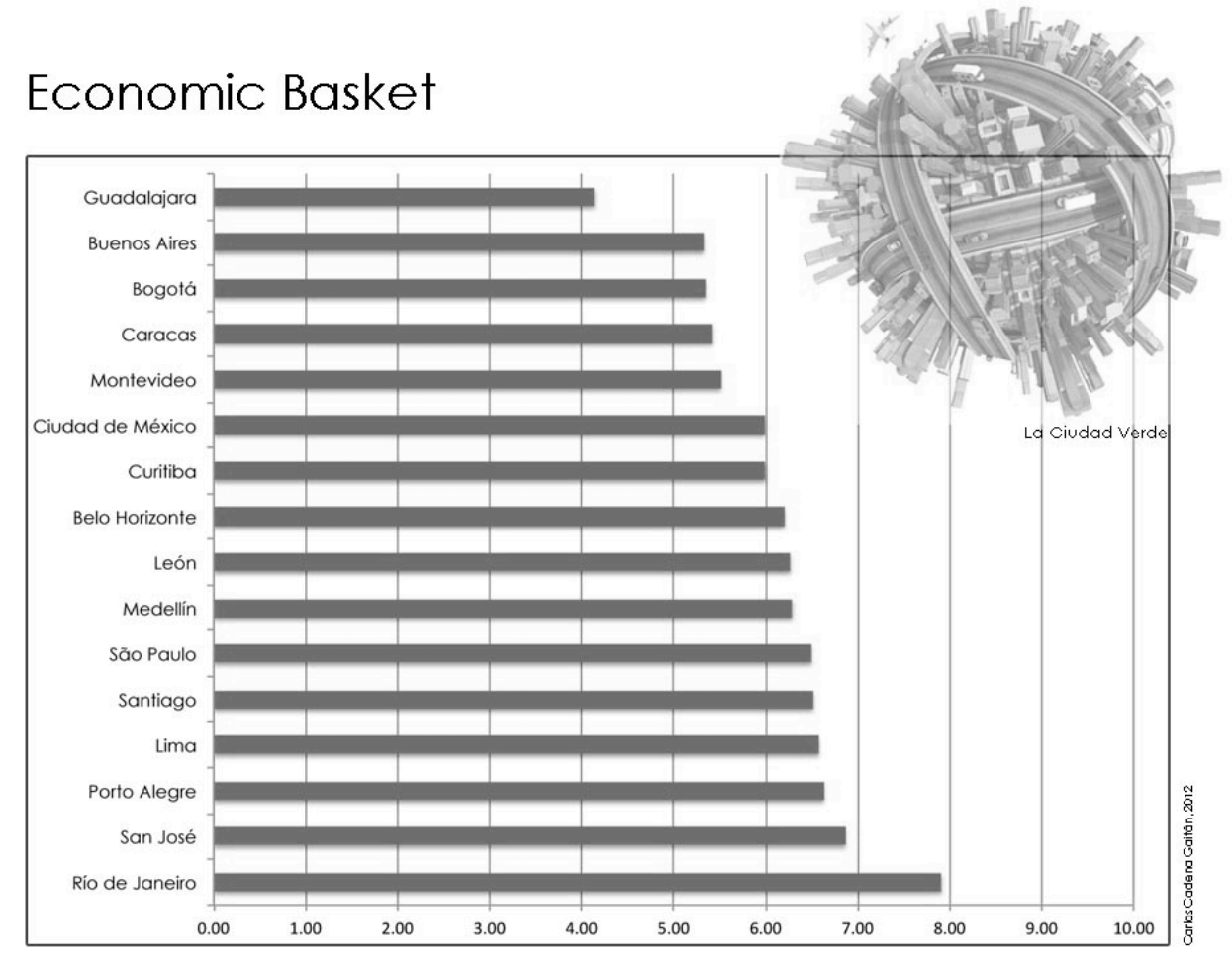

Own calculations based on: CAF (2009); EIU (2010); Secretaría de Tránsito y Transporte de Medellín, Metro de Medellín, Área Metropolitana del Valle de Aburrá.

\subsection{Patterns in Transport Sustainability}

There is no simple answer to why some Latin American cities are doing better on transport sustainability than others. The exploration began by focusing on the potential explanatory power of commonly referred to variables. However, it was found that city performance in the GTI does not easily correlate to GDP per capita, size of the city, size of the population, nor population density; although this last variable does raise some interesting thoughts. At the end, political variables seem to have higher explanatory power for cities in this region.

Urban sustainability is a complex phenomenon permanently influenced by a wide diversity of factors. For example, size is usually proposed as a factor directly affecting the urban environmental balance. However, it is not necessarily the case that "the bigger the city, the worse its climate profile" 
(KPMG 2010); certainly, the size of a city and the size of its population affect any urban balance, but this relationship is not at all straightforward. Having larger populations means having more people that need to gain access to resources, and more people that generate waste; similarly, covering larger areas could mean that resources previously located within city boundaries, now can only be found outside of them, with the negative consequences in transport and energy costs that this may bring. Nevertheless, the magnitude of these effects could actually depend on the urban forms that have taken place historically in any specific area. Thus, generating a mix of higher and lower sustainability levels in the results, with no direct correlation to the size of the city, nor the population.

Similarly, the average income levels of urban dwellers are often proposed as a fundamental variable affecting urban sustainability. Some studies show that urban carbon footprints increase as the incomes of its inhabitants increase. At the national level, for instance, a doubling of consumption levels brings, in average, an increase of $57 \%$ in its carbon footprint (WWF 2010). In the context of developing countries, income levels are often tightly related to motorization. Some authors argue that there is a specific income threshold at which people move into cars; Ohmae set this threshold at USD 5000 in his studies of Asian cities during the 1990's, for example (Ohmae 1996). Many others, have also provided empirical evidence to conclude that in developing world cities, "rising incomes are the major driving force for car ownership" (Mohamad \& Kiggundu 2007, p.1). Furthermore, the economic benefits brought about by the car industry (i.e. taxes, provision of inputs, direct and indirect jobs, etc.), could result in strong links with the cities that house them. Yet, in the case of the cities studied, neither GDP per capita, size of the city or size of the population seem to correlate with the ultimate ranking in transport sustainability. 
Figure IV-8: Total energy consumption and population density

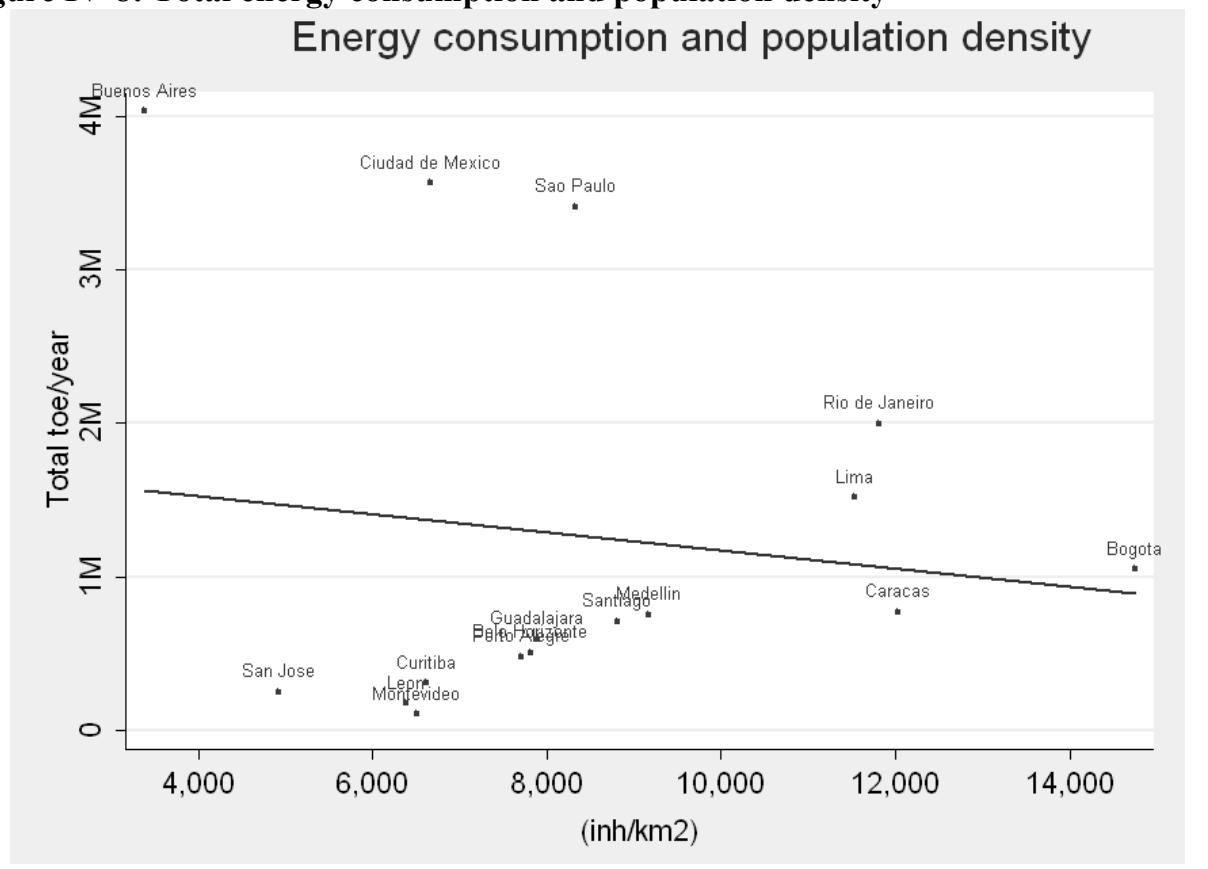

Source: EIU 2010, América Economía 2010; own calculations.

Population density is also often quoted as influencing urban sustainability (Breheny 1992; Benoit Lefèvre 2009; Bertaud 2004). Precisely because "it is the [urban] density that makes particular energy and climate measures effective (or not)" (KPMG 2010, p.12). Some of the pioneers in urban transport sustainability research, Newman and Kenworthy, provide evidence for a correlation between urban density and transport-related energy consumption. Their famous 1989 hyperbola ${ }^{15}$ planted the idea that lowdensity urban areas are repeatedly correlated with high car-dependence, and thus, high (transport-related) energy consumption per capita. On the other hand, their studies offer the idea that high-density urban areas exhibit greater use of collective transport modes, hence totalling much lower average rates of energy consumption per capita. It must be noted that these studies did not include Latin American cities at the time.

The results in this chapter show a weak correlation between overall transport-related energy consumption levels and overall population density for the Latin American cities analyzed. Although some highly energy intensive cities, such as Buenos Aires, and Ciudad de México have lower

${ }^{15}$ See (P. Newman \& J. Kenworthy 1989). 
than average population densities, there seems to be no clear trend relating these two variables for the studied cases (see Figure IV-8).

Figure IV-9: Total energy consumption and population density (without the 3 MegaCities of Buenos Aires, Ciudad de México and Sao Paulo)

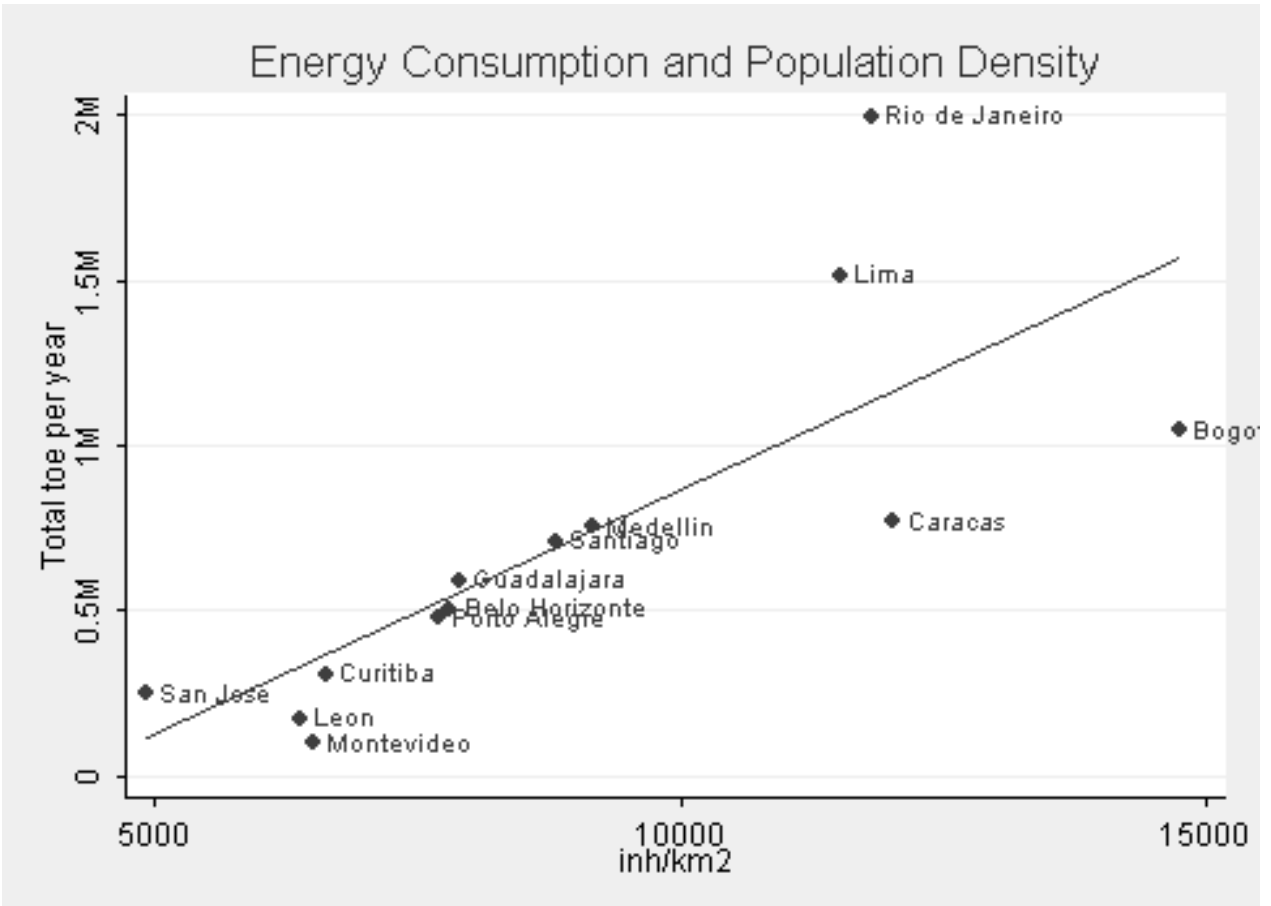

Source: EIU 2010, América Economía 2010; own calculations.

In fact, if we are to manually exclude the three mega-cities of Buenos Aires, Ciudad de México and Sao Paulo from the analysis, the slight downward trend, now becomes a clear upward trend, reflecting an unexpected situation in which cities with higher population densities seem to correlate with higher total energy consumption from transport (see Figure IV-9).

On the other hand, when exploring transport-related energy consumption per capita and population density, a relationship that is better fitted to theoretical expectations is found. Although there are no crisp correlation between higher densities and lower rates of energy consumption per capita, most of the cities' performances correspond to the expectations (see Figure IV-10). 
Figure IV-10: Energy consumption per capita and population density

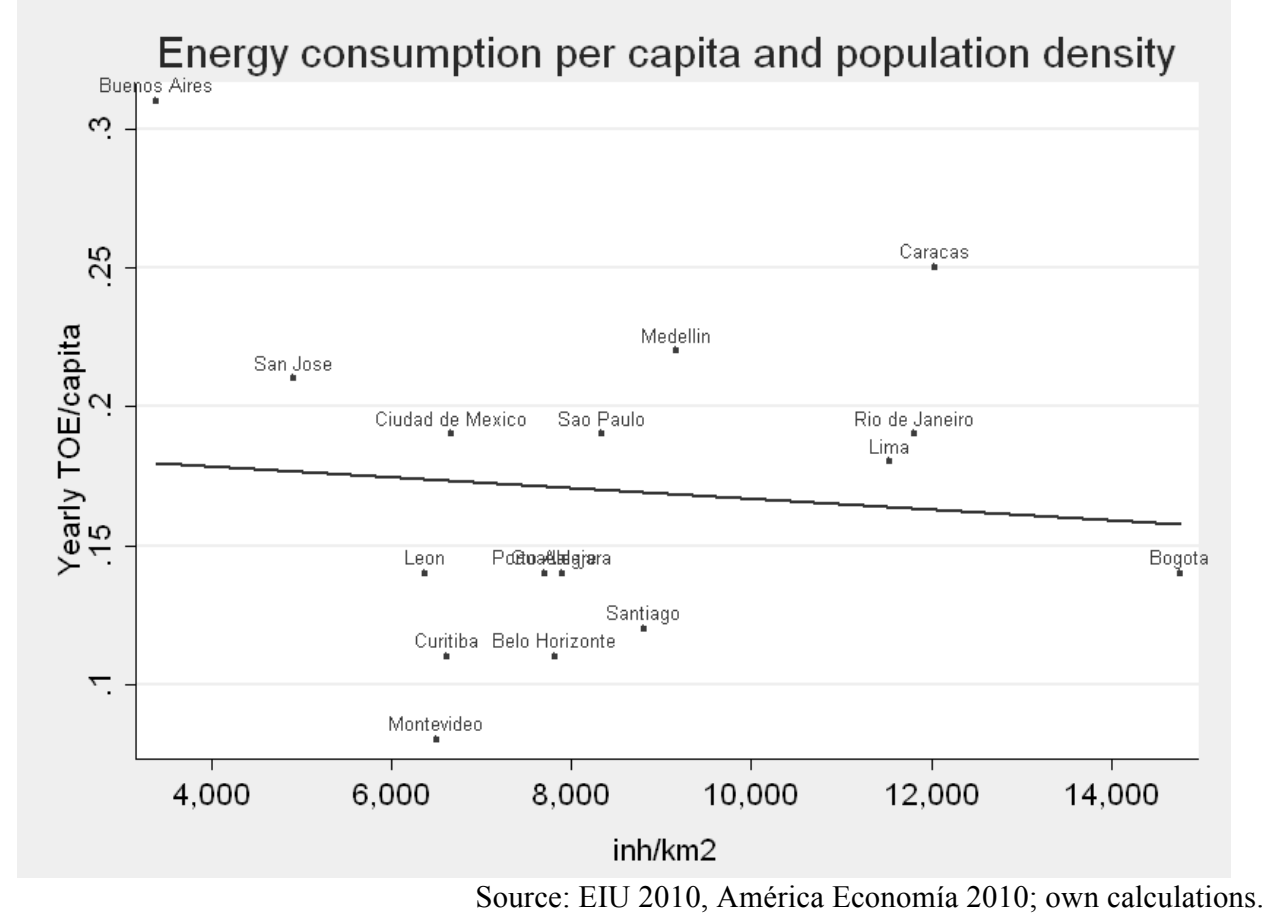

This relationship becomes even more interesting if only those cities with below average population densities are considered (see Figure IV-11); here, as population density increases, transport-related energy consumption per capita decreases. Thus, agreeing with previous studies suggesting that higher densities allow for shorter travel distances, and as a consequence, smaller transport-related energy consumption levels. When performing this same exercise for cities with above-average population densities, no clear correlations are found (see Figure IV-12). Nonetheless, these contradictions pose attractive questions as to the additional political determinants that explain the diverse transport conditions in these cities. 
Figure IV-11: Energy consumption per capita in cities with below-average population densities

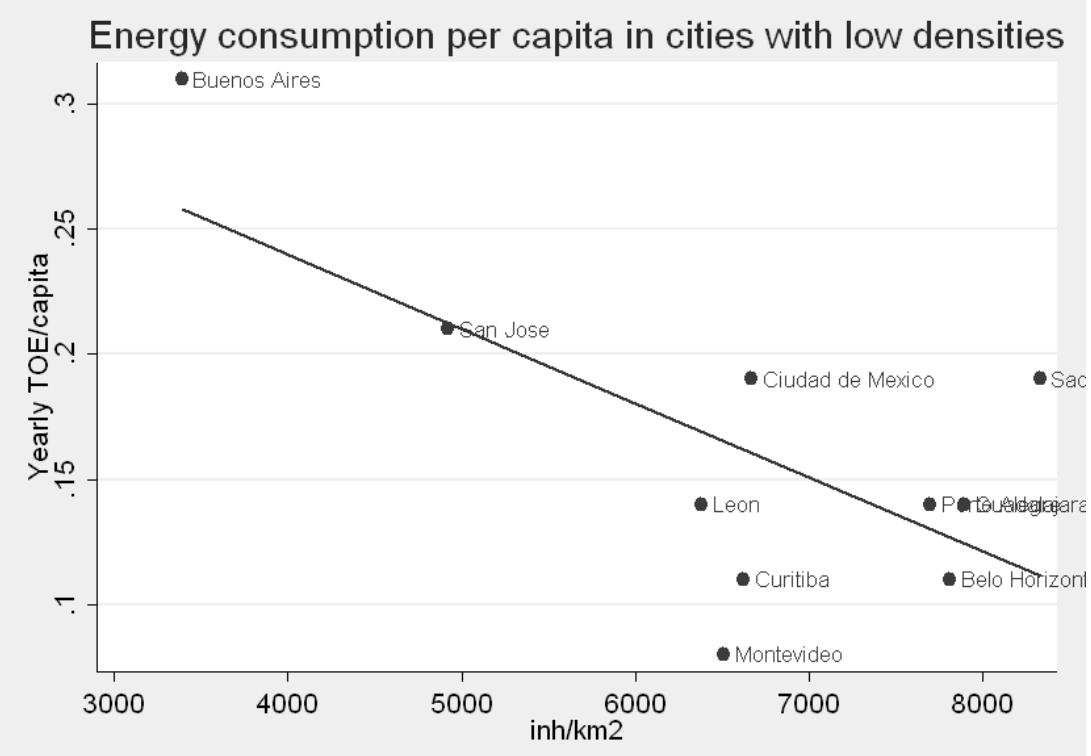

Source: EIU 2010, América Economía 2010; own calculations.

Figure IV-12: Energy consumption per capita in cities with above-average population densities

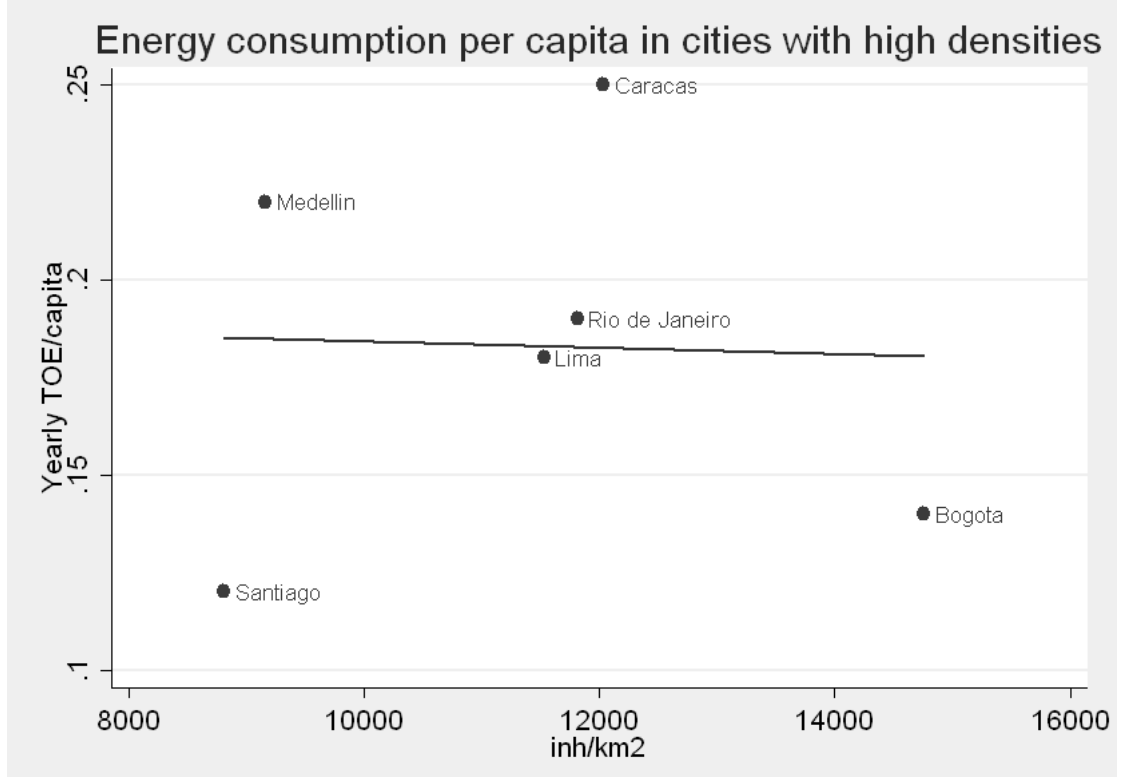

Source: EIU 2010, América Economía 2010; own calculations. 
When analysing the relationship between overall population density and the results of the GTI, an interesting ascending trend between higher densities and higher results in the index is found, once again, with some seemingly outlying cases (Curitiba, Santiago, Guadalajara and Caracas), whose specific political conditions, seem to generate merits for further qualitative analysis (see Figure IV-13).

\section{Figure IV-13: Green Transport Index and population density}

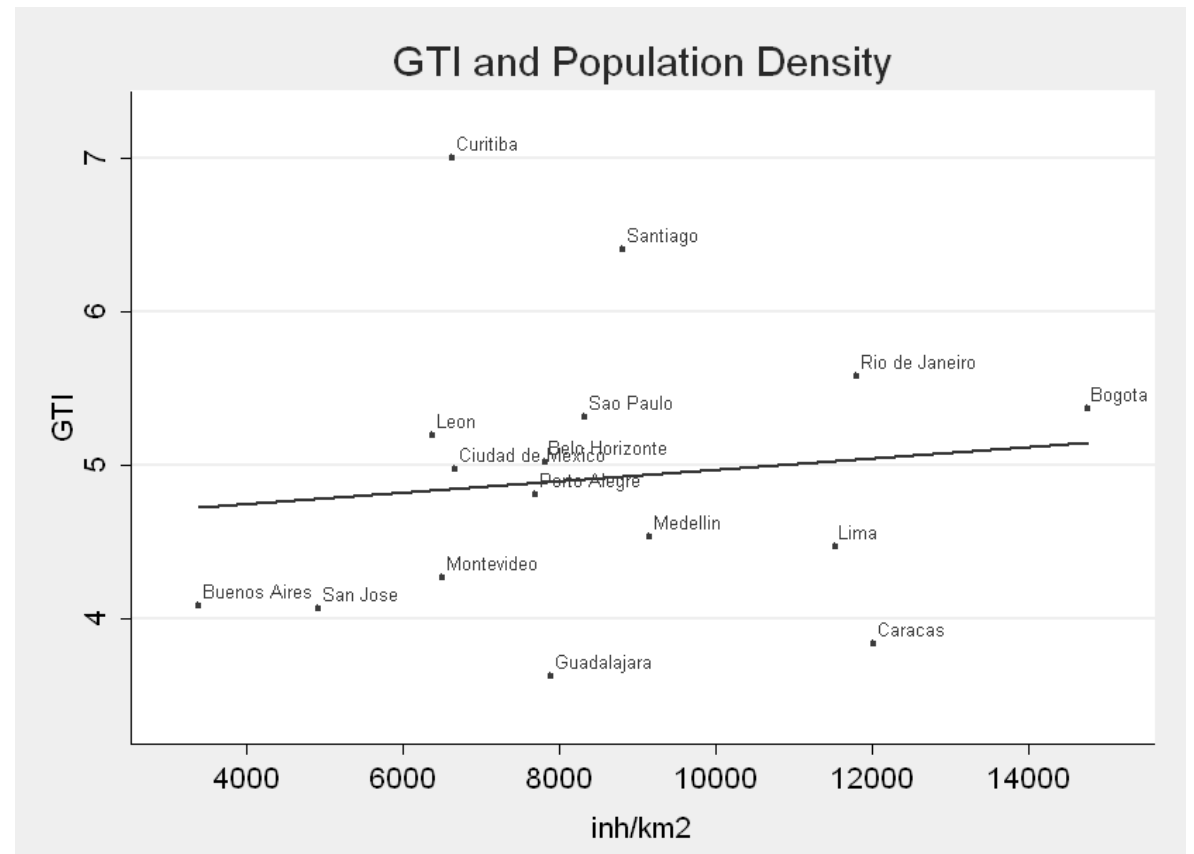

Source: EIU 2010, América Economía 2010; own calculations.

Evidently, since energy consumption is considered as one of the key indicators for the index, it is only natural that lower levels of overall transport-related energy consumption per capita seem to be correlated with overall rankings in the GTI (although with a very small $\mathrm{R}^{2}$ of 0.2 ). However, once again, some apparent outliers present interesting cases for further study (see Figure IV-13): Guadalajara has a below-average energy consumption per capita level, yet, ranks last in the index, Montevideo tops the rankings in energy consumption (and overall environmental performance) yet ranks low in the ultimate index, while Curitiba and Santiago, although with very low energy use rates, rank at the top. 
Figure IV-13: Green Transport Index and energy consumption per capita

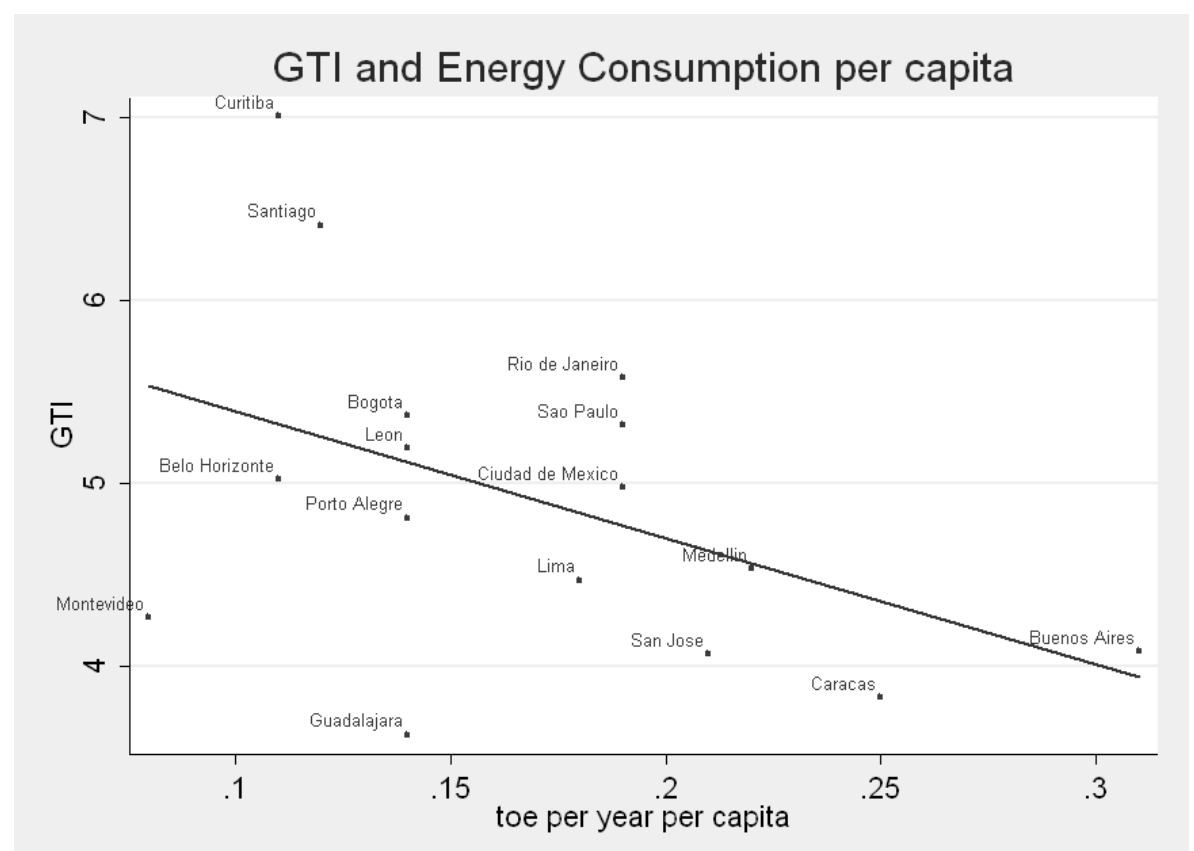

Source: EIU 2010, América Economía 2010; own calculations.

Two additional dimensions that must be accounted for when trying to understand patterns in transport sustainability for Latin American cities are recognized: history and politics. History refers to the one aspect that -by definition- city officials can do nothing about. The consequences of all decisions and actions previously taken should be seen actively affecting transport sustainability today. Some cities have followed particular urban development strategies for years, with evident consequences in terms of transport modal share and energy consumption today. Such seems to be the case of Curitiba, where a political decision was taken in the 1970's to allow for the growth of the city along the broad BRT lanes with the appropriate participation of technical institutions such as Urbanização de Curitiba (URBS) and the Instituto de Pesquisa e Planejamento Urbano de Curitiba (IPPUC); or the case of Medellín, where due to mediocre urban planning, the city dwellers massively invaded the surrounding hills of the city, thus creating difficult conditions for collective and non-motorized transport modes. If present transport sustainability outcomes are a consequence of the 
natural and historical conditions of a city, then it is interesting to study the effect of path dependent urban dynamics.

Similarly, public policies framing the sustainability of transport systems depend highly on the "involvement of various stakeholders (departments, other governments, private parties, etc.) with varied interests, powers, competences and responsibilities" (KPMG 2010, p.13). As will be detailed in the following chapters of this dissertation, what ends up happening in real life scenarios is that the secretary or cabinet member responsible for transport often has little power over public works, social development programs, and/or environmental protection. This results in ordinary political compromise dynamics; a completely different power game that permeates ultimate transport sustainability decisions, for any modern city. It is imperative to recognize the broader context in which sustainable transport policies are discussed, decided on, and implemented when comparing transport sustainability levels. As Bertolini asserts, "[there is a] need to shift the focus of the effort from devising policy packages to understanding the factors enabling, or impeding their implementation, and thus towards a more experimental, interactive attitude towards policy making" (Bertolini 2008, p.71).

The timing could not prove to be better for Latin American cities in advancing their transport sustainability. Many of the studied conurbations still present very low private vehicle modal shares, and corresponding large shares for collective (specially bus) and non-motorized transport (specially walking). This, however, might not account necessarily for policies aiming at increasing transport sustainability, but rather for the relative income of these cities. For many decades, succeeding in acquiring a car was a privilege for the very few; thus, leaving no other option for vast percentages of urban populations but to move about the city using bus services or walking. The relative underdevelopment in the planning of many Latin American cities should also contribute in avoiding the errors of others, while taking advantage of the large percentages of citizens that still have not become fully motorized. Likewise, city authorities stand in an advantageous position to take leadership in these issues. Not only do they have the power to plan the future of their transport systems, but also hold diverse regulatory powers.

The results in this section suggest the need for a deeper exploration into urban transport sustainability levels in Latin America, and their relationship 
to the political processes framing long-term urban policies. It is clear that numerous cities in the region are actively finding ways to promote their urban sustainability and mitigate GHG emissions (WWF 2010), however, there is no clear evidence regarding the political conditions that have allowed some of the cities to advance much more than other conurbations sharing similar structural characteristics.

\subsection{Conclusion}

An empirical characterization of the general trends in transport sustainability for sixteen Latin American cities has been presented. In the context of accelerated urbanization throughout the globe, the situation in this region is special; it is expected that $86 \%$ of its population will live in cities by 2030 (EIU2010). With financially weak governments and enduring social inequalities, these growing urbanization trends pose worrying prospects to urban sustainability.

One of the central issues to consider when studying urban sustainability, concerns transport systems; both in terms of their positive and negative externalities. This applies especially to those regions where ancient cardependent transport planning modes, continue to be the ruling paradigm. With greater awareness of its dangers, and sufficient empirical evidence, "there is [now] a growing consensus on the need for more sustainable patterns of transport" (UNEP 2011, p.380).

An index that rates the performance of the studied cities in terms of transport sustainability has been created. This Green Transport Index (GTI) presents separate outcomes for the social, economic, and environmental components of transport sustainability, framed under a 'sustainabletransport-inspired' structure composed heavily by collective transport modes and non-motorized transport modes. This initiative aims at becoming a recurring exercise, ultimately serving as a benchmark, and concomitantly providing incentives for political actors in the region to pursue more sustainable transport policies.

There is great potential in converting this green transport ranking into a benchmarking exercise for the region's cities. This would transcend from a performance measurement for the urban transport systems, to an avenue for influencing the effectiveness of public policies. By identifying front-runners 
and leading practices, "cities can benefit from the knowledge and experience of colleagues in other cities to assist sustainability policy development" (KPMG 2010, p.10). An obvious requirement for a potential benchmarking exercise would be to measure city performance over time; thus allowing for improvements to be tracked. The key constraint to this possibility in Latin America continues to be the availability of reliable data.

An argument for more sustainable transport systems, as necessary components for modern cities is made. Previous studies show that cities need new approaches to urban development that privilege the collective well-being. Sustainable transport systems not only need to provide space and resources for new comers, but must also be structured so as to tackle inequalities, while protecting the environment, and promoting economic growth.

As previously discussed, increasing sustainability in transport requires solid urban governance. Moving towards sustainability obviously necessitates appropriate technology and funds; however, it is precisely sound governance, correct planning, and strong implementation capabilities that become crucial in attaining urban sustainability (UN-HABITAT 2002). As such, there seems to be a need for high level research focused on effective institutions, successful public policies, and good governance that correlates with high levels of urban sustainability. This exercise sets the stage for one crucial question to be tackled in the next chapters of this dissertation: which are the political and institutional variables that determine different levels of transport sustainability in Latin American cities? 


\title{
5. Chapter V
}

\section{Political Complexities of Transport Sustainability in Latin America}

\author{
"Power doesn't change people, it just reveals their real being" \\ -Pepe Mujica
}

\subsection{Introduction}

This chapter presents the key themes arising from an in-depth analysis of the recent developments in urban transport sustainability, for Curitiba (Brazil), Guadalajara (Mexico), and Medellín (Colombia). Aiming at contributing to the wider debate on sustainable transport in developing countries, this section deviates from previous studies that have focused on analyzing urban sustainability technically and in developed nations, and instead, concentrates on mapping political determinants of urban sustainability for the Latin American region. Using first hand data from key informant interviews in each of the cities, the levels of engagement towards transport sustainability of these metropolitan areas are qualitatively contrasted.

This chapter first provides a description of the conceptual operationalization of the research question. Then, it opens an insight into the broad themes of the cross-case comparison, and later expands it in detail for the three case cities. Finally, it maps the key political determinants identified in this section; allowing for the optimization of working hypotheses.

\subsection{Representation of Dependent and Explanatory Variables}

Building on the results of the GTI presented in Chapter IV a deeper exploration into the mechanisms explaining the variety in outcomes for transport sustainability in the studied cities is opened. Ultimately, the goal is to map and contrast the political and institutional determinants of these variations, across the three selected case studies. Three cities have been chosen on the basis of their transport sustainability outcome and the broader theoretical context. 
This design is used to:

(a) Seek explanations for the variation in transport sustainability outcomes for the three cities, and

(b) Determine if the empirical facts meet the theoretical expectations.

In order to translate the way in which the various explanatory variables influence the sustainability of urban transport in the three case studies, each explanatory variable is rated against the dependent variable, using the information collected during the interviews. As such, each category may have a positive or negative influence on transport sustainability, and contribute to explaining the GTI results for each city.

The role of these explanatory variables offered central underlying prompts during the interviews. In this section, they are used as guiding structures for identifying the central themes from the cross-case analysis, and result in the construction of the working hypotheses offered at the end of this chapter:

1. Degree of centralization of authority in metropolitan governance: by analyzing the metropolitan governance arrangements in place for each metropolitan area, and identifying the influence of the key institutional players at the local level.

2. Institutional coordination: by mapping the coordination links across the pertinent institutions responsible for urban transport planning, construction and operation.

3. Interactions between political players: by selecting the dimensions that characterize the crucial political interactions for each metropolitan area. An emphasis is placed on the specific weight of the local mayor(s), the conflicts amongst political players and technical players, and the strength of organized interest groups.

4. Type of initial stimulus: by considering the context and conditions allowing for the successful introduction of key urban transport policies. As emphasis in financial incentives is placed in this section.

As described in Chapter III, to select the cases a focus has been placed on both, the transport sustainability outcomes from the GTI, and the broader theoretical context; thus guaranteeing theoretical relevance. Conversely, in order to minimize variation for the set of structural variables discussed above, and guarantee that the chosen cities in fact share similar structural characteristics, all efforts have been made to select three cities with similar 
population, area, GDP per capita, and population density. Hence, the selection of Curitiba, Medellín and Guadalajara, as depicted in Table V-1.

Table V-1: The Three Chosen Case Studies

\begin{tabular}{|c|c|c|c|c|c|}
\hline City & $\begin{array}{c}\text { Total } \\
\text { Population }\end{array}$ & $\begin{array}{c}\text { Area of } \\
\text { city } \\
\text { (km2) }\end{array}$ & $\begin{array}{c}\text { GDP per } \\
\text { capita } \\
\text { (2009US\$) }\end{array}$ & $\begin{array}{c}\text { Population } \\
\text { Density } \\
\text { (inh/km2) }\end{array}$ & GTI \\
\hline Curitiba & $2,815,036$ & 425 & 10,797 & 6,624 & 7.00 \\
\hline Medellín & $3,500,000$ & 382 & 5,548 & 9,162 & 4.83 \\
\hline Guadalajara & $4,298,715$ & 544 & 9,409 & 7,896 & 3.62 \\
\hline $\begin{array}{c}\text { Average for } \\
\text { the sixteen } \\
\text { studied cities }\end{array}$ & $6,818,664$ & 943 & 10,400 & 8,396 & 4.91 \\
\hline
\end{tabular}

\subsection{Cross-Case Comparison}

The initial empirical findings place Curitiba as the regional leader in transport sustainability; thus confirming theoretical expectations. However, this is only implied in relative terms, as later qualitative analysis contributes, when analyzing the present situation in this city.

Although Curitiba leads in overall transport sustainability performance, comparing the performance of these three cities across the three baskets brings interesting conclusions. The environmental performance of Guadalajara is significantly better than that of Medellín, and only marginally worse than that of Curitiba; scoring 6.89 out of 10 , Guadalajara's environmental result in the GTI stands above the average for all 16 cities, of 6.13. Moreover, Medellín has a slightly better result than Curitiba on the economic basket of the GTI, scoring 6.29, compared to Curitiba's 5.99. Nevertheless, both cities stand significantly close to the 16-city average of 6.09 (see Figure V-1). 


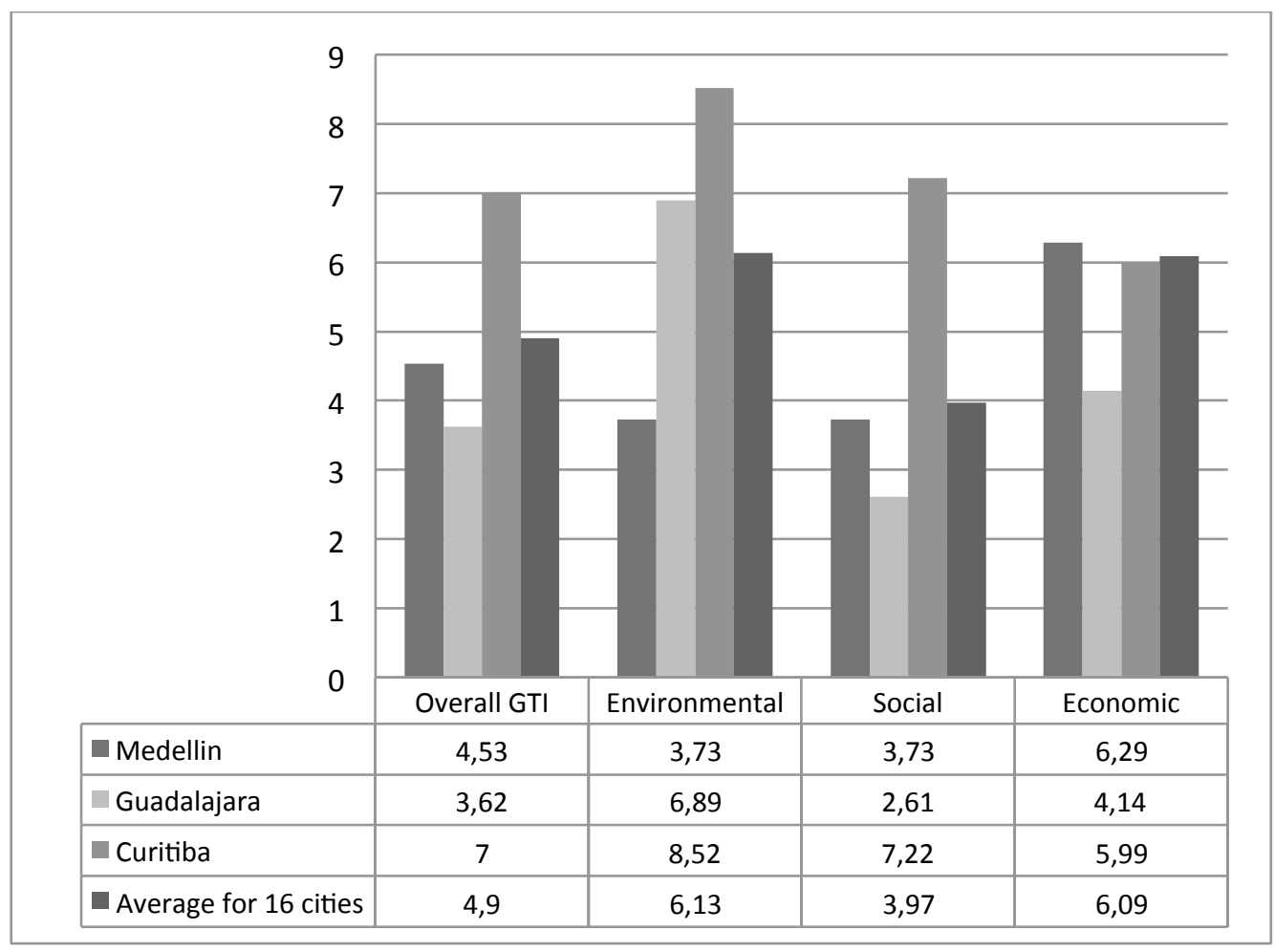

Source: own elaboration

Previous findings provide valuable evidence about the role of institutional arrangements at the metropolitan level and political will, in the context of higher levels of transport sustainability (Monzón 2005; Dimitriou \& Gakenheimer 2011; Cadena-Gaitan et al. 2013). As such, a special emphasis is placed on the role of urban governance (rather than the availability of technology, infrastructure and funds), in the context of the specific institutional conditions in Latin America.

\subsection{Transport Sustainability Trends}

Clearly pointing at specific conditions that could explain the variation in transport sustainability outcomes is a daunting task for the Latin American region. Some commonly referred structural variables, such as GDP per 
capita, size of the city, and size of the population, do not seem to explain why some cities are doing better than others.

Hence a deeper inquiry is directed towards the possible explanatory power of population density. Its influence on transport sustainability could be found -inter-alia- via higher trends of energy consumption per capita, as the key studies by Newman and Kenworthy (1989) describe. However, and as was described in Chapter IV, this does not necessarily imply that highdensity urban areas always exhibit higher levels of transport sustainability, as can be concluded from the initial empirical characterization for Latin American cities aforementioned, and other similar studies (i.e. (Benoit Lefèvre 2009; Economist Intelligence Unit 2009).

For the three cases under study, the relationship between population density and transport sustainability does not match any theoretical expectations (see Figures IV-12; IV-13). Nevertheless, when asking transport experts from the region, about their perceptions on common city characteristics and their influence on transport, a majority of them do perceive population density to have a direct correlation with the sustainability level of urban transport in the region. While the three cities have a population density that does not stray more than one standard deviation from the average of all studied cities, their GTI ranking deviates greatly. Thus, throughout the case study, the city with the highest transport sustainability, Curitiba, the city with the lowest, Guadalajara, and a city with a score less than one half standard deviation away from the average GTI, Medellín, are contrasted.

\subsection{Political and Institutional Complexities}

During the interviews, three major thematic frameworks that were recurring throughout the three cities were identified, as having explanatory value towards both high and low transport sustainability (see Figure V-2).

The identified themes, or thematic frameworks are:

(a) The role of a development model built around the car,

(b) The role of metropolitan governance,

(c) The role of powerful institutional players.

These major themes are mapped in code trees along with the most common explanatory factors mentioned by the key informants, aiming at visualizing the paths towards low and high transport sustainability identified in these 
three cities. While these major thematic frameworks refer to the roles of three often-cited phenomena for the three cities, the specific explanatory factors within these major themes, are described in detail in Chapter VI.

As mentioned earlier, the theoretical paradigm used values those transport policies and projects providing incentives against car-dependent models, in favour of clean collective transport, and in favour of non-motorized transport, as avenues towards higher transport sustainability. In order to highlight the key political interactions relating to the three thematic frameworks, the principal conditions found in each city are described:

Figure V-2: The Three Thematic Frameworks

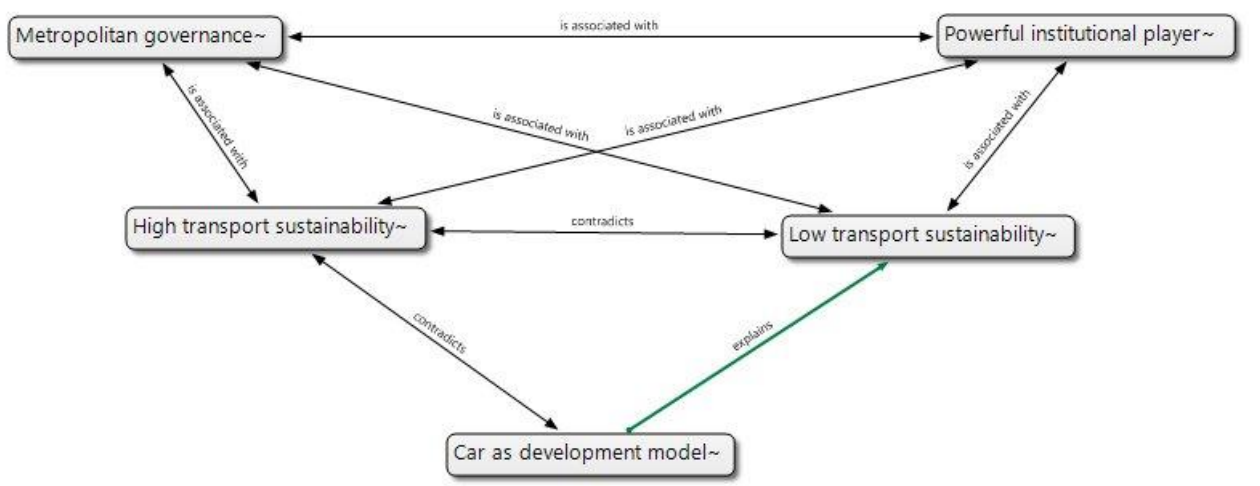

Source: own elaboration

\subsubsection{Curitiba, Brazil:}

A vital economic centre of southern Brazil, Curitiba was the city where the official invention of the Bus Rapid Transit (BRT) system took place. Many decades later, the BRT has now become a global alternative to metro systems. Its metropolitan area extends across twenty-six municipalities, of which, the transport administration (URBS) covers thirteen; including the ten nuclei municipalities and three that do not share a border with Curitiba proper: Bocaiuva do sul, Contenda, and Mandirituba (see Figure V-3). In 2010 the city received the Globe Sustainable City Award, and has managed to maintain a city brand related to sustainability. As one of the key respondents says: "There is high awareness from the citizens that we have advanced much more in relation to other Latin American cities [here, everybody] knows that we won a prize as the most sustainable city on 
earth" ${ }^{16}$. Among academic circles, Curitiba is also regarded as the sustainable transport leader in Latin America. Due to a well-known urban transformation process started in the 1970's, it has led numerous transport innovations that have been later implemented by other cities around the world.

One such innovation is the BRT; its promoters tout it as the perfect substitute for mass metro systems in developing world cities, as it can carry similar numbers of passengers (per hour/direction) as those of an ordinary metro, yet, its construction costs a fraction of that for an average metro (EMBARQ 2010). Curitiba is also home to a famously extensive and disputed ${ }^{17}$ pedestrian street, and to one of the most recognized city planning institutes of the region, the Instituto de Pesquisa e Planejamento Urbano de Curitiba (IPPUC), credited with drafting many of the master urban planning policies often connected with the high transport sustainability of the city.

Although most of those interviewed agreed with the historical urban planning achievements in the city, a vast majority of them expressed their worries about the most recent development in terms of urban transport; "Curitiba has been a global reference in sustainable mobility for 30 years, but has not contributed with any [sustainable transport] innovation during the last 10 years" $"$.

Often quoted structural problems in the system include the lack of agreement between the high densities along the main corridor lines of the BRT, and the housing locations of the actual users of the system. Due to the lack of proper regulation, the high land prices next to the main BRT corridors have resulted in high real estate prices, which only the rich (who own a car) can afford.

\footnotetext{
${ }^{16}$ Personal communication, prof. Harry Bollmann. PUCPR, August 8, 2012.

${ }^{17}$ Rua XV de Novembro was converted from a car way, to a pedestrian-only street in 72 hours, during 1972. Although facing much public protests, it became the first major pedestrian street in the country.

${ }^{18}$ Personal communication, journalist Alexandre Costa Nascimento, Ir e Vir de Bike, August 2, 2012.
} 


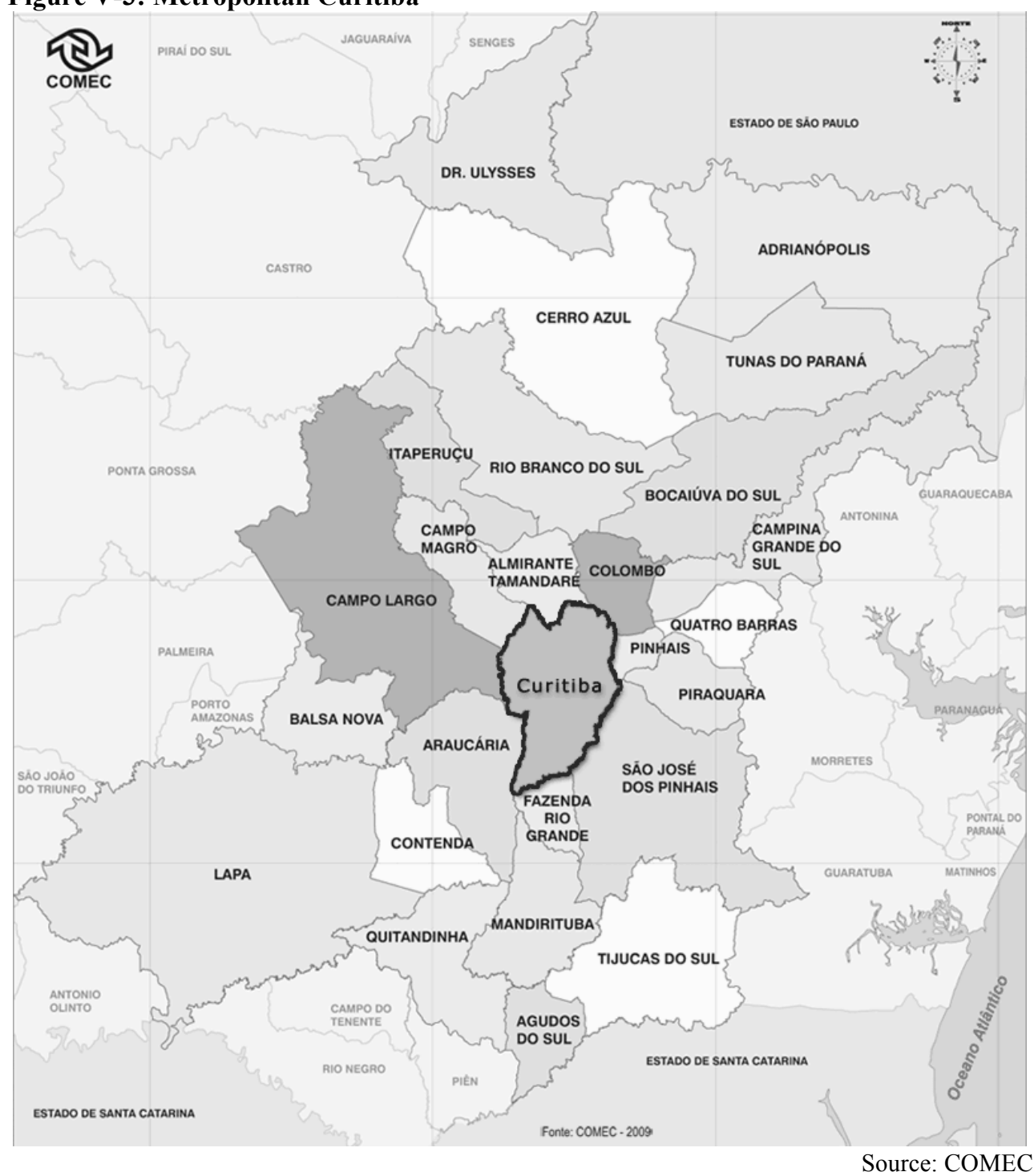

Thus, "it is not true that the people who live close to the main corridors use public transport, the people who actually use it, come all the way from the end points of the BRT lines [neighbouring municipalities], and mostly go towards the centre [of Curitiba]" ${ }^{19}$. If indeed, the existence of vast kilometres of bus-only lanes, is not correlated with high accessibility for its direct users (living in the neighbouring municipalities), then the social

${ }^{19}$ Personal communication, prof. Giselene Pereira UFPR, August 12, 2012. 
sustainability of this system would be harshly impacted. Similarly, the interviewees often criticized the weaknesses of the bicycle transport system. Although the city exhibits an above average number of bicycle lanes (120 kilometres) for the Latin American region, "these were designed to connect parks during the 1970's"20, and thus, "were never designed for transport, but rather, only for leisure. Disconnected bicycle lanes that go outside of the city are not useful for day to day use" 21 .

Nonetheless, the true purpose in this research is not to controvert what the empirical characterizations have already portrayed, but rather, to discuss the political conditions explaining the level of transport sustainability in the selected cases, as reflected by the GTI. As such, one key variable often quoted by the respondents refers to the form of government in Curitiba (and Brazil), during the times of the implementation of the crucial master plans, ultimately allowing for the development of the Rede Integrada de Transporte (RIT), the powerful integrated transport network of modern Curitiba. Brazil was ruled by a military dictatorship from March 1964 to March 1985. During this period, the horizontal interactions and power struggles between institutional stakeholders were changed for more topdown decision-making processes.

Hence, "many of the decisions that we now find to be key, were taken within a dictatorial system, in which there is no participation from the civil society, [and in which] conflicts between technical staff and public servants are minimized" 22 . One of the key processes concerns the election and reelection of city mayors. During the dictatorship, several political leaders were chosen to serve what was popularly called a cargo bionico; "the military leadership selected the mayor of Curitiba, via the Governor of Paraná. Jaime Lerner ${ }^{23}$ was selected by the military dictatorship to become mayor during his first two terms, without having to worry about votes"24. Another crucial matter pertains the usual conflicts between planners, policymakers, and managers of the public budget; "the military dictatorship strongly favoured technical solutions. [At that time] the only city that had

\footnotetext{
${ }^{20}$ Personal communication, architect Liana Vallicelli, IPPUC, August 9, 2012.

${ }^{21}$ Personal communication, prof. Fabio Scatolin, advisor to Mayor Fruet August 6, 2012.

${ }^{22}$ Personal communication, prof. Mario Procopiuck PUCPR, August 17, 2012.

${ }^{23}$ Lerner, a globally renowned urban-planner, is often recognized as the father of the "Curitiba Model". After his first term in office from 1971 to 1974, he later served as mayor of Curitiba from 1979 to 1982, and was elected during democratic elections, to serve from 1989 to 1992. Moreover, he also served as Governor of Paraná from 1995 to 2002.

${ }^{24}$ Personal communication, prof. Fabio Scatolin, advisor to Mayor Fruet August 6, 2012.
} 
contracted [master city] plans was Curitiba. They selected it as the laboratory for that massive urban transformation project, and compromised the money needed; there was no opposition" 25 .

The most powerful institutional player influencing the development of the well-planned city of Curitiba was the military dictatorship. During the 1950's and 1970's, when the key urban transport and urban planning innovations of Curitiba were implemented, the centralization of authority blocked the need for extraordinary institutional/metropolitan coordination, and funds were directly made available for promoting public transport; as Eduardo Vasconcellos states: "the only time in the history of Brazil when there was a massive investment on public transport made, was during the dictatorship". ${ }^{26}$ A crucial decision, as we know that investments in relatively low-cost BRT systems still have to compete with road and rail (Wright 2011; Allport 2011).

A clear contribution towards higher transport sustainability levels in two decades after the dictatorship was derived from this powerful central planning legacy. This long-term influence on the overall sustainability of the transport system of Curitiba is thus, partly due to the path dependent nature of many of the major public policy decisions in favour of the RIT system in the 1960's and 1970's.

An additional recurrent theme during the interviews concerns the role of metropolitan coordination. In Brazil, "by definition, all municipalities are much stronger than any metropolitan agency, [hence] the metropolitan scale is not a governmental scale"27. This municipal autonomy becomes a huge challenge when implementing metro-wide policies, such as those related to air quality and urban mobility. The case of Curitiba, is obviously a difficult one, as it is the hub for a metropolitan region accounting for 25 municipalities (CAF 2011).

This situation, a common obstacle to metropolitan planning in Latin American cities was not a problem during the 1960's and 1970's. Back then, the IPPUC ${ }^{28}$ "was charged with vast planning responsibilities in transport, transit, and land-uses, which had an influence over the core metropolitan

\footnotetext{
25 Personal communication, Prof. Magnus de Mello. UFPR, August 18, 2012.

${ }^{26}$ Personal communication, Dr. Eduardo Vasconcellos, ANTP, August 14, 2012

27 Personal communication, Prof. Fabio Duarte, PUCPR, August 15, 2012.

28 Created in 1965.
} 
region"29. This municipal autonomy, however, is often threatened by the enormous clout of the federal government. At the Federal level, "Brazil traditionally has supported car production industrial policies, low interest policies for car buying, and lowering gasoline prices"30.

This portrays what many of the interviewees recognized as the wide push for a car-centred development model in Brazil. This push has been active since the 1930's, "when the elite was able to decide constitutionally, that the country would no longer push for trains, but rather, move completely to the 'road'. Thus, giving birth to a vast automotive industry [...] the rodoviario model" 31 . Some decades later, the mythical president who led the construction of Brasilia, Juscelino Kubitschek, "often reminded Brazilians that governing meant 'opening roads'; that economic development started with building roads" ${ }^{, 32}$.

If there is such vast support for the car industry from the federal government ("up until now, all federal governments have supported the car development model" 33 ); if having a car nowadays is simply cheaper than the overcrowded buses ("today, in $5-6 \mathrm{~km}$ trips, the car is cheaper than the bus" ${ }^{34}$ ); if the city of Curitiba is now the city with the highest number of cars per capita in Brazil: one for every 1.4 inhabitants (CAF 2009) ("they projected that by the year 2000, each family would have maximum, one car. Today, each family has $2^{, 35}$ ); and if the particular culture of Brazil calls for owning cars as the ultimate social goal ("when you ask the average citizen in Brazil [and Curitiba] what their dream is, they answer: having a $0 \mathrm{~km}$ [brand new] car" ${ }^{\text {"36 }}$, then, why does Curitiba still stand as the best performing city in the region?

\footnotetext{
29 Personal communication, Liana Vallicelli, IPPUC, August 9, 2012

30 Personal communication, transport specialist Pablo Guerrero, IADB, August 13, 2012

31 Personal communication, Dr. Eduardo Vasconcellos, ANTP, August 14, 2012.

32 Personal communication, transport specialist J Pedro Correa, Volvo, August 10, 2012. This refers

to the famous quote by president Washington Luis in 1926, when he stated that "governar é abrir estradas".

33 Personal communication, Dr. Eduardo Vasconcellos, ANTP, August 14, 2012.

${ }^{34}$ Personal communication, Antonio Marchezetti. Logitrans, August 17, 2012.

35 Personal communication, Prof. Fabio Duarte, PUCPR, August 15, 2012.

36 Personal communication, Leny Mary de Goes. Secretaria de Meio Ambiente de Curitiba. August 9, 2012 .
} 
Figure V-4: Explanatory Factors to High Transport Sustainability

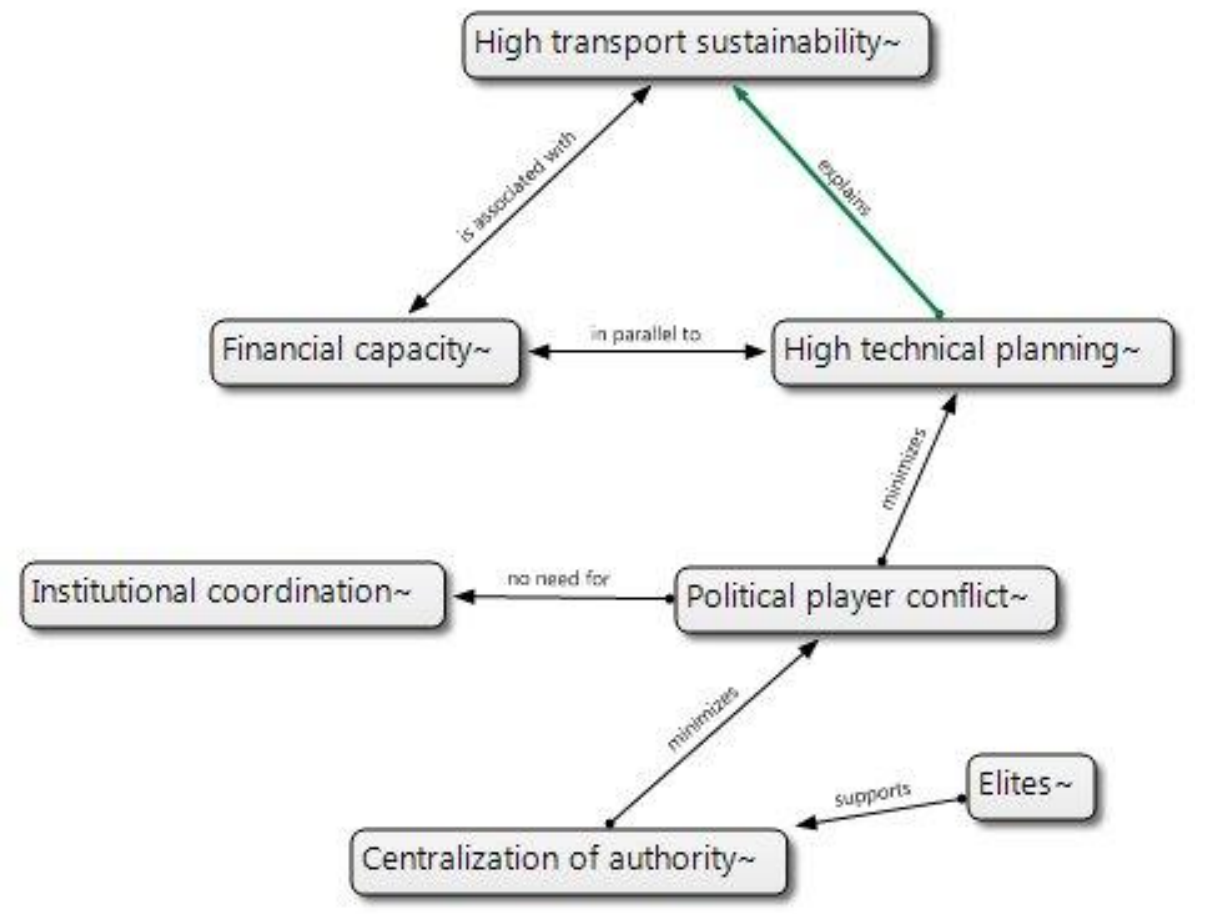

Source: own elaboration

To explain high transport sustainability in this city the outcome from the interviews implies that the form of government of the time, a centralization of authority that allowed for the creation of a powerful institutional player, led to a specific political agenda pushing for strong technical planning in favour of public transport (see Figure V-4). For Curitiba, one must look back to the specific historical period, during which the strong IPPUC led the development of a mixed land-use and RIT moulded-after city; "the project led by the political elite of the 1930's [the car as development model] has been successful. It had interruptions during the dictatorship, and then during the oil crisis, but then it came back." 37

\subsubsection{Medellín, Colombia:}

37 Personal communication, Dr. Eduardo Vasconcellos, ANTP, August 14, 2012. 
Medellín is the second largest city in Colombia. An industrial powerhouse, capital of the Antioquia region, it is home to 3.5 million people in its metropolitan area, composed by 10 autonomous municipalities (see Figure V-5). The particularities of its geography (fully established within a natural valley), make it highly vulnerable to environmental threats. Even though it is the only Colombian city with a metro system and integrated cable cars, its weak ranking in the GTI is partly explained due to its historic neglect for pedestrians and cyclists, a traditionally chaotic bus scheme, and high levels of transport emissions, due principally to old transport technologies and low-quality fuels supplied by the national oil company, Ecopetrol.

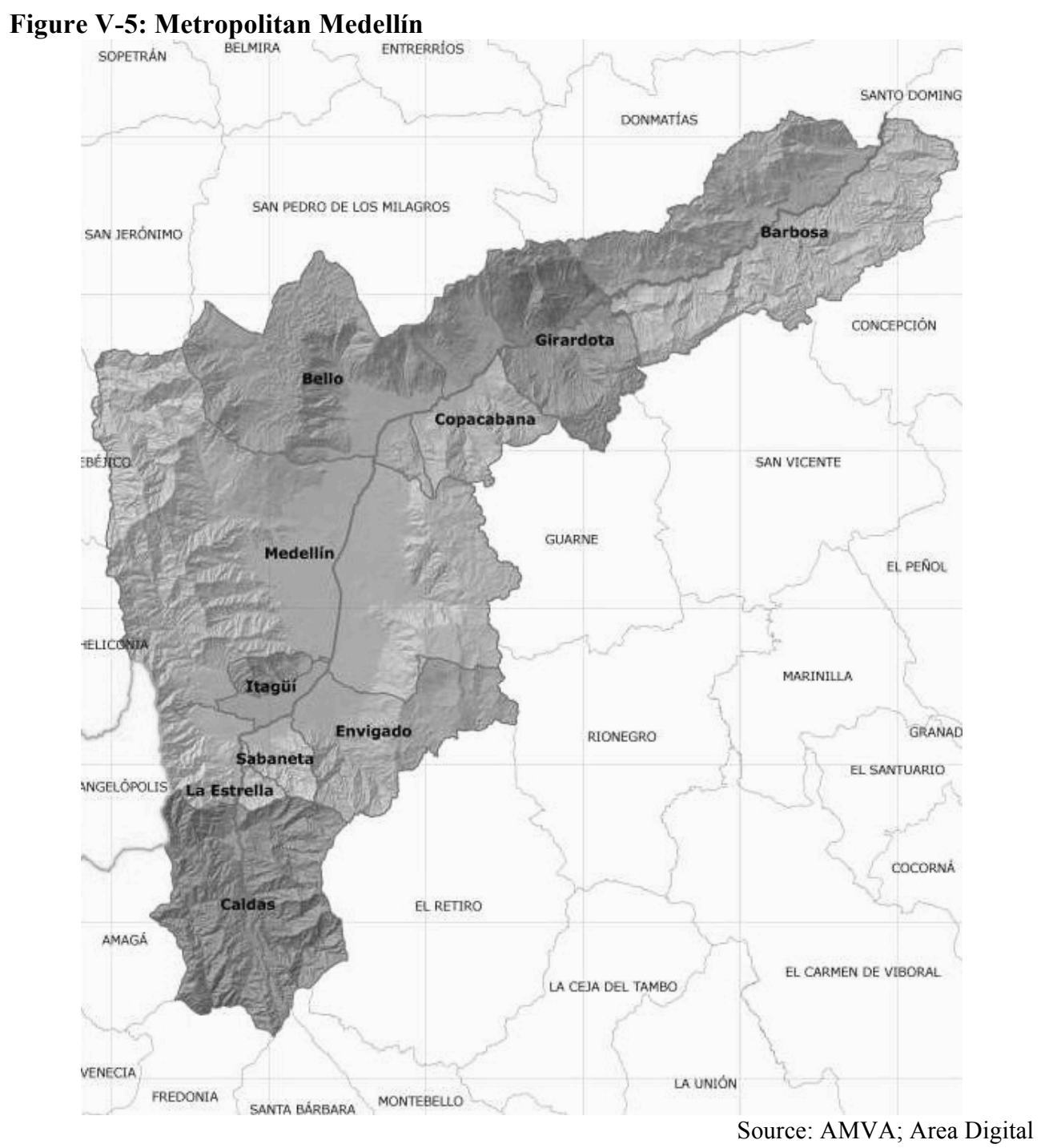


Respondents were not surprised by the average ranking of the city within the GTI. A clear trend amongst those interviewed concerns the lack of a clear institutional definition of what sustainable mobility means, or a holistic programme to increase the level of sustainability of the transport system in the city; "we did not promote a formal definition of this [sustainable mobility]. What we promoted was a tacit agreement about the crucial social and economic role of mobility [...] about the importance of an urban transport system. That was, however, not the top problem on the agenda" $" 38$.

There are a number of crucial institutions that have influenced the current set-up of the transport system in metropolitan Medellín. However, "the only two institutions that could actually lead sustainable transport for the full metropolitan area are the Medellín Metro and the AMVA ${ }^{39,40}$. The top institution, as far as the pertinent legislation goes, is the Metropolitan Area of the Aburrá Valley (AMVA), a public administrative entity that associates $9^{41}$ out of the 10 municipalities that make up the metropolitan area of the Aburrá Valley (Medellín, Barbosa, Girardota, Copacabana, Bello, Itagüi, La Estrella, Sabaneta and Caldas). Its main objective is to promote joint territorial planning. Amongst its responsibilities (as decreed by the national government) is acting as the sole environmental and mass transport authority for the metropolitan region. In practice, however, this is not entirely the case, as "there exists a constitutional order principle, guaranteeing the autonomy of municipalities, and thus, the ultimate planning and regulation of public transport is done directly by them" 42 .

A crucial institution to consider is the Medellín Metro. Founded in 1979, it is a semi-private entity ${ }^{43}$, with outstanding reputation across a wide variety of societal segments; likewise, it is frequently rated as the most admired organization by Medellín citizens ${ }^{44}$. The Medellín Metro administers an

\footnotetext{
38 Personal communication, David Escobar, Chief of Staff to Mayor Sergio Fajardo. September 20, 2011.

${ }^{39}$ Área Metropolitana del Valle de Aburrá.

40 Personal communication, Rodrigo Salazar. Former Medellín Secretary of Transport. September 20, 2011.

41 Envigado is not part of the AMVA.

42 Personal communication, Marta Suárez. Director for Mobility AMVA. September 20, 2011.

43 Officially a "State-owned Commercial and Industrial Enterprise, at the municipal level".

${ }^{44}$ As measured by the annual citizen's perception survey, coordinated by Medellín Cómo Vamos (www.medellincomovamos.org)
} 
important transport network, composed by various transport modes (high capacity metro, BRT, and cable-cars), which is fully integrated (physically and in fares) across 6 municipalities of the metropolitan area. The mass influence, technical and financial capacity of this institution often raises calls for it to lead the overall development of the transport system for the metropolitan area, "... of course it should be the Metro leading the integrated [transport] system. Who else has the power and capacity to do it? [...] this evolves while informal groups claim to be the true leaders of our urban transport system: the private bus companies. And yes, they have controlled the system for a long time [unfortunately]"45.

Nonetheless, this is legally not possible. Formally, the Metro is only one (of many) transport companies, which must adhere to the mass transport authority of the AMVA, even if the latter is much weaker in that industry, and does not own nor operate mass transport modes. Furthermore, "the Medellín Metro cannot be a legal authority, if so, we would be the 'judge, jury, and executioner' [...] How can you plan when there are 12 concomitant authorities? The Ministry [of Transport], 10 municipalities, and the AMVA?"46

Other powerful institutional players have influenced the current mix of transport policies defining the level of transport sustainability of the city. The national government has had a crucial influence on a number of funding decisions. As a matter of fact, during a recent process to receive international funding for a tramway project, the Medellín Metro was required to secure the green light by the national government, "but the unnecessary obstacles [from the National Planning Agency] were immense, even though it only meant a formal acceptance by the national government. It is unbelievable how our system allows for a middle-level public servant in Bogotá [the capital city], to block massive well-structured projects, with superb technical staff behind them [like those belonging to the Medellín Metro] ${ }^{\prime 47}$. All interviewees were well aware of the political nature of those processes influencing the transport system in the city: "the discussion about the costs and benefits of this system cannot be only technical; it has to be political [...] sitting on a political table, using technical arguments" 48 .

\footnotetext{
45 Personal communication, Jose Fernando Angel. Former Medellín Secretary of Transport. September 6, 2011.

46 Personal communication, Ramiro Márquez. CEO. Medellín Metro September 15, 2011.

47 Personal communication, Felipe Targa. Former Vice-Minister for Transport. October 1, 2012.

48 Personal communication, Mauricio Faciolince. Director. AMVA. October 26, 2011.
} 
Likewise, the Medellín City Council has often influenced the transport system of the city. One particular mobility project that was born out of the City Council concerns its public bike-sharing system, EnCicla. Against all odds, Medellín was the first city in Colombia to successfully design and implement a bike-sharing system between 2010 and 2011. Although "it started with a small-scale operation, targeted to university students during its initial fully functional experimental phase" ${ }^{\text {"49 }}$, the system is currently undergoing its second major expansion. It was councilmen Federico Gutiérrez and Bernardo Guerra who pushed for a municipal accord that would promote the scheme. Ultimately, the project was led by the AMVA as part of an integral strategy to improve sustainable mobility within its jurisdiction, "we analyzed the project and decided to go all in; even without having technical studies. It is clear to us, that if we want to achieve that institutional jump, we must go all in"

Car dependency also plays an important role for in this city. Although Medellín exhibits the lowest number of cars and motorcycles per capita ${ }^{51}$ in the GTI, mayors have often found immense vote potential in proposing carcentred policies, "the city has been planned for the private car; the structural codes have been designed for major highways, vast car-only bridges..." Additionally, having a car is an important social symbol in a historically poor country, "we suffer from a devotion towards the car; it is a very important mode of social ascent" $"$. Just like many other cities in the region, non-motorized modes are not routinely considered within the budget for alternative modes to the car (Figueroa et al. 2013), in Medellín, "very little investments have been made for both cyclists and pedestrians historically [...] the car is King. Furthermore, all efforts 'against the car' are highly unpopular. The media immediately jumps against this, with the excuse that this goes against sources of employment. Remember that they [writing the stories in the media] are not moving around in any other way than driving," $"$.

\footnotetext{
49 Personal communication, Jesús Acero. Director. EnCicla. October 10, 2011.

50 Personal communication, Alejandro González. Director of Environment. AMVA. October 20, 2011.

510.07 vehicles per capita.

52 Personal communication, Juan Pablo Ospina. Transport Specialist. BIO 2030. October 14, 2011.

53 Personal communication, Rafael Nanclares. Transport Secretary. City of Medellín. October 25, 2011.

54 Personal communication, Alvaro Restrepo. Transport Specialist. Independent consultant October $13,2011$.
} 
The third key thematic framework was built around metropolitan governance. Surprisingly, cultural factors seem to provoke discussions about the feasibility of constructing metropolitan-wide entities. "Selfishness is a cultural trait in our society. The municipalities in the metropolitan area [of Medellín] behave as if they were islands, with complete selfishness. If we think about generating brotherhoods amongst these municipalities, these must be based on complementarities, via win-win metropolitan-level accords" $" 55$. Some even go as far as claiming that the lack of metropolitan coordination is precisely the reason for the low performance of Medellín, as compared to other cities in the region, "we are still behind because of that, the big reason is coordination [lack of thereof]"

Other levels of government sometimes makes things worse, "although the city is responsible for its own development, you must remember that a few years ago, the Transport Minister used to come here every 3 months to force his opinions about the minor details of the route for the Metroplús [BRT]"57. This also has negative financial consequences, "the lack of interest in coordination is so pronounced, that they prefer to say no to funds, if this means requirements for coordination" ${ }^{\text {"58 }}$. This low level of coordination is not new and has been the traditional planning approach for Medellín and its neighbours; moreover "we have absolute clarity that, in the short run, there will not be one sole leader for the metropolitan region"59.

When analyzing institutional conditions behind the transport system of the Medellín metropolitan area, Holuigue highlights that an administrative entity should have the power to coordinate and align all actors involved, in order to generate more sustainable transport programs (Holuigue 2011). However, all interviewees agree that there is not an easy way to achieve this. According to the books, the AMVA is the institution that should do it, "the AMVA is the institution, theoretically, charged with this [planning

\footnotetext{
55 Interview Carlos H Jaramillo with Medellín Cómo Vamos. Former Planning Director of Medellín. July 4, 2013.

56 Personal communication, Jose Fernando Angel. Former Medellín Secretary of Transport. September 6, 2011.

57 Personal communication, David Escobar, Chief of Staff to Mayor Sergio Fajardo. September 20, 2011.

58 Personal communication, Jose Muñoz. Intermediary between regional and local governments. October 20, 2011.

59 Interview Carlos H Jaramillo with Medellín Cómo Vamos. Former Planning Director of Medellín. July 4, 2013.
} 
mobility for the metropolitan region], but it needs sharper teeth and greater capacity than what it has" ${ }^{\circ 0}$. Furthermore the Medellín Metro contends that leadership, "it is a super-powerful institution, which not only has the influence to manipulate policy, but also immense territorial power, and a great planning capacity" ${ }^{\prime \prime}$. With powerful forces behind the car, and a critical need for greater metropolitan cooperation, there does not seem to be a single powerful institutional player capable (or willing?) to break the status quo, "it is all political at the end: let us not forget that he director of the AMVA is selected directly by the Mayor of Medellín",62.

To explain the events leading to higher transport sustainability in this city, the outcome from the interviews imply that the role of powerful (although highly disconnected) individual players has contributed significantly. The Metro is quoted permanently as the only institution with a solid agenda in favour of promoting more and better public transportation. Although coordination with other powerful institutions (such as the AMVA) is rare, this condition is crucial, as it has allowed for various political agendas to drift towards public policies in favour of higher transport sustainability, as the electoral cycles offer the conditions for these political agendas to be profitable for those involved.

On the other hand, explaining the events leading to lower transport sustainability in Medellín, the outcome of the interviews strongly implies that the lack of metropolitan governance arrangements serves as a significant obstacle to the implementation of holistic policies in favour of transport sustainability. This, coupled with the omnipresent push towards a development model dependent on the car suggests conditions leading to lower levels of transport sustainability (see Figure V-7).

\subsubsection{Guadalajara, Mexico:}

The second largest metropolitan area in the country extends across the eight autonomous municipalities of Guadalajara, Zapopan, Tlaquepaque, Tonalá,

\footnotetext{
${ }^{60}$ Interview Alejandro Echeverri with Medellín Cómo Vamos. Director. Urbam. July 4, 2013.

${ }^{61}$ Personal communication, Alejandro González. Director of Environment. AMVA. October 20, 2011.

62 Personal communication, Rodrigo Salazar. Former Medellín Secretary of Transport. September 20, 2011.
} 
El Salto, Juanacatlán, Tlajomulco de Zúñiga and Ixtlahuacán de los Membrillos (see Figure v-6). A number of key actors have been actively advocating for sustainable transport in the metropolitan area of Guadalajara, however, the city ranked last in the GTI, due to a combination of political dynamics that have succeeded in generating entrenched path dependencies. "Although the key institutional players talk about sustainable mobility, at the end the actual public policy continues promoting car-based mobility over and over" ${ }^{\prime 63}$. Today, the organized public transport system collides with a weakly regulated private bus system, a high rate of auto ownership, and a practically non-existent bicycle network.

None of the interviewees reacted with great surprise about Guadalajara's low ranking in the GTI, insinuating a high awareness of the recent local crises in terms of sustainable mobility. In fact, while almost all of the interviewees were impressively informed about the technicalities of what the latest literature about sustainable mobility implies, this does not seem to be the case with many of the actual decision-makers, "it is hard to identify a metropolitan public policy aimed at improving the sustainability of our mobility. To start with, this is evident from the disproportionate public investment annually destined to vehicular infrastructure, and the very limited resources destined to sustainable modes",64.

A variety of powerful institutional players have influenced the level of sustainability of the transport system in this city. Political parties account for an extraordinary weight when explaining the last decade's developments on transport. A country, with a protracted tradition of strong national parties $^{65}$, suffers from what some have called "a dictatorship controlled by the political parties" "66. This dynamics are also entrenched at the regional level, "here [the State of Jalisco], we have had historically a duopoly, with then PAN $^{67}$ and the PRI" ${ }^{\prime 68}$. Thus, it is precisely via the action of the State governments, and the interaction with the Municipal governments that political parties end up having a huge effect on the local transport agenda.

\footnotetext{
63 Personal communication, Key informant \#34.

64 Personal communication, Maria de la Torre. Urban planner with the Zapopan government. Abril 20, 2013.

65 The Partido Revolucionario Institucional (PRI), for instance, famously maintained hegemonic power in the country for the last 70 years in the $20^{\text {th }}$ century.

66 Personal communication, Prof. Oscar Castro. ITESO. February 7, 2013.

67 Partido de Acción Nacional.

68 Personal communication, Alfredo Hidalgo. Strategic Projects Director. Zapopan. February 5, 2013.
} 


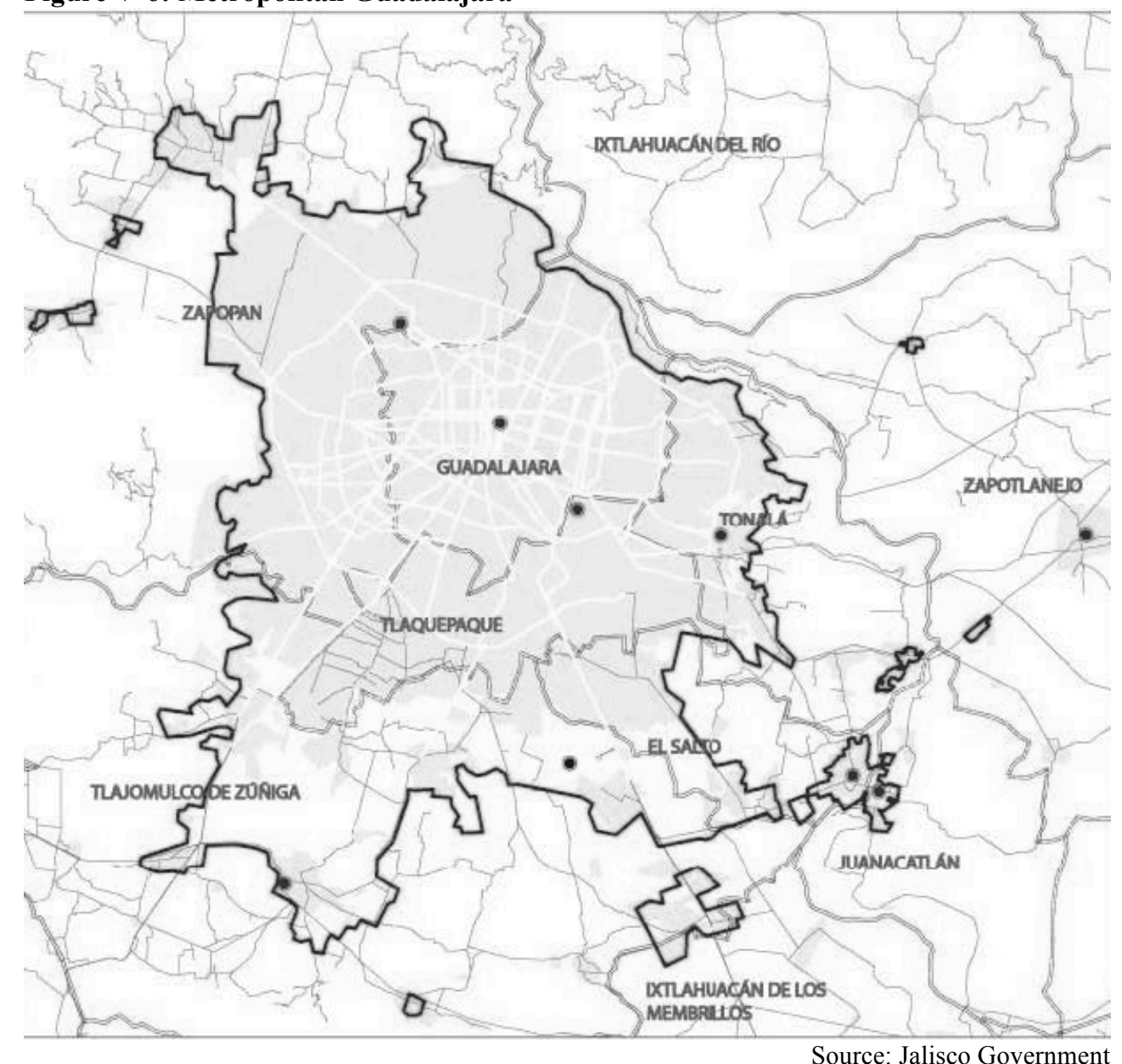

For all municipalities in the metropolitan area of Guadalajara, "the transport policy is defined by the State [of Jalisco]. Although it is often discussed with the municipal governments, the major financing comes from the State, and hence, is the one that can make the largest moves, be it [that these are] positive or negative" ${ }^{, 69}$. Unfortunately, the broad transport agenda, dictated by the state government, and influenced by the municipal governments has become increasingly partisan, "in our land, it is easy to attack policies by

69 Personal communication, Hugo Luna. Director. Movimiento Ciudadano Political Party. February $10,2013$. 
making them partisan [...] our people boast a high lack of technical understanding, and historical low levels of trust for official authorities"70.

Figure V-7: Explanatory Factors to Low Transport Sustainability

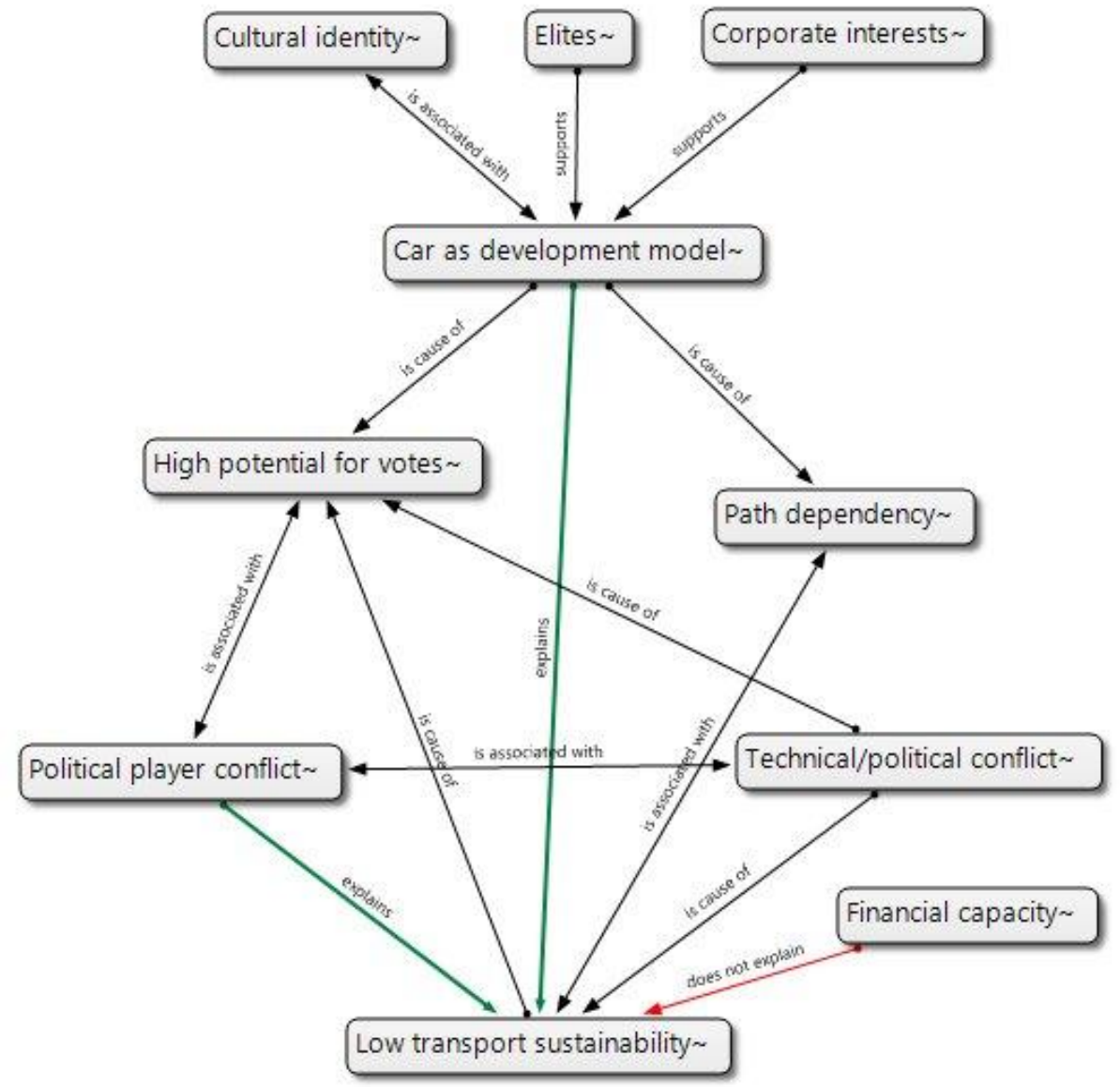

Source: own elaboration

The best example of this harmful partisan politics dynamic is definitely the fiasco with the Macrobús Linea 2 BRT project. While the National Government "had pledged U\$100 million [for the BRT line 2], the local mayors [of Guadalajara, Zapopan and Tlaquepaque] rejected the money and killed the project. Guadalajara later got into a U\$120 million to re-surface

70 Personal communication, Diego Monraz. Secretary of Transport. February 11, 2013. 
roads" $"$. Curiously, these three mayors, members of the PRI, opposed a project led by a PAN Governor ${ }^{72}$, which had successfully implemented the first line of the BRT; thus communicating the idea that the BRT model was a "PAN project". On the other hand, and only 1 year and a half before, the BRT Line 1 "was successful only because the political circumstances allowed the Governor [of Jalisco] to impose its conditions. All municipalities were being led by the PAN, and there was a majority of the PAN in the State Congress. The opposition from the PRI was important, but not sufficient to generate obstacles" $" 73$.

Not just because of the magnitude of the BRT project (in its several future lines), but also due to the symbolic nature of mass transport being a priority of the PAN government, the second half of Governor Emilio González's six-year term in office did not see many advances in sustainable transport; "having blocked our BRT, they also managed to collapse the governability of our State to implement other projects"74. One additional variable adds greater complexity to the ordinary partisan politics in Mexico: "governors, mayors, and legislative bodies are elected at the same time, but go in at different times. Plus, the governor is elected for six years, while the mayors are elected for 3 with no re-election"75. This means that "municipalities end up reinventing themselves every three years, while the states do it every 6 ; that is fatal for long-term projects" ${ }^{76}$.

This refers not only to the particularities of a spoil system, but also to the maintenance of long-term visions in urban planning, which is crucial for transport sustainability. Our system "does not allow us to plan in the long term. The municipal administration elected for the first three years [coinciding with the first three years of the State administration] will always have less time and fewer resources. The second one is an administration contaminated with the particular interests of those politicians thinking about the next election" 77 . The preparations for elections were mentioned by most of the interviewees along with the power of political parties, as those key variables influencing the current level of transport sustainability in the city,

\footnotetext{
71 Personal communication, Mario Silva. Director. CEJ. February 6, 2013.

72 Emilio González Márquez.

73 Personal communication, prof. Oscar Castro. ITESO. February 7, 2013.

74 Personal communication, Diego Monraz. Secretary of Transport. February 11, 2013.

75 Personal communication, Alfredo Hidalgo. Strategic Projects Director. Zapopan. February 5, 2013.

76 Personal communication, Carlos Romero. Director. Non-motorized mobility. OCOIT. February 5, 2013.

77 Personal communication, Alfredo Hidalgo. Strategic Projects Director. Zapopan. February 5, 2013.
} 
"it is clear, the defeat of the BRT Line 2 project was only staged for electoral purposes, it was never for the benefit of the city"78.

Three years later, as a matter of fact, the former mayor of Guadalajara, Aristóteles Sandoval, who led the opposition to the BRT line 2, was elected Governor of Jalisco. Moreover, the partisan politics dynamics exhibited along the Macrobús project discussions often are replicated at further local levels, and further national levels; "the political parties are practically the owners of all the public power [in Mexico]. If it is not through them, it is almost impossible to influence public policies in Mexico"79.

As has been recurrently identified across all studied cities, a development model based on the car has also had an immense effect on Guadalajara. Even with the massive investments done during the last decade on infrastructure for the car, the city's traffic continues to be collapsed, "everybody knows it. We live in one of the cities with the highest number of cars per capita [...] we have about 2.6 people per car, and more than 300 new cars are incorporated daily" ${ }^{80}$. Some of the interviewees claim it has become a pride of the city, "for example, the Matute Remus bridge cost enough to advance all the strategic actions stipulated in the Non-Motorized Mobility Plan [...] the technology of that bridge is as if one would use it to cross the Hudson river; the only difference being that here, there is no river under it. If you were to make an opinion poll, it would certainly come out as the new tapatio [local] symbol" $"$.

Of course, the actual numbers do support the theories of those that claim the car has been the official development model followed by the local governments here: the city has passed from having 750.00 cars in the year 2000 , to more than 1.525 .000 in 2009 "82 ; 9 out of 10 pesos spent in infrastructure have been invested in the car, while $70 \%$ of the people wish it was spent in public transport" ${ }^{\prime 83}$. This protracted preference for car-centred investments finds horizontal and vertical institutional echoes. For example, the former president of the country, Felipe Calderón, showed his support for the car industry, "he even had as one of his term slogans, the 'infrastructure

\footnotetext{
78 Personal communication, José Comer. Director of Control. SITEUR. February 7, 2013.

79 Personal communication, prof. Oscar Castro. ITESO. February 7, 2013.

80 Personal communication, Etienne von Bertrab. Founder Ciudad para Todos. February 4, 2013.

${ }^{81}$ Personal communication, Mario Delgado. Entrepreneur. BKT. February 8, 2013.

82 Personal communication, Mario Silva. Director. CEJ. February 6, 2013.

83 Personal communication, Carlos Romero. Director. Non-motorized mobility. OCOIT. February 5, 2013.
} 
six-year term', which in reality meant the construction of highly visible and expensive infrastructure, like our urban bridges" ${ }^{84}$. This was probably worse in terms of the coordination between dependencies of the State government, while the Department of Transport claims to have been pushing for non-motorized transport, they also identify their colleagues at the Urban Development Department (SEDEUR) as the biggest enemies of it, "they could not care less about cyclist and pedestrians [...] in fact, the State government, through them, has spent $95 \%$ on the car, and $5 \%$ on the others [...] it should be minimum 50-50"

Metropolitan coordination is the second thematic framework that I identified as vital. In principle, the fact that the State of Jalisco can plan transport for the whole metropolitan area of Guadalajara should be a major plus. However, this advantage rarely has resulted in higher levels of transport sustainability during the last decade. Confrontations between entities that share responsibilities are common, "apart from the Transport Department, we also have other decentralized entities like OCOIT ${ }^{86}$, SITEUR $^{87}$ and $\mathrm{CEIT}^{88}$ that often clash. Moreover, although the Transport Department is charged with regulating public transport in the State, there is not one single entity that can manage public transport entirely" ${ }^{\prime \prime}$.

Similar confrontations are also frequent amongst municipalities, who try their best to get more out of the State government, "in terms of mobility, it is the State that controls; but the municipalities can operate in issues of sidewalks and bicycle lanes" 90 , which means that they have an incentive to block certain initiatives that would directly affect their turfs. Additionally, coordination amongst them is not facilitated by the State, nor a supramunicipal entity, "the Mexican Federal Constitution states clearly that coordination amongst municipalities is not mandatory [...] and here, with eight power asymmetries, it is impossible to leave the coordination under one hegemonic power" ${ }^{91}$. This is not to say that coordination amongst

\footnotetext{
${ }^{84}$ Personal communication, Etienne von Bertrab. Founder Ciudad para Todos. February 4, 2013.

85 Personal communication, Diego Monraz. Secretary of Transport. February 11, 2013.

${ }^{86}$ Coordinating Organism for the Integral Operation of the Transport System (Organismo Coordinador de la Operación Integral del Servicio de Transporte).

87 Urban Electric Train System (Sistema de Tren Eléctrico Urbano).

88 State Centre for the Investigation of Roads and Transport (Centro Estatal de Investigación de la Vialidad y el Transporte).

89 Personal communication, José Comer. Director of Control. SITEUR. February 7, 2013.

90 Personal communication, Alfredo Hidalgo. Strategic Projects Director. Zapopan. February 5, 2013.

91 Personal communication, Mario Silva. Director. CEJ. February 6, 2013.
} 
municipalities just does not happen in Guadalajara, "there are cases when it has been done informally, most of the times facilitated by the fact that the municipal governments were all members of the same political party" ${ }^{92}$. However, this rarely is significant enough to generate major changes to a highly path dependent system, "because these relationships are characterized by total subordination to the State decisions, and never suppose a dialogue amongst equals" ${ }^{93}$. The eternal discussions regarding the institution of a supra-municipal planning entity, have repetitively failed, "the parties involved are quite aware that such an institute would negatively impact their well-established power turfs" 94

The case of Guadalajara contributes to this research with an additional component: the role of organized interest groups. A lack of trust towards the political class has been a common phenomenon in some segments of this country and politicians are well aware of this, "Mexico is a country of disbelievers [...] you cannot tell people that we will take their [gasoline] subsidy away, to invest it in better public transport. They won't believe it"95. Additionally, in Guadalajara, the poorest social strata have been ignored, "our political class is absolutely distanced from the citizens [...] in terms of transport they only focus on what the rich people want: more roads, more tunnels, more avenues [...] and what is worse, this recipe has been followed by all political parties" 96 .

This lack of trust is magnified by perceptions of corruption, "up until now, we have only had politicians that provide evidence of their corruption, and their interest in pursuing policies that benefit them at the individual level"97. Nevertheless, the aforementioned combination of negative factors has resulted in an above average social infrastructure. Guadalajara maintains highly active citizen groups, and dynamic economic unions actively participating in policy decisions. The stronger social groups were born at the beginning of Governor González's term, "a detonating factor was the State government's decision to build an urban highway along the López Mateos corridor. This happened right when many of us were studying about

\footnotetext{
92 Personal communication, Eugenio Arriaga. Former Director Non-Motorized Transport. Guadalajara. April 5, 2013.

93 Ibid.

94 Personal communication, prof. Oscar Castro. ITESO. February 7, 2013.

95 Personal communication, Senator Ninfa Salinas. Mexican Senate. January 29, 2013.

96 Personal communication, Etienne von Bertrab. Founder Ciudad para Todos. February 4, 2013.

97 Personal communication, Key informant \#34.
} 
sustainable mobility"98. From that moment on, the well-organized citizen groups faced the challenge of influencing policies, without bearing any type of decision-making power, "all these groups that aim at positioning sustainable mobility on the political agendas share a specific view of what sustainable mobility means. So deep, that they have transitioned into a metropolitan platform with specific demands to the different levels of government" 99 .

One additional power player constitutes the vast network of renowned businessmen agglomerated under the Guadalajara 2020 group. Due to their economic power, their influence transcends that of the activist groups, as was seen during the Via Express incident, "when the State government insisted that they would build the second-level highway, we suddenly found powerful unexpected allies: the COPARMEX ${ }^{100}$ employer's association, and the industrial chambers of the State ${ }^{101}$.

Notwithstanding their capacity to influence decision-makers, the efforts of these organized interest groups do not seem to have produced significant long-term changes in favour of greater transport sustainability. This could be explained due to their lack of institutionalization. Both of the major groups in Guadalajara correspond to "coalitions" or "social movements", and thus, have only limited and informal access to the policy-making process (see Table V-2).

The powerful role of the political parties in Mexico, undoubtedly affects the transport agendas in Guadalajara. It is a political problem and not related to the availability of resources "the chaos is related to the political dysfunctionalities [...] governments rotate, and processes are always terminated"102. Against the backdrop of a highly car addicted system, the role of some organized interest groups starts to have an effect on urban transport policies: "we have targeted a wide variety of politicians and decision makers, irrespective of their political party affiliation. What we want to show them is that sustainable mobility is not only a possibility for the developed countries, it is also possible and necessary here" 103

\footnotetext{
98 Personal communication, Héctor Castañón. Director. Plan V Vecinos en Red. February 6, 2013.

99 Personal communication, Maria de la Torre. Urban planner with the Zapopan government. Abril 20, 2013.

${ }^{100}$ Mexican Employers’ Association (Confederación Patronal de la República Mexicana).

101 Personal communication, Mario Silva. Director. CEJ. February 6, 2013.

102 Personal communication, Patricia Martinez. Activist. GDL en Bici. February 7, 2013.

103 Personal communication, Tomás López. Guadalajara 2020. February 11, 2013.
} 
Table V-2: Typology of Organized Interests

\begin{tabular}{|c|c|c|c|c|c|}
\hline Actor & Purpose & $\begin{array}{l}\text { Control over } \\
\text { Resources }\end{array}$ & Stability & $\begin{array}{l}\text { Organizational } \\
\text { Structure }\end{array}$ & $\begin{array}{l}\text { Access to } \\
\text { Policy-making } \\
\text { Process }\end{array}$ \\
\hline Associations & $\begin{array}{l}\text { Collective } \\
\text { purpose }\end{array}$ & $\begin{array}{l}\text { Collective } \\
\text { control }\end{array}$ & $\begin{array}{l}\text { Stable, } \\
\text { permanent }\end{array}$ & $\begin{array}{l}\text { Stable, } \\
\text { corresponding to } \\
\text { governance } \\
\text { structure }\end{array}$ & Institutionalized \\
\hline Clubs & $\begin{array}{l}\text { Separate } \\
\text { purpose }\end{array}$ & $\begin{array}{l}\text { Collective } \\
\text { control }\end{array}$ & $\begin{array}{l}\text { Stable, } \\
\text { permanent }\end{array}$ & $\begin{array}{l}\text { Stable, } \\
\text { corresponding to } \\
\text { governance } \\
\text { structure }\end{array}$ & Institutionalized \\
\hline $\begin{array}{l}\text { Social } \\
\text { Movements }\end{array}$ & $\begin{array}{l}\text { Collective } \\
\text { Purpose }\end{array}$ & $\begin{array}{l}\text { Separate } \\
\text { control }\end{array}$ & $\begin{array}{l}\text { Fluid, } \\
\text { temporary }\end{array}$ & $\begin{array}{l}\text { Flexible, } \\
\text { corresponding to } \\
\text { issue and } \\
\text { involved } \\
\text { actors/institutions }\end{array}$ & Informal \\
\hline Coalition & $\begin{array}{l}\text { Separate } \\
\text { Purpose }\end{array}$ & $\begin{array}{l}\text { Separate } \\
\text { Control }\end{array}$ & $\begin{array}{l}\text { Fluid, } \\
\text { temporary }\end{array}$ & $\begin{array}{l}\text { Flexible, } \\
\text { corresponding to } \\
\text { issue and } \\
\text { involved } \\
\text { actors/institutions }\end{array}$ & Informal \\
\hline
\end{tabular}

Source: Adapted from Scharpf 1997, p.55; and Hassel 2010, p.4.

To explain the events leading to lower transport sustainability in this city, the outcome from the interviews imply that the car as development model has had the sustained support of powerful institutional players. The right incentives have been in place to assure that this support is maintained. For many of these key actors, following this model has meant a high potential for votes, and the conflictive metropolitan governance arrangements have not proved to be capable to undermine these well-established path dependencies. The role of the elites and the role of cultural identity have 
also been widely cited when explaining the survival of this paradigm (see Figure V-7).

High levels of institutional coordination, and conceivably, the existence of a unique metropolitan institution, with sufficient power and capacity to plan, implement, and regulate transport for the full metropolitan region was also identified by the interviewees, as a best-case scenario for a contemporary governance mode with the power to promote more sustainable transport system in the studied cities. Nonetheless, previous studies offer evidence that in Latin American cities, this is often not the case (Holuigue 2011). As the studied cases show, the frequent autonomy of municipalities that compose a single metropolitan area, seriously hampers the integrated transport planning aimed at increasing sustainability. Furthermore, the legal competencies and responsibilities are often commissioned to other levels of government (national, regional, local), or even to private or semi-private entities. Thus, generating dynamics that usually end up benefiting the car development models so entrenched in this region's cities.

\subsection{Conclusion}

A description of the key thematic frameworks identified during the analysis of the recent development in urban transport sustainability, for Curitiba (Brazil), Guadalajara (Mexico), and Medellín (Colombia) has been presented. Using first hand data from key informant interviews in each of the cities, the aim has been to identify crosscutting conditions affecting the levels of transport sustainability in the studied cities. The case study methodology allows for explaining the variation in transport sustainability outcomes for these three cities; which was found when applying the initial GTI. Moreover, it permits the connection with the mechanisms of these outcomes.

It can be concluded that empirical facts partly meet theoretical expectations. Although those explanatory variables referring to political interactions, metropolitan governance, and the role of powerful groups are consistently highlighted by the interviewees, very few mentions were made in regards to the availability of financial resources as a crucial condition for increasing transport sustainability in the recent context of the studied cities.

Moreover, the guiding assumptions introduced in Chapter III are further developed in the light of the application of the conceptual framework to the 
results from the initial index, and the cross-case comparison. These hypotheses apply only to the studied cities:

H1. Political conditions seem to sway the implementation of key urban transport policies, more directly than financial conditions.

H2. Greater metropolitan institutional coordination facilitates the move towards higher levels of sustainability in transport.

H3. Previously taken decisions influence vital urban transport decisions, which become essential when increasing transport sustainability.

The results from the cross-case comparison do not seem to support the hypothesis that political conditions are equally important to financial conditions in increasing levels of transport sustainability. The lack of financial resources does not seem to explain the highly car dependent trajectories of the studied cities; nevertheless, this rests to be assessed in further chapters.

Higher levels of transport sustainability in the studied cities seem to be much easier to explain via the minimization of political player conflicts, either through the direct imposition by powerful institutional players, as was the case of Curitiba during the military rule, or through high levels of metropolitan coordination amongst key multilevel actors. Furthermore, the active role of varied interest groups was emphasized frequently during the interviews, and will further be evaluated in the subsequent chapters.

Since dictatorial forms of government are out of the question in the modern Latin American region, there is no intention to highlight this as a necessary condition for greater transport sustainability. However, the particular form of government of both the country and the city seems to be of utmost importance. $43 \%$ of those interviewed in the three cities referred to this condition as the most crucial condition with the power to determine the level of sustainability of the transport system in their city.

In sum, the cities of Curitiba, Medellín and Guadalajara have been chosen as a representative mix of all levels of transport sustainability in Latin American cities. In Curitiba, while the high level of transport sustainability often exhibited in similar studies is confirmed by the GTI, it was highly contested by the key informants interviewed in the city. Whether the current 
situation deviates from the historical urban planning achievements rests to be proved; however, the positive path dependencies generated from these previous decisions do seem to be accounted for in my initial empirical characterizations. In Medellín, most respondents agreed that sustainable transport has not been a priority, and as such has never been high on the public agenda. However, the main discussion seems to revolve around the lack of metropolitan coordination, and the high obstacles (and incentives) for this collaboration, deemed vital to achieve higher levels of transport sustainability. Finally, in Guadalajara, most respondents agreed with the low level of transport sustainability of the city. Surprisingly, the high awareness about sustainable mobility of citizens is not reflected amongst key decisionmakers, but finds a crucial representation via the action of organized interest groups. For this city, the role of political parties was mentioned as the top variable influencing the current mix of transport alternatives, and thus, explaining the level of sustainability of this system (see Figure V-8).

Figure V-8: Summary of Thematic Framework as Derived from Interviews

\begin{tabular}{|c|c|c|c|}
\hline $\begin{array}{l}\text { Thematic } \\
\text { framework } \\
\text { [applied to each city } \\
\text { independently] }\end{array}$ & Curitiba & Guadalajara & Medellín \\
\hline $\begin{array}{c}\text { Car as } \\
\text { development } \\
\text { model }\end{array}$ & $\begin{array}{l}\text { Local experts agree it } \\
\text { has had a negative } \\
\text { influence on transport } \\
\text { sustainability, in this city }\end{array}$ & $\begin{array}{l}\text { Local experts agree it } \\
\text { has had a negative } \\
\text { influence on transport } \\
\text { sustainability, in this city }\end{array}$ & $\begin{array}{l}\text { Local experts agree it } \\
\text { has had a negative } \\
\text { influence on transport } \\
\text { sustainability, in this city }\end{array}$ \\
\hline $\begin{array}{l}\text { Metropolitan } \\
\text { governance } \\
\text { arrangements }\end{array}$ & $\begin{array}{l}\text { Local experts agree that } \\
\text { arrangements have } \\
\text { been in place, to } \\
\text { advance transport } \\
\text { sustainability in this city }\end{array}$ & $\begin{array}{l}\text { Local experts agree that } \\
\text { arrangements have not } \\
\text { been in place, to } \\
\text { advance transport } \\
\text { sustainability in this city }\end{array}$ & $\begin{array}{l}\text { Local experts agree that } \\
\text { arrangements have not } \\
\text { been in place, to } \\
\text { advance transport } \\
\text { sustainability in this city }\end{array}$ \\
\hline $\begin{array}{c}\text { Powerful } \\
\text { institutional } \\
\text { players } \\
\text { [the role of] }\end{array}$ & $\begin{array}{l}\text { Local experts agree it } \\
\text { has had a positive } \\
\text { influence on transport } \\
\text { sustainability, in this city }\end{array}$ & $\begin{array}{l}\text { Local experts agree it } \\
\text { has had a negative } \\
\text { influence on transport } \\
\text { sustainability, in this city }\end{array}$ & $\begin{array}{l}\text { Local experts agree it } \\
\text { has had a positive } \\
\text { influence on transport } \\
\text { sustainability, in this city }\end{array}$ \\
\hline
\end{tabular}




\title{
6. Chapter VI
}

\section{Determinants of Transport Sustainability in Curitiba, Guadalajara and Medellín}

\author{
"Cities have the capability of providing something for everybody, only because, and only \\ when, they are created by everybody" \\ -Jane Jacobs
}

\subsection{Introduction}

This chapter provides an insight into the specific institutional and political conditions related to transport sustainability in Curitiba, Guadalajara, and Medellín. The factors that seem to determine variations in transport sustainability outcomes across the studied cities are identified. By qualitatively contrasting the hypotheses generated in Chapter $\mathrm{V}$ with the levels of engagement towards transport sustainability, cross-case explanations are presented, resulting in theory refinement. This chapter is developed respecting the methodology set out in Chapter III.

This section is organized as follows: first, a justification for the new hypotheses generated is offered. Each of these is reworked into an operative mode, following natural unit examples from the first hand data. Secondly, each explanatory condition is assessed for the studied cities, from a comparative perspective. Finally, the hypotheses from the previous chapter are distilled into the strategic premises that steer the generation of the theoretical claims offered in Chapter VII.

\subsection{Representation of Dependent and Explanatory Variables}

In this chapter, the dependent variable sets the stage against which key actor interactions and institutional arrangements are analyzed. All interviewees are aware of the way in which this dependent variable (sustainability of urban transport) has been operationalized, and have been informed of the specific outcome for their city. Nevertheless, all interviewees have their own reading of the level of transport sustainability; thus, the pure investigative 
intention of this research is to allow them to answer the questions based on their own reading of the local conditions.

The study has an inductive nature. Possible explanatory variables were initially proposed as tools for uncovering the mechanisms of higher levels of transport sustainability in the studied cities. Similarly, although it is acquiesced that while making use of this study design, some hypotheses will arise during the process of the research, guiding assumptions were offered since Chapter III.

Table VI-1: Inputs for Hypotheses

\begin{tabular}{|c|c|c|}
\hline Hypothesis & Guiding Assumption & $\begin{array}{c}\text { Postulates from } \\
\text { Explanatory Variables }\end{array}$ \\
\hline H1 & $\begin{array}{l}\text { Political conditions are } \\
\text { equally important to } \\
\text { financial conditions in } \\
\text { increasing levels of } \\
\text { urban transport } \\
\text { sustainability. }\end{array}$ & $\begin{array}{l}\# 1 \text { - Degree of } \\
\text { centralization of } \\
\text { authority in } \\
\text { metropolitan } \\
\text { governance. } \\
\text { \#3 - Interactions } \\
\text { between political } \\
\text { players. } \\
\text { \#4 - Type of initial } \\
\text { stimulus. }\end{array}$ \\
\hline $\mathrm{H} 2$ & $\begin{array}{l}\text { Some institutional } \\
\text { conditions in Latin } \\
\text { American cities result in } \\
\text { higher levels of } \\
\text { sustainability in } \\
\text { transport. }\end{array}$ & $\begin{array}{l}\text { \#2 - Institutional } \\
\text { coordination. }\end{array}$ \\
\hline H3 & $\begin{array}{l}\text { Previously taken } \\
\text { decisions determine the } \\
\text { major public policies } \\
\text { implemented in urban } \\
\text { transport in Latin } \\
\text { American cities. }\end{array}$ & $\begin{array}{l}\text { \#4 - Type of initial } \\
\text { stimulus. }\end{array}$ \\
\hline
\end{tabular}


Throughout this section, the working hypotheses obtained in Chapter V are considered as framing themes of the analysis. These hypotheses integrate some of the explanatory variables initially prompted by the literature review, and some additional themes identified to be critical, during the fieldwork process (see Table VI-1). As opposed to the previous chapters, this time, the hypotheses refer only to the cross-case comparison for the findings in Curitiba, Guadalajara and Medellín.

The first hypothesis was derived from the research project's original guiding assumption \#1, as described in Chapter III. This assumption targeted the influence of both political and financial conditions in determining particular levels of urban transport sustainability. Moreover, it was refined, following the postulates assigned to the explanatory variables 1, 3 and 4. As such, it reads:
H1. Political conditions seem to sway the implementation of key urban transport policies, more directly than financial conditions.

The second hypothesis was derived from the research project's original guiding assumption \#2, as described in Chapter III. This assumption targeted the influence of certain institutional conditions in determining particular levels of urban transport sustainability. It was refined, via the institutional mappings on urban transport decisions, as suggested in explanatory variable \#2. This hypothesis proposes that:

\section{H2. Greater metropolitan institutional coordination facilitates the move towards higher levels of sustainability in transport.}

The third hypothesis was derived from the research project's original guiding assumption \#3, as described in Chapter III. This assumption targeted the influence of previously taken decisions in determining particular levels of urban transport sustainability. This hypothesis now is refined to include a closer link between key urban transport policies and their contribution to transport sustainability: 
H3. Previously taken decisions influence vital urban transport decisions, which become essential when increasing transport sustainability.

In order to assess each hypothesis cross-comparatively, the top five themes that were mentioned by the key informants were selected as central conditions influencing the current mix of urban transport policies within the city, which ultimately determines the overall sustainability of the transport system (see Table VI-2). These central themes are used as indicators of the pertinence of each hypothesis in explaining the outcome variation for the dependent variable, across the three studied cities. While the analysis presented in this section is based on the gathered data, the process is supported by the concepts derived from the sustainable mobility paradigm, and the inquiries related to the tenets of metropolitan governance, which have guided the organization and classification of the data.

\subsection{Cross-Case Comparison}

The central themes for each hypothesis correspond to a condensation of meanings found repetitively across the three cities. Some examples of the specific statements related to these themes are described in Table VI-2. In order to systematically infer how each of these themes indicates a potential rejection of its corresponding hypothesis, the analysis is done crosscomparatively across the three cities for each individual hypothesis. As aforementioned, the approach to the data analysis follows the tradition of a theory-guided approach; making links between the data and with what is already known about the phenomena of interest.

\subsection{Central Themes for Hypothesis 1}

The dichotomy posed by financial and political factors seems redundant. It seems obvious that financial resources could be a crucial condition for the implementation of a vast majority of policies that could impact transport sustainability positively. However, the previous stages of this research have insinuated that certain political factors have been more significant in 
generating certain transport policy decisions in the studied cities, than what financial factors have been. Hence, the contribution of three potential explanatory variables that have been drawn directly from the development of the key informant semi structured interviews is now explored in detail. The variables are: the political agenda, the high potential for votes, and the availability of funds.

Table VI-2: Themes Explored for each Hypothesis

\begin{tabular}{|c|c|c|}
\hline $\begin{array}{c}\text { Corresponding } \\
\text { hypothesis }\end{array}$ & Central Themes & Natural Unit Examples \\
\hline$H 1$ & $\begin{array}{l}\text { 1. Political Agenda } \\
\text { 2. High Potential } \\
\text { for Votes } \\
\text { 3. Availability of } \\
\text { Funds }\end{array}$ & $\begin{array}{l}\text { "The political } \\
\text { interests are stronger } \\
\text { than the economic } \\
\text { ones; and above all, } \\
\text { much stronger than } \\
\text { the mobility } \\
\text { interests". Key } \\
\text { informant \#5 } \\
\text { "Repealing the line } 2 \\
\text { of the BRT was used } \\
\text { as a political banner; } \\
\text { solely with electoral } \\
\text { purposes". Key } \\
\text { informant \#31 } \\
\text { "When there is a } \\
\text { budget shortage, it } \\
\text { doesn't make any } \\
\text { sense to prioritize } \\
\text { transport". Key } \\
\text { informant \#58 } \\
\text { "At that time, the } \\
\text { state leadership was } \\
\text { very close to the } \\
\text { Dictatorship; they } \\
\text { had sufficient } \\
\text { financial support, so } \\
\text { money was not an }\end{array}$ \\
\hline
\end{tabular}




\begin{tabular}{|c|c|c|}
\hline & & $\begin{array}{l}\text { issue". Key informant } \\
\# 4\end{array}$ \\
\hline$H 2$ & $\begin{array}{l}\text { 4. Metropolitan } \\
\text { Coordination }\end{array}$ & $\begin{array}{l}\text { - “Here, we don't have } \\
\text { any formal } \\
\text { metropolitan } \\
\text { government } \\
\text { structure...we just } \\
\text { have non-binding } \\
\text { voluntary } \\
\text { agreements". Key } \\
\text { informant \#27 } \\
\text { "There is a 'soft' } \\
\text { mechanism in place } \\
\text { since } 2006: \text { a } \\
\text { municipal } \\
\text { association". Key } \\
\text { informant \#35 }\end{array}$ \\
\hline H3 & $\begin{array}{l}\text { 5. Previous } \\
\text { Decisions }\end{array}$ & $\begin{array}{l}\text { - "There clearly are } \\
\text { critical junctures that } \\
\text { can explain the } \\
\text { current governance } \\
\text { arrangements". Key } \\
\text { informant \#16 } \\
\text { "In 1996, an accord } \\
\text { was signed between } \\
\text { the state and the } \\
\text { local governments, so } \\
\text { that one sole entity } \\
\text { would administer the } \\
\text { metropolitan } \\
\text { transport services". } \\
\text { Key informant \#19 }\end{array}$ \\
\hline
\end{tabular}

Source: own elaboration

\subsubsection{Political Agenda}

When referring to the "political agenda", a focus is placed on grasping the major political interests that stimulate particular acting strategies in 
promoting urban transport policies, as drawn from the interviews. It is assumed that those particular issues that are central to a political agenda of any government are more likely to become addressed specifically during the policy making process.

This fully applies to local governments in Latin American cities, like the ones central to this research, and implies that if sustainable transport were to enter the agenda as a top priority for the local administration, it is more likely that specific public policies become implemented to address the issue. Furthermore, it applies in both ways, comprising also the moments during which sustainable transport is not pushed into the agenda by any actor, as it has been the case for Medellín during the early half of the $21^{\text {st }}$ century: "sustainable mobility was just not a priority in the agenda. It came much further after education, transparency, coexistence [...] it was also not a communal clamour [...] and remember that politicians are there to solve the problems that people have"104.

Nevertheless, this basic assumption brings about a few major queries. First, is it possible to argue that by guaranteeing the implementation of public policies to address an issue that stands at the top of a political agenda, then this means that this issue will be dealt with successfully? In the case of sustainable transport, for example, would the fact that public policies are implemented, under the political banner of increasing transport sustainability, would that necessarily be correlated with measurable higher levels of urban transport sustainability?

In this chapter it is argued that the answer to both of these questions -in the context of the developments in Curitiba, Guadalajara and Medellín- is no. A majority of those interviewed in Guadalajara and Curitiba state that there is a high awareness about sustainable mobility issues in their cities. Thus, political discourse from various levels indeed includes sustainable mobility as a priority, leaving ordinary observers with a sour feeling, about the issue actually standing at the top of local agendas.

In Guadalajara, the official discourse does not seem to be supported by the actual policy actions: "while the official discourse consistently includes mentions to the light rail, debates about the BRT model, and promises the construction of $\mathrm{X}$ number of bicycle lane kilometres, the major policies

104 Personal communication, David Escobar, Chief of Staff to Mayor Sergio Fajardo. September 20, 2011 
implemented during the last five years directly represent road expansion [...] look at the López Mateos viaduct, the Matute Remus bridge, the Avila Camacho-Circunvalación node..." ${ }^{105}$. In Curitiba, the historic discourse seems to be kept alive as a city brand, but not as a broad public policy bet: "we became the role model city from the South [in terms of urban sustainability], so now people think we don't need to work on that issue anymore. Moreover, people choose not to recognize the current problems, and thus, politicians do not act upon them"106.

On the other hand, even if there is in fact a correlation between the implementation of policies, for an issue that stands at the top of a local political agenda, and the improvement of the particular phenomenon that it is intending to ameliorate, in the context of this research, an effort has been made to identify the factors facilitating that particular such issues rise to the top of a local political agenda. Notwithstanding the fact that rising to the top of the agenda, might not be directly correlated with a positive output in urban transport sustainability, identifying the specific conditions allowing for this rise to occur, has important policy relevance.

Several issues have made it to the agenda, but were never transformed into implemented actions. In Guadalajara, for example, the Director of the Transport Department for the Jalisco State Government summarized this to me as the 'unwanted pregnancy phenomenon':

"From the state level, at the beginning of the term, a plan [the pedestrian and cycling master plan (Plan Peatonal Ciclista)] was drawn to implement specific nonmotorized mobility actions; however, by the time the local elections came [three years later], we lost consensus with the new local authorities [...] it is like an 'unwanted pregnancy phenomenon'; the paternity of these long term products is rejected, and then we are left with an active project that is no longer in the agenda of the local government [...] bear in mind that local governments are the authority over the use of public space, especially as it concerns the sidewalks" ${ }^{, 107}$.

\footnotetext{
105 Personal communication, Key informant \#34.

106 Personal communication, prof. Gislene Pereira. UFPR. August 12, 2012.

107 Personal communication, Diego Monraz. Secretary of Transport. February 11, 2013.
} 
Political agendas also define the ways in which various actors intervene in the policy making process. Actors will contribute to the process with differing degrees of knowledge and values regarding every specific issue, which will also vary according to the factors framing the negotiation. As it relates specifically to urban transport, some factors might include, for instance, the different dimensions of transport decision making, and the overall context within which transport decision making is happening (Joumard \& Gudmundsson 2010).

If we are to use the levels of consensus and knowledge about urban transport problems, then we can identify acting strategies and the 'structuredness'. As implied by Joumard \& Gudmundsson (2010), the structuredness of the issues to be addressed affects the way in which each actor contributes to the discussion. These acting strategies may range between problem solving engagement to simple problem recognizing, and include also mediation and advocating as middle-range options, depending on the degrees of knowledge and values consensus (see Figure VI-1). In Medellín, for example, there seems to have been very low consensus on whether bicycles should be promoted as a transport mode, accompanied by a concomitant low level of institutional knowledge about the issue.

As such, key actors, simply took "problem recognizing" strategies. The director for the EnCicla public bicycle scheme recounts this situation: "when the project was originally proposed by the City Council, it started bouncing back and forth across entities, various departments of the city government, the Metro, the AMVA, etc. When the AMVA offered the resources to advance the feasibility studies, several other institutions claimed they could not due this, due to a lack of technical expertise. Hence, nothing was done for a long time" ${ }^{108}$. The opposite case happened during the construction of the second cable-car system in Medellín. Since the first cable-car had been a huge success, when the second one was proposed there was high consensus on both knowledge and values, from the key actors involved: "the direct contribution from the city to implement MetroCable was framed as a contribution towards improving quality of life; more than improving mobility is was targeted as a social investment for the area"109.

108 Personal communication, Jesús Acero. Director. EnCicla. October 10, 2011.

109 Personal communication, Ramiro Márquez. CEO. Metro de Medellín. September 12, 2011. 
Figure VI-1: 'Structuredeness' of different types of transport decision-making and acting strategies

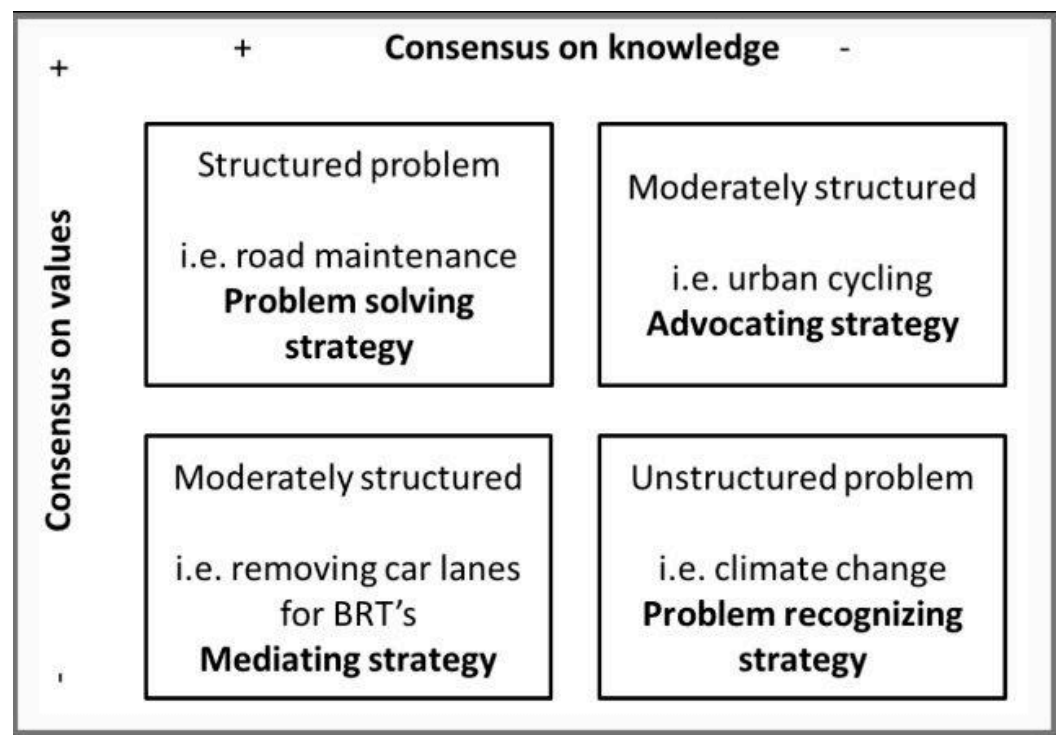

Source: Adapted from Joumard \& Gudmundsson (2010), p. 82; De Ridder \& Petersen (2008)

Furthermore, the choice of each acting strategy implies very different stances on the way in which a political agenda is pushed through by various actors. In Guadalajara, unstructured problems were dealt with in much different ways, as the agendas changed. The implementation of the Macrobús BRT, implied the removal of road space for the car. Moreover, it included the removal of a number of businesses in certain junctures, and the obvious daily inconveniences caused to the project's neighbours during the development of the works. Nevertheless, while the line 1 was built in record time, with valuable public and citizen groups actively mediating towards those against the project, the projected line 2 was shot down from the start due to an agenda change for some of the actors: "Line 1 of the Macrobús was on everybody's agenda. All local mayors and the State congress agreed with the Governor; the case for the line 2 was much different; it was only the governor's agenda, and died there" 110 .

On the other hand, however, an issue like bicycle transport is more of a moderately structured problem due to the lack of consensus on knowledge;

110 Personal communication, prof. Oscar Castro. ITESO. February 7, 2013. 
while some think it will contribute to solving congestion, others think that biking is not a real urban transport option. In Guadalajara, it has been faced with a consistent advocating strategy by organized groups. A planner for the Zapopan municipality highlights the discipline of these groups: "when certain groups started using the bike en masse, talking about sustainable mobility, this slowly started creating a growing latent debate that started to influence the agenda; we now have a serious interest from the local government to promote cycling as an option"111.

Local and regional government agendas are strongly influenced by national agendas. The range of possible policy actions in the three cities, Curitiba, Guadalajara and Medellín seems to be framed by the way in which urban transport is conceptualized from the national government. While the three national governments have a record of promoting the car industry as an economic growth base, the national government during the dictatorship carries much of the responsibility for the vast pro-public transport actions developed in Curitiba then, as described in Chapter V.

The Brazilian transition in 2003 offers an interesting case-study, as the rise to power of the leftist Partido dos Trabalhadores (PT) brought about false expectations about a possible nationally-driven policy promoting urban sustainable transport. A Ministry for Cities (Ministério das Cidades) was created, and included the promotion of better transport as one of its top priorities $^{112}$ :

"The creation of the Ministério das Cidades brought about high expectations. It was seen as an early victory of Lula's government in 2003. However, there was no real interest in the topic. Its leadership was later 'given' to a group that has no interest in its promotion [sustainable transport]. For example, the previous secretary in charge of urban mobility was far from being an expert, and never manifested himself. The one that followed him is pretty much the same. This is just not in their agenda" $" 113$.

\footnotetext{
111 Personal communication, Alfredo Hidalgo. Strategic Projects Director. Zapopan. February 5, 2013.

112 Its official website offers a strong stance in favour of sustainable mobility in the context of increased urbanization:

Last accessed on November 252013.

113 Personal communication, Dr. Eduardo Vasconcellos, ANTP, August 14, 2012.
} 
However, the Ministry has had very few clear successes in promoting urban sustainable transport, while it has seen four ministers leading it since its creation: Olívio Dutra, Márcio Fortes de Almeida, Mário Negromonte, and Aguinaldo Ribeiro. Their agenda has seemingly continued to place the car, as the top priority for urban transport: "you need only look at the PT actions in favour of the car. Don't forget that Lula [former president Luiz Inácio Lula da Silva] worked for the auto industry. The real issue for them is 'economic growth'; so even the few key members of the PT that formerly criticized the model, now simply state that the automotive industry is vital for the Brazilian economy"114.

Perhaps, the most critical challenge resulting from analyzing local political agendas comes from the fact that these are highly dynamic. Not only do these change permanently, but they also can take quite confusing turns. In Curitiba, the overall agenda frequently has proved to be more important than the technical needs of the city; a lot of it has to do with the role of the opposition, as a Professor at the PUCPR puts it, "if my political enemy has been actively promoting policies in a certain field, then I promote weaker policies for that field"115. An interesting situation was found in Medellín, where an orphan shared bicycle project was suddenly taken up as a priority by the AMVA; although this institution had never promoted the use of the bicycle before. As previously discussed, after the shared bicycle scheme was proposed by the city council, no entity included it within its agenda. Nonetheless, "when the AMVA becomes the environmental and mass transport authority for the conurbation, it now has an incentive to generate its own transport project. The director of the AMVA himself took it under his lead. Thus, the feasibility studies were cancelled, and were changed for a fully functional pilot project. The fact that he moved it to the top of his agenda, allowed for the full avoidance of several institutional obstacles, which are common in these types of projects" ${ }^{" 116}$. The Director himself confirmed this move, stating that "we took into under our lead and decided to go all in; it was a big challenge, but has been a success"117.

The results from the research seem to indicate that the specific local political agenda greatly influences the specific policy decisions taken, in terms of

\footnotetext{
114 Personal communication, Dr. Eduardo Vasconcellos, ANTP, August 14, 2012.

115 Personal communication, Prof. Fabio Duarte, PUCPR, August 15, 2012.

116 Personal communication, Jesús Acero. Director. EnCicla. October 10, 2011.

117 Personal communication, Mauricio Faciolince. Director. AMVA. October 26, 2011.
} 
urban transport. While policy decisions frequently do not materialize into real actions, they also are highly influenced by the agendas of regional and national governments. Furthermore, the acting strategies of the key actors setting the agendas are highly prone to changes, due to its existence within a dynamic political context. In this sense, unexpected agenda changes might be partly explained by the potential for votes that each action has.

\subsubsection{High Potential for Votes}

When referring to the "high potential for votes", a focus is placed on grasping the electoral incentives that seem to have promoted sustainable urban transport policies, as drawn from the interviews. In analyzing the vote potential for candidates at the local, regional and national level, an emphasis is also placed on the decision making models behind these actions.

Basic decision making models are useful in analyzing why certain urban transport decisions are taken at certain moments in Latin America. Different decisions reflect a correspondence with these models, according to a number of factors during the process, i.e. (1) the availability of time and information needed for taking the decisions; (2) the extent to which decision makers have access to all the alternatives; (3) the stability and speed of the decisionmaking environment; and, (4) the ambiguity in the decision process.

A contingency model of decision making, as developed by Thompson and Tuden (1959), and adapted by Joumard \& Gudmundsson (2010), is used to delineate the broad possible avenues. Means and ends uncertainty refer to the level of certainty in the 'how' and 'why' for taking a specific action (see Figure VI-2). The resulting possibilities range from the fuzziest "garbage can" model, which is permeated by high ambiguity during the process, to the highly crisp "rational" model. 
Figure VI-2: Contingency model of decision making

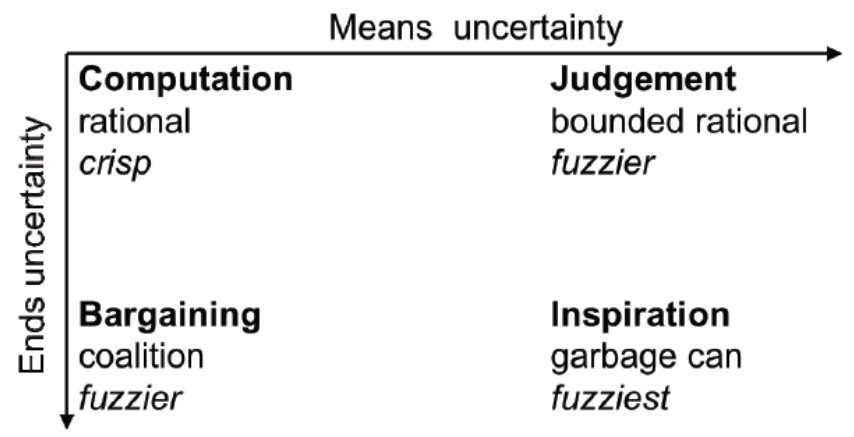

Source: Joumard \& Gudmundsson (2010), p. 87; Adapted from original by Thompson \& Tuden

The clashes between technical propositions and political desires bring about the first set of interesting dynamics. In the three studied cities, a clear pattern can be identified: while technical planners often advocate for what they consider to be the best technical solutions, political players find it attractive to endorse solutions that may provide higher electoral profitability.

The BRT system has been the broad platform over which the transport system of Curitiba has been built. Moreover, its implementation, and continuous innovation explains the fact that it has given this city, global recognition as a sustainable mobility leader. Nonetheless, the possibility of building a metro system has been consistently making an appearance during the last 2 decades; curiously, "this happens approximately six months before every election"118. More recently, due to the selection of Curitiba as one of the host cities for the 2014 FIFA World Cup, the metro project was finally given a green light again, after several periods of frozen activity.

This massive project, however, has not been preferred by a broad array of technical transport planners in the city due to its high ends uncertainty: "the metro system may not be the best solution for this city. Bear in mind that one-third of its total cost is paid for by the city itself, and a lot could be done with that money to improve the bus system further" least 100 times more expensive to build a metro than a BRT [...] the current

118 Personal communication, Prof. Fabio Duarte, PUCPR, August 15, 2012.

119 Ibid. 
ticket price does not fully cover the operative costs of the RIT. This means that it will ultimately be up to the government to subsidize the metro, in order to allow for the low ticket price" ${ }^{120}$. Even if this is the case, there are no doubts, at any scale, that building a metro will guarantee significant electoral profits, in a culture that highly values modernity as a sign of social progress. It is not surprising then, that all actors involved in this decision, joined the metro project, exhibiting a marked rational decision-making model.

A very similar situation took place in Guadalajara, where the changes in the potential for votes, due to the timing of the electoral cycle, modified support for the various legs of the BRT. While Line 1 of the Macrobus was proposed and implemented (even though the city already had a light rail system), Line 2 was cancelled, because electoral timings were completely different. Seemingly, the time needed for building (and inaugurating a project) has a lot to do with the issue, "the electoral cycle does not allow for the construction of 19 stations of underground light rail [the number of light rail stations that the city currently has]; on the other hand the 27 stations of Macrobús were built in only 13 months, and the system was inaugurated on March 10, 2009, with President Calderón riding the bus along with governor Emilio González Márquez"121.

This success opened the possibility for those ruling party $(P A N)$ leaders involved, to push through the subsequent Line 2. Nevertheless, during the mid-term local elections, the three mayoralties involved were lost to the opposition party $P R I$, whose leaders -following a clear rational decisionmaking model- took the banner of anti-BRT. Mayors Aristóteles Sandoval (Guadalajara), Héctor Vielma (Zapopan) and Miguel Castro (Tlaquepaque), jointly announced their decision to reject the FONADIN ${ }^{122}$ funds for the construction of Line 2 on October 27, 2010. As previously explained, this brought about havoc within the State Government mobility plans, and "probably gave Mayor Sandoval the votes that later allowed him to win the State elections" $"$. As Governor, he has now moved back to supporting the BRT, by proposing the construction of two additional BRT lines for greater

\footnotetext{
120 Personal communication, Julio de Almeida. IPPUC planner. August 8, 2012.

121 Personal communication, José Comer. Director of Control. SITEUR. February 7, 2013.

122 Fondo Nacional de Infraestructura (National Infrastructure Fund).

123 Personal communication, Jesús Soto. Founder Ciudad Para Todos. February 6, 2013.
} 
Guadalajara ${ }^{124}$, in what seems to be a product of another crisp and rational decision-making model.

Some elected officials in Latin American cities seems to think that implementing certain transport infrastructure, may produce a valuable lasting legacy for their own political careers. The symbolism of having their names tied to the highly visible projects, seems to matter more than actually resolving the problems, as proposed by the technical planners. In this sense, if decisions are taken with the intention to maximize one's own voting potential, very little uncertainty about means and ends can be detected.

The debates about building one tramway line, or instead, bet on the expansion of the BRT system generated interesting conclusions in Medellín. On the one hand, 'a disagreement between the City and State governments made it imminent that they would lose the contribution from the National Government, via a CONPES ${ }^{125}$ meant to cover $50 \%$ of the project's cost"126, nevertheless, on the other hand, Mayor Alonso Salazar made the tramway project a top priority for his government although it is much more expensive than an average BRT project; "with the money that we are spending on the tramway, we could have built three BRT corridors; it is not a financially feasible project in terms of the operational income for that stretch. However, it became a personal quest by Mayor Salazar, who said he wanted to leave the tramway as a legacy of his term" ${ }^{27}$.

The relationship between political agendas and vote potential in the studied cities is a close and dynamic one. Although certain projects have been completely rejected from inclusion into some political agendas, they have later been included, as the potential for votes is perceived to increase, in regards to those projects. Likewise, some other projects that have stood firm on political agendas have suddenly lost all support, as a continued push for these seemingly implied a high political cost for elections.

\footnotetext{
124 "Line 2 of Macrobús to Start Next Year". El Informador. http://www.informador.com.mx/jalisco/2013/489899/6/la-inversion-para-linea-2-del-macrobusiniciara-el-proximo-ano.htm. Last accessed November 25, 2013.

125 Consejo Nacional de Política Económica y Social (National Council for Social and Economic Policy).

126 Personal communication, Jose Muñoz. Intermediary between regional and local governments. October 20, 2011.

127 Personal communication, Rodrigo Salazar. Former Medellín Secretary of Transport. September 20, 2011.
} 
Let's look at the broad issue of sustainable mobility in Curitiba. Even though the city entered the $21^{\text {st }}$ century as the undisputable leader in the Latin American region, the topic lost its importance within the electoral discourse. A young Councilman highlights the electoral swing in this respect: "the change in awareness about sustainable mobility has been noticeable. While during the last campaign, I was one of the only candidates pushing for the need for a sustainable mobility plan, today the topic is mentioned by everybody, and has become one of the principal discussions in the local elections" $" 128$.

Furthermore, as the author had the chance to advance the fieldwork in this city, during the midst of the local elections, it was possible to attest that dozens of candidates to various offices had made the bicycle the symbol of their campaign; however, key informants made it clear that this was not the case four years ago: "what we see now is that campaigns are focusing on the bicycle. It is clear that the electorate wants that, so it is the first time that major candidates go around in their bikes showing themselves off [...] aside from health and security, they know it is now mobility that gets them elected"129.

Some key transport projects could have defined elections. In Guadalajara, for example, the Sunday cycling open streets project, the Via Express, and the BRT have had important effects on the electorate. Firstly, the implementation of the Sunday open streets project, called Via RecreActiva, was an immense popularity booster for then Mayor González: "at the beginning, Emilio González Márquez was not too convinced about the project. However, one of his aides was Raul Monjaráz, who was the key person pushing for this from the inside. At the end, Gonzalez gave it the green light, and this undoubtedly was the project that gave him the popularity level that later allowed him to become governor"130. Later on, the Via Express turned from a landmark project for Governor González, into a few highly criticized YouTube videos: "The Via Express never existed as a real project $[. .$.$] it was not meant to be constructed. It was simply a trifle$

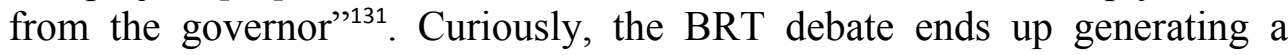
conclusion that can be used to sum up the broad transport policies for

\footnotetext{
128 Personal communication, Jonny Stica. Councilman of Curitiba. August 15, 2012.

129 Personal communication, Prof. Fabio Scatolin, advisor to Mayor Fruet August 6, 2012.

130 Personal communication, Tomás López. Founder of Guadalajara 2020. February11, 2013.

131 Personal communication, Carlos Romero. Director. Non-motorized mobility. OCOIT. February 5, 2013.
} 
Guadalajara during this past decade: "when the PAN started with the BRT, the PRI revived their light rail project, and actively started to lobby against the BRT. At the end, their only agreement was about road expansion, they all agreed with this idea, and they always have" ${ }^{\text {132 }}$.

In the context of urban transport decisions for the studied cities, the prevailing decision making model seems to be one of rational decision making. Reflecting high levels of means and ends certainty about the specific actions needed to maximize the potential for future votes. The short electoral cycles, and the possibility for elected politicians in Brazil, Colombia and Mexico to run for a future election, act as incentives for key political leaders to use transport decisions as tools for maximizing their vote potential.

\subsubsection{Availability of Funds}

When referring to the "availability of funds", a focus is placed on grasping the extent to which the funding possibilities seem to have promoted (or curtailed), the implementation of key sustainable urban transport policies, as drawn from the interviews. Although this region is considered as a developing region of the world, Latin America had been considered been thought to be a blessed land during the times of the conquest; otherwise known as the mythical land of El Dorado ${ }^{133}$. The availability of funds at the local level today is related to a variety of conditions.

One of the key issues to explore in terms of urban transport and availability of funds refers to the responsibilities of each level of government in terms of tax revenue and government expenditure (Rojas 2005; Monzón 2005). Although the traditional structure reflected a paternalistic tradition by which sub-national politicians would just take the money and run (Willis et al.

\footnotetext{
132 Personal communication, Etienne von Bertrab. Founder Ciudad para Todos. February 4, 2013.

133 The legend of El Dorado refers to the lost city of gold located somewhere in South America. It was never found by the Spanish invaders. During his Nobel Lecture, one of the greatest Latin Americanists in recent history, Gabriel García Márquez reminds us of the once common abundance of rare metals in the region: "As late as the last century, a German mission appointed to study the construction of an inter-oceanic railroad across the Isthmus of Panama concluded that the project was feasible on one condition: that the rails not be made of iron, which was scarce in the region, but of gold".
} 
1999), the recent waves of decentralization have changed this trend (see Table VI-3).

For the countries in the case study, Mexico stands out as the most centralized in terms of tax revenue, where, as Willis et al. (1999) explain, most of the taxing powers remain concentrated in the hands of the central government. Mexico also rates as the least decentralized in terms of expenditures. Brazil, on the other hand stands out as the most decentralized of the three, both in terms of expenditure and revenue. Moreover, Brazil also showcases "the most significant change in taxing powers being transferred to the state level" (Willis et al. 1999, p.11). Colombia stands mid-way between the decentralization levels of Mexico and Brazil in both revenue and expenditures.

If the possibility for sub-national units to incur their own debt implies that they are more autonomous, then a similar pattern applies for these three nations. The central government in Mexico exercises great discretion over the amount and use of intergovernmental transfers, and Brazil stands at the opposite end of this spectrum, with Colombia once again falling in between (Willis et al. 1999).

The crucial question in terms of urban transport for the studied cities concerns then whether there are sufficient funds available to implement serious transport policies. These funds may come from the direct budgets of the cities, or from higher levels of government, in which case it is imperative to understand to what extent they make these funds available to the cities.

A majority of the key informants interviewed in Curitiba, Guadalajara and Medellín consider that there have been sufficient funds available to promote transport projects framed under the concept of sustainable mobility: "there is a clear growing consensus on the idea that it is not funding availability that obstructs the implementation of key sustainable mobility projects [...] There is wide availability for funds, but many times there is little availability of well-structured projects, with sufficient local political support, and technical contributions"

134 Key informant \#17. August 13, 2012. 
Table VI-3: Revenue and Taxes by Level of Government

\begin{tabular}{|c|c|c|c|c|}
\hline \multirow[t]{2}{*}{ Country } & \multicolumn{2}{|c|}{$\begin{array}{c}\text { Share of total government tax } \\
\text { revenue collected by level of } \\
\text { government (\%) }\end{array}$} & \multicolumn{2}{|c|}{$\begin{array}{c}\text { Share of total government } \\
\text { expenditure by level of } \\
\text { government (\%) }\end{array}$} \\
\hline & $\begin{array}{c}\text { Before } \\
\text { Decentralizati } \\
\text { on }\end{array}$ & $\begin{array}{c}\text { After } \\
\text { Decentralizati } \\
\text { on }\end{array}$ & $\begin{array}{c}\text { Before } \\
\text { Decentralizati } \\
\text { on }\end{array}$ & $\begin{array}{c}\text { After } \\
\text { Decentralizati } \\
\text { on }\end{array}$ \\
\hline \multicolumn{5}{|l|}{ Brazil } \\
\hline Central & 59.8 & 47.1 & 50.2 & 36.5 \\
\hline State & 36.9 & 49.4 & 36.2 & 40.7 \\
\hline Local & 3.8 & 3.6 & 13.6 & 22.8 \\
\hline \multicolumn{5}{|l|}{ Colombia } \\
\hline Central & 82.2 & 81.6 & 72.8 & 67.0 \\
\hline $\begin{array}{l}\text { Department } \\
\text { al }\end{array}$ & 12.2 & 11.1 & 16.7 & 15.7 \\
\hline Local & 5.6 & 7.3 & 10.5 & 17.3 \\
\hline \multicolumn{5}{|l|}{ Mexico } \\
\hline Central & 90.7 & 82.7 & 90.2 & 87.8 \\
\hline State & 8.3 & 13.4 & 8.8 & 9.5 \\
\hline Local & 1.0 & 3.9 & 1.0 & 2.8 \\
\hline
\end{tabular}

In Curitiba, important funds have been available for transport since the reinstatement of democracy. Even during the dictatorship, as previously discussed, there were no significant budget constraints in terms of urban transport for this city. More recently, the central industrial activities of the city have guaranteed funds availability; "We have had a very powerful industrial district, pushed forward by the automotive industry; cars, auto parts, etc. This is not a poor city"135

Furthermore, the national government has also proved to be a significant source of funds for transport projects. This does not necessarily mean that funds earmarked for urban transport are invested in projects promoting sustainability; "there is more than sufficient funding for sustainable mobility projects in Brazil, we have the second bank in the world ${ }^{136}$, in terms of infrastructure investment, after the Bank of China [...] Our problem is that

\footnotetext{
135 Personal communication, Prof. Fabio Duarte, PUCPR, August 15, 2012.

136 BNDES, Banco Nacional de Desenvolvimento Econômico e Social.
} 
bureaucracy is immense, projects are rarely structured technically and correctly from the beginning, and political will is weak"137. However, when the political variables have been in place, important contributions to transport sustainability have been made, as is the case with metro line currently being built.

Lastly, international funds have been available when the conditions have been met: "there have always been plenty of international financial funds for Curitiba, thanks to the existence of the IPPUC, and to its fame as a powerful

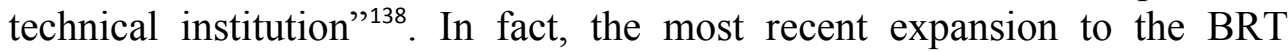
system; the Linha Verde was partly paid for using international funds.

In Guadalajara, there is a greater dependence from higher levels of government. Even though a municipality like Guadalajara "does not have enough funds to cover its entire planned transport infrastructure projects, this money will be procured via other sources, be it the State or the National government; however, this depends from the political context"139. Such was the case with the Line 1 of the Macrobús, which was "paid for completely with State resources" 140 .

Notwithstanding the fact that the Line 2 was buried due to political agendas, it is pertinent to recall the statement offered by President Felipe Calderón, during the inauguration of the first BRT line:

"I want all jalicienses and tapatios to know that in the extension of lines one, two, three, and maybe even four, you are not alone; the national government will support Jalisco until the cap allowed by the National Infrastructure Fund"141.

In Medellín, there also seems to be consensus on the availability of funds. Its above average budget relates to its direct ownership of the highly profitable public utilities company, $E P M^{142}$; "Medellín has a significant

\footnotetext{
137 Personal communication, Patrizia Bittencourt. CIFAL Curitiba. August 9, 2012.

138 Ibid.

139 Personal communication, Alfredo Hidalgo. Strategic Projects Director. Zapopan. February 5, 2013.

140 Personal communication, Carlos Romero. Director. Non-motorized mobility. OCOIT. February 5, 2013.

141 Macrobús inauguration speech by. President Felipe Calderón. March 10, 2009.

142 EPM. Empresas Públicas de Medellín.
} 
budget, based on constant sources of revenue. Its dependence on EPM could be calculated to around $27 \%$ ",143

This partial financial autonomy results in important contributions to sustainable mobility, that has had no financial contributions from other levels of government. Line K of the Metrocable cable car, for instance was built by the Metro and the city together: "the city contributed with $55 \%$ of the cost, and we covered the remaining $45 \% " 144$.

Perhaps more important than fund availability, is the use that is given to such funds. As previously described, these cities face the broad dichotomy of using transport funds to promote car-based mobility, public transport, or motorized transport (or a combination of these). A seldom cited trade-off then, corresponds to the fact that the more money is spent in the car, the less money is available for the other options. In Guadalajara, for example, most of the money continues to be spent directly to promote a car-based system: "We have tried to get SEDEUR ${ }^{145}$ to invest the resources for mobility differently. They continue to spend a vast majority of the budget, on the car. We have been pushing for at least a 50-50 split between the car and public transport/non-motorized transport [...] the money spent in car-centred infrastructure amounts to at least $90 \%$ of the mobility budget" ${ }^{\prime 146}$. Of course, in developing nations like Mexico, those who own a car, are on average, the richest people. Meaning that the transport investment from the government is directly benefiting those who need it the least: "We work the other way around here. The most sumptuous car infrastructure in this metropolitan area has been developed precisely in the richest municipalities [composing it]; Guadalajara and Zapopan. The richer the municipality, the more it invests in the car"147.

Timing for investing also merits evaluation. Some periods of each electoral term usually see more investment flowing from other levels of government: "there is a repetitive trend in the availability of financial resources during a political term. While the funding capacity usually stays at a certain level during the first years, the last year always shows a pronounced increase" ${ }^{\text {148 }}$.

143 Personal communication, Federico Restrepo. CEO. EPM. October 19, 2011.

144 Personal communication, Ramiro Márquez. CEO. Metro de Medellín. September 12, 2011.

145 SEDEUR. Secretaría de Desarrollo Urbano de Jalisco. (Jalisco State Urban Development

Department).

146 Personal communication, Diego Monraz. Secretary of Transport. February 11, 2013.

147 Personal communication, Patricia Martinez. Activist. GDL en Bici. February 7, 2013.

148 Personal communication, prof. Fabio Scatolin, advisor to Mayor Fruet August 6, 2012. 
If the city sees no need to wait for other levels of government, then it can go ahead and push it through autonomously, with the time-saving consequences that this may bring. In Medellín, for example, for the construction of Metrocable Line J, "the nation did not participate with money, the project was born out of the Metro planning department, the city decided to fund it because it promised to be finished soon [...] very few transport projects of this magnitude can be started and finished during one period in office" $" 149$.

On the other hand, certain international funds do require the approval of the national government. Such was the case with the approval of the funds for the construction of the Tramway Line 1 in Medellín. These funds were procured and secured directly by the city; yet, the national government stalled the delivery for several months: "a single public servant at the national planning department has the power to stop massive projects in full. It has happened before with the Medellin Metro projects, even though the money is meant for the city, and procured by it [...] there is a negative perception about the national investment in Medellín, which goes back to the financing fiasco of the Medellín Metro in the 1980's. Although today $60 \%$ of the cost of the project is taken up by the region/city itself, some people still do not know this" ${ }^{\text {} 150}$.

In the context of urban transport decisions for the studied cities, the availability of financial resources does not rank as the top condition for advancing sustainability. The structural conditions of Brazil, Colombia and Mexico offer an additional perspective about the value of the cases selected. The three countries follow a similar pattern in terms of the share of tax revenue and government expenditure by level of government, as well as in terms of the possibility for sub-national units to incur their own debt. In some of them, there is greater dependence from higher levels of government. This is the case of Guadalajara, where although money seems to be available, it frequently is captured by political dynamics in the interactions between government levels.

\footnotetext{
149 Personal communication, David Escobar, Chief of Staff to Mayor Sergio Fajardo. September 20, 2011.

150 Personal communication, Felipe Targa. Former Vice-Minister for Transport. October 1, 2012.
} 
The contribution of metropolitan coordination to guarantee higher levels of sustainable transport might not be the first condition that comes to our mind. Nonetheless, the previous stages of this research have iteratively suggested this issue to be critical for all studied cities. This section explores in detail the way in which metropolitan coordination arrangements have influenced the current mix of urban transport in Curitiba, Guadalajara and Medellín.

Monzón (2005) describes perfect coordination in urban transport in the context of: "the existence of a unique administrative entity in charge of all transport modes. The competencies that need to be coordinated include road infrastructure (streets and urban roads) and their management (traffic light regulation and control, reserved lanes and public transport priorities, parking management, etc.) also included is the coordination amongst the various public transport modes; buses, metros, tramways and rail. Finally, these activities must be coordinated with bicycle lanes and pedestrian mobility" (Monzón 2005, p.422).

Using the measurement scales suggested by Walker (1987) and MitchellWeaver et al. (2000), it is intended to assess the various magnitudes of intergovernmental coordination at the metropolitan level in the three studied cities. This scale describes the various arrangements, with different magnitudes of coordination, which are possible within metropolitan patterns of rule (see Figure VI-3).

When referring to "metropolitan coordination", a focus is placed on grasping the arrangements that have been successfully put in place in the studied cities, and their corresponding effect on the promotion of sustainable urban transport policies, as drawn from the interviews. There is no evidence to suggest that any of the studied cities has achieved any of the 'moderately difficult' or 'hardest' types of intergovernmental coordination during the last decade. Nevertheless, the only period during which symptoms of twotier restructuring could be identified, corresponds to the Curitiba of the military dictatorship.

Type 16 of intergovernmental coordination does not seem to match the municipal autonomy principles of the post-decentralization wave in Latin America. A 'two-tier' restructuring in this sense would imply a full centralization of power to the federal/national government, in the way of a 
broad federal structure. Evidently, having a highly hierarchical decisionmaking structure could prove to be beneficial for certain urban projects, as was the case for Curitiba during the military dictatorship (addressed in detail in Chapter V); yet, the lack of concomitant military governments in Colombia and Mexico implies that other types of intergovernmental coordination arrangements must also be explored in detail. This also applies to more contemporary conditions for highly decentralized Latin American nations.

Figure VI-3: Types of Intergovernmental Coordination Identified in the Studied Cities

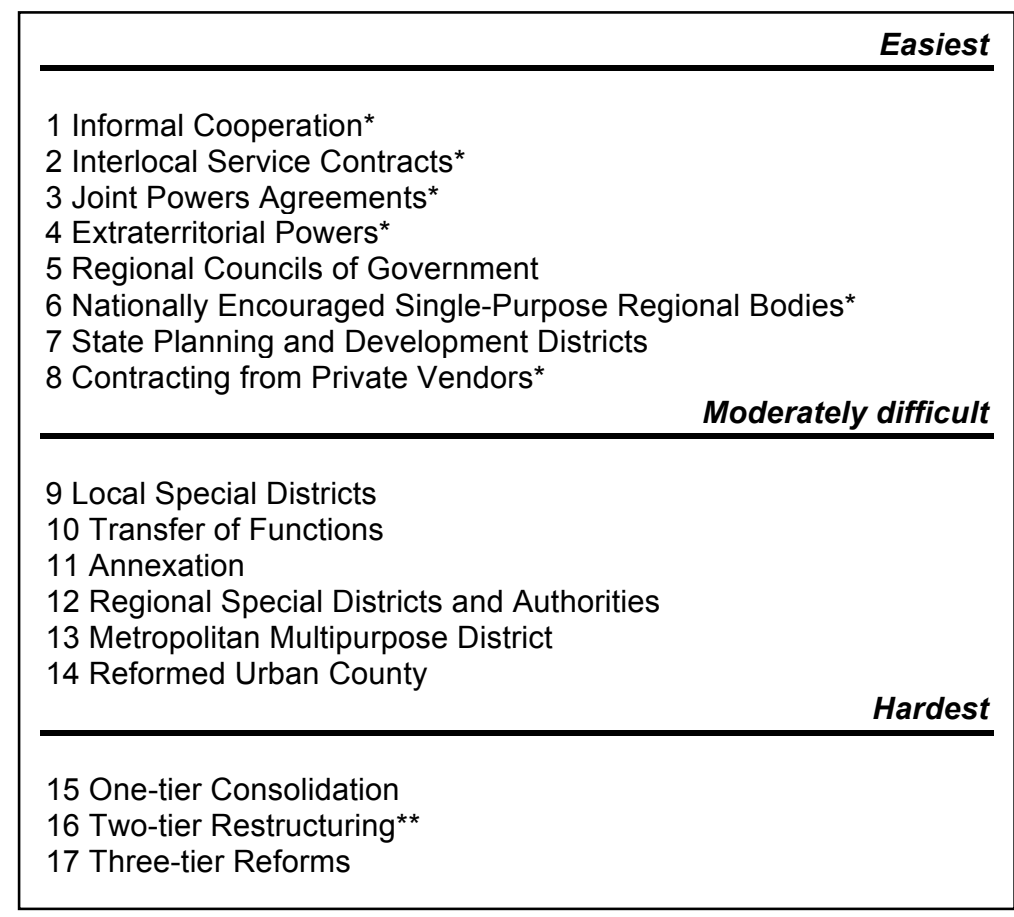

*Evidence of existence in the studied cities

**Partly applied in Curitiba outside of the time range studied in this dissertation.

Source: Adapted from Mitchell-Weaver et al. (2000) and the original by Walker (1987)

The three nations in this study represent highly decentralized countries (as compared to the regional trends), and have elected provincial and local governments that possess different levels of formal autonomy, as seen in Table VI-4. This structure reflects the broad intents for strengthening subnational governments, both politically and administratively during the last 
decades. This fits the recent decentralization trends in the region; according to Rojas (2005), local governments in Latin America are electing its leaders directly, much more frequently than ever before. In 1980 only three countries elected their mayors using the popular vote, while in 1997, 17 out of the 26 IADB members, used this election method (Rojas 2005). Historically centralized countries like Mexico, with strong presidents and highly centralized political parties face the challenge differently to those countries which have granted more extensive power to regional and local official, such as Brazil.

Nonetheless, when concentrating on that mid-tier level of government at the metropolitan scale, the three nations follow a very similar pattern that allow for the natural development of types $1,2,3$, and 8 of intergovernmental coordination. Types 4 and 6 were referred to frequently, but the incentives for their development are not that clear.

Table VI-4: Countries with High Political Decentralization in Latin America

\begin{tabular}{|c|c|c|c|}
\hline Country & $\begin{array}{c}\text { Constitutional } \\
\text { Structure }\end{array}$ & $\begin{array}{c}\text { State Selection of } \\
\text { Executive }\end{array}$ & $\begin{array}{l}\text { Local Selection of } \\
\text { Executive }\end{array}$ \\
\hline Argentina & Federal & $\begin{array}{c}\text { Elected since } \\
1983\end{array}$ & $\begin{array}{c}\text { Elected since } \\
1983\end{array}$ \\
\hline Brazil & Federal & $\begin{array}{c}\text { Elected since } \\
1982\end{array}$ & $\begin{array}{c}\text { Elected since } \\
1985\end{array}$ \\
\hline Colombia & Unitary & $\begin{array}{c}\text { Elected since } \\
1992\end{array}$ & $\begin{array}{c}\text { Elected since } \\
1988\end{array}$ \\
\hline Mexico & Federal & Elected & Elected \\
\hline Venezuela & Federal & $\begin{array}{c}\text { Elected since } \\
1989\end{array}$ & $\begin{array}{c}\text { Elected since } \\
1989\end{array}$ \\
\hline
\end{tabular}

The standard set-up now for Latin America, usually makes local governments subordinate to other levels of government, with less powers and responsibilities, while key decisions about powers and finances get taken at other levels (John 2006). However, local governments are usually stronger than any metropolitan arrangement; "In Brazil, the metropolitan scale simply does not exist as a government scale. By definition, the 
municipalities are much stronger than any possible metropolitan agency, period" ${ }^{\prime 151}$. Although this administrative strength usually is not accompanied by a similar financial decentralized strength, it does pose a threat to intermunicipal coordination; "when full autonomy was granted to municipalities in the 1980's, they became autonomous in administrative terms only [...] because most of the money continues to be controlled by the State. However, their municipal egos grew, thus generating obstacles to intermunicipal coordination" ${ }^{152}$. In fact, the intents to impose metropolitan scale arrangements are often met with suspicion from individual municipalities, who want to protect their turfs; "it is valuable that the National Government granted the AMVA with the authority to organize mass transport in the region, but this has increased the mistrust from the other municipalities" ${ }^{\text {"153 }}$.

In the three cases analyzed, there are various institutions from all levels of government competing for planning or implementation powers over metropolitan areas, which results in the need for negotiation mechanisms to be put in place. These negotiations usually end up in informal cooperation or joint power agreements. The most basic condition for this refers to the use of land in any inter-municipal transport project; "since all municipalities are autonomous, they have the right to decide over the use of land within their jurisdiction. This means neighbouring municipalities are destined to negotiate amongst them" ${ }^{154}$. Similarly, the interjections from national governments are not that rare; in Medellín, for instance, "we had the Minister of Transport ${ }^{155}$ here every 3 months, giving his opinions about the specific turns to be taken for certain routes" ${ }^{\text {"156. }}$. Moreover, as frequently cited in all three cities, these negotiations often extend to various departments within each single municipality, placing further layers of complexity. In Jalisco, the disconnection between key departments responsible for transport in the metropolitan areas of Guadalajara is evident:

"When the BRT line 2 was blocked, we lost our governability power, and thus we lost the opportunity to

\footnotetext{
151 Personal communication, Prof. Fabio Duarte, PUCPR, August 15, 2012.

152 Personal communication, Alfredo Hidalgo. Strategic Projects Director. Zapopan. February 5, 2013.

153 Personal communication, Alvaro Restrepo. Transport Specialist. Independent consultant October 13,2011

154 Personal communication, Liana Vallicelli. IPPUC. August 9, 2012.

155 Minister Andrés Uriel Gallego, under President Alvaro Uribe Vélez.

156 Personal communication, David Escobar, Chief of Staff to Mayor Sergio Fajardo. September 20, 2011.
} 
coordinate with other entities to push through additional crucial projects $[\ldots]$ my department does not decide which infrastructure is built. In fact, the Secretary for Public Works, Sergio Carmona, has never established a true dialogue with me. Thus, major decisions are taken by him, in conjunction with the Governor. It is different for other topics. Education, for instance, requests that certain school be built, and decides the topics to be taught there. We, on the contrary have no chance to decide how the transport infrastructure is built. The end customer [Department of Transport] is not consulted about its own topic" ${ }^{, 157}$.

Informal cooperation and joint power agreements are prompted by, and also affected by political dynamics. In Guadalajara, "the greatest advances have been non-binding voluntary agreements of collaboration between municipalities. Plus, our municipalities become irrelevant in transport

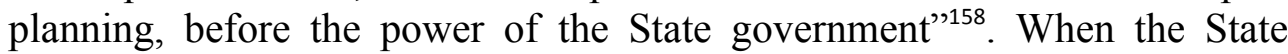
moves in, traditional party politics may frame the discussions; "the state defines the transport policies independently with each municipality. And this is framed by the political colour. When we were in power, the state government was from another political party, and we were not their favourite" ${ }^{\prime 59}$.

While there is not one single authority planning, building and implementing transport for the full metropolitan area in any of the studied cases, the case of Curitiba does produce tremendous lessons in this sense. To understand these arrangements, it is imperative to review the legislative developments setting the stage for intergovernmental cooperation in transport, in each city.

National legislation in Brazil, Colombia and Mexico timidly encourages the creation of single-purpose regional bodies, as implied in type 6 of intergovernmental coordination. In Mexico, article 115 of the National Constitution calls for joint metropolitan visions for inter-state bordering municipalities $^{160}$, "but fails to do the same for same-state municipalities"161.

\footnotetext{
157 Personal communication, Diego Monraz. Secretary of Transport. February 11, 2013.

158 Personal communication, Eugenio Arriaga. Former Director Non-Motorized Transport. Guadalajara. April 5, 2013.

159 Personal communication, Hugo Luna. Director. Movimiento Ciudadano Political Party. February 10,2013

${ }^{160}$ Constitutional article 115 (II. I, 1993). Retrieved from http://info4.juridicas.unam.mx/ijure/fed/9/116.htm?s Last accessed November 27, 2013.

161 Personal communication, prof. Oscar Castro. ITESO. February 7, 2013.
} 
The obvious consequence for this, is that incentives for metropolitan coordination are extremely weak; "this article [constitutional article 115] grants so much autonomy to municipalities, that there are no incentives for coordination. Nobody understands co-dependence here"162. In fact, if one sticks only to the Federal Constitution, as the supreme collection of national norms, the message is quite clear: "the Mexican Federal Constitution clearly states that coordination is not obligatory"163

The State also has the power to encourage the creation of single-purpose regional bodies, for a metropolitan area. Unfortunately, such has not been the case in Jalisco, where only until 2011, a law in that respect was passed. The 'Metropolitan Coordination Law' was approved by the State legislature in January 13, 2011, calling for the "creation of metropolitan coordination agreements amongst municipalities" 164 . It also mandates the establishment of a Metropolitan Coordination Council, a Metropolitan Planning Institute, and a Citizens Council. Notwithstanding this advance, at the time this dissertation was written, the Municipal Planning Institute, which would probably be a valuable addition to metropolitan coordination, was still not a reality; "there are more than 50 municipal planning institutes in the country, but many of them, although they were approved, still do not exist" ${ }^{\prime 65}$. The real type of intergovernmental coordination for Guadalajara can more clearly be related to informal cooperation: "although Vialidad [the State Transport Department] regulates transport, there are many other entities with specific responsibilities: SITEUR, OCOIT, CEIT, etc. We are far from having a single entity capable of administering transport for the metropolitan area holistically"166.

In Colombia, municipal autonomy is also emphasized in the National Constitution. Since "the Constitution says that autonomy of municipalities must be respected, if municipalities feel like they want to change the transport within their own borders, they will do it as they wish" ${ }^{\text {"167 }}$. Article 288 of the Constitution calls for the "competencies attributed to different territorial levels to be exercised according to the principles of coordination,

\footnotetext{
162 Personal communication, Tomás López. Founder of Guadalajara 2020. February11, 2013.

163 Personal communication, Mario Silva. Director. CEJ. February 6, 2013.

${ }^{164}$ Law 23486/LIX/11. Retrieved from http://www.jalisco.gob.mx/es/gobierno/normatividad/leyesestatales/855. Last accessed November 27, 2013

165 Personal communication, Carlos Romero. Director. Non-motorized mobility. OCOIT. February 5 , 2013.

166 Personal communication, José Comer. Director of Control. SITEUR. February 7, 2013.

167 Personal communication, Marta Suárez. Director for Mobility AMVA. September 20, 2011.
} 
concurrency, and subsidiarity"168, but at the same time, the spirit of the 1991 Constitution implied the need for strong metropolitan areas. Law 128 of $1994^{169}$ created and regulated these; "when metropolitan areas were created, the normative was not clear as to how municipalities would transfer authority to metropolitan areas [...] in Law 128, metropolitan areas are voluntary institutions" ${ }^{\text {170 }}$. However, a crucial turn for Medellín came when the National Government, via the Ministry of Transport, established the AMVA as the supreme mass transport authority for the full metropolitan area. Laws 105 of 1993 and 336 of 1996 had already suggested the need for greater coordination in transport services within single metropolitan areas, but it was not until the implementation of Resolution 1371 of $2008^{171}$, that the full influence area for the system was established in Medellín. This advance effectively corresponds to a type 6 intergovernmental coordination.

In Brazil, the National Constitution also highlights municipal autonomy; Article 30 of 1988 establishes municipal competencies in this respect ${ }^{172}$. Nevertheless, a crucial agreement ${ }^{173}$ signed in 1996 between the State and City governments, delegates in URBS ${ }^{174}$ transport planning and administration activities for the metropolitan region ${ }^{175}$. In practice, this means that URBS is allowed to control the Rede Integrada de Transporte for 13 of the 26 municipalities ${ }^{176}$ within the broader metropolitan area of

\footnotetext{
${ }^{168}$ Article 288 of the Colombian Constitution. Retrieved from

http://www.constitucioncolombia.com/titulo-11/capitulo-1/articulo-288. Last accessed November 27, 2013.

${ }^{169}$ Law 128 of 1994. Retrieved from http://www.elabedul.net/Documentos/Leyes/1994/Ley 128.pdf. Law 128 of 1994 was recently abrogated by Law 1625 of 2013. Retrieved from http://wsp.presidencia.gov.co/Normativa/Leyes/Documents/2013/LEY\%201625\%20DEL\%2029\%20 DE\%20ABRIL\%20DE\%202013.pdf

Both documents were last accessed on November 27, 2013.

170 Personal communication, Felipe Targa. Former Vice-Minister for Transport. October 1, 2012.

${ }^{171}$ Resolution 1371 of 2008 . Retrieved from https://www. mintransporte.gov.co/descargar.php?idFile=1080. Last accessed November 27, 2013.

${ }^{172}$ Article 30, 1988. National Constitution of Brazil. Retrieved from http://www.planalto.gov.br/ccivil 03/constituicao/constituicao.htm. Last accessed November 27, 2013.

${ }^{173}$ Agreement COMEC - URBS $\quad$ signed on 31/01/1996. Retrieved from

http://www.urbs.curitiba.pr.gov.br/uploads/legislacaoArquivo/7716cffa41695c58b47f7bf726f759c6de 684faf.pdf. Last accessed November 27, 2013.

174 The Curitiba Transport Agency (Urbanização de Curitiba).

175 Personal communication, Silvia dos Santos Ramos. URBS. August 19, 2012.

${ }^{176}$ Greater metropolitan Curitiba includes 26 municipalities. URBS administers metropolitan transport services for Curitiba, the nine municipalities that share a border with it, and also Bocaiuva do sul, Contenda, and Mandirituba.
} 
Curitiba; a crucial step allowing for types 4,6 , and 8 of intergovernmental coordination.

Nevertheless, rarely does one see that there are incentives for pushing a shared metropolitan vision. This shared vision would mean that some municipalities would have to sacrifice decisions that they perceive to be advantageous for their own municipal benefit. The most common result of this is a lack of coordination between the various municipal and state level departments, entities, and companies involved in transport services. Even in Curitiba, where IPPUC and URBS have been regarded as role model entities, a recent law ${ }^{177}$ has created municipal planning and transit departments for the city. Even though they have much smaller attributions, this institutional atomization might end up obstructing metropolitan coordination.

When metropolitan coordination has in fact taken place, enormous advances have been secured for transport sustainability in the studied cities. In regards to the huge success of the Macrobús Line 1, "the key was the political coordination: The municipality of Guadalajara, the State government, the Secretaries involved (transport, security, infrastructure), the university faculties involved [...] since all of them were collaborating, the project was finished in record time" ${ }^{178}$. Even for the golden decades of Curitiba, "the great innovations happened when URBS and IPPUC were the undisputed leaders for the metropolitan region. While URBS was the planning leader for all transport matters, IPPUC was the macro planner for the conurbation" $" 179$.

Nevertheless, as it seems to happen frequently in Latin America, metropolitan coordination arrangement can also be weakened at any time. Power asymmetries do not allow the centralization of power under one single leadership, when several leaders perceive they could increase their own control; "every single entity that has tried to reform this coordination

\footnotetext{
${ }^{177}$ Law N 13.877 of 2011 created the Secretaria Municipal de Planejamento e Gestão, SEPLAN and the Secretaria Municipal de Trânsito, SETRAN. Retrieved from https://www.leismunicipais.com.br/a/pr/c/curitiba/lei-ordinaria/2011/1387/13877/lei-ordinaria-n13877-2011-cria-a-secretaria-municipal-de-transito-setran-e-a-secretaria-municipal-de-planejamentoe-gestao-seplan-altera-dispositivos-das-leis-n-s-7671-de-10-de-junho-de-1991-e-4-369-de-25-desetembro-de-1972-revoga-a-lei-n-9-236-de-23-dezembro-de-1997-e-da-outras-providencias-2011-1124.html. Last accessed December 1, 2013.

178 Personal communication, José Comer. Director of Control. SITEUR. February 7, 2013.

179 Personal communication, Antonio Marchezetti. Logitrans, August 17, 2012.
} 
system, has always ended up being co-opted by power [...] both sides have

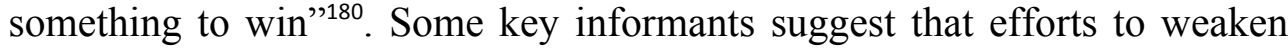
metropolitan coordination arrangements have succeeded in Curitiba; "[former Mayors] Beto Richa and Luciano Ducci have been able to disarticulate the last independent branches of urban planning, and transferred these under their own power [...] nothing but politicking""181.

In order to generate public policies at the local city level, governments often have to coordinate efforts with regional, national and/or international institutions. Thus, coordination capabilities turn out to be crucial attributes in designing and implementing metropolitan-wide policies for transport. Efforts at institutional coordination take the form of various arrangements with different results. There is no evidence to suggest that any of the studied cities has achieved any of the 'moderately difficult' or 'hardest' types of intergovernmental coordination during the last decade; however, the discussions with key informants seem to indicate that solid metropolitan coordination arrangements are one crucial variable facilitating a move towards higher levels of transport sustainability in the selected Latin American cities. Empirical outcome meets theoretical expectations, suggesting that building urban sustainability cannot just be a local technical dynamic; rather, it must be constructed and contested at various governance levels and through multiple political spaces. It is clear that most valuable coordination in the studied cities has been short-lived, fragile and highly politically motivated, tied to vote potential and permeated by electoral cycles.

\subsection{Central Theme for Hypothesis 3 - Previous Decisions}

Previous decisions have the power to frame the future possibilities for policymaking in urban transport. The previous stages of this research have confirmed the importance of this phenomenon, suggesting that current decisions in the studied cities have already been influenced by the inertia of policies, programmes, and infrastructure already put in place by previous decisions. In this section, a focus is placed on grasping the key decisions that seem to have prompted critical junctures for the sustainability of the

\footnotetext{
180 Personal communication, prof. Oscar Castro. ITESO. February 7, 2013.

181 Personal communication, Prof. Magnus de Mello. UFPR, August 18, 2012.
} 
transport systems in Curitiba, Guadalajara and Medellín, as drawn from the interviews.

Technological advances play a role in influencing transport sustainability. New transport technologies have the potential to promote cleaner, lower carbon transport systems. In evaluating the potential of strategic niche management as a transition tool, Kemp et al. (1998) identify various barriers that impede a shift towards more sustainable transport technologies; "creating path dependencies too early by focusing on a specific technology may lead to a mismatch between emerging application conditions and the chosen new technology" (Kemp et al. 1998, p.187).

History also matters. More specifically, urban history matters, when studying the sustainability of urban transport. As Pflieger et al. (2009) explain when studying urban transport in Europe, there are some 'decisive factors' which have allowed some cities to adopt a different transport policy, while dozens of other cities are stuck in car-dependent models. This section concentrates on three elements that may be considered when analyzing the trajectories followed by transport policies: reproduction, innovation and contingency.

Typical trajectories of reproduction in the long term have been identified in the three cities to varying degrees. While Guadalajara had the chance to reverse the trends in terms of transport-related decisions during the initial phase of the Macrobús, its full blown political burial halted any possible series of successive events that could have been triggered by that highly specific and contingent policy choice. Some years after the BRT fiasco, "the discussion at the political level continues to be active, as to whether a metro system is more convenient than a BRT; yet, at the end all of these politicians are making sure that urban highway construction is not stopped"182. The system follows a regular, continues, and cumulative nature, by which "the mobility budget is mostly spent in infrastructure for the car [...] which brings more cars, and thus, you end up having to spend more money in that" ${ }^{\prime 183}$.

The case of Medellín is an extraordinary one; although several contingent transport decisions have been powerful enough to trigger a break from the

\footnotetext{
182 Personal communication, Etienne von Bertrab. Founder Ciudad para Todos. February 4, 2013.

183 Personal communication, Carlos Romero. Director. Non-motorized mobility. OCOIT. February 5, 2013.
} 
traditional trajectory, this has not happened yet. For example, the construction of the only metro system in existence in that country, continues to be an unprecedented decision for Medellín. Although a relatively small system, it has been a powerful institution promoting its own agenda. Nevertheless, sustainable mobility has only started to permeate local political agendas until recently, and thus, traditional policies to serve the car have monopolized transport policy for decades. The Metro has also suffered from the power of these short-sighted politicians: "we made a proposal to the municipal government to remove two car lanes in the 80th Avenue, in the context of the project for the construction of a tramway there. The answer was an emphatic no; on the contrary, they made it clear they need more car lanes there"184. The reproduction of a car-centred system has its own inertia; "our people simply pay homage to the car here" 185 .

Curitiba, on the other hand, has seen the reproduction of a contingent choice, leading to higher levels of transport sustainability. The bet on the Rede Integrada de Transporte and the BRT system has undoubtedly given Curitiba several decades of above average transport sustainability. Nevertheless, the conditions sparking these developments must be understood from their full historical perspective. According to historian Magnus de Mello, we have to look back to the 19th century:

"This city has always been developed around a founding myth of technical progress as the main cultural thread of the city, fuelled by the strong immigrant groups from Germany, Italy, Poland, Ukraine that compose the identity of the city [...] there has always been an interest for producing plans and high level engineering as a solution for problems. When the military came to power, they also believed in technical solutions. When thinking about the possibility of transforming a city via planning, they choose the only city that had the correct characteristics: ready-made plans, the right size. It was the perfect pilot project"186.

Dr. Eduardo Vasconcellos also refers to the particularities of the city and its people; "Curitiba was the only city that did not fit the historical urban development model in Brazil. The stereotypical citizen of Curitiba, values

\footnotetext{
184 Personal communication, María Elena Restrepo. Planning Director. Metro. September 15, 2011. 185 Personal communication, Rafael Nanclares. Transport Secretary. City of Medellín. October 25, 2011.

186 Personal communication, Prof. Magnus de Mello. UFPR, August 18, 2012.
} 
planning, and long term visions" ${ }^{187}$.However, more recent events have started to negatively affect the inertia of this innovation path dependency. The role of the federal governments since the re-establishment of democracy has been crucial due to the incentives triggered; "all federal governments until now have supported the "car is king model""188. Moreover, the ways in which dynamic political agendas have challenged the previous technical monopoly of the IPPUS-URBS duo, has curtailed their strength to maintain the inertia; 'since the late 1990's, the IPPUC is having to react to the challenges posed by the car, and planning for the car, thus creating more transport problems [...] due to the car" ${ }^{\text {"189 }}$.

The creation of new urban artefacts in some of the studied cities has the power to trigger a break away from earlier transport trajectories. Even though the BRT based transport system has been active in Curitiba for more than three decades, the eternal opposition from metro system supporters has had an influence in the transport mix; "think about there the inflection points of the bus system in Curitiba are [...] the great innovations have always come at the same time during which those promoting the metro have been close to succeeding [...] "since the 1960's, and every four years (beginning approximately 6 months before the elections), the metro discussion revives" ${ }^{\prime 190}$.

However, a contingent decision made during the 1970's to bet on a busbased transport system does not guarantee that the growing opportunity costs of building a metro, will make that an unfeasible option at some point (especially if it is highly profitable politically); "since the 1970's we were not thinking about the metro, we were centred on expanding and improving the bus system, in which so much time and money had already been

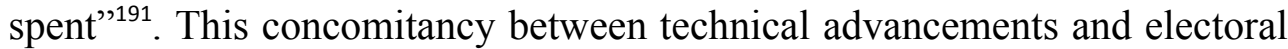
dynamics is a vital signature of urban politics in Latin America; "if governments do not innovate, they can quickly lose their validity. One-sizefits-all transport policies are easy because they follow what has been proposed before, but they do not lead to sustainability"192.

\footnotetext{
187 Personal communication, Dr. Eduardo Vasconcellos, ANTP, August 14, 2012.

188 Personal communication, Dr. Eduardo Vasconcellos, ANTP, August 14, 2012.

189 Personal communication, prof. Fabio Scatolin, advisor to Mayor Fruet August 6, 2012.

190 Personal communication, Prof. Fabio Duarte, PUCPR, August 15, 2012.

191 Personal communication, Julio de Almeida. IPPUC planner. August 8, 2012.

192 Personal communication, Felipe Targa. Former Vice-Minister for Transport. October 1, 2012.
} 
Contingency has framed the development of the award-winning Curitiba model. It is hard to predict the specific developments of the Curitiba transport model, from the general laws on the transformation of societies in Latin America. The conjunction between the military dictatorship's choice of Curitiba for the development of a pilot urban design plan, and the invention of the BRT system, led to the specific chain reaction that decades later still places Curitiba at the fore-front of transport sustainability in the region. By the time the dictatorship came to power in Brazil, Curitiba already had experience with master planning; in fact, "the first official director plan for the city was drawn in 1943, with a radial structure, leading towards the centre"193. Furthermore, when the time came to think about an innovative bus-based solution, technical capabilities were already in place; "one must remember that Volvo had entered Brazil since 1934, and the only Volvo factory is in Curitiba. From this alliance between Volvo and the municipality, is that the famous articulated buses are born" ${ }^{\text {"194 }}$.

On the other hand, some other contingent events have triggered immense challenges to the status quo in these three cities. In Curitiba, for instance, the role of land speculators has critically hurt the accessibility to the main bus corridors. Since mostly expensive housing has been built in the high density destined lands next to the corridors, this means that real users of the BRT system travel very long distances; most of those living close to the BRT stations own and drive their cars: "after certain interest groups managed to take over the lands next to the main transport axes, the municipality has not been able to implement recuperation instruments. It is too costly financially and politically now"195. In Guadalajara, the sudden closure of a road to convert it into an urban highway triggered a series of events that are still influencing transport policy: "although sustainable mobility was already an active discourse, not much action had been done in that respect [...] until the sudden closure of the pedestrian crossings along the López Mateos avenue, to convert it into a de facto urban highway. That was the detonating event that generated the organized reaction from the citizenship" "196. In Medellín, the invention of the Metrocable, as a fully integrated cable-car to the metro system has triggered the interest from global experts, as a replicable solution in many countries. As such, the

\footnotetext{
193 Personal communication, Liana Vallicelli, IPPUC, August 9, 2012.

194 Personal communication, transport specialist J Pedro Correa, Volvo, August 10, 2012.

195 Personal communication, Prof. Giselene Pereira UFPR, August 12, 2012.

196 Personal communication, Héctor Castañón. Director. Plan V Vecinos en Red. February 6, 2013.
} 
discussions on sustainable mobility have gained strength in a city that otherwise has already had positive structural elements to promote sustainable transport. Certain subsequent events seem to have profited from this contingent decision.

Theory posits that present urban policies are predetermined by previous decisions, which implies high reversal costs for making major changes to the system. In the context of urban transport, path dependence means that there are economies from staying in the same course, and high transaction costs often rule out a complete change in policies of transport. In strict terms, one cannot talk of path dependencies in relation to the transport system of Guadalajara, since the origins of the current car-dependent pattern is non-contingent and simply reflect the dynamics of modernist era urban planning, and the consequential inertia caused by a car-based development model. Nevertheless, the case of Curitiba does imply the existence of an innovation path dependency, rooted on the BRT based Rede Integrada de Transporte, and its reproduction. Whether more recent multilevel decisions affecting transport can continue to weaken this trajectory for urban transport, rests to be seen. Finally, the case of Medellín offers a variety of contingent events that still have not developed the inertia to reproduce into greater transport sustainability for the city. The creation of the world's first cable-car fully integrated to a metro system, the implementation of the first public bicycle sharing system in the country, the approval of a tramway line to complement the current metro system, and even -going back to the 1990 's - the inauguration of the only metro system in the country, all seem to be crucial events for the local transport policy. Nevertheless, the broad strategy continues to be one advocating for the private automobile. Whether this innovative strength will actually morph into reproduction of a series of events increasing the sustainability level of the city rests to be seen.

\subsection{Conclusion}

This section presented an assessment of the specific institutional and political conditions related to transport sustainability in Curitiba, Guadalajara, and Medellín. The hypotheses refined in Chapter V were contrasted qualitatively with the levels of engagement towards transport sustainability in each city. The cross-case explanations generated indicate the factors that determine empirical variations in transport sustainability across the studied cities. 
When evaluating the extent to which political factors and financial factors can explain the current levels of transport sustainability, the evidence strongly implies that political factors are essential. The specific local political agenda, the acting strategies of the key actors setting the agendas, and the potential for votes that various actors see in alternative decisions greatly influence the current mix of transport policies in these cities. Moreover, the short electoral cycles and high incentives for participation in future elections explain the 'rational' decision making model prevailing across cases.

Even though funds are necessary for implementing every single transport policy, the evidence from the cross-case analysis insinuates that the availability of these has not been the determinant factor for triggering reproduction of transport trajectories. Hence, the availability of funds is found to be a necessary but not sufficient condition for the promotion of higher levels of transport sustainability in the studied cities.

Building on this conclusion, hypothesis one has been reworked to:

H1. Political conditions are more crucial than financial conditions in increasing levels of urban transport sustainability.

The diversity in outcomes on transport sustainability for the studied cities can partly be explained by the various metropolitan coordination arrangements, which have been in place at different times. Coordination capabilities with other local, regional, and national institutions are a crucial attribute in successfully implementing metropolitan-wide policies for transport. Although no evidence to suggest that any of the studied cities has achieved any of the 'moderately difficult' or 'hardest' types of intergovernmental coordination during the last decade is found, there are significant indications from the discussions with the key informants, that solid metropolitan coordination arrangements are one of the most crucial variables facilitating higher levels of transport sustainability in Latin American cities.

Building on this conclusion, hypothesis two has been reworked to:

H2. Better metropolitan governance arrangements result in higher levels of sustainability in transport. 
The explanatory power of previous decisions proves to be determinant in explaining the current transport mix for the studied cities. Contingent events have set into motion event chains with deterministic properties on the transport system of Curitiba; the city still profits from the inertia of decades of reproduction. Although the situation for Guadalajara and Medellín does not clearly exhibit positive path dependent characteristics in relation to transport sustainability, several particular contingent events merit detailed analysis. Furthermore, the phenomenon of the car as a broadly accepted development model continues to reproduce across the studied cities. Whether crucial technological or institutional innovations in these cities generate the conditions for a trajectory change remains to be seen.

Building on this conclusion, hypothesis three has been reworked to:

H3. Previously taken decisions determine the implementation of key urban transport public policies. 


\section{Chapter VII}

\section{A Convergence to Transport Sustainability in Latin American Cities}

"The key in science is not to repeat that we know what works and what does not work. The key is to revise hypotheses and create new realities" -Gunter Pauli

\subsection{Introduction}

This chapter presents an assessment of various factors not originally included in the guiding assumptions of this research. Although not considered at the start, these were often cited by key experts interviewed, as potentially intervening to transport sustainability in Curitiba, Guadalajara, and Medellín. These factors are qualitatively contrasted across the studied cites, exploring the extent to which they determine variations in transport sustainability outcomes. The section follows the methodology set out in Chapter III.

First, the strategic premises presented in Chapter VI are offered as the groundwork over which these intervening factors seemingly operate. Then, a cross-case comparison contributes to theory refinement, and is accompanied by a final categorization for all factors assessed throughout this dissertation. Lastly, the premises generated from the qualitative analyses are compiled as a theoretical contribution to the way in which political factors determine transport sustainability outcomes in Latin American cities.

\subsection{Representation of Dependent and Explanatory Variables}

The dependent variable is given a consistent treatment to that of Chapter VI. Sustainability of urban transport continues to be the foremost analytical objective of this section. The initial guiding assumptions offered in Chapter III, are now replaced by the strategic premises presented in Chapter VI as the central explanatory variables to the variations in transport sustainability outcomes described using the GTI in Chapter V. 
Furthermore, the inductive nature of this study implies the possibility of additional explanatory variables to arise during all stages of the process. As follows, this section looks particularly at the explanatory potential of three additional variables uncovered during the research (see Table VII-1). The intervening nature of these further themes is explored cross-comparatively, emphasizing the potential explanatory role of local contexts. Current theory posits that aside from policy quality, successful low carbon transport strategies also depend highly on context: "the literature strongly reflects on how context can determine policy success in one case and failure in another" (Figueroa \& Ribeiro 2013, p.8).

The analysis presented in this section is based on the gathered data, which is supported by the strategic premises previously offered in this dissertation, and the original guiding concepts derived from the sustainable mobility paradigm and the tenets of metropolitan governance. On this basis, two additional assumptions are presented tentatively:

H4. When interest groups organize sufficiently, they are capable of steering key urban transport policy decisions.

H5. Specific cultural compositions facilitate advances towards greater urban transport sustainability.

Even though neither of these were originally considered within the guiding assumptions of this research project, the interactions with the key informants opened he possibility for their inclusion. It must be clarified that one of the secondary postulates from original explanatory variable \#3, did insinuate the role of organized interest groups. As such, these assumptions target the role of the civil society, corporate interests, and other organized groups in influencing the level of transport sustainability, as well as the role of particular cultural compositions in facilitating higher transport sustainability. 


\begin{tabular}{|c|c|c|}
\hline $\begin{array}{l}\text { Variables to be } \\
\text { explored }\end{array}$ & $\begin{array}{c}\text { Postulates from } \\
\text { Original Explanatory } \\
\text { Variables }\end{array}$ & Natural Unit Examples \\
\hline $\begin{array}{l}\text { 6. Civil Society } \\
\text { 7. Corporate } \\
\text { Interests } \\
\text { 8. Cultural } \\
\text { Identity }\end{array}$ & $\begin{array}{l}\# 3 d \text { - Strength of } \\
\text { organized interest } \\
\text { groups } \\
\text { *Additional postulate: } \\
\text {-The role of culture }\end{array}$ & $\begin{array}{l}\text { - } \text { "Although it seems } \\
\text { like that project was } \\
\text { stopped by the } \\
\text { citizens, at the end } \\
\text { it was the } \\
\text { opposition party } \\
\text { who killed it". Key } \\
\text { informant \#29 } \\
\text { "We have not seen } \\
\text { organized citizens } \\
\text { pressuring for a } \\
\text { change on this } \\
\text { specific topic". Key } \\
\text { informant \#44 } \\
\text { "Our people are } \\
\text { convinced that their } \\
\text { quality of life is } \\
\text { directly linked to } \\
\text { their level of } \\
\text { consumption". Key } \\
\text { informant \#13 }\end{array}$ \\
\hline
\end{tabular}

\subsection{Cross-Case Comparison}

The assessment of all central themes for each hypothesis in Chapter VI generated descriptions for the conditions determining the variation in transport sustainability outcomes in the three studied cities (see Figure VII1). Building on these links, propositions about the validity of the strategic premises -against the backdrop of additional context-based variables- are offered. 
Figure VII-1: Conditions determining Transport Sustainability Outcomes

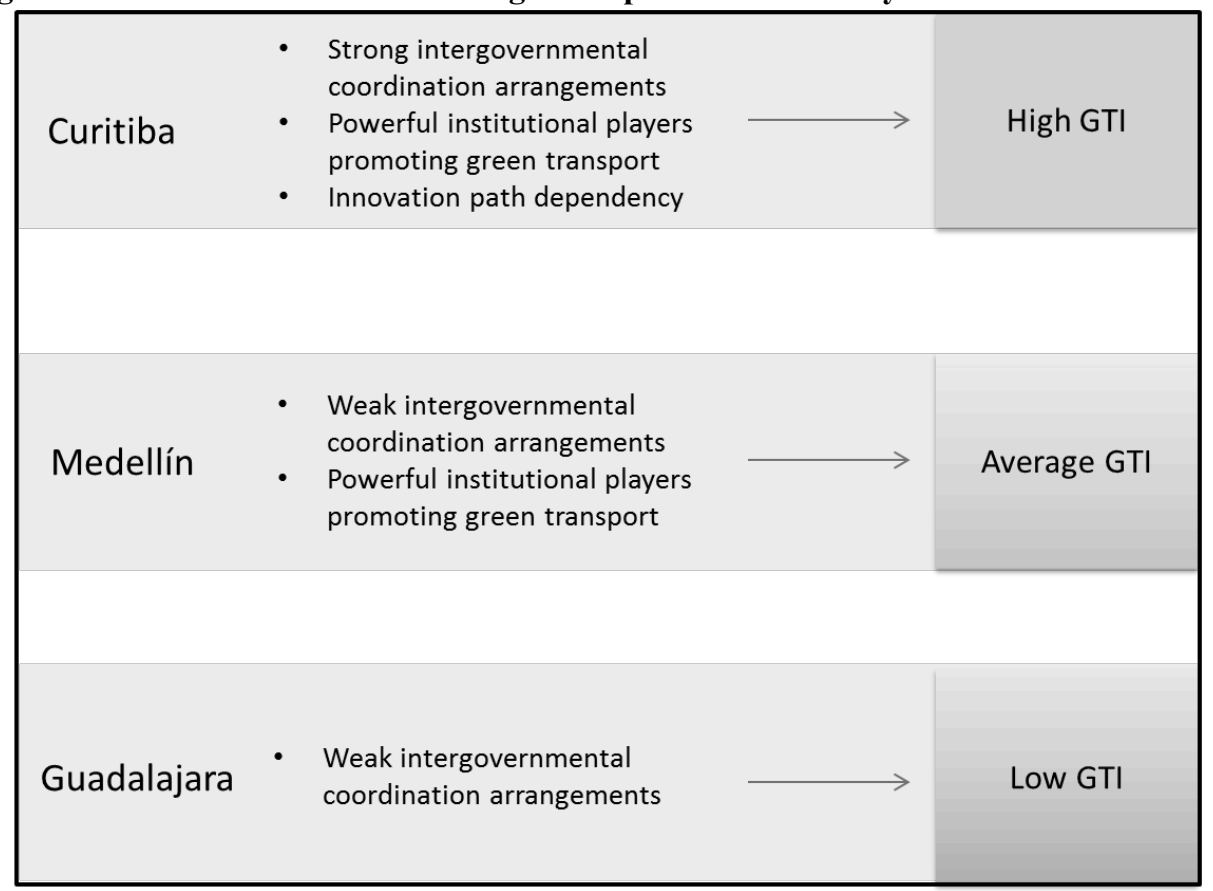

Source: own elaboration

\subsection{Civil Society}

When referring to the "civil society", a focus is placed on grasping the extent to which social pressure seems to have promoted sustainable urban transport policies, as drawn from the interviews. This section targets the direct contributions from organized citizen groups intending to influence policymaking in the transport arena at the metropolitan scale, in what would reflect Arnstein's (1969) ladder top three rungs of citizen participation; those presented as "degrees of citizen power". Conversely, the more formal participation path of popular elections is not considered as a form of civil society pressure.

Even though policy making attributions are generally the prerogative of public servants and elected politicians, citizens could also influence specific 
decisions in a number of ways. Pushing certain issues to the policymakers' agendas and holding them accountable for their actions are two of the key alternatives (Roberts 2004; Cairncross et al. 1994). However, both of these possibilities could work both ways; if citizens are not active enough, it rests to be analyzed to what extent policymakers and politicians could read that as an indicator of low civil society disagreement with the current state of affairs.

Such seems to have been the case for Curitiba and Medellín during the last decade, with very few civil society groups actively organized to promote transport sustainability. Few exceptions can be found, although most of them sprang at the end of the decade, with CicloIguaçu and other groups around the Bicicletaria Cultural in Curitiba, and La Ciudad Verde, Siclas and Túnel Verde in Medellín being the foremost examples; in Curitiba, "it has been a continuous process, by which the citizens have understood that they need to mobilize systematically, to push politicians to include [our view of sustainable mobility] in their agenda [...] if citizens don't mobilize, politicians have no incentive to do it"197. In Medellín, "there was simply no organized pressure from the civil society to pursue sustainable mobility policies" $"$.198.

The possibility to hold public servants accountable is equally interesting. Elected politicians offer a set of proposals during their campaigns, which later if elected, should come to fruition, while appointed functionaries indirectly represent the voters; thus, defending the collective wellbeing over the individual one (Przeworski et al. 1999). Both groups are therefore ultimately accountable to the citizens. However, without proper organization from civil society groups, actual citizen power stays at degrees of tokenism such as basic informing and consultation (Arnstein 1969). Furthermore, without sufficient access to valid data, it is harder to guarantee affirmative citizen participation. Some valuable initiatives in Guadalajara and Medellín point in this direction, through independent observatories collecting primary data to supervise the work of the local government. Jalisco Cómo Vamos and Medellín Cómo Vamos are valuable initiatives in this sense, because they "set up their own indicators, collect their own data [...] to see the clear picture $[. .$.$] it is hard to supervise the work of government if you use its$

197 Personal communication, journalist Alexandre Costa Nascimento, Ir e Vir de Bike, August 2, 2012.

198 Personal communication, David Escobar, Chief of Staff to Mayor Sergio Fajardo. September 20, 2011. 
own data" ${ }^{199}$. Nevertheless, they only have a voice, and their suggestions are fully optional for any public servant to take or even listen.

Proactive organized participation from the citizenship is not as common as reactive participation. While citizen groups have only modestly intervened in transport policy decisions in Curitiba and Medellín, the case of Guadalajara has been completely different: "the disastrous car-centred policies in the city are directly responsible for the construction of a citizens movement dedicated to promoting more sustainable transport policies"200. This broad amalgamation of groups includes representatives from various social and economic backgrounds, and has the power to massively mobilize people and the media. Seemingly, a crucial moment for the consolidation of a citizens movement in favour of sustainable mobility came with the BRT line 2 fiasco: "when the citizens movement joined the business federations to reject the line 2 fiasco it was a very powerful message [...] they went out together for a press conference [...] although they had different incentives according to their interests" ${ }^{201}$. Nevertheless, this decision was not reversed, as it had already been announced by the three PRIista mayors Aristóteles Sandoval (Guadalajara), Héctor Vielma (Zapopan) and Miguel Castro (Tlaquepaque).

Although public decisions regarding the BRT line 2 were not changed by the active participation of citizens, the case of the Via Express offers an alternative scenario. When the project for this elevated urban highway was presented by the Jalisco State Government, the full range of citizen groups already active in the city, once again joined the powerful business federations to reject the project; "they went in together again, because they

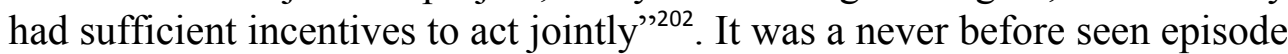
in Guadalajara: "the classiest of the corporate sector, with the most alternative of the activist stratum" ${ }^{203}$. Whether the cancellation of this project was, in fact partly due to the push by the civil society, remains to be tested. Nevertheless, it is clear that "the terrible transport decisions of the recent years have contributed to the organization of civil society. At least

199 Personal communication, Carlos Romero. Director. Non-motorized mobility. OCOIT. February 5, 2013.

200 Personal communication, Alfredo Hidalgo. Strategic Projects Director. Zapopan. February 5, 2013.

201 Personal communication, Mario Silva. Director. CEJ. February 6, 2013.

202 Personal communication, Héctor Castañón. Director. Plan V Vecinos en Red. February 6, 2013.

203 Personal communication, Alfredo Hidalgo. Strategic Projects Director. Zapopan. February 5, 2013. 
now they [public servants] have to socialize their decisions, and have to face fierce criticism"204.

Some decisions have transformed urban paradigms, triggering a spontaneous protection by the civil society. The EnCicla shared bicycle scheme in Medellín moved from being an unfunded, weakly supported project by the local government in 2011, to the role-model institution for all bicycle promotion citizen groups in the city in 2013. The 'Curitiba sustainability brand' reflecting the successes of the late twentieth century, is a broadly shared value of the city dwellers. In Guadalajara, the Sunday 'open streets' event (Via RecreActiva) became the primary urban entertainment venue for tapatios. It has evolved to cover 64 kilometres of urban corridors and more than 245.000 attendants each weekend ${ }^{205}$. Closing the streets completely to car traffic was unthinkable before, "it was hard to establish, but today, the Vía RecreActiva is a social structural column for this city $[\ldots]$ it is untouchable by politicians, because citizens have made it theirs, and would react massively if it was threatened"206.

Influencing decisions in the long run is the true challenge, if citizens aim at impacting transport sustainability levels in their cities. Piecemeal contributions to the discussions are valuable, but far-seeing and sustained actions by citizens are preferred in order to keep the issue at the top of the agenda; "although the civil society groups have managed to generate high media coverage, and have started to influence the policymakers decisions, it is still not enough" 207 .

In the context of urban transport decisions for the studied cities, the actions by the civil society do not seem to be a top condition for advancing sustainability. Even though reactive events to certain public decisions have featured highly in Guadalajara, no major citizen movements have been found to be responsible for significant policy decisions in any of the studied cities. From the viewpoint of Arnstein's (1969) ladder of citizen participation, most citizen initiatives stay within the range of manipulation

\footnotetext{
204 Personal communication, Eugenio Arriaga. Former Director Non-Motorized Transport. Guadalajara. April 5, 2013.

205 As recorded by 8-80 cities. Last accessed on December 3, 2013:

206 Personal communication, Carlos Romero. Director. Non-motorized mobility. OCOIT. February 5, 2013.

207 Personal communication, Maria de la Torre. Urban planner with the Zapopan government. Abril 20, 2013.
} 
to placation, when faced to powerful institutional actors such as those described above. Steering the urban transport mix of each city continues to be the full prerogative of elected politicians and appointed functionaries; "at the end it is not the responsibility of the civil society to guarantee more sustainable urban policies" ${ }^{208}$.

\subsection{Corporate Interests}

When referring to the "corporate interests", a focus is placed on grasping the extent to which specific interests from enterprises and business associations seem to have promoted sustainable urban transport policies, as drawn from the interviews. The possibility that these corporate interests have negatively influenced the sustainability of urban transport is also explored crosscomparatively.

Traditional business leaders in Latin America are often influenced by the corporate social responsibility premise of "giving back" to the community. This frequently evolves into activities outside of the strategic scope of the enterprise. In Guadalajara, the highly visible business federation Guadalajara 2020 (GDL 2020), has made urban sustainability as one of its focus areas; "for the last 10 years, we have dedicated as many hours as we have had available to improving the planning of this city" ${ }^{209}$. Their involvement is directly responsible for the continuous visits of globally renowned urban sustainability experts such as Enrique Peñalosa and Alfonso Vegara, which to a certain extent impacts the political agenda, "Peñalosa came and started changing minds about sustainable mobility in several key group [...] his visits have only one explanation: the intervention of GDL 2020" 210 .

The fact that they also have a direct line to policymakers is valuable when intending to impact policies. During the Via Express confrontations, "they were able to line up COPARMEX Jalisco ${ }^{211}$ and the $C C I J^{212}$ against the

\footnotetext{
208 Personal communication, Eugenio Arriaga. Former Director Non-Motorized Transport. Guadalajara. April 5, 2013.

209 Personal communication, Tomás López. Guadalajara 2020. February 11, 2013.

210 Personal communication, Carlos Romero. Director. Non-motorized mobility. OCOIT. February 5, 2013.

211 COPARMEX - El Centro Empresarial de Jalisco is the confederation of business federations of the State.
} 
project as well"213. Obviously, the fact that all these business associations were against the development of a massive infrastructure project like the Via Express raises doubts. Their specific corporate interests did not alienate with the possibilities offered by the project structure; "they originally were not against the Via Express, because it of course meant big business. However, when they heard that the contractors had already been picked by hand, and would come from the capital, they turned against the project [...] the contracts would not stay here" ${ }^{214}$.

Selling their products to maximize their profit is another avenue through which corporate interests indirectly influence transport sustainability. This applies to the car industry in the same way as it applies to the motorcycle, bus, and train industry. As acknowledged in Chapter V, nationally supported development models based on the car are backed by the job creation rationale of the broad car-manufacturing industry. The case of the motorcycle is a similar one, with stark support from various federal governments across the regions. In Brazil, this has allowed the creation of a massive national motorcycle industry:

"The great decision that pushed the motorcycle industry was the setting up of a Duty Free Zone in Manaus in 1993-1994. From that moment on the national [motorcycle] industry was developed, receiving public subsidies for both production and purchase [...] today, you can get a motorcycle by paying only 100 USD per month [...] and more than half of the homes in Brazil now have a car or a motorcycle",215.

Notwithstanding the indirect influence that corporate interests might have on an urban transport mix, their greatest influence might come from directly intervening in the policy making process. In Curitiba, "business men have always known that entering politics is a necessary avenue to maintain their power. In the transport sector, they have started going into politics during the mid-1980s" ${ }^{216}$. The car industry has also pursued these positions

$212 \mathrm{CCIJ}$ - Consejo de Cámaras Industriales de Jalisco, is the association of the sectoral commerce chambers.

213 Personal communication, Mario Silva. Director. CEJ. February 6, 2013.

214 Ibid.

215 Personal communication, Dr. Eduardo Vasconcellos, ANTP, August 14, 2012.

216 Personal communication, prof. Mario Procopiuck PUCPR, August 17, 2012. 
strategically, and now "the industry is so powerful that they have secured vast production subsidies. The government says that this means jobs" ${ }^{217}$. In Guadalajara, the transport sector is so powerful that their participation is said to have obstructed the construction of the BRT line 2; "traditional bus enterprises under Jorge Higareda Magaña and Clodomiro Martínez strongly opposed the construction of the BRT, although the Alianza de Camioneros de Jalisco won the tender to operate the line $1^{" 218}$. In Medellín, the busbased system continues to be mostly private with a breadth of independent companies owning buses and routes; "this means that the drivers have an incentive to move as many passengers as possible, because they get paid by the number of passengers transported"219. On the other hand, the Metro actively lobbies against the policymakers to protect their own business: "we are mandated, as a commercial and industrial State Enterprise, to be profitable. We can't lose our social objective, but we have to balance out these two mandates" 220 . This is the reason why they have been able to modify routes for future city projects, for instance; "the Metro has to protect its business, that is why they were not supportive of Metroplús for a while [...] it was considered as competition if it was to go all the way until Industriales station. Now, when it was transformed to get to Aguacatala, they gave it their approval",221.

Direct influences to transport sustainability might also come from corporate sectors not related to transport. In Medellín and Curitiba, the role of the construction sector has also been significant. Actively advocating for greater construction densities and occupational indices in some of the higher areas of the valley (as opposed to the flat areas next to the main Metro corridor), $C A M A C O L$ and the $S A I$ have negatively influenced the development of a more balanced urban transport system in Medellín. On the other hand, real estate speculators have disturbed the organic organization of Curitiba around its mass transport axes; "when the main corridors where designed, the speculators immediately moved in to buy the bordering areas [...] expensive housing was built along the main public transport corridors,

217 Personal communication, Leny Mary de Goes. Secretaria de Meio Ambiente de Curitiba. August 9, 2012 .

218 Personal communication, Mario Silva. Director. CEJ. February 6, 2013.

219 Personal communication, Alvaro Restrepo. Transport Specialist. Independent consultant October 13,2011

220 Personal communication, Ramiro Márquez. CEO. Medellín Metro September 15, 2011.

221 Personal communication, Juan Pablo Ospina. Transport Specialist. BIO 2030. October 14, 2011. 
where rich people drive their cars [...] and now you have public transport users that live 70 kilometres away from their destinations"222.

In the context of urban transport decisions for the studied cities, corporate interests and their strategic actions do not seem to be a top condition for advancing sustainability. More often than not, their strategic profit maximizing actions end up negatively influencing transport sustainability, as portrayed by the actions of the car and motorcycle industries, and their negative externalities. However, their contribution is not consistent enough in any direction to argue that they have been irrefutable players in determining the transport sustainability outcome in any of the studied cities.

\subsection{Cultural Identity}

When referring to the "cultural identity", a focus is placed on grasping the extent to which particular local cultural structures seem to have facilitated or curtailed advances towards more sustainable urban transport, as drawn from the interviews. Broader social constructs and historical conditions are also considered as possible intervening factors.

The answer to why transport sustainability has not been a priority for many governments in Latin America might be simpler than previously proposed. In this region, elites have the capacity to influence various spheres of daily life (Higley \& Gunther 1992). Furthermore, the remaining strata of society usually look up to them, and take to imitation, in order to provide a measure of their own societal progress; "it is simple, people want cars; when they buy their car, they stick to their car, period"223. Such symbolic power is even stronger in such an unequal region as Latin America, as it reflects ideas of "liberation, empowerment and social inclusion, while inability to drive may lead to feelings of social exclusion and disempowerment in cultures of automobility" (Sheller 2004, p.230).

The actions of elites relate to urban transport in different ways. In Brazil, "the elites want to behave as if they were people from the United States; living in the United States [...] they want this to be like the United States" ${ }^{224}$. As such, certain transport modes are broadly preferred over

\footnotetext{
222 Personal communication, Antonio Marchezetti. Logitrans, August 17, 2012.

223 Personal communication, Prof. Magnus de Mello. UFPR, August 18, 2012.

224 Personal communication, Dr. Eduardo Vasconcellos, ANTP, August 14, 2012.
} 
others: "the bicycle was never an option here. Our culture says that it is to be used only for leisure or by the poor people [...] the bus is also considered to be for the poor only"225. It is not too farfetched to think that the average citizen in this region would prefer to move around by car, if they see this as a vital socioeconomic goal, in their quest to ascend socially.

Similarly, only certain sources of knowledge are accepted as valid when imitating mobility models that certain groups deem to be desirable (Urry 2004). Local experts are often regarded as sufficient, and perspectives that are not mainstream enough can be blocked; "people will tell you: "what do you mean expert? We already know everything here; we can plan our city ourselves" "226. If the role model of "progress" is found in the average United States city, then people will candidly support proposals for more US-style highways, rather than proposals for collective or non-motorized modes; "you can hear politicians here telling you [the technical planner] 'don't give us projects from other cities in Latin America, show us advanced projects from the United States",227. Even though an average citizen might not have all the information available, this cultural construction, evident to every person from the very same moment of birth, seemingly already generates behavioural preferences; "even without knowing it, our quality of life is closely linked to consumption levels"228.

Identity issues need also be addressed. Even if average citizens desire to imitate their elites, the particular features of their identity as a people affect preferences (Chen \& Li 2009). Guadalajara is a massive city, home to more than four million people; however, some key informants point towards the perceptions of it being a small town, which may be reflected in urban transport preferences; "we should feel like a metropolis here, but our people think they live in a little town, and act like that" 229 . Identity issues in Curitiba are also relevant. Created after the subdivision of the former São Paulo State, and later receiving mass immigration influxes from various European nations, Curitiba did not have a solid identity historically; "we don't have a Curitiban people [...] the migratory communities still live

\footnotetext{
225 Personal communication, prof. Harry Bollmann. PUCPR, August 8, 2012.

226 Personal communication, Antonio Marchezetti. Logitrans, August 17, 2012.

227 Ibid

228 Personal communication, Leny Mary de Goes. Secretaria de Meio Ambiente de Curitiba. August

9, 2012.

${ }^{229}$ Personal communication, Mario Delgado. Entrepreneur. BKT. February 8, 2013.
} 
isolated from each other" ${ }^{230}$. However, the fact that this "identity" is heavily influenced by a variety of solid migratory groups seemingly influenced the disposition of the city for the original implementation of the BRT model, as previously discussed; "having all these groups made a difference [...] the Germans, Italians, Poles [...] they have a life-state-society relationship that is more European; accepting discipline and planning" ${ }^{231}$.

On the other hand, the case of Medellín insinuates a particular cultural composition that facilitates the development of and implementation of practices thought to be unique for the country. The traditional inhabitants of this city are proud of their paisa heritage and as such, exhibit extraordinary support for their city's successes; "the locals want to guarantee that their city comes out first in every ranking [...] sometimes it works, because they push through projects that otherwise could have been impossible"232.

The construction of the Metro seems to support this premise. The project started in 1979 and was pushed by this extraordinary idea of the local tenacity. Although it went through innumerable obstacles, it was finally inaugurated in 1995.To date, it continues to be the only such system in the country, and a source of pride to many of its inhabitants, who support its work en masse; "everybody trusts the Metro [...] it is well known that they will finish what they start, and their proposals are widely accepted"233. This undivided support for the Metro is not derived necessarily from a general interest in sustainable mobility as a concept, but the fact that is has been kept alive for more than three decades, already makes it extraordinary; "anything that still exists for more than 25 years in Latin America, deserves to be celebrated. We don't value the long term" ${ }^{234}$.

Rejections of technical propositions also find root in cultural frameworks. The best technical solutions might not always comply with local priorities. In fact, Latin American culture on average values shortcuts, trickery and chicanery, "the best technical decision, is often much more politically costly. If this is the case, it will never be done here. Here, the cheapest and

\footnotetext{
230 Personal communication, prof. Harry Bollmann. PUCPR, August 8, 2012.

231 Personal communication, Dr. Eduardo Vasconcellos, ANTP, August 14, 2012.

232 Personal communication, Felipe Targa. Former Vice-Minister for Transport. October 1, 2012.

233 Personal communication, David Escobar, Chief of Staff to Mayor Sergio Fajardo. September 20, 2011.

234 Personal communication, transport specialist J Pedro Correa, Volvo, August 10, 2012.
} 
most popular option is what gets done"235. This also implies a higher propensity for corrupt practices; "the Jeitinho [devious shortcut] is accepted. People can break rules, because they know that even if they get caught, they can negotiate the bribe" ${ }^{\text {236 }}$.

Politicians are good at reading how these cultural aspects might serve their purposes. If used correctly, these social constructions can reframe certain concepts. In Brazil, high road accident mortality was for long attributed to faith based explanations; "one of the worst years was 1986, we had 27.300 deaths in road accidents. People were told that it was the divine will [...] they believed it" ${ }^{\prime 237}$. Similarly, the specific visions that the average citizen can have about sustainability might be far from the real possible alternatives. In Guadalajara, "people answer opinion polls saying that they want more public transport, but what is their vision of that? They probably imagine a modern, clean metro station right in front of their house [...] and politicians play with these ideas" 238 . This holds, even though on average, Latin Americans have very low trust towards their politicians; as Senator Salinas puts it, in describing Mexico: "this is a country of disbelievers"239.

In the context of urban transport decisions for the studied cities, cultural identity seems to be a relevant factor influencing the level of transport sustainability. Social mindsets and historical characteristics have both facilitated and curtailed advances towards more sustainable transport policies. Even though it might not be a determinant factor, this implies that the success of most transport policies, and discussions about their implementation is highly context dependant. This finding reflects previous observations by Monzón (2005), when studying sustainable transport in Latin America: "it is crucial to consider that the economic, social, and cultural context of Latin America [...] it is necessary to use simple mechanisms, with special emphasis on citizen awareness programs, and agreements amongst the involved parties..." (Monzón 2005, p.465).

\footnotetext{
235 Personal communication, Mario Delgado. Entrepreneur. BKT. February 8, 2013.

236 Personal communication, Patrizia Bittencourt. CIFAL Curitiba. August 9, 2012.

237 Personal communication, transport specialist J Pedro Correa, Volvo, August 10, 2012.

238 Personal communication, Alfredo Hidalgo. Strategic Projects Director. Zapopan. February 5, 2013.

239 Personal communication, Senator Ninfa Salinas. Mexican Senate. January 29, 2013.
} 


\subsection{Overall Relationship between Transport Sustainability Levels and its Determinants}

Even if this research started out as an open exploratory quest, the ensuing developments throughout the process provided strong indications of the power of certain variables, in explaining the variety of transport sustainability outcomes across the studied cities. In-depth content analysis of the data has allowed for a systematic identification of the key determinants to transport sustainability in three Latin American cities. To test these claims and complement the findings, a categorization of the meanings of the interviewees' statements has been developed.

This categorization targets the connection between the current transport sustainability level of each city, and the top determinants, identified from the rhetorical claims of the key informants. As such, statements of confirmation and disconfirmation for each of the eight central themes explored in Chapters VI and VII, were tallied and presented graphically. This basic quantification of the frequency of references to the categories provides a background for understanding how typical the quotes used in the previous chapters were, for the overall interview material.

Figure VII-2: Categorization of Overall Transport Sustainability-Identified Determinants Relationship

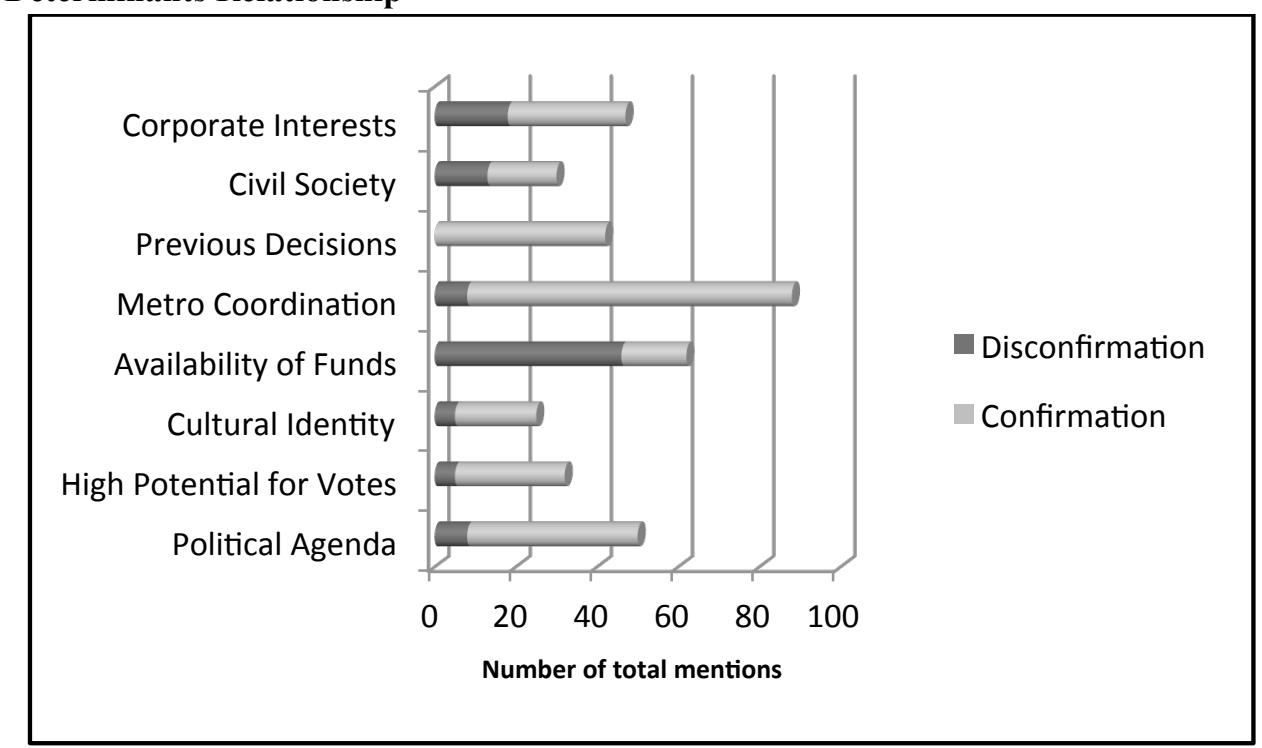

Source: own elaboration 
Figure VII-2 reports the overall confirmation/disconfirmation tallies for all categories across the three studied cities. The results make a strong case for the importance of metropolitan coordination in facilitating the implementation of sustainable transport policies, with eighty mentions confirming this category as a top priority across the studied cities. The political agenda, the high potential for votes, and previous decisions categories also rank high according to the confirmation/disconfirmation ratio of responses from all key informants.

\section{Figure VII-3: Categorization of Transport Sustainability-Identified Determinants} Relationship in Curitiba

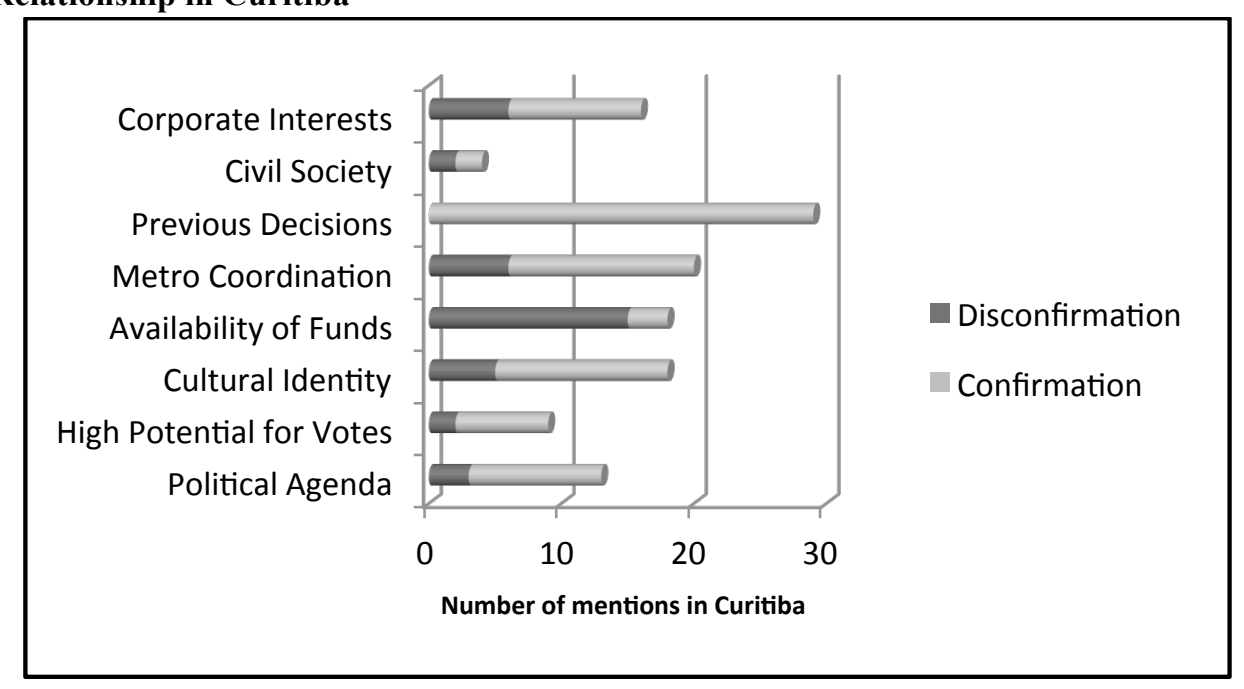

Source: own elaboration

Even if metropolitan coordination continues to be confirmed by a majority of the experts interviewed, it is not the most interesting category when tallying up only the interview material for Curitiba. Previous decisions now come up as the most often confirmed category by the key experts. Almost thirty mentions corroborate the explanatory power that previous decisions have had over the current levels of transport sustainability in the city (see Figure VII-3). This categorization reaffirms the findings presented in Chapter VI, but also sheds light on the sweeping agreement amongst interviewees, as no specific mentions were recorded disconfirming previous decisions, as a top determinant to Curitiba's still prevailing transport sustainability level. 
Cultural identity and availability of funds also stand out as thoughtprovoking categories. Cultural identity was frequently confirmed by key experts, providing an indication of its role in influencing transport sustainability in Curitiba. These results endorse previous claims made in this chapter that first, the specific cultural mix of the city provided higher acceptance for planning and discipline, during the early times of the RIT planning; and then, that overall recent cultural paradigms in Brazil facilitate the adoption and development of car-based systems over non-motorized and transit-based models. The availability of funding was frequently disconfirmed by experts as a top priority determining the level of transport sustainability showcased in Curitiba. These results are also in line with previous claims made in Chapter VI, regarding the secondary importance nature of fund availability, when planning and implementing several key policies that explain the above-average level of transport sustainability in the city, as measured by the GTI.

\section{Figure VII-4: Categorization of Transport Sustainability-Identified Determinants} Relationship in Guadalajara

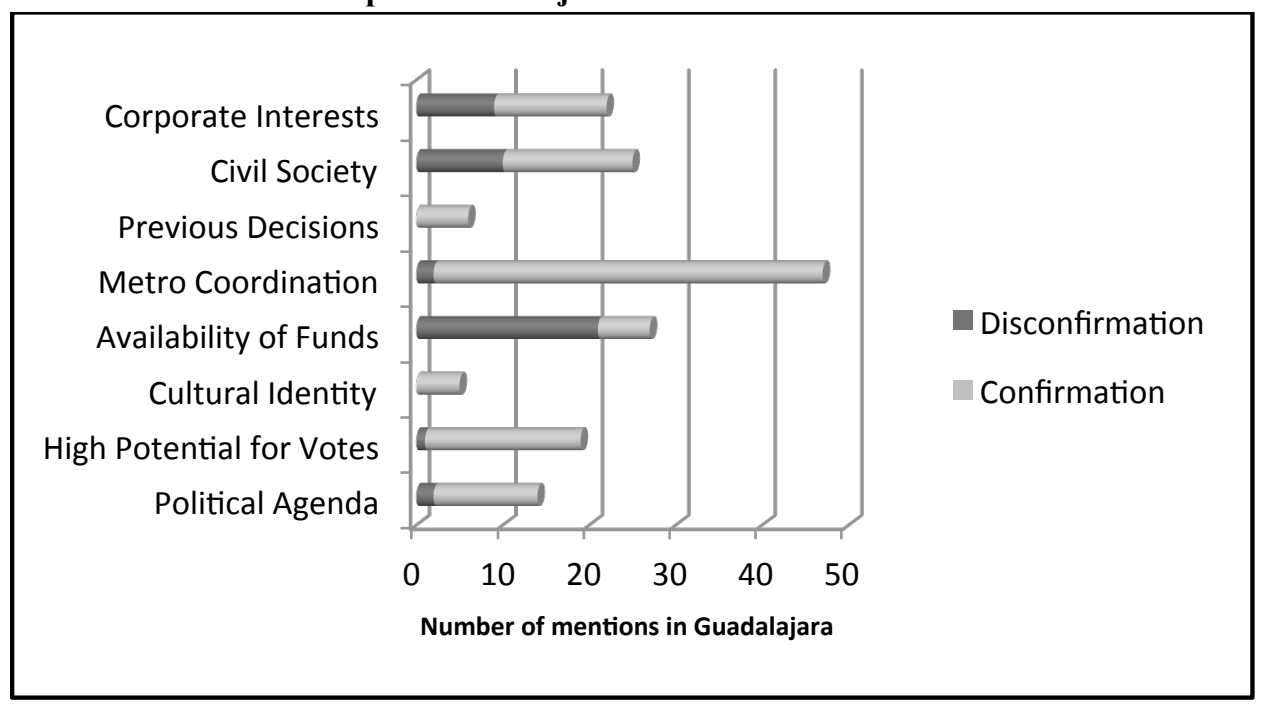

Source: own elaboration

The categorization of the relationship between transport sustainability and its identified determinants in Guadalajara confirms the importance that key experts attach to metropolitan coordination (see Figure VII-4). The interview material referring only to Guadalajara surprisingly exhibits very 
few statements either confirming or disconfirming the influence of previous decisions on the current level of transport sustainability. As such, this specific result does not seem to corroborate previous claims from Chapter VI, regarding the role that historical developments have had in promoting an accumulation of car-centred transport policies. On the other hand, this could be explained by the lack of a powerful contingent event triggering a series of clearly identifiable and continuous events, impacting the transport system in the city.

Metropolitan coordination and availability of funds are once again confirmed by experts as key categories to be considered when exploring the current levels of transport sustainability in this city. Metropolitan coordination is highly regarded as a prominent influence to Guadalajara's urban transport mix by the key experts interviewed, hence confirming previous claims about the weak intergovernmental arrangements at the metropolitan scale, as the foremost constraint to the implementation of more sustainable transport policies in the long term. Availability of funds as a category receives almost twenty disconfirmation mentions by the experts, insinuating that they generally do not perceive fund availability as the top determining condition for the low level of transport sustainability in Guadalajara.

The results from the categorization for Medellín lean towards the role of the political agenda (see Figure VII-5). Seemingly, the key experts interviewed find this category to be crucial when explaining the current level of transport sustainability in the city. Previous claims in Chapter VI describe the way in which other public issues were clearly and broadly regarded as more important by public and private actors during the past decades. Nevertheless, this poses questions about the indirect consequences on transport sustainability of the metro system, even while it was not at the top of the city's public agenda. The key role of the metro (both the institution and the train system), does not seem to be clearly recognized by the experts in these data. Although the results for the previous decisions category modestly insinuate a contribution in this respect, it does not come close to representing the breadth of output material from the interviews. It was previously argued in this dissertation that the implementation of the metro was a contingent event that triggered additional events, which have positively affected transport sustainability in this city; with the recent Metrocable innovation being an example of this. 


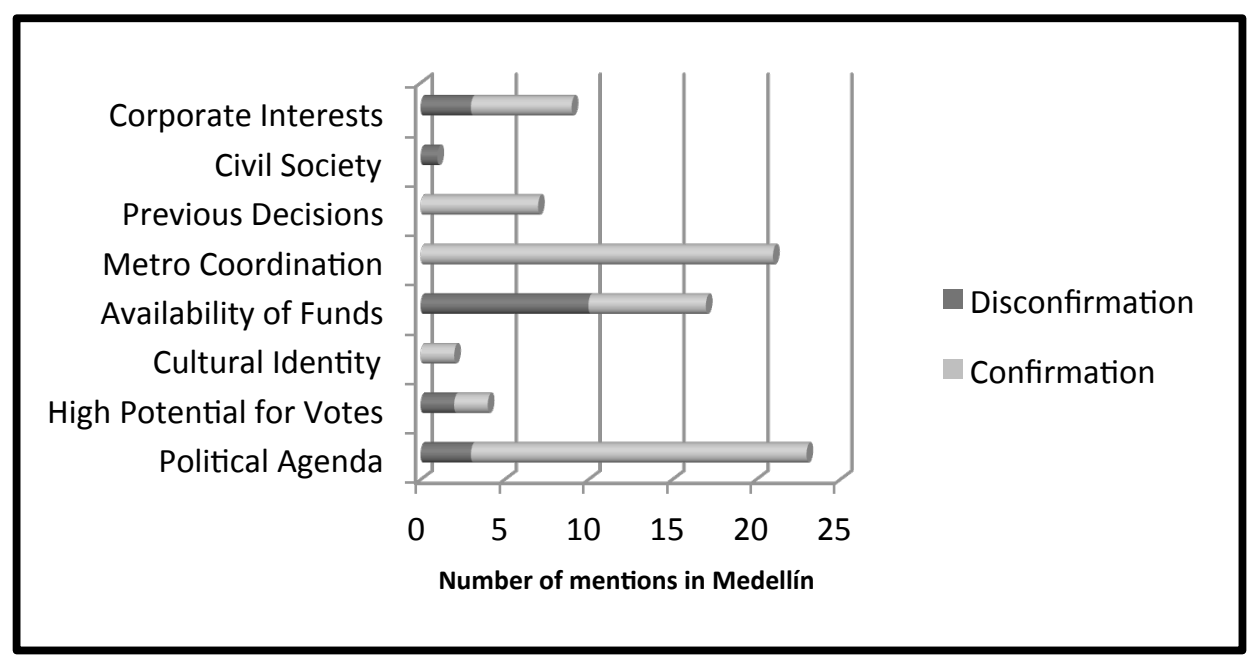

Source: own elaboration

Metropolitan coordination is once again verified as a critical factor facilitating greater transport sustainability. The dynamics around the relationship with the regional and national governments, as well as the dubious empowerment of the AMVA to plan, regulate, and operate transport across the metropolitan area are identified by the experts as being determinant to current transport sustainability. Finally, fund availability receives almost the same number of confirmation and disconfirmation mentions. This corroborates previous claims suggesting that the availability of funds is a necessary but not sufficient condition for advancing transport sustainability in the studied cities.

Using meaning categorization, 210 pages of interview transcription were summarized graphically. This basic quantification of mentions by the experts, serves to counterbalance potential selective interpretations previously claimed by the author, while also complementing the final strategic premises proposed. The findings for the categorization exercise generally support hypotheses one, two, and three, as stated at the end of Chapter VI. 


\subsection{Theoretical Compilation}

Finding paths towards more sustainable transport is a critical priority for the survival of the planet. With $50 \%$ of the world's population already living in cities, these not only generate the majority of global greenhouse gases, but also use over two-thirds of the world's energy (KPMG 2010). Transport is responsible for approximately one quarter of the total global demand, with almost three-quarters of this, used solely for road passenger and goods movement (IEA 2012).

Urban transport challenges in the developing world differ significantly from those found in urban areas of the developed world (Dotson 2011). According to the United Nations Population Division, Latin America is the most urbanized region in the developing world, with $81 \%$ of its population living in cities; a number that is expected to reach $86 \%$ by 2030 . These fast urbanization trends will continue to correlate with fast private motorization rates, higher energy demands, and urban pollution (UN-HABITAT 2013).

Dimitriou and Gakenheimer (2011), argue that the greatest need of urban transport in the developing world is for improved public decision-making in urban transport policy making, planning and management. On the other hand, Dotson (2011) argues that in the context of dynamic institutional change, there is no consensus on the specific political conditions promoting urban sustainable transport. This research was designed to identify the political factors that determine variations in transport sustainability outcomes across Latin American cities.

The study has been an exploratory one, building on current literature about urban transport sustainability, and targeting the specific institutional, political, and cultural conditions in Latin American cities. The main interest has gravitated towards the potential contributions to transport sustainability of: metropolitan intergovernmental arrangements, the role of powerful institutional players, and the way in which previous decisions frame the future possibilities. Therefore, this research contributes to the broader discussion of metropolitan governance and transport sustainability in Latin American cities.

Sixteen cities in the region were characterized empirically through the generation of the Green Transport Index, while three cities were chosen to represent the full variation of urban transport sustainability outcomes in the 
region: Curitiba, Guadalajara, and Medellín. The cross-case comparison resulting from this analysis generates a broad picture of the key developments on sustainable transport for this set of cities, and insinuates the political and institutional conditions that have facilitated these transport mixes. Figure VII-6 serves as a visual summary of the major transport decisions taken in the three studied cities, in the context of the identified metropolitan governance arrangements, and the identified powerful players promoting sustainable transport during the last five decades. 


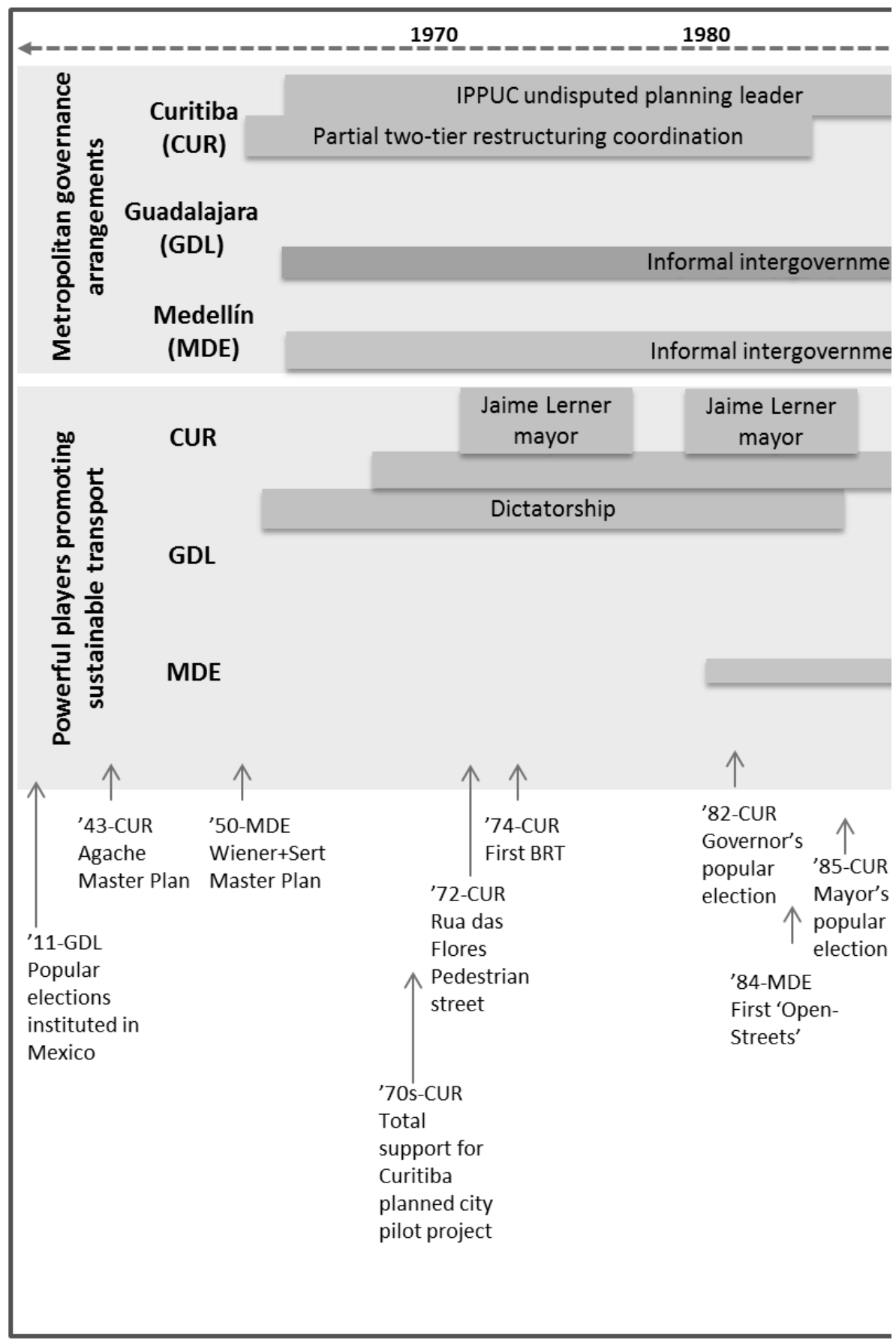

Source: own elaboration

Figure VII-6: Timeline of Transport Decisions for Curitiba, Guadalajara and Medellín (Part 2 ) 200 


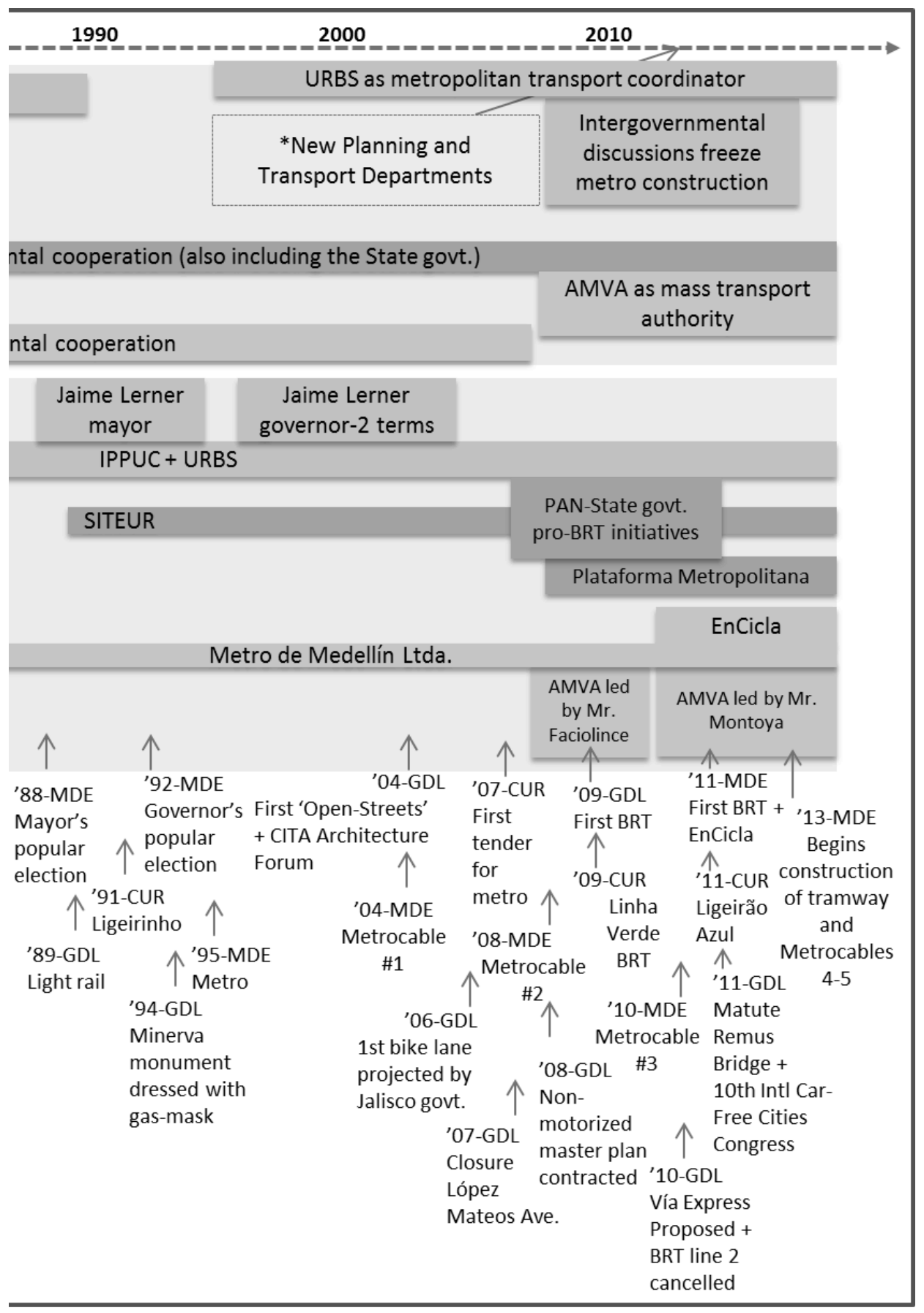

Source: own elaboration 


\subsection{Strategic Premises}

1. Better metropolitan governance arrangements result in higher levels of sustainability in transport.

The differing urban transport trajectories for the studied cities can be understood by assessing key developments in parallel. Informal and formal metropolitan governance arrangements and the presence of those powerful players promoting sustainable transport, provide a backdrop for contextualizing critical decisions. While the presence of the IPPUC and the URBS in Curitiba reflects more formal metropolitan governance arrangements based in technical capacity since the 1970's, Guadalajara and Medellín reflect mostly informal intergovernmental cooperation arrangements during most of this time. The recent empowerment of the AMVA in Medellín as an institution with the potential to plan, administer and implement transport policies for the whole metropolitan area could prove to be a determinant for higher transport sustainability in the near future for this conurbation, as supported by some of the critical decisions during the last few years (see Figure VII-1). The atomization of responsibilities amongst local, regional and national entities in regards to metropolitan transport in Guadalajara seems to imply that 'moderately difficult' or 'hardest' types of intergovernmental coordination arrangements will continue to be distant for this conurbation.

In summary, certain urban functions should be administered by agencies at the appropriate geographical scale. For transport (and green transport in particular), that is a metropolitan scale. The coordination patterns identified across the selected set of cities could indicate that more advanced metropolitan governance arrangements, based on high intergovernmental cooperation, are a necessary condition to facilitate advances in urban transport sustainability in Latin American cities.

2. Political conditions are more crucial than financial conditions in increasing levels of urban transport sustainability, in contemporary Latin America.

Political conditions such as the potential for votes and the variety of agendas determine the mix of players promoting sustainable transport in the long run. The powerful political players that have promoted sustainable transport agendas are very dissimilar amongst the studied cities. While Curitiba saw a period during which at least three potent blocks had a concomitant positive 
outlook on transport sustainability, Medellín and Guadalajara have only until recently seen the rise of powerful players promoting this agenda. The decade of the 1970's saw the convergence of a military dictatorship promoting strict urban planning and a pilot project for a city that complied with all necessary conditions, with the creation of powerful planning and transport operation institutes, and topped by the local leadership of a creative and visionary politician who promoted the innovative BRT structured urban growth model for the city, even without necessarily having pursued specific "green transport" goals at the time. Medellín and Guadalajara only saw the creation of the first important entities until 1979 and 1989 respectively, with the founding of the Metro, and SITEUR, correspondingly. Their technical contribution, however, was not accompanied by proper metropolitan governance arrangements to facilitate the triggering of a trajectory towards greater urban transport sustainability.

In summary, the actions of powerful political players promoting transport sustainability could facilitate greater moves towards sustainability than the availability of funds. Although funds are regarded as a necessary but not sufficient condition for improving the sustainability of an urban transport system, following car-centred urban transport trajectories in Latin American cities could be further influenced by cultural constructions and political agendas, than by the necessary funds implied to change course.

3. Previously taken decisions determine the implementation of key urban transport public policies, which could increase sustainability levels.

The collection of previous decisions determines the current transport mix for the studied cities. While Curitiba profits from crucial decisions increasing transport sustainability levels since the 1960's, Medellín and Guadalajara only saw crucial decisions in this regard being taken some decades later. Nevertheless, the contingent events particular to Curitiba have set into motion event chains with deterministic properties on its transport system, whereas several significant decisions in Medellín and Guadalajara did not become contingent events triggering positive trajectory changes for transport sustainability. By 2010, on the other hand, both Medellín and Guadalajara continued to broadly promote car-centred transport policies, proactively framing the decision possibilities for the future. Path dependent trajectories also apply to this alternative, by which a 'lock-in' to the carcentred model is exposed. As Urry (2004) explains, this 'lock-in' has vast social consequences, as "social life more generally [becomes] irreversibly 
locked in to the mode of mobility that automobility generates and presupposes"(Urry 2004, p.27).

In summary, previous decisions taken in the three cities under study continue to influence the current developments of their transport systems. While Medellín and Guadalajara showcase the consequences of fragile political alliances and small successes towards true metro-scale sustainable transport agendas, the role of civil society in pushing for more emphatic public policy advances, is left over as an issue that merits further investigation. In addition, since most of the initial dynamics explaining Curitiba's current level of transport sustainability are connected to the original contingent events during the dictatorship, this study may not provide sufficient evidence that the transformation of institutional arrangements converging with the action of powerful players promoting sustainable transport, may allow a territory to break away from earlier trajectories, and perhaps even, generate innovation path dependencies towards more sustainable transport systems. However, it does insinuate the possibility of this avenue to be further explored as a determinant of higher transport sustainability in contemporary Latin American cities.

\subsection{A Convergence for Transport Sustainability}

The strategic premises offered in this section insinuate a possible avenue to facilitate advances towards higher transport sustainability in Latin American cities. Two broad conditions are proposed as determining categories: (1) formal vs. informal governance arrangements, and (2) sufficient vs. insufficient powerful players pushing for sustainable transport. The resulting typology describes the convergence of formal metropolitan governance arrangements and sufficient powerful players pushing for sustainable transport, as the most optimal avenue for facilitating the improvement of sustainability levels in urban transport systems, for cities in the region (see Figure VII-7). Curitiba is chosen to represent this preferred box, as a reflection of the convergence of factors that facilitated the initial contingent events which later triggered the reproduction of a system that continues to rank at the top of transport sustainability in Latin America. Guadalajara stands at the opposite corner with informal metropolitan governance arrangements during the last decades, combined with insufficient powerful players pushing for sustainable transport. The highly active civil society groups in this city are thus not considered to be powerful enough. Finally, 
Medellín ranks in the intermediary categories, which means that although there are powerful players pushing for sustainable transport in this city (i.e. the Metro, several key public servants at selected entities, and most recently the EnCicla), the presence of informal metropolitan governance arrangements until 2008, seems to explain the negative disjointed transport decisions for the conurbation during the last decades.

This convergence typology does not argue for causation; it highlights the fact that ceteris paribus, there is a relationship between metropolitan governance arrangements, accompanied by powerful political players pushing an agenda, and the dependant variable of this research: sustainability of urban transport.

Figure VII-7: A Convergence for Transport Sustainability

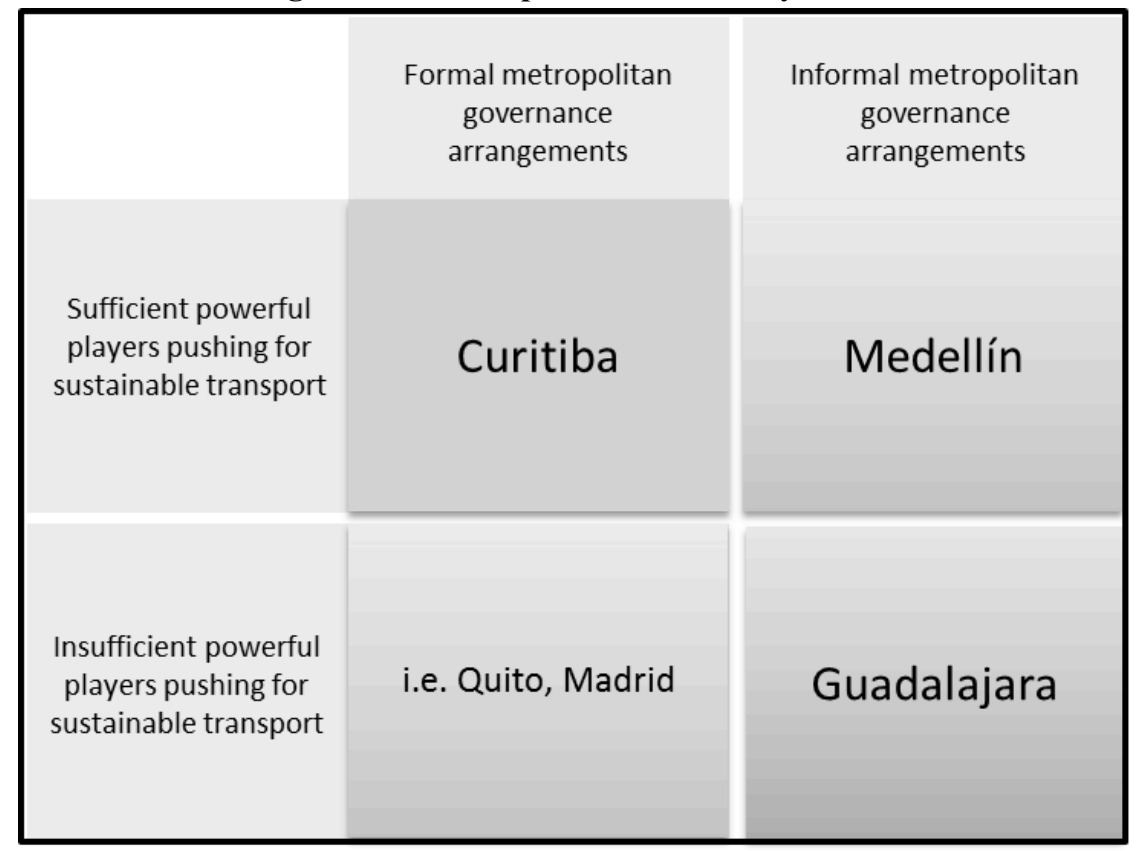

Source: own elaboration

\subsection{Conclusion}

This section followed a theory-guided approach linking the gathered data with current theory about metropolitan governance and urban sustainable transport in Latin America. Various factors not included in the original guiding assumptions of this research are assessed in the context of the 
strategic premises generated in Chapter VI. From this analysis across the selected cities, the role of culture is identified as a valuable contribution to the conclusions of this research.

All previously identified potential determinants of transport sustainability in Curitiba, Guadalajara and Medellín are then categorized according to the meanings given by key experts and the outputs from this analysis is presented graphically using a timeline, which combines (1) the identified mechanisms for metropolitan governance arrangements, (2) powerful players promoting sustainable transport, and (3) critical decisions in the three cities.

Lastly, limited generalizations about the converging role of metropolitan governance arrangements and powerful political players, in influencing transport sustainability are generated; hence, insinuating a typology that could be used to identify patterns common to a broader set of Latin American cities. 


\section{Chapter VIII}

\section{Lessons Learned}

"Latin America must study Amsterdam more than what it does Miami" - Enrique Peñalosa.

This chapter summarizes the contributions of this research. In doing so, brief commentaries on the background of the study, the approach chosen, and the relevance of the findings are offered. Finally, limitations are highlighted and some key opportunities for further research and analysis are identified.

\subsection{Background and Motivation for the Research}

The research contributes directly to the recent sustainable development discourse, where urban transport fits as a vital component. Although there is not one single recipe to advance a transport sustainability agenda, "there is a growing consensus on the need for more sustainable patterns of transport" (UNEP 2011, p.380). On the other hand, there are emphatic calls from the global community for action in this respect. When Secretary-General of the United Nations, Ban Ki-moon, launched his '5-year action agenda' in January 2012, he identified sustainable transport as one of the major building blocks of sustainable development; stressing the need for urgent action to develop more sustainable urban transport systems that can address rising congestion and pollution, and proposing a focus on developing country cities, because that is where "approximately $90 \%$ of global population growth will occur in the coming decades" (UN-HABITAT 2013, p.V).

Furthermore, this research builds on contemporary literature on governance and its implications at a metropolitan scale. The implications of a shift from "government" to "governance", as an avenue to strengthen metropolitan services has been assessed, under the perspective that a movement from the "hierarchical, top-down exercise of power and rules of state-based systems, to more horizontal, networked systems reliant on the interaction of independent and inter-dependent actors who share a degree of trust" (Davila 
2009, p.41), could facilitate a move towards more sustainable urban transport systems in Latin American cities.

\subsection{Approach of the Study}

This dissertation follows a social constructivist paradigm. The intention has been to construct knowledge from the realities analyzed, instead of discovering it as dictated by what could be a more positivist stance. Reality has been understood throughout this thesis as being subjective, multiple, and strongly influenced by culture. Likewise, this research looks not to construct parsimonious rules for all cities in the world; instead, the objective has been to identify limited generalizations about the political and institutional determinants to sustainability of transport in the set of studied cities.

This exploratory study adopted an evidence-based research approach. A decision that is justified by the nature of the phenomena analyzed; while there is no clarity about the institutional and political factors that determine variations in transport sustainability outcomes across Latin American cities, there is great potential in analyzing real cases, with actual experts and practitioners, to identify what has actually worked in the studied cities. As such, this study links the gathered data from the local experts, with current theory about metropolitan governance and urban sustainable transport in Latin America, to construct theory.

This dissertation is composed of two broad phases. First, an empirical characterization of the urban transport systems in sixteen metropolitan areas of Latin America is offered. This exercise has been named the Green Transport Index (GTI). Secondly, an inductive strategy is applied within a comparative case study design. Three cities have been selected, based on theoretical relevance and the outcomes of the GTI, to produce an in-depth analysis of the political and institutional conditions that explain the variety of outcomes for transport sustainability in the initial set of cities characterized.

Within this process, some elements of the abductive theory are also used. Initial explanatory variables are offered as guiding threads of the project, acknowledging that the specific hypotheses may arise during the process of the research. This form of reasoning agrees with the possibility that explanatory variables and theories be generated while studying the facts 
(Haig 2005). As such, the central hypotheses of this study have been refined iteratively throughout the subsequent stages, until conclusive premises are offered.

The results from both broad phases are highly policy relevant for the region. While the GTI provides a rating of the performance of a meaningful variety of Latin American cities in terms of transport sustainability, it has the power to become a recurring exercise. If that was the case, its use as a benchmark could provide an incentive for local actors to pursue more sustainable transport policies, and for other stakeholders to act upon the results of the ranking over time.

On the other hand, the comparative case study approach suggests a powerful role for metropolitan governance and various political conditions in facilitating greater transport sustainability in Curitiba, Guadalajara, and Medellín. Although this exercise was performed on a limited number of cities, and using a purposive sample of key informants (which does not allow for the empirical generalization of findings throughout the region), it does provide significant clues as to the possible avenues for other cities in the region, exhibiting similar structural characteristics to the ones studied.

\subsection{Theoretical Concepts}

As urban sustainable transport has climbed to the top of the agenda in global policy discussions, there have been significant theoretical contributions. There are abundant studies detailing the specific goals to be targeted in order to move towards cleaner, safer, and more sustainable transport systems (SUTP 2010; UN-HABITAT 2013; Litman 2013; Figueroa et al. 2013). Furthermore, there are calls for greater research on the role of institutions, public policies and governance, in promoting greater transport sustainability (UN-HABITAT 2002; Dotson 2011). This research was designed to fill this gap, while making a specific contribution in the context of Latin American cities.

A fundamental standpoint has been the idea that cities are key to sustainability (Rees \& Wackernagel 2012). Correspondingly, this study initiates from acknowledging the robust contribution of transport to the sustainability of cities based, amongst others, on the concept of automobile dependence as identified by (Newman \& Kenworthy 1989). Cities are 
understood as full metropolitan areas, and positioned in the context of an economic system that has transitioned towards a network of 'global cities' (Sassen 2001). The traditional 'primate city' model in Latin America (Jefferson 1989; Klink 2005) has now given way to a greater contribution from what used to be smaller and economically weaker cities a few decades ago.

While using cities as the unit of analysis, this research has stood on traditional definitions for highly contested concepts such as 'sustainable development' and 'sustainable mobility'. Sustainable development has been understood as "development that meets the needs of the present without compromising the ability of future generations to meet their own needs" (WCED 1987; p. 5). Likewise, sustainable mobility has been operationalized using the UNEP's concept of 'green transport' as described in Chapter II, reflecting a transport paradigm that acknowledges our high dependence on cheap mobility, and emphasizes positive social externalities of greater accessibility and security, a concept which continues to be discussed by several authors (Bertolini et al. 2005; Cervero 2001; Bocarejo S. \& Oviedo H. 2012; Banister et al. 2011).

This study has not assessed technical solutions for transport sustainability problems. Rather, it has focused on the potential for improving transport sustainability via political and institutional ingredients. It has been assumed that improved public decision-making is a crucial need of urban transport in the developing world, as argued by (Dimitriou \& Gakenheimer 2011), and that there is no consensus on the specific political conditions promoting urban sustainable transport, in a context of what Dotson (2011) calls 'dynamic institutional change'. Moreover, this study has been constructed on the basic dilemma for service provision in contemporary metropolitan areas, that urban areas are typically defined following "somewhat arbitrary political units" (Zegras 2005a, p.20).

As such, theories on metropolitan government and governance have been fundamental throughout this dissertation. The mismatch between legal boundaries and the actual geographical limits of metropolitan areas pose obstacles for government functions and service provision. Hence, this research has stood on previous calls for metropolitan coordination as a relevant practice in correcting for these potential distortions, following theoretical contributions by Walker (1987); Mitchell-Weaver et al. (2000); Lefèvre (1998); Sharpe (1995); Rojas (2005), and others. Correspondingly, 
the theoretical standpoints offered by studies on subsidiarity (Bermann 1994), public choice (Tiebout 1956), decentralization and reterritorialisation (Willis et al. 1999; Rojas 2005), and decision-making models (Thompson \& Tuden 1959) have informed this research.

Urban transport is assessed from a cultural approach to historical institutionalism, in terms of what Bevir (2009) and Thelen (1999) have previously described in institutionalism and governance literature. It is assumed that human actors are vital agents in both generating historical changes, and in being influenced by these changes. Moreover, the explanatory power of path dependence has been considered as a structural force in understanding urban transport decisions in Latin American cities. Path dependence has been regarded as the historical sequences in which contingent events set into motion institutional patterns or event chains that have deterministic properties, in line with arguments by Mahoney (2000).

Previous studies have explored similar issues in the context of Latin America. The comprehensive contributions by Economist Intelligence Unit (2010) and CAF (2011) have shed light on the urban sustainability conditions, and urban mobility trends for cities in the region, correspondingly. These studies however, have not included the same cities, and their valuable descriptive exercise has not attempted to reach profoundly into the conditions allowing for the significant variations in transport sustainability outcomes, across Latin America cities. On the other hand, the exhaustive work by Rojas et al. (2005) has served a good purpose in studying the variety of challenges for managing metropolitan areas in Latin America. Although the specific focus of this study has not been transport, it does include one relevant chapter solely dedicated to this subject.

Even though comparative studies on sustainable transport are not that frequent for the Latin American region, research on local and metropolitan government has been quite profuse. Some valuable recent additions comprise Nickson's (2011) comparative work on local government in Latin America, and Devas' (2005) study on metropolitan governance and its implications for urban poverty. On the other hand, selected studies analyzing links between metropolitan government and urban phenomena include Steinberg's (2005) study of strategic urban planning processes in selected Latin American cities, and Paiva's (2003) work on metropolitan 
government and its implications for urban planning and transport in Caracas and Monterrey.

Specific studies on urban transport for Curitiba have also been frequent, due to the well-documented successes of that city in transport innovation. Rabinovitch \& Leitman (1996); Rabinovitch (1996); Smith \& Raemaekers (1998); and Parra \& Garcias (2005) have contributed with valuable studies on Curitiba's urban planning model, and BRT-based transport system. It is worth to mention that the study by Parra \& Garcias (2005) provides a valuable comparative perspective with the more recent urban transport developments in Bogotá. Similarly, Ardila's (2004) work offers what could be perhaps one of the most far-reaching comparative studies on the urban transport dynamics for these two Latin American cities. Nonetheless, Ardila is primarily concerned with the role of planners in interacting with political actors and other stakeholders, when generating new transit modes. It is crucial to mention that none of these studies have included direct comparisons with cities that are structurally similar to Curitiba, when assessing the sustainability of urban transport.

Medellín and Guadalajara, on the other hand, have not featured as prominently in recent literature on transport sustainability. The only exception might concern a fresh interest on the urban consequences of Medellín's Metrocables as an urban transport innovation. The preeminent work on this respect is Davila's (2012) comprehensive review of the Metrocable as an urban transformation tool being replicated around the world. Some contributions by the Institute for Transportation and Development Policy's (ITDP) Mexico office also merit mention, such as ITDP (2013b) and ITDP (2013a), through which thorough descriptions of the road ahead for transport in Mexican cities are offered. None of these however, aim at analyzing the local urban conditions by utilizing interregional comparative approaches.

Finally, important recent contributions to the global discussion on urban transport and its sustainability challenges include the works of Dimitriou \& Gakenheimer (2011) and UN-HABITAT (2013); both of which shed light on the vast diversity of challenges ahead, offer advanced diagnosis of the key components of urban transport, and identify specific developments for contemporary components of transport systems in the developing world. Both of these recent contributions call for more research on the links 
between transport sustainability and governance in the developing world cities.

\subsection{Relevance of Findings}

This study targets the specific knowledge gap concerning the political and institutional determinants of transport sustainability in Latin American cities. To the best of my knowledge, it is the only such study with a significant focus on comparing the cities of Curitiba (Brazil), Guadalajara (Mexico), and Medellín (Colombia).

Aside from offering a fresh perspective on the outlook for transport sustainability in Latin American cities, the relevance of this research's findings resides within these three spheres:

1. The Green Transport Index: ranks the performance for sixteen large cities across economic, social and environmental baskets; the index has the power to be used as a benchmarking tool by political actors and other stakeholders in the region.

2. The Case Study: this phase allowed for an in-depth comparison of the three chosen cities, which was based on a unique dataset constructed from primary data directly acquired by the author, via key expert interviews. The conclusions from this phase describe the conditions that have allowed Curitiba to rank high in the GTI, Medellín to rank average, and Guadalajara to rank low, when compared with each other.

3. Theoretical contributions: based on the empirical findings of the research, the following contributions are made:

a. Several previous propositions explaining the variety of outcomes in transport sustainability for the studied cities are challenged or confirmed.

b. A typology is introduced concerning the role of metropolitan arrangements and political player participation, in facilitating higher levels of urban transport sustainability in Latin America.

c. Strategic premises are offered, providing limited generalizations from the findings that may be applied to other cities in the region. These premises are: 
i. Better metropolitan governance arrangements result in higher levels of sustainability in transport.

ii. Political conditions are more crucial than financial conditions in increasing levels of urban transport sustainability, in contemporary Latin America.

iii. Previously taken decisions determine the implementation of key urban transport public policies, which could increase sustainability levels.

It is important to mention that all these theoretical contributions share a vital characteristic: the ability to be falsified by future studies in the subject.

\subsection{Limitations}

The limitations encountered during the development of this research project include a variety of partly expected and fully unexpected challenges. Anticipating the approaches, consequences of certain decisions, and problem-solving strategies was part of the initial stages of this study. However, upon embarking in the data collection, the author soon discovered a colossal range of factors influencing the original plans. This applies specially to the fieldwork phases in three different countries, where all efforts were made to collect the necessary data, and gain a superior knowledge of the specific context in the selected cities. Staying within the strategic lines of the research proposal, while allowing for sufficient flexibility to realize the project, was the first major challenge.

It must also be noted that this study carries some methodological limitations to be optimized in later revisions of this same subject matter. The information systems and data collecting capacities of many cities in the region continue to be fragile. This is the primary reason why the used methodological approach was chosen from the beginning, but also the reason why the index was only performed for the selected sixteen cities, and for only one year. During the last three years of this project, frequent approximations to the CAF were tried, in order to secure additional and fresher data sets for cities in the region. Unfortunately, all efforts were in vain.

In regards to the dataset used for the GTI, it is acknowledged that some of the data points used (although official), might reflect altered version of the 
actual conditions in place. All possible efforts have been made to verify the consistency of data, but it is acquiesced that second-hand data from public sources at the local level in Latin America carries this limitation almost by definition. On the other hand, when ranking the initial set of cities, it did not become possible to control for variables describing the historical vocation of each conurbation. It remains likely that different transport challenges could arise for cities with large ports, cities housing national government branches, industrial cities, and hub cities enclaved in rough terrains. As such, these structural historical conditions would help characterize their present urban transport systems.

During the second half of the research, however, all efforts were made to minimize structural differences amongst the studied cities, and thus, the selection of Curitiba, Guadalajara, and Medellín, aimed at contrasting cities with very similar characteristics, while exhibiting different levels of transport sustainability. Furthermore, as previously mentioned, the case studies were based on data collected in a limited number of cities, and using a purposive sample of key informants. Unfortunately, this sample has a disproportionate ratio of men to women, and raises issues about men continuing to figure more prominently in certain knowledge areas, in Latin America. All these issues imply that it is not possible to empirically generalize the findings throughout the region.

Finally, the author acknowledges that all potential omissions or mistakes are solely his responsibility.

\subsection{Opportunities for Further Research}

Based on the lessons learned throughout this process, and considering the aforementioned limitations, several opportunities for further research can be identified.

Firstly, the Green Transport Index introduced in this study can be optimized and expanded to include many more cities in the region. Using this tool to measure city performance in a field that needs to be addressed urgently such as urban transport sustainability, could provide great benefits. Some contributions might come in terms of new knowledge, public policy influence, and even technical assistance in the long run. If such benchmarking exercises are performed over time, "cities can benefit from the knowledge and experience of colleagues in other cities to assist 
sustainability policy development" (KPMG 2010, p.10). As previously mentioned, the fundamental constraint to this possibility in the region, continues to be the availability of reliable data.

Secondly, the theoretical contributions of this study could be tested in a different set of cities in the region. Evaluating the interactions between metropolitan governance arrangements, powerful political actors and sustainable transport levels makes sense for small, medium-sized and large cities in Latin America. Moreover, the conclusions from this study could also be tested in the same set of cities at a future time, in order to test the strategic premises offered.

Thirdly, generating specific research designs to evaluate the longitudinal effect on transport sustainability of specific changes in metropolitan coordination arrangements, the role of powerful institutional players, funding availability, or any other of the explanatory variables described in this study, could further clarify the influence of political factors on any chosen city's transport system.

Finally, based on the conditions hereby identified, a detailed prescriptive list of macro and micro policy changes needed in any of the three case study cities could be generated. Such a contribution would be highly policy relevant, but would depend on improbable interest from a series of political actors about the implementation of such policy changes.

“Como nadie camina, los carros ya no caben en los parqueaderos de las iglesias en las idas a misa"

- Héctor Abad Faciolince 


\section{Annexes}

\subsection{Valorisation Addendum}

This section discusses the valorisation opportunities offered by this research project. In order to analyse these opportunities, the relevance of the study is reviewed with a focus on potential beneficiary groups, and the degree of innovation ingrained in the research activities.

This research is highly policy relevant. It deals with a frequent challenge for cities of all sizes in both the developing, and the developed world. Moreover, it offers pragmatic calls for action targeted at large Latin American cities, which could inform debate, transform political processes, or generate replicable policy actions from civil society groups, public servants, political actors, and private sector actors.

The study offers a fresh perspective on the outlook for transport sustainability in urban Latin America, at a time when this specific topic is central to public debates in hundreds of cities in the region. Thus, contributing to building a bridge between the highly academic -and sufficiently aged-discussions about the topic, on the one hand, and more citizen level discussions about cities, urban sustainability, and urban mobility, on the other hand.

Even though this study targets the specific knowledge gap concerning the political and institutional determinants of transport sustainability in several Latin American cities, it selects a unique set of three cases to study in depth. To the best of my knowledge, it is the only such study with a significant focus on comparing the cities of Curitiba (Brazil), Guadalajara (Mexico), and Medellín (Colombia).

The Green Transport Index introduced in this study also serves as an innovative product to be applied pragmatically. By independently ranking performance for sixteen large cities across economic, social and environmental baskets, the index has the power to be used as a benchmarking tool by political actors and other stakeholders in the region. If used as a benchmarking tool, or recurrent exercise, a variety of actors would directly benefit. Not only could politicians use it to highlight their advances or justify their proposals, but also civil society groups and the media, could 
use it to call for policy and planning changes, or simply to get their messages across.

Building on the comparative case studies, several previous propositions explaining the variety of outcomes in transport sustainability for the studied cities are challenged or confirmed. This results in a typology concerning the role of metropolitan arrangements and political player participation, in facilitating higher levels of urban transport sustainability in Latin America. This tool has the potential to be complemented, optimized, and replicated if applied in other regional contexts, be it within Latin America, or in other developing regions, where similar structural conditions are found.

The strategic premises offered provide limited generalizations from the findings, which may be applied to other cities in the region. The premises are focused on the role of metropolitan governance arrangements, the interaction between political and financial conditions, and the role of previously taken (transport or non-transport related) decisions. These contributions frame the circumstances that could explain moves towards more sustainable transport systems in other cities with similar conditions.

This research contributes directly to the recent sustainable development discourse, where urban transport fits as a vital component. Furthermore, it builds on contemporary literature on governance and its implications at a metropolitan scale. The study makes part of the recent academic strands advocating for a shift from "government" to "governance", as a way to better understand metropolitan government performance. Since this dissertation has not assessed technical solutions for transport sustainability problems, it has, focused on the potential for improving transport sustainability via political and institutional ingredients. Hence, theories on metropolitan government and governance have been fundamental, and add value to that discussion in Latin America.

Previous studies have explored similar issues in the context of Latin America, as has been detailed in Chapter VIII. The most comprehensive ones, have not included the same cities, and have not attempted to reach profoundly into the conditions allowing for the significant variations in transport sustainability outcomes, across Latin America cities. Some other crucial ones have not held a specific focus on urban transport issues, while several other works with similar depth and methodological perspective, have not dealt with transport nor urban issues at all. There are some valuable works focusing on transport issues in Curitiba, Guadalajara, and Medellín; 
nevertheless, to the best of my knowledge, this is the first time all three cities are jointly studied, as has been previously described.

9.2. Annex 1 - Code Book (next page) 


\section{Q atlas.ti report}

\section{Codes: Code Book}

Number of Codes: 74 , commented: 73

\section{Code Info}

Academia

Against new

technology

Alternatives to

car

Appreciation

Car as de velopment

model

Case Studies

Centralization of authority

City

characteristics

Corporate

interests

Cost of fuel

Cultural identity

Daily trips

Definition

sustainable

mobility

\section{Comment}

Author

Role of the academia in inflhencing transport. Super

- Actors or actions against the introduction of new transport Super technologies.

In not by car, how do people mobilize? Super

- Higher prices for lands and buildings as a result of urban Super transformations.

n As model and symbol Following ancient car-centered paradigm Super

- The 3 case studies for this study are Curitba, Guadalajara and Super Medellin.

- Does the level of centralization of authority explain the level of transport sustainability in the city?

- Structural variables of the city, particularities in its planning or birth. Inchding sprawlissues.

In Actions from the corporations against sustainability of transport.

Super

n Reflects the relative cost of having a car. In our index, it is Super calculated as: gas litres that can be bought with one minimum wage.

In Infuence of bcal culture on system of transport in the city.

Super

IV Reflects the amount of trips in the city. In our index, it is calculated as.walking, biking, individual, and collective transport trips, per capita.

I Does it exist officially?

Super 
Economic Sustainability

Electoral cycle

Elites

Emissions

Energy consumption

Environmental Sustainability

Financial capacity

Form of

government

Formal strategy to improve sustainability

Global

recognition

Green Transport Index

High air quality

High awareness of sustainability

High colaboration between levels of government

High cost of public transport
In The economic basket of transport sustainability aims to measure the costs of travel for users, the levels of car and motorcycle ownership, the costs of energy use, and the public prioritization of investment in superior modes of collective transport.

In Type of cycles for the election of the local leaders. Also in terms of Super coordination with elections to other positions at the regional and national level

II Role of elites in infhencing transport system

In Reflects air quality. In our index, it is calculated as: $\mathrm{CO}, \mathrm{Nox}, \mathrm{SO} 2$, Super $\mathrm{PM}, \mathrm{CO} 2$ emissions in tons, for individual and collective transport. Per capita, per year.

II Reflects energy used by transport. In our index, it is calculated as Super equivalent tons of oil for individual and collective transport. Per capita, per year.

In The environmental basket of transport sustainability aims to capture Super each city's contribution to global warming.

n. Does the availability of money explain the level of transport sustainability in the city?

- Type of governmental regime

I- By the authorities, within the city, during the hast 10 years.

- Policies, decisions, actions related to increasing global recognition of city.

In Scores 16 cities from 9 Latin American countries on transport sustainability.

I. Actions related to the improvement of air quality.

= Do people know about it? talk about it? push for it?

= Coordination between different levels of government.

n Costs of using PT. Both financially and in terms of time and comfort. Inchudes references to prices and subsidies to PT.
Super

Super

Super

Super

Super

Super

uper$$
\text { per }
$$

Super

Super

Super

Super 

High me tropolitan $=$ Coordination between municipalities in the same metropolitan area. Super
coordination

\begin{tabular}{|c|c|c|c|}
\hline $\begin{array}{l}\text { High potential for } \\
\text { votes }\end{array}$ & $=$ & $\begin{array}{l}\text { What kind of proposals/projects do candidates think will give them } \\
\text { votes. }\end{array}$ & Super \\
\hline $\begin{array}{l}\text { High technical } \\
\text { planning }\end{array}$ & $=$ & $\begin{array}{l}\text { Good technical capacity and infuence of technical planning in } \\
\text { decision making. }\end{array}$ & Super \\
\hline $\begin{array}{l}\text { High transport } \\
\text { sustainability }\end{array}$ & = & According to our GTI & Super \\
\hline $\begin{array}{l}\text { In favour of new } \\
\text { technology }\end{array}$ & = & $\begin{array}{l}\text { Actors or actions in favour of the introduction of new transport } \\
\text { technologies. }\end{array}$ & Super \\
\hline Initial stimulus & = & $\begin{array}{l}\text { Does the kind of initial stimulhs to particular projects explain the } \\
\text { level of transport sustainability in the city? }\end{array}$ & Super \\
\hline Innovation & ш & New sohtions & Super \\
\hline $\begin{array}{l}\text { Institutional } \\
\text { coordination }\end{array}$ & $=$ & $\begin{array}{l}\text { Does the level of coordination between key institutional players } \\
\text { explain the level of transport sustainability in the city? }\end{array}$ & Super \\
\hline $\begin{array}{l}\text { Investment in } \\
\text { superior public } \\
\text { transport }\end{array}$ & = & $\begin{array}{l}\text { Reflects the investment in superior public transport options. In our } \\
\text { index, it is calculated as: investment in superior modes of transport } \\
\text { (lightrail, trolleybus, BRT, train, tram, subway) as proportion of } \\
\text { investment in roads. }\end{array}$ & Super \\
\hline $\begin{array}{l}\text { Land planning } \\
\text { de vices }\end{array}$ & $=$ & $\begin{array}{l}\text { Technical devices to plan cities: zoning, use classes, building height, } \\
\text { lot coverage, residential occupancies, etc. }\end{array}$ & Super \\
\hline $\begin{array}{l}\text { Low institutional } \\
\text { coordination }\end{array}$ & " & Coordination between municipalities in the same metropolitan area. & Super \\
\hline $\begin{array}{l}\text { Low transport } \\
\text { sustainability }\end{array}$ & " & Conditions/determinants of lower transport sustainability & Super \\
\hline $\begin{array}{l}\text { Mass transport } \\
\text { network }\end{array}$ & = & $\begin{array}{l}\text { Reflects the availability of mass transport options. In our index, it is } \\
\text { calculated as: total length of all train, tram, subway, bus and other } \\
\text { mass transport routes within the city's coundaries; measured in } \\
\mathrm{km} / \mathrm{km} 2 \text {. }\end{array}$ & Super \\
\hline Media & = & Role of the media in infuencing transport & Super \\
\hline Metro planning & $=$ & Plaming for the full metropolitan area. & Super \\
\hline $\begin{array}{l}\text { Metropolitan } \\
\text { governance }\end{array}$ & = & Organization of local governments in metro areas. & Super \\
\hline
\end{tabular}


Metropolitan government

Mixed-use development

Mortality index

Multilevel

governance

Negotiations for new technology

Organized

interest group

strength

Path dependency

Personal mobility index

Political agenda

Political le ader (character/weight)

Political player conflict

Population

density

Power

Powerful institutional player

Prionity for cyclists

Prionity for pedestrians

Prionity for public
- The existance/lack of metro govt as explanation for the transport system

- Blending combination of residential, commercial cultural, institutional, industrial uses. Physical and fincionatlly integrated finctions, with pedestrian connections.

neflects deaths due to transport. In our index, it is calculated as: yearly deaths in traffic accidents, per capita.

- Many interacting authority structures at work.

Super

- Between the city officials and other key groups.

Super

n. Does the strength of organized interest groups explain the level of transport sustainability in the city?

Super

- The past matters. "dependencia del camino".

Super

In Reflects the capacity of movement for average citizens. In our index, it is calculated as: number of daily trips per inhabitant inchuding all modes.

n. How to make it into the political agenda?

Super

- Does the type of central political leader explain the level of transport Super sustainability in the city?

Does the level of conflict between key political phyers explin the level of transport sustainability in the city?

n For the metro area.

Super

[no entry]

Super

- Existence of a powerfil institutional player impacting the metropolitan area

Super

- Reflects the possibilities for cyclists to move around easily. In our Super index, it is calculated as: $\mathrm{kms}$ of priority lanes for cyclists.

n Reflects the possibilities for pedestrians to move around easily. In our index, it is calculated as: $\mathrm{Kms}$ of pedestrian only streets.

Super Reflects the possibilities for people to move around easily by public 
transport

Public space

nefinitions of public space

Relative cost of a 9km trip

Relative cost of public transport

Rules and regulations

Social pressure

Social

Sustainability

Stock of cars and motorcycles

Subsidies

Superior public transport network

Technical progress

Technical/political conflict

Territorial integration

Travel time sustainability in the city? transport. transport. In our index, it is calculated as: $\mathrm{kms}$ with priority demarcation for collective transport modes.

n Reflects the relative cost of using a car vs. using public transport. In Super our index, it is calculated as: For cars and motorcycles: [(gas use coefficient $\{\mathrm{it} / \mathrm{km}\} * 91 \mathrm{~km}) *$ (cost of gas coefficient)]. For public transport: average price of ticket.

In Reflects the relative cost of using public transport. In our index, it is calculated as: relative weight of 50 bus tickets on minimmm wage.

- Inchuding official normatives and informal rules.

- Does the level of social pressure explain the level of transport

n The social basket of transport sustainability favours highly mobile societies with bw dependence on the automobile, as well as broad urban systems that offer affordable and equitable opportunities to mobilize about the city, via collective and/or non-motorized

- Reflects level of motorization. In our index, it is calculated as: total stock of cars and motorcycles, with half-weighting allocated to motorcycles; measured in vehicles per person.

In Subsidies promoting alternatives to the private car.

neflects the availability of superior public transport options. In our index, it is calculated as: total length of all superior modes of transport (lightrail, trolleybus, BRT, train, tram, subway) within the city's coundaries; measured in $\mathrm{km} / \mathrm{km} 2$.

- As an explanation of higher transport sustainability

- Does the level of conflict between key politicaltechnical players explain the level of transport sustainability in the city?

In Perceiving municipalites as being part of the same territory.

n- Reflects travel times. In our index, it is calculated as: average minutes per trip. Individual transport, walking and collective transport.
Super

Super

Super

Super

Super

Super

Super

Super

Super

Super

Super

Super 
9.3. Annex 2 - Full list of key informants interviewed

\begin{tabular}{|c|c|c|c|c|}
\hline Name & Affiliation & Date & Gender & Place \\
\hline \multicolumn{5}{|c|}{ Curitiba (19 interviews) } \\
\hline Jonny Stica & $\begin{array}{l}\text { Councilman, city } \\
\text { of Curitiba }\end{array}$ & 15-Aug-12 & Male & Curitiba \\
\hline $\begin{array}{l}\text { Eduardo } \\
\text { Vasconcellos }\end{array}$ & $\begin{array}{l}\text { Academic } \\
\text { Researcher and } \\
\text { ANTP Expert }\end{array}$ & 14-Aug-12 & Male & São Paulo \\
\hline $\begin{array}{l}\text { Alexandre } \\
\text { Costa }\end{array}$ & $\begin{array}{l}\text { Journalist, } \\
\text { Gazeta do Povo }\end{array}$ & 2-Aug-12 & Male & Curitiba \\
\hline $\begin{array}{l}\text { Wellington } \\
\text { Pereira }\end{array}$ & $\begin{array}{l}\text { Professor } \\
\text { Universidade } \\
\text { Federal de } \\
\text { Paraná }\end{array}$ & 2-Aug-12 & Male & Curitiba \\
\hline $\begin{array}{l}\text { Fabio } \\
\text { Scatolin }\end{array}$ & $\begin{array}{l}\text { Senior advisor to } \\
\text { Gustavo Fruet } \\
\text { (Mayor of } \\
\text { Curitiba 2013- } \\
\text { 2016) }\end{array}$ & 6-Aug-12 & Male & Curitiba \\
\hline $\begin{array}{l}\text { Silvia dos } \\
\text { Santos } \\
\text { Ramos }\end{array}$ & $\begin{array}{l}\text { Specialists - } \\
\text { Transport } \\
\text { Department } \\
\text { Curitiba - URBS }\end{array}$ & 19-Aug-12 & Female & Curitiba \\
\hline $\begin{array}{l}\text { Fabio } \\
\text { Duarte }\end{array}$ & $\begin{array}{l}\text { Professor } \\
\text { Pontifícia } \\
\text { Universidade } \\
\text { Católica do } \\
\text { Paraná }\end{array}$ & 15-Aug-12 & Male & Curitiba \\
\hline $\begin{array}{l}\text { Mario } \\
\text { Prockopiuck }\end{array}$ & $\begin{array}{l}\text { Professor } \\
\text { Pontifícia } \\
\text { Universidade } \\
\text { Católica do } \\
\text { Paraná }\end{array}$ & 17-Aug-12 & Male & Curitiba \\
\hline $\begin{array}{l}\text { Julio } \\
\text { Augusto de } \\
\text { Almeida }\end{array}$ & $\begin{array}{l}\text { Transport } \\
\text { engineer - IPPUC }\end{array}$ & 8-Aug-12 & Male & Curitiba \\
\hline Patrizia & Director CIFAL & 9-Aug-12 & Female & Curitiba \\
\hline
\end{tabular}

225 


\begin{tabular}{|c|c|c|c|c|}
\hline Bittencourt & Curitiba & & & \\
\hline $\begin{array}{l}\text { Harry } \\
\text { Bollmann }\end{array}$ & $\begin{array}{l}\text { Professor } \\
\text { Pontifícia } \\
\text { Universidade } \\
\text { Católica do } \\
\text { Paraná }\end{array}$ & 8-Aug-12 & Male & Curitiba \\
\hline $\begin{array}{l}\text { Leny Mary } \\
\text { de Goes }\end{array}$ & $\begin{array}{l}\text { Specialist, } \\
\text { Environment } \\
\text { Department of } \\
\text { Curitiba }\end{array}$ & 9-Aug-12 & Female & Curitiba \\
\hline $\begin{array}{l}\text { Magnus de } \\
\text { Mello } \\
\text { Pereira }\end{array}$ & $\begin{array}{l}\text { Professor } \\
\text { Universidade } \\
\text { Federal de } \\
\text { Paraná }\end{array}$ & 18-Aug-12 & Male & Curitiba \\
\hline $\begin{array}{l}\text { Liana } \\
\text { Valicelli }\end{array}$ & $\begin{array}{l}\text { Planning } \\
\text { specialist, Urban } \\
\text { Planning } \\
\text { Department - } \\
\text { IPPUC }\end{array}$ & 9-Aug-12 & Female & Curitiba \\
\hline $\begin{array}{l}\text { Anna } \\
\text { Cavalheiro }\end{array}$ & $\begin{array}{l}\text { Planning } \\
\text { specialist with } \\
\text { Campo Largo } \\
\text { Municipality }\end{array}$ & 10 -Aug-12 & Female & Curitiba \\
\hline $\begin{array}{l}\text { Gislene } \\
\text { Pereira }\end{array}$ & $\begin{array}{l}\text { Professor } \\
\text { Universidade } \\
\text { Federal de } \\
\text { Paraná }\end{array}$ & 12-Aug-12 & Female & Curitiba \\
\hline $\begin{array}{l}\text { Antonio } \\
\text { Carlos } \\
\text { Marchezetti }\end{array}$ & $\begin{array}{l}\text { Operations } \\
\text { Director for } \\
\text { Logitrans }\end{array}$ & 17-Aug-12 & Male & Curtiba \\
\hline $\begin{array}{l}\text { J Pedro } \\
\text { Correa }\end{array}$ & $\begin{array}{l}\text { Road Safety } \\
\text { Specialist }\end{array}$ & 10 -Aug-12 & Male & Curtiba \\
\hline $\begin{array}{l}\text { Pablo } \\
\text { Guerrero }\end{array}$ & $\begin{array}{l}\text { Transport } \\
\text { Specialist, Inter- } \\
\text { American } \\
\text { Development } \\
\text { Bank } \\
\end{array}$ & 13-Aug-12 & Male & Via Skype \\
\hline
\end{tabular}


Annex 2 - Full list of key informants interviewed (continued)

\begin{tabular}{|c|c|c|c|c|}
\hline Name & Affiliation & Date & Gender & Place \\
\hline \multicolumn{5}{|c|}{ Guadalajara (20 interviews) } \\
\hline $\begin{array}{l}\text { Alfredo } \\
\text { Hidalgo }\end{array}$ & $\begin{array}{l}\text { Director Special Urban } \\
\text { Projects, Zapopan } \\
\text { municipality }\end{array}$ & 5-Feb-13 & Male & Guadalajara \\
\hline $\begin{array}{l}\text { Mario } \\
\text { Delgado }\end{array}$ & $\begin{array}{l}\text { Founder, Bikla bicycle } \\
\text { sharing program }\end{array}$ & 8-Feb-13 & Male & Guadalajara \\
\hline $\begin{array}{l}\text { Carlos } \\
\text { Mojica }\end{array}$ & $\begin{array}{l}\text { Transport Specialist, } \\
\text { Inter-American } \\
\text { Development Bank }\end{array}$ & 15-Feb-13 & Male & Via Skype \\
\hline $\begin{array}{l}\text { Carlos } \\
\text { Romero }\end{array}$ & $\begin{array}{l}\text { Non-motorized } \\
\text { mobility Director, } \\
\text { Jalisco State }\end{array}$ & 5-Feb-13 & Male & Guadalajara \\
\hline $\begin{array}{l}\text { Manu } \\
\text { Padilla }\end{array}$ & $\begin{array}{l}\text { Founder, CasaUrb } \\
\text { urban planning }\end{array}$ & 7-Feb-13 & Male & Guadalajara \\
\hline $\begin{array}{l}\text { Diego } \\
\text { Monraz }\end{array}$ & $\begin{array}{l}\text { Transport Director, } \\
\text { State of Jalisco }\end{array}$ & 11-Feb-13 & Male & Guadalajara \\
\hline $\begin{array}{l}\text { Etienne } \\
\text { von } \\
\text { Bertrab }\end{array}$ & $\begin{array}{l}\text { Founder, Ciudad Para } \\
\text { Todos NGO }\end{array}$ & 4-Feb-13 & Male & Guadalajara \\
\hline $\begin{array}{l}\text { Eugenio } \\
\text { Arriaga }\end{array}$ & $\begin{array}{l}\text { Former Social } \\
\text { Promotion Secretary, } \\
\text { city of Guadalajara }\end{array}$ & 27-Feb-13 & Male & Guadalajara \\
\hline $\begin{array}{l}\text { Tomás } \\
\text { López }\end{array}$ & $\begin{array}{l}\text { Leader of } \\
\text { entrepreneurs } \\
\text { association } \\
\text { Guadalajara } 2020\end{array}$ & 11-Feb-13 & Male & Guadalajara \\
\hline $\begin{array}{l}\text { Héctor } \\
\text { Castañón }\end{array}$ & $\begin{array}{l}\text { Former Planning } \\
\text { Director, city of } \\
\text { Guadalajara }\end{array}$ & $6-F e b-13$ & Male & Guadalajara \\
\hline $\begin{array}{l}\text { Hugo } \\
\text { Luna }\end{array}$ & $\begin{array}{l}\text { Director Movimiento } \\
\text { Ciudadano political } \\
\text { party }\end{array}$ & 10-Feb-13 & Male & Guadalajara \\
\hline $\begin{array}{l}\text { José } \\
\text { Manuel } \\
\text { Comer }\end{array}$ & $\begin{array}{l}\text { Control and } \\
\text { Technology Director, } \\
\text { SITEUR }\end{array}$ & 7-Feb-13 & Male & Guadalajara \\
\hline $\begin{array}{l}\text { Jesús } \\
\text { Soto }\end{array}$ & $\begin{array}{l}\text { Founder, Ciudad Para } \\
\text { Todos NGO }\end{array}$ & 6-Feb-13 & Male & Guadalajara \\
\hline $\begin{array}{l}\text { Juan } \\
\text { Ponce }\end{array}$ & $\begin{array}{l}\text { Director, Urban } \\
\text { Technology Lab }\end{array}$ & 11-Feb-13 & Male & Guadalajara \\
\hline
\end{tabular}




\begin{tabular}{|l|l|r|l|l|}
$\begin{array}{l}\text { María } \\
\text { Elena de } \\
\text { la Torre }\end{array}$ & $\begin{array}{l}\text { Advisor to Special } \\
\text { Projects of Zapopan } \\
\text { municipality }\end{array}$ & $\begin{array}{r}\text { 10-Mar- } \\
13\end{array}$ & Female & Guadalajara \\
\hline $\begin{array}{l}\text { Mario } \\
\text { Silva }\end{array}$ & $\begin{array}{l}\text { Director, Colectivo } \\
\text { Ecologista de Jalisco }\end{array}$ & 6-Feb-13 & Male & Guadalajara \\
\hline $\begin{array}{l}\text { Oscar } \\
\text { Castro }\end{array}$ & Professor, ITESO & 7-Feb-13 & Male & Guadalajara \\
\hline $\begin{array}{l}\text { Patricia } \\
\text { Martinez }\end{array}$ & $\begin{array}{l}\text { Member of GDL en } \\
\text { Bici NGO }\end{array}$ & 7-Feb-13 & Female & Guadalajara \\
\hline $\begin{array}{l}\text { Ninfa } \\
\text { Salinas }\end{array}$ & $\begin{array}{l}\text { Senator, Mexican } \\
\text { Congress }\end{array}$ & 29-Jan-13 & Female & Mexico City \\
\hline $\begin{array}{l}\text { Tom } \\
\text { Kessler }\end{array}$ & $\begin{array}{l}\text { Entrepreneur in } \\
\text { transport } \\
\text { technologies }\end{array}$ & 4-Feb-13 & Male & Guadalajara \\
\hline
\end{tabular}


Annex 2 - Full list of key informants interviewed (continued)

\begin{tabular}{|c|c|c|c|c|}
\hline Name & Affiliation & Date & Gender & Place \\
\hline \multicolumn{5}{|c|}{ Medellín (17 interviews) } \\
\hline $\begin{array}{l}\text { Ramiro } \\
\text { Márquez }\end{array}$ & $\begin{array}{l}\text { CEO, Metro de } \\
\text { Medellín }\end{array}$ & $\begin{array}{r}\text { 15-Sep- } \\
11\end{array}$ & Male & Medellín \\
\hline $\begin{array}{l}\text { Alejandro } \\
\text { González }\end{array}$ & $\begin{array}{l}\text { Under-Secretary for } \\
\text { Environment }\end{array}$ & $\begin{array}{r}20-\text { Oct- } \\
11\end{array}$ & Male & Medellín \\
\hline $\begin{array}{l}\text { Alvaro } \\
\text { Restrepo }\end{array}$ & $\begin{array}{l}\text { Transport Specialist, } \\
\text { Former Under- } \\
\text { Secretary for Special } \\
\text { Proyects at the } \\
\text { Metropolitan Area; } \\
\text { former Transport } \\
\text { Under-Secretary in } \\
\text { Medellin }\end{array}$ & $\begin{array}{r}13-\text { Oct- } \\
11\end{array}$ & Male & Medellín \\
\hline David Escobar & $\begin{array}{l}\text { Vice-president, UNE } \\
\text { Telecommunications. } \\
\text { Former Private } \\
\text { Secretary to Mayor } \\
\text { Sergio Fajardo }\end{array}$ & $\begin{array}{r}\text { 20-Sep- } \\
11\end{array}$ & Male & Medellín \\
\hline $\begin{array}{l}\text { Federico } \\
\text { Restrepo }\end{array}$ & $\begin{array}{l}\text { CEO, Empresas } \\
\text { Públicas de Medellín. } \\
\text { Former Planning } \\
\text { Director for Medellin }\end{array}$ & $\begin{array}{r}19-\text { Oct- } \\
11\end{array}$ & Male & Medellín \\
\hline Jesús Acero & $\begin{array}{l}\text { Director of Public } \\
\text { Bike Sharing System }\end{array}$ & $\begin{array}{r}10-\text { Oct- } \\
11\end{array}$ & Male & Medellín \\
\hline $\begin{array}{l}\text { Jorge Mario } \\
\text { Giraldo }\end{array}$ & $\begin{array}{l}\text { Chairman Expreso } \\
\text { Campo Valdez Public } \\
\text { Transport Company. } \\
\text { Co-owner } \\
\text { Cootrasana }\end{array}$ & $\begin{array}{r}10-\text { Oct- } \\
11\end{array}$ & Male & Medellín \\
\hline $\begin{array}{l}\text { José Eugenio } \\
\text { Muñoz }\end{array}$ & $\begin{array}{l}\text { President Alumina } \\
\text { Group, Former } \\
\text { transport negotiator } \\
\text { between the city and } \\
\text { the transport } \\
\text { companies. }\end{array}$ & $\begin{array}{r}20-\text { Oct- } \\
11\end{array}$ & Male & Medellín \\
\hline $\begin{array}{l}\text { José Fernando } \\
\text { Angel }\end{array}$ & $\begin{array}{l}\text { Professor and } \\
\text { Transport Specialist, } \\
\text { Former Transport } \\
\text { Secretary of }\end{array}$ & $\begin{array}{r}\text { 6-Sep- } \\
11\end{array}$ & Male & Medellín \\
\hline
\end{tabular}




\begin{tabular}{|c|c|c|c|c|}
\hline & Medellín & & & \\
\hline $\begin{array}{l}\text { Luis Alfonso } \\
\text { Escobar }\end{array}$ & $\begin{array}{l}\text { Director } \\
\text { Corantioquia } \\
\text { (Regional } \\
\text { Environmental } \\
\text { Corporation) }\end{array}$ & $\begin{array}{r}24-O c t- \\
11\end{array}$ & Male & Medellín \\
\hline Marta Suárez & $\begin{array}{l}\text { Under-Secretary for } \\
\text { Transport, } \\
\text { Metropolitan Area of } \\
\text { the Aburrá Valley }\end{array}$ & $\begin{array}{r}20-S e p- \\
11\end{array}$ & Female & Medellín \\
\hline $\begin{array}{l}\text { Mauricio } \\
\text { Faciolince }\end{array}$ & $\begin{array}{l}\text { Director, } \\
\text { Metropolitan Area of } \\
\text { the Aburrá Valley }\end{array}$ & $\begin{array}{r}26-\text { Oct- } \\
11\end{array}$ & Male & Medellín \\
\hline Felipe Targa & $\begin{array}{l}\text { Former Under- } \\
\text { Minister for } \\
\text { Transport of } \\
\text { Colombia }\end{array}$ & $\begin{array}{r}1-O c t- \\
12\end{array}$ & Male & $\begin{array}{l}\text { Via } \\
\text { Skype }\end{array}$ \\
\hline $\begin{array}{l}\text { Maria Elena } \\
\text { Restrepo }\end{array}$ & $\begin{array}{l}\text { Planning Director, } \\
\text { Metro de Medellín }\end{array}$ & $\begin{array}{r}\text { 15-Sep- } \\
11 \\
\end{array}$ & Female & Medellín \\
\hline $\begin{array}{l}\text { Rafael } \\
\text { Nanclares }\end{array}$ & $\begin{array}{l}\text { Transport Secretary, } \\
\text { City of Medellin }\end{array}$ & $\begin{array}{r}25-\text { Oct- } \\
11 \\
\end{array}$ & Male & Medellín \\
\hline Rodrigo Salazar & $\begin{array}{l}\text { Transport Specialist, } \\
\text { Former Transport } \\
\text { Secretary of } \\
\text { Medellín }\end{array}$ & $\begin{array}{r}20-S e p- \\
11\end{array}$ & Male & Medellín \\
\hline $\begin{array}{l}\text { Juan Pablo } \\
\text { Ospina }\end{array}$ & $\begin{array}{l}\text { Coordinator Urban } \\
\text { Mobility, Plan BIO } \\
2030\end{array}$ & $\begin{array}{r}15-S e p- \\
11\end{array}$ & Male & Medellín \\
\hline
\end{tabular}


HU: HU v1 Carlos Cadena

File: [I: \Atlas HU Cadena \HU v1 Carlos Cadena.hpr7]

Edited by: Super

Date/Time: 2014-03-17 $15: 18: 22$

P 4: Key Informant \#4.docx - 4:1 [Lo raro es Curitibaitiba, el resto ... (17:17) (Super)

Codes: [Path dependency - Families (3): All, Explanatory, Results] No memos

Lo raro es Curitibaitiba, el resto es normal.

P 4: Key Informant \#4.docx - 4:2 [Región sur de Brasil (los 3 es... (19:19) (Super)

Codes: [Cultural identity - Families (2): All, Popular keywords]

No memos

Región sur de Brasil (los 3 estados) son diferentes del resto de Brasil (culturalmente), población muy grande de alemanes, italianos y polacos. Que comenzaron en 1840, 1870 respectivamente. Esas populaciones tienen una relación de vida, estado sociedad, más europea. Acepta más la idea de disciplina y planeamiento.

\section{P 4: Key Informant \#4.docx - 4:3 [Historia de planeamiento viene..] (20:20) (Super) \\ Codes: [High technical planning - Families (2): All, Popular keywords] No memos}

Historia de planeamiento viene desde el principio del siglo 20!

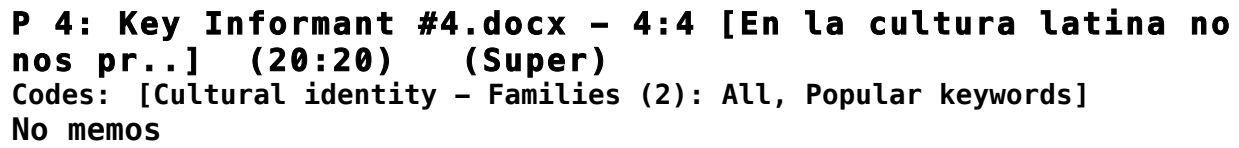

En la cultura latina no nos preocupamos por el futuro 
P 4: Key Informant \#4.docx - 4:5 [Ellos hicieron su proceso en u...] (24:24) (Super)

Codes: [City characteristics - Families (2): All, Explanatory]

No memos

Ellos hicieron su proceso en una ciudad muy pequeña. En ese entonces300.000-400.000 personas. Pocos vehículos circulando. $=$ menos conflictos, si usted decide intervenir, interviene y listo.

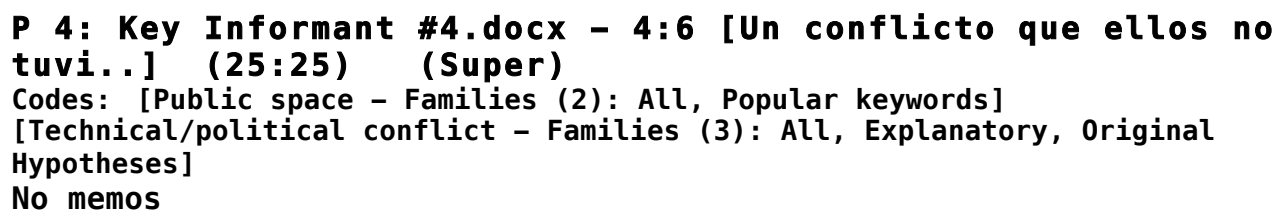

Un conflicto que ellos no tuvieron que enfrentar, fue disputar el espacio público con los automóviles. (Cosa que Sao Paulo nunca ha querido hacer).

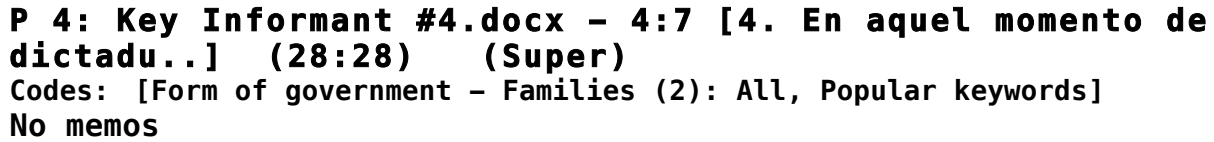

4. En aquel momento de dictadura, el liderazgo política de Paraná era muy amiga de los militares. Por tanto tenían apoyo político y dinero.

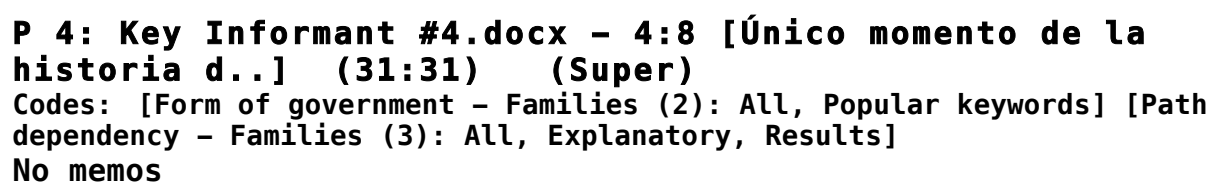

Único momento de la historia de Brasil, en periodo de dictadura, que resolvieron hacer una gran inversión en el transporte público

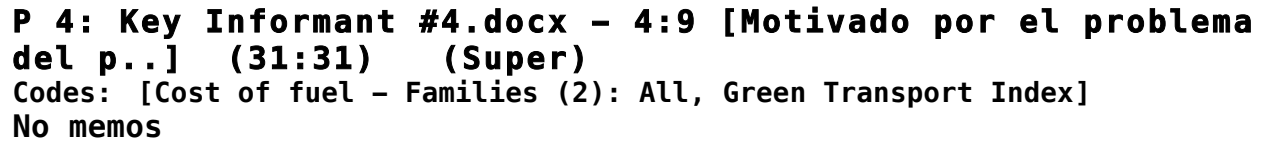

Motivado por el problema del petróleo, porque Brasil estaba 
aumentando importación de petróleo de manera insostenible. Con la crisis del petróleo, los militares dijeron que había que hacer un plan de 30 ciudades. Implantaron corredores de ómnibus en varias ciudades Ninguna tan grande como CURITIBA. Solo que cuando la crisis pasó, solo CURITIBA sobrevivió. Todos los otros, sin sustentación cultural, fueron desapareciendo.

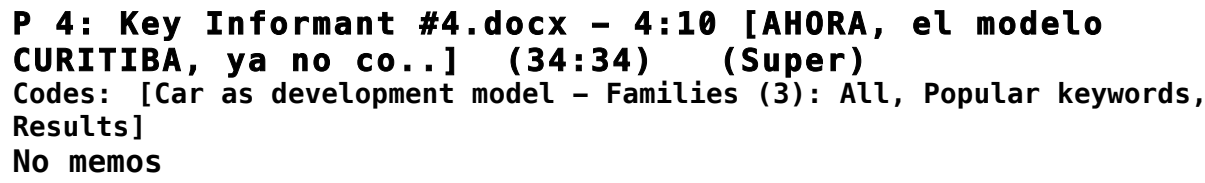

AHORA, el modelo CURITIBA, ya no consigue asegurar la prioridad de TC, no es culpa del prefecto, sino que hasta ahora, TODOS los gobiernos nacionales apoyaron el modelo de Carro es Rey.

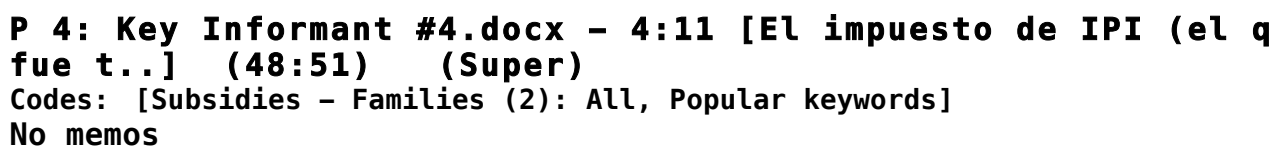

El impuesto de IPI (el q fue transformado en cero). Subsidio en producción de ómnibus.

En la tarifa decide el prefecto.

Si el salario mínimo sube, esto impacta al motorista, ó chofer. Quien va a tener descuentos en los buses? Una parte es el alcalde, otra parte es la constitución brasilera.

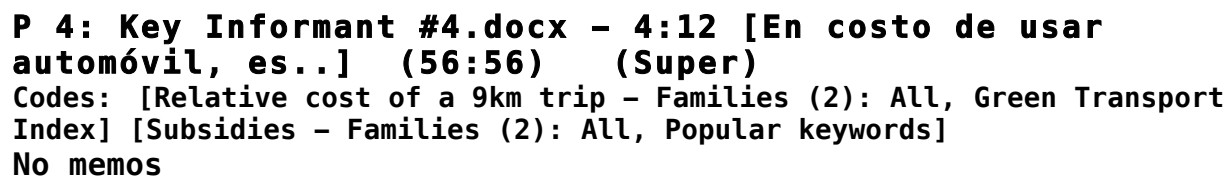

En costo de usar automóvil, es el Gob. federal: gas, impuesto

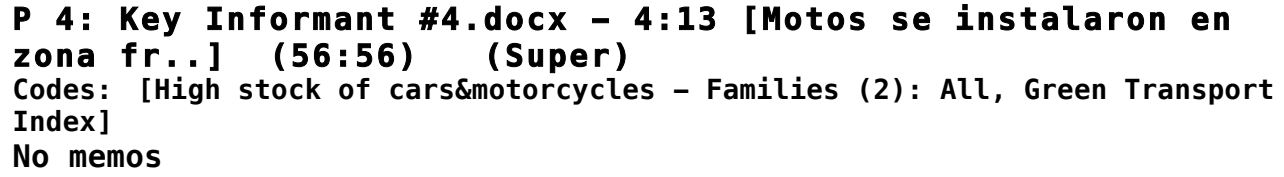


Motos se instalaron en zona franca de Manaos. Gran impulso del 93-94. Una decisión de gran impacto porque a partir de ahí se formó la industria nacional de motos (con subsidio en fabricación y crédito). Con 100 dólares por mes se compra moto. La industria fabrica 2 millones por año ahora

P 4: Key Informant \#4.docx - 4:14 [Se revolucionó toda la sosteni..] (56:57) (Super)

Codes: [Mortality index - Families (2): All, Green Transport Index] No memos

Se revolucionó toda la sostenibilidad por esa decisión se revolucionó todo. Hasta el 2014, morirán 100.000 personas en accidentes de moto.

El PT va a matar 100.000 personas!

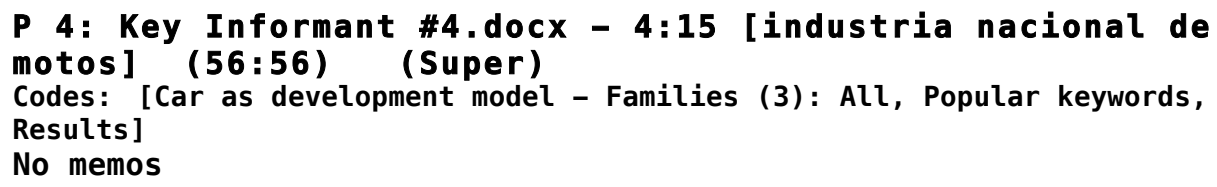

industria nacional de motos

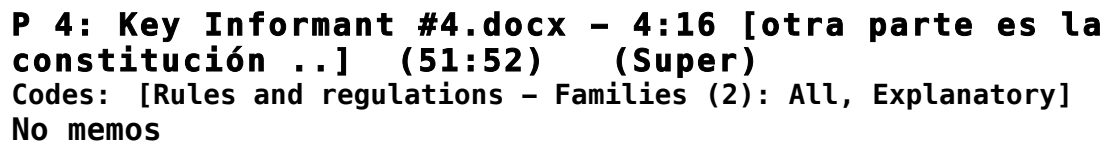

otra parte es la constitución brasilera.

Sistema transporte colectivo privado, gobierno contrata operadores con empresas. 2,60 Reales. Si uno es trabajador por cuenta propia paga todo, si es empleado por empresa tiene derecho a vale de transporte. Máximo 6\% del ingreso mensual en transporte, el patrón paga el restante. (Ley federal) Una de las excepciones de acto de equidad. Solo beneficia a personas de mercado formal. Ley del 85 que se volvió obligatorio en el 87 (antes era facultativa).

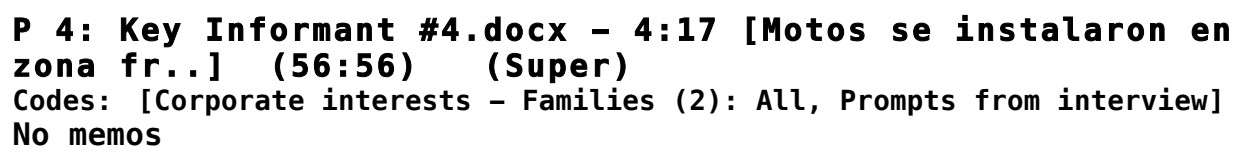


Motos se instalaron en zona franca de Manaos. Gran impulso del 93-94

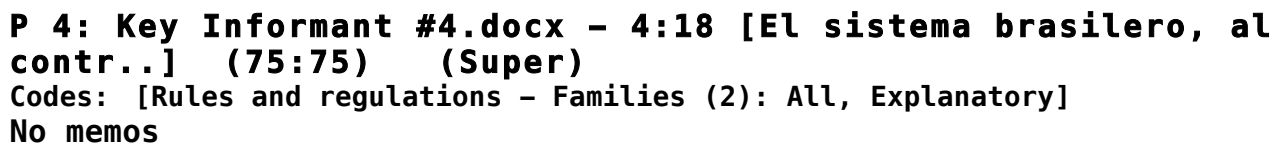

El sistema brasilero, al contrario de todos los países de Latinoamérica, es fuertemente reglamentado y operado por empresas.

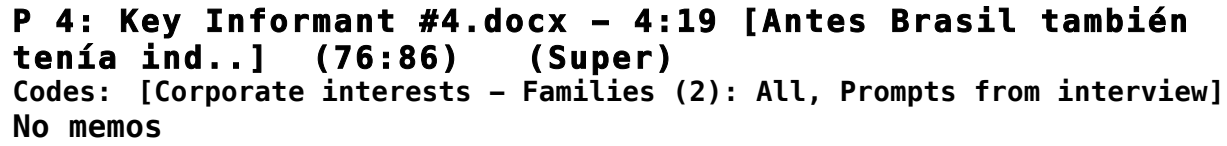

Antes Brasil también tenía individuos manejando busetas, etc.

Por alguna razón tomó la decisión de organizarse en empresas. Hoy, son empresas de BUS.

Más o menos en la década de 40, pero en la madurez se completó el proceso de formalización y reglamentación. La autoridad es el alcalde, contrata define reglas y tarifas.

Se formó un grupo empresarial muy grande y fuerte porque hasta la década del 90, el bus era dominante en todo Brasil. Hoy, nuestro sistema cubre ciudades encima de 60.000 habitantes. Más o menos 1000 ciudades de un total de 5500. Ahí está el 70\% de todo.

Más o menos 100.000110 .000 buses grandes. La industria brasilera de ómnibus es fuerte porque el sistema es reglamentado y los buses tienen que ser substituidos (se formó marco polo, etc.).

Grupo empresarial que fabrica ómnibus muy fuerte.

12000 millones de dólares anuales. Grandes negocios traen grandes poderes.

Ese grupo y el grupo q opera el sistema tiene grande poder y dinero. En congreso por ej.

Hay intereses económico hay corrupción, hay todo.

Los fabricantes tienen su organización

Los operadores tienen su organización.

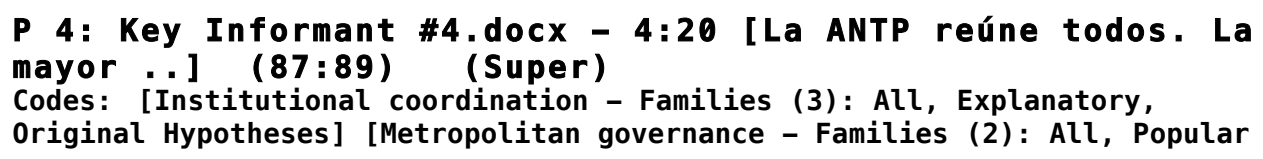


keywords] [Organized interest group strength - Families (3): All,

Explanatory, Original Hypotheses] [Powerful institutional player - Families (2): All, Explanatory]

No memos

La ANTP reúne todos.

La mayor parte de los miembros son técnicos de los gobiernos. Es la gran arena de discusión de políticas.

Tiene comisiones técnicas, 8 muy activas.

\section{P 4: Key Informant \#4.docx - 4:21 [Gran impacto en discusión de p...] (92:93) (Super)}

Codes: [Organized interest group strength - Families (3): All, Explanatory, Original Hypotheses] [Technical/political conflict - Families (3): All, Explanatory, Original Hypotheses]

No memos

Gran impacto en discusión de políticas públicas.

Cuando se trata de transformarla a acción, eso es diferente. A veces se consigue convencer partes del Gob. a hacer alguna cosa, a veces no consigue.

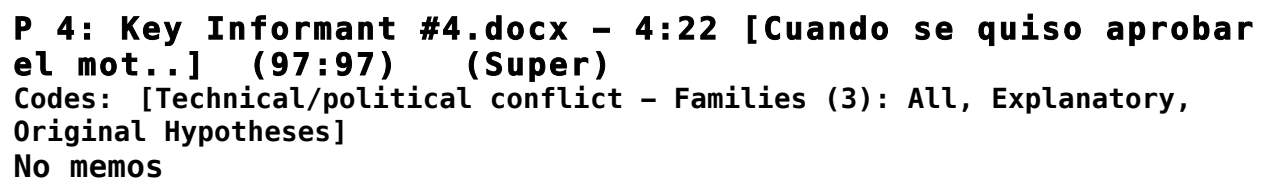

Cuando se quiso aprobar la moto taxi, la ANTP perdió. Ley federal q legaliza la existencia, luego los alcaldes deciden si será permitido o no.

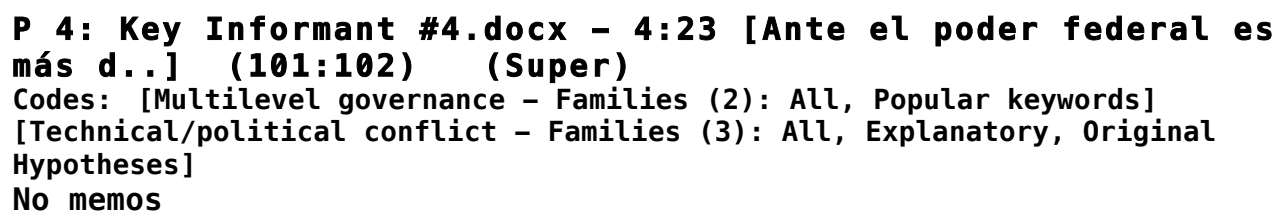

Ante el poder federal es más difícil.

Logra seguir libre de interferencias políticas directas.

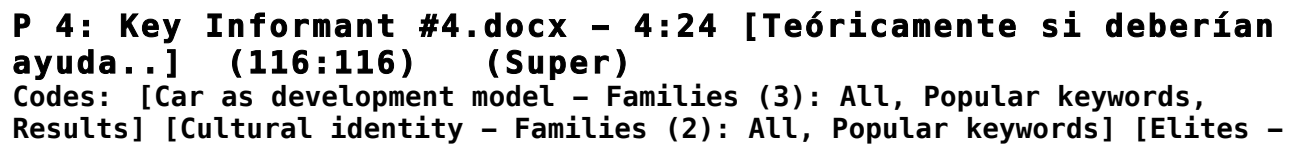


Teóricamente si deberían ayudar, pero la elite brasilera no quiere eso! Es una minoría que defiende el transporte sostenible. Modelo brasilero es de privatización, carro y moto. Deseo de la elite brasilera de enterrar el ómnibus.

P 4: Key Informant \#4.docx - 4:25 [Modelo vencedor es el carro y ... (117:118) (Super)

Codes: [Car as development model - Families (3): All, Popular keywords, Results] [Cultural identity - Families (2): All, Popular keywords] [Path dependency - Families (3): All, Explanatory, Results]

No memos

Modelo vencedor es el carro y moto.

"TC es cosa de pobre"

P 4: Key Informant \#4.docx - 4:26 [Solo los ambientalistas y los .. ] (119:119) (Super)

Codes: [Definition sustainable mobility - Families (2): All, Prompts from interview] [Formal strategy to improve sustainability - Families (2): All, Prompts from interview] [High awareness of sustainability - Families (3): $A l l$, Explanatory, Results ]

No memos

Solo los ambientalistas y los jóvenes están presionando por modelo sustentable.

P 4: Key Informant \#4.docx - 4:27 [En 1930 ya la elite decidió po..] (120:121) (Super)

Codes: [Car as development model - Families (3): All, Popular keywords, Results] [Rules and regulations - Families (2): All, Explanatory] No memos

En 1930 ya la elite decidió por constitución, trabajar no más con trenes, y mudar todo a la carretera y el carro. Creando gran industria automotriz y de camiones y carga.

"MODELO Rodoviario"

P 4: Key Informant \#4.docx - 4:28 [Basta ver todas las acciones d...] (123:123) (Super)

Codes: [Political agenda - Families (2): All, Popular keywords] [Powerful institutional player - Families (2): All, Explanatory]

No memos 
Basta ver todas las acciones de PT a favor del carro

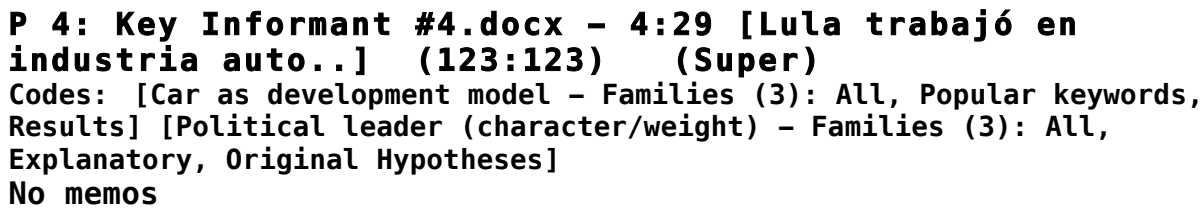

Lula trabajó en industria automovilística

P 4: Key Informant \#4.docx - 4:30 [Lo que sobró del PT que antes... (123:123) (Super)

Codes: [Car as development model - Families (3): All, Popular keywords, Results ]

No memos

Lo que sobró del PT que antes criticaba el modelo dicen simplemente, industria automovilística es esencial para la economía brasilera.

P 4: Key Informant \#4.docx - 4:31 [Peor todavía es la liberación...] (125:126) (Super)

Codes: [Corporate interests - Families (2): All, Prompts from interview] [High cost of public transport - Families (3): All, Explanatory, Results] [High stock of cars\&motorcycles - Families (2): All, Green Transport Index] [Relative cost of public transport - Families (2): All, Green Transport Index ]

No memos

Peor todavía es la liberación de la motocicleta en Brasil. 2 millones de motos por año. Industria de 6000 millones de dólares. Mitad de los usuarios compran la moto para no usar más el TC.

Más de la mitad de los domicilios en Brasil ya tienen carro ó moto.

P 4: Key Informant \#4.docx - 4:32 [EL proyecto de política públic..] (127:127) (Super)

Codes: [Car as development model - Families (3): All, Popular keywords, Results] [Elites - Families (2): All, Popular keywords] [Political agenda Families (2): All, Popular keywords]

No memos

El proyecto de política pública de la élite política de los $\mathbf{3 0}$ fue exitoso. Tuvo interrupción durante la dictadura, durante la crisis de 
petróleo, duro 10 años, y se acabó todo. Había esperanza de que con el PT en el poder cambiara todo.

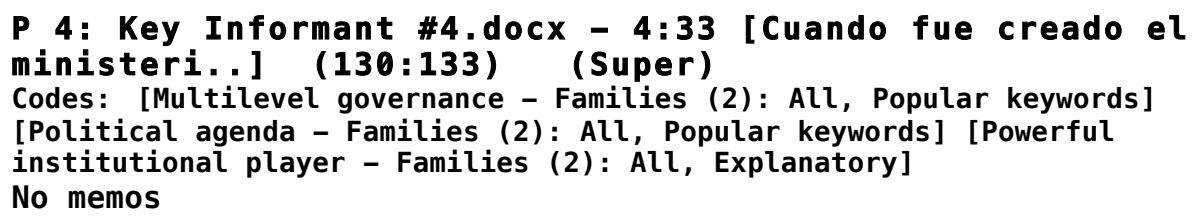

Cuando fue creado el ministerio, porque parecía una victoria para ellos. El primer grupo que entró era del PT. Pero quedo con muchos conflictos a enfrentar. No lograron tomar control. No había decisión desde el centro. Se creó en el 2003, primer gobierno Lula. Pero no había interés.

En función del proyecto de PT políticamente, 2-3 años después el PT hizo re-división de los ministerios y se lo dio a un grupo que no tiene ningún interés de promover. El Secretario de movilidad urbana es una persona q es extraterrestre, no entiende nada, nunca se manifestó, nunca hace nada durante 5 años. Ahora sigue otro pelele. Es un partido de derecha.

Este ministerio no puede ayudar directamente al carro. Esos son finanzas, industria, ciencia y tecnología, etc. (impuesto industrial va a bajar a cero por la crisis, moto puede entrar a Brasil (ciencia y tecnología),

El min simplemente no hace nada a favor del TC (son culpables de inacción)

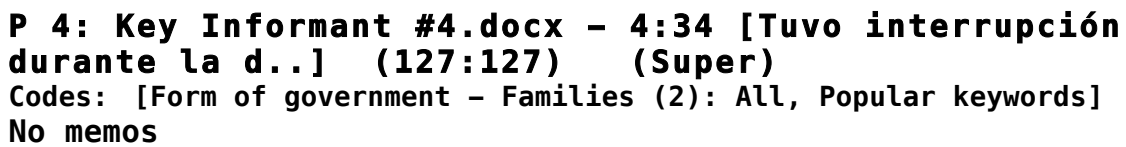

Tuvo interrupción durante la dictadura,

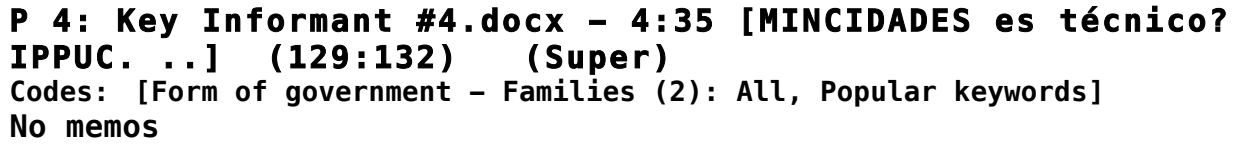

MINCIDADES es técnico? IPPUC.

Cuando fue creado el ministerio, porque parecía una victoria 
para ellos. El primer grupo que entró era del PT. Pero quedo con muchos conflictos a enfrentar. No lograron tomar control. No había decisión desde el centro. Se creó en el 2003, primer gobierno Lula. Pero no había interés.

En función del proyecto de PT políticamente, 2-3 años después el PT hizo re-división de los ministerios y se lo dio a un grupo que no tiene ningún interés de promover. El Secretario de movilidad urbana es una persona q es extraterrestre, no entiende nada, nunca se manifestó, nunca hace nada durante 5 años. Ahora sigue otro pelele. Es un partido de derecha.

Este ministerio no puede ayudar directamente al carro. Esos son finanzas, industria, ciencia y tecnología, etc. (impuesto industrial va a bajar a cero por la crisis, moto puede entrar a Brasil (ciencia y tecnología),

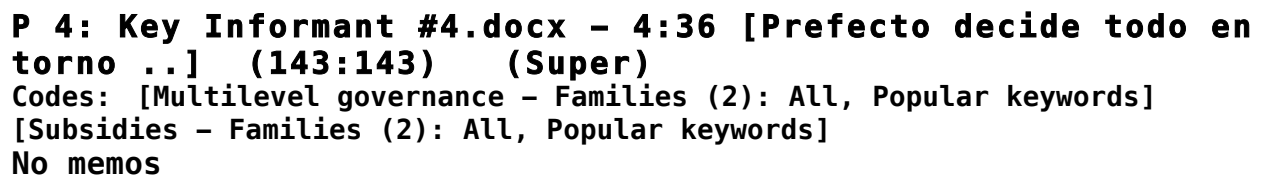

Prefecto decide todo en torno al transporte, pero hay muchas decisiones desde el Gob. Federal que no le incumben. GRADO de SUBSIDIO al transporte.

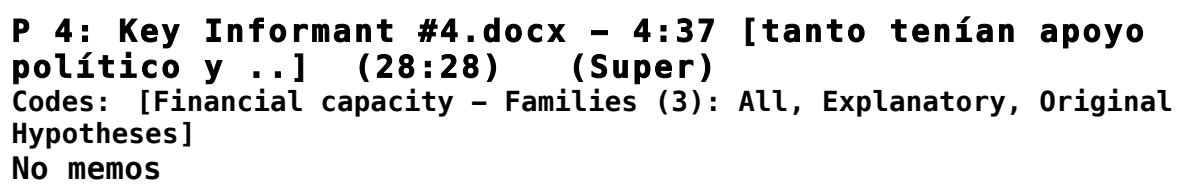

tanto tenían apoyo político y dinero.

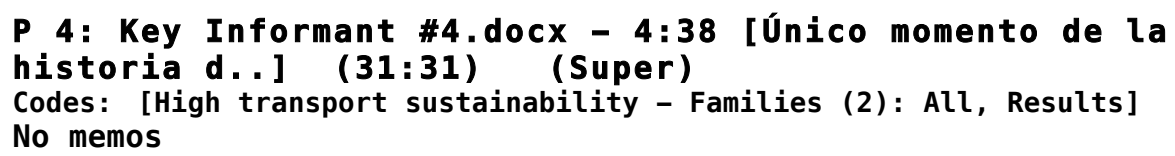

Único momento de la historia de Brasil, en periodo de dictadura, que resolvieron hacer una gran inversión en el transporte público.

P 4: Key Informant \#4.docx - 4:39 [TODOS los gobiernos 
nacionales...] (34:34) (Super)

Codes: [Centralization of authority - Families (3): All, Explanatory, Original Hypotheses] [Form of government - Families (2): All, Popular keywords] [Path dependency - Families (3): All, Explanatory, Results] [Political agenda - Families (2): All, Popular keywords] [Political player conflict - Families (3): All, Explanatory, Original Hypotheses]

No memos

TODOS los gobiernos nacionales apoyaron el modelo de Carro es Rey.

P 4: Key Informant \#4.docx - 4:40 [AHORA no va a pasar nada, la ú...] (103:104) (Super)

Codes: [Centralization of authority - Families (3): All, Explanatory, Original Hypotheses] [Form of government - Families (2): All, Popular keywords] [Path dependency - Families (3): All, Explanatory, Results] [Political agenda - Families (2): All, Popular keywords] [Political player conflict - Families (3): All, Explanatory, Original Hypotheses]

No memos

AHORA no va a pasar nada, la última fuerza política que podría (el PT) no lo va a hacer.

Tiene que aparecer una nueva fuerza política.

P 4: Key Informant \#4.docx - 4:41 [Grandes negocios traen grandes...] (82:82) (Super)

Codes: [Power - Families (2): All, Explanatory]

No memos

Grandes negocios traen grandes poderes.

P 4: Key Informant \#4.docx - 4:42 [Ese grupo y el grupo q opera e..] (83:83) (Super)

Codes: [Power - Families (2): All, Explanatory]

No memos

Ese grupo y el grupo q opera el sistema tiene grande poder y dinero. 


\section{References}

Abah, J., 2012. Strong Organisations in Weak States: Atypical Public Sector Performance in Dysfunctional Environments, Maastricht: MGSoG Dissertation Series, nr. 28.

Adcock, R., Bevir, M. \& Stimson, S.C., 2007. Modern Political Science: AngloAmerican Exchanges since 1880, Princeton University Press.

Alberti, M., 1996. Measuring urban sustainability. Environmental Impact Assessment Review, 16(4-6), pp.381-424.

Allport, R., 2011. Rail rapid transit advances. In Urban Transport in the Developing World: A Handbook of Policy and Practice. Edward Elgar Publishing, pp. 456-487.

Ardila, A., 2004. Transit Planning in Curitiba and Bogotá. Roles in Interaction, Risk, and Change, $\mathrm{PhD}$ thesis at the Massachusetts Institute of Technology.

Arnstein, S.R., 1969. A ladder of citizen participation. Journal of the American Institute of planners, 35(4), pp.216-224.

Banister, D., 1998. Barriers to the implementation of urban sustainability. International Journal of Environment and Pollution, 10(1), pp.65-83.

Banister, D., 2008. The sustainable mobility paradigm. Transport Policy, 15(2), pp.73-80.

Banister, D. et al., 2011. Transportation and the Environment. Annual Review of Environment and Resources, 36(1), pp.247-270.

Berger, P.L. \& Luckmann, T., 2011. The Social Construction of Reality: A Treatise in the Sociology of Knowledge, Open Road Media.

Bermann, G.A., 1994. Taking subsidiarity seriously: federalism in the European Community and the United States. Columbia Law Review, 94(2), pp.331456.

Bertaud, A., 2004. The Spatial Organization of Cities: Deliberate Outcome or Unforeseen Consequence? 
Bertolini, L., 2008. Urban transportation planning in transition. Transport Policy, 15(2), pp.69-72.

Bertolini, L., le Clercq, F. \& Kapoen, L., 2005. Sustainable accessibility: a conceptual framework to integrate transport and land use plan-making. Two test-applications in the Netherlands and a reflection on the way forward. Transport policy, 12(3), pp.207-220.

Bevir, J.M., 2008. Meta-methodology: Clearing the Underbrush. In The Oxford Handbook of Political Methodology. Oxford Handbooks Online, pp. 48-70.

Bevir, M., 2009. Key Concepts in Governance, SAGE.

Black, W., 2000. Toward a Measure of Transport Sustainability, Washington D.C.: Paper prepared for the 79th Annual Meeting of the Transportation Research Board.

Blaikie, N., 2010. Designing Social Research, Polity.

Blumberg, B., Cooper, D.R. \& Schindler, P.S., 2008. Business Research Methods, McGraw-Hill Education.

Bocarejo S., J.P. \& Oviedo H., D.R., 2012. Transport accessibility and social inequities: a tool for identification of mobility needs and evaluation of transport investments. Journal of Transport Geography. Available at: http://linkinghub.elsevier.com/retrieve/pii/S0966692311002286 [Accessed May 28, 2012].

Boisier, S., 1997. Centralización y Descentralización en América Latina a mediados de los 90. Revista Interamericana de Planificación, 29, pp.7-15.

Breheny, M., 1992. The contradictions of the compact city: A review. In Sustainable Development and Urban Form. London, pp. 138-159.

Brenner, N., 1999. Globalisation as reterritorialisation: the re-scaling of urban governance in the European Union. Urban studies, 36(3), pp.431-451.

CAF, 2011. Desarrollo urbano y movilidad en América Latina, Caracas: Corporación Andina de Fomento.

CAF, 2009. Observatorio de Movilidad Urbana para América Latina Información para mejores políticas y mejores ciudades, Caracas: Corporación Andina de Fomento. 
Cadena-Gaitan, C., Escobar-Garcia, D. \& Garcia-Orozco, F., 2013. Political determinants and impact analysis of using a cable system as a complement to an urban transport system, United Nations University, Maastricht Economic and social Research and training centre on Innovation and Technology. Available at: http://ideas.repec.org/p/dgr/unumer/2013017.html [Accessed August 2, 2013].

Cairncross, L., Clapham, D. \& Goodlad, R., 1994. Tenant participation and tenant power in British council housing. Public Administration, 72(2), pp.177200.

Cervero, R., 2001. Integration of Urban Transport and Urban Planning. In M. Freire, ed. The Challenge of Urban Government: Policies and Practices. Washington DC: The World Bank Institute, pp. 407-427.

Chen, Y. \& Li, S.X., 2009. Group identity and social preferences. The American Economic Review, pp.431-457.

Cook, N. \& Wagenaar, H., 2003. Understanding policy practices: action, dialectic and deliberation in policy analysis. In M. A. Hajer \& H. Wagenaar, eds. Deliberative Policy Analysis: Understanding Governance in the Network Society. Cambridge University Press.

Creswell, J.W., 2013. Qualitative Inquiry and Research Design: Choosing Among Five Approaches, SAGE Publications.

Dalvi, M.Q. \& Martin, K.M., 1976. The measurement of accessibility: some preliminary results. Transportation, 5(1), pp.17-42.

Davila, J. D ed., 2012. Movilidad Urbana \& Pobreza: Aprendizajes de Medellín y Soacha, Colombia, Development Planning Unit - UCL.

Davila, Julio D, 2009. Being a mayor: the view from four Colombian cities. Environment and Urbanization, 21(1), pp.37-57.

Denzin, N.K. \& Lincoln, Y.S., 1994. Handbook of qualitative research, Sage Publications.

Devas, N., 2005. Metropolitan governance and urban poverty. Public Administration and Development, 25(4), pp.351-361. 
Dimitriou, H.T. \& Gakenheimer, R.A., 2011. Urban Transport in the Developing World: A Handbook of Policy and Practice, Edward Elgar Publishing.

Dotson, E., 2011. Institutional and political support for urban transport. In Urban Transport in the Developing World: A Handbook of Policy and Practice. Edward Elgar Publishing, pp. 262-304.

EMBARQ, 2010. Modernizing Public Transport: Lessons Learned from Major Bus Improvements in Latin America and Asia, Washington, DC: World Resources Institute.

Easterly, W., 2007. The White Man's Burden: Why the West's Efforts to Aid the Rest Have Done So Much III and So Little Good, Oxford University Press.

Economist Intelligence Unit, 2010. Latin American Green City Index, London.

Economist Intelligence Unit, D., 2009. European Green City Index.

Eisenhardt, K.M., 1989. Building Theories from Case Study Research. The Academy of Management Review, 14(4), pp.532-550.

Fagerberg, J., Mowery, D. \& Verspagen, B., 2009. Innovation, Path Dependency, and Policy:The Norwegian Case: The Norwegian Case, OUP Oxford.

Figueroa, M.J., Fulton, L. \& Tiwari, G., 2013. Avoiding, transforming, transitioning: pathways to sustainable low carbon passenger transport in developing countries. Current Opinion in Environmental Sustainability, 5(2), pp.184190.

Figueroa, M.J. \& Ribeiro, S.K., 2013. Energy for road passenger transport and sustainable development: assessing policies and goals interactions. Current Opinion in Environmental Sustainability, 5(2), pp.152-162.

Filion, P., 1999. Rupture or continuity? Modern and postmodern planning in Toronto. International Journal of Urban and Regional Research, 23(3), pp.421-444.

Flyvbjerg, B., 2006. Five misunderstandings about case-study research. Qualitative inquiry, 12(2), p.219.

Flyvbjerg, Bent, 2001. Making Social Science Matter: Why Social Inquiry Fails and How it Can Succeed Again, Cambridge University Press. 
GIZ, 2013. International Fuel Prices 2012 / 2013, Deutsche Gesellschaft für Internationale Zusammenarbeit (GIZ).

Gakenheimer, R., 2004. Drivers of Travel Demand in Cities of the Developing World. In W. B. C. for S. Development, ed. Mobility 2030: Meeting the Challenges to Sustainability.

Geddes, B., 1990. How the Cases You Choose Affect the Answers You Get: Selection Bias in Comparative Politics. Political Analysis, 2(1), pp.131-150.

Gerring, John, 2007. Case Study Research: Principles and Practices, Cambridge University Press.

Gerring, John, 2012. Social Science Methodology: A United Framework (second edition), Cambridge University Press.

Gerring, J., 2007. The case study: what it is and what it does. In C. Boix \& Susan Carol Stokes, eds. The Oxford Handbook of Comparative Politics. Oxford Handbooks Online, pp. 90-122.

Gillham, B., 2005. Research Interviewing: The Range of Techniques, McGraw-Hill International.

Gold, J.R., 1998. Creating the Charter of Athens: CIAM and the functional city, 1933-43. Town Planning Review, 69(3), p.225.

Goodman, R., 1971. After the planners, Simon and Schuster.

Gouvea-Campos, V., Rodrigues Ramos, R. \& de Miranda e Silva Correia, D., 2009. Multi-Criteria Analysis Procedure for Sustainable Mobility Evaluation in Urban Areas. Journal of Advanced Transportation, 43(4), pp.371-390.

Gray, G.E., 2004. Concise Guide to Evidence-Based Psychiatry, American Psychiatric Pub.

Gustavson, K.R., Lonergan, S.C. \& Ruitenbeek, H.J., 1999. Selection and modeling of sustainable development indicators: a case study of the Fraser River Basin, British Columbia. Ecological Economics, 28(1), pp.117-132.

Haig, B.D., 2005. An abductive theory of scientific method. Psychological methods, 10(4), p.371. 
Haig, B.D., 1995. Grounded theory as scientific method. Philosophy of education, 28(1), pp.1-11.

Hajer, M.A. \& Wagenaar, H., 2003. Deliberative Policy Analysis: Understanding Governance in the Network Society, Cambridge University Press.

Hall, P.A. \& Taylor, R.C., 1996. Political Science and the Three New Institutionalisms*. Political studies, 44(5), pp.936-957.

Hammer, S. et al., 2011. Cities and Green Growth: A Conceptual Framework. OECD Regional Development Working Papers.

Harvey, D., 1987. Flexible accumulation through urbanization: reflections on "post-modernism"in the American city. Antipode, 19(3), pp.260-286.

Hassel, A., 2010. Multi-level governance and organized interests. In H. E. Michael Zürn, ed. To be published in: Handbook of Multi-Level Governance. Cheltenham, Northampton, MA: Edward Elgar.

Henderson, V., 2003. The urbanization process and economic growth: The sowhat question. Journal of Economic Growth, 8(1), pp.47-71.

Higley, J. \& Gunther, R., 1992. Elites and democratic consolidation in Latin America and Southern Europe, Cambridge University Press. Available at: http://books.google.com/books?hl=es\&lr=\&id=mkfEamELMFAC\&oi=fnd\& $\mathrm{pg}=P R 7 \& d q=$ latin+america+elites\&ots=10hO7QC8oX\&sig=bVGhX9JCcg3Y O5H-BqGXZpWWMm4 [Accessed March 16, 2014].

Hoffman, K. \& Centeno, M.A., 2003. The lopsided continent: inequality in Latin America. Annual Review of Sociology, pp.363-390.

Holuigue, C., 2011. Institucionalidad y transporte público urbano Santiago y Medellin.

Hull, A., 2008. Policy integration: What will it take to achieve more sustainable transport solutions in cities. Transport Policy, 15(2), pp.94-103.

IADB, 2006. La política de las políticas públicas: progreso económico y social en América Latina I.-A. D. B. (IADB) Harvard University, ed., Editorial Planeta.

IADB, 2012. Methodological guide Emerging Sustainable Cities Initiative, Washington, DC. 
IEA, 2012. Energy Technology Perspectives, Paris: International Energy Agency.

ITDP, 2013a. Desarrollo Orientado al Transporte: Regenerar las Ciudades Mexicanas para Mejorar la Movilidad, Instituto de Políticas para el Transporte y Desarrollo México.

ITDP, 2013b. Hacia una Política Nacional de Ciudad: Cinco Propuestas para el Plan Nacional de Desarrollo 2013-2018, Instituto de Políticas para el Transporte y Desarrollo México. Available at: http://mexico.itdp.org/wpcontent/uploads/Hacia-una-politica-nacional-de-ciudad.pdf [Accessed December 19, 2013].

ITDP \& Gehl Architects, 2010. Our Cities Ourselves: Ten Principles of Transport in Urban Life, New York.

Jacobs, A. \& Appleyard, D., 1987. Toward an urban design manifesto. Journal of the American Planning Association, 53(1), pp.112-120.

Jacobs, J.M., 1961. The Death and Life of Great American Cities, Modern Library.

Jaramillo, S., 2012. Urbanización informal: diagnósticos y políticas. Una revisión al debate latinoamericano para pensar líneas de acción actuales, UNIVERSIDAD DE LOS ANDES-CEDE. Available at: http://ideas.repec.org/p/col/000089/009820.html [Accessed March 11, 2014].

Jefferson, M., 1989. Why Geography? The Law of the Primate City. Geographical Review, 79(2), pp.226-232.

Jensen, M., 1999. Passion and heart in transport-a sociological analysis on transport behaviour. Transport Policy, 6(1), pp.19-33.

John, P., 2001. Local Governance in Western Europe, SAGE.

John, P., 2006. Why study urban politics?, Presentation to the Political Studies Association Conference: University of Manchester.

Joumard, R. \& Gudmundsson, H., 2010. Indicators of Environmental Sustainability in Transport, Institut national de recherche sur les transports et leur sécurité - INRETS.

KPMG, 2010. Sustainable Insight: City Typology as the Basis for Policy., Amsterdam. 
Kemp, R., Schot, J. \& Hoogma, R., 1998. Regime shifts to sustainability through processes of niche formation: the approach of strategic niche management. Technology Analysis \& Strategic Management, 10(2), pp.175-198.

Kenworthy, J., 2011. An international compaative perspective on fast-rising motorization and automobili dependence. In H. T. Dimitriou \& R. Gakenheimer, eds. Urban Transport in the Developing World: A Handbook of Policy and Practice. Edward Elgar Publishing, pp. 71-111.

Klink, J., 2005. La función de la gobernabilidad metropolitana en la economía global: Definición de ciudad-región y áreas metropolitanas. In E. C.-R. Rojas, ed. Gobernar las Metrópolis. Washington D.C.: Universidad Alcalá de Henares, Inter-American Development Bank (IADB), pp. 127-191.

Kvale, S. \& Brinkmann, S., 2009. InterViews: Learning the Craft of Qualitative Research Interviewing, SAGE Publications.

Landman, T., 2008. Issues and Methods in Comparative Politics: An Introduction, Routledge.

Lattes, A., 1995. Urbanización, crecimiento urbano y migraciones en América Latina. Pensamiento iberoamericano, (28). Available at: http://www.cepal.org/publicaciones/xml/1/34411/LCG.164_p7.pdf [Accessed March 11, 2014].

Lee, D.R.W. et al., 2003. Toward sustainable transportation indicators for California, Mineta Transportation Institute, San José State University.

Lefèvre, B., 2010. Urban Transport Energy Consumption: Determinants and Strategies for its Reduction.. An analysis of the literature. SAPIENS. Surveys and Perspectives Integrating Environment and Society, (2.3).

Lefèvre, Benoit, 2009. Urban Transport Energy Consumption: Determinants and Strategies for its Reduction. SAPIENS, 2(3).

Lefèvre, C., 1998. Metropolitan government and governance in western countries: a critical review. International journal of urban and regional research, 22(1), pp.9-25.

Lefévre, C., 2005. Gobernabilidad democrática de las áreas metropolitanas: Experiencias y lecciones internacionales para las ciudades latinoamericanas. In E. C.-R. Rojas, ed. Gobernar las Metrópolis. 
Washington D.C.: Universidad Alcalá de Henares, Inter-American Development Bank (IADB), pp. 195-261.

Litman, T., 2013. Developing Indicators for Sustainable and Livable Transport Planning. Victoria Transport Policy Institute.

Litman, T., 1999. Exploring the paradigm shifts needed to reconcile transportation and sustainability objectives. Transportation Research Record: Journal of the Transportation Research Board, 1670(-1), pp.8-12.

Litman, T., 2010. Sustainable Transport and TDM. Available at: http://www.vtpi.org/tdm/tdm67.htm.

Litman, T., 2009. Sustainable Transportation Indicators: A Recommended Research Program For Developing Sustainable Transportation Indicators and Data.

Lor, P.J., 2014. International and Comparative Librarianship: A Thematic Approach, K. G. Saur Verlag GmbH.

Mahoney, J., 2000. Path dependence in historical sociology. Theory and Society, 29(4), pp.507-548.

March, J.G. \& Olsen, J., 1989. Rediscovering Institutions, New York: Simon and Schuster.

Massiris Cabeza, A., 2012. Políticas Latinoaméricanas de Ordenamiento Territorial. Realidad y Desafíos. In Procesos de Ordenamiento en América Latina y Colombia. Bogotá: Instituto Hábitat, Ciudad y Territorio.

Mathison, S., 1988. Why Triangulate? EDUCATIONAL RESEARCHER, 17(2), pp.1317.

May, A.D. et al., 2012. An option generation tool for potential urban transport policy packages. Transport Policy, 20, pp.162-173.

Meadows, D.H. et al., 1972. The Limits to Growth: A Report to The Club of Rome (1972), Universe Books, New York. Available at: http://www.askforce.org/web/Global-Warming/Meadows-Limits-to-Growth-Short1972.pdf [Accessed October 29, 2013].

Meyer, J.W. \& Rowan, B., 1977. Institutionalized organizations: Formal structure as myth and ceremony. American journal of sociology, pp.340-363. 
Meyer, M. \& Miller, E., 2001. Urban transportation planning: a decision-oriented approach. Second ed., New York: McGraw-Hill.

Millard-Ball, A. \& Schipper, L., 2011. Are we reaching peak travel? Trends in passenger transport in eight industrialized countries. Transport Reviews, 31(3), pp.357-378.

Mitchell-Weaver, C., Miller, D. \& Deal Jr, R., 2000. Multilevel Governance and Metropolitan Regionalism in the USA. Urban Studies (Routledge), 37(5/6), pp.851-876.

Mohamad, J. \& Kiggundu, A.T., 2007. Rise Of The Private Car In Kuala Lumpur, Malaysia. IATSS RESEARCH, 31(1), p.69.

Monzón, A., 2005. Gestión del transporte metropolitano. In E. C.-R. Rojas, ed. Gobernar las Metrópolis. Washington D.C.: Universidad Alcalá de Henares, Inter-American Development Bank (IADB), pp. 409-469.

Moomaw, R.L., 1988. Agglomeration economies: localization or urbanization? Urban Studies, 25(2), pp.150-161.

Moser, P.K., 2005. The Oxford Handbook of Epistemology, Oxford Handbooks Online.

Mumford, L., 1961. The City in History: Its Origins, Its Transformations, and Its Prospects, MJF Books.

Nakamura, R., 1985. Agglomeration economies in urban manufacturing industries: a case of Japanese cities. Journal of Urban Economics, 17(1), pp.108-124.

Naumes, W. \& Naumes, M.J., 2006. The Art \& Craft of Case Writing, M.E. Sharpe.

Neuendorf, K.A., 2002. The content analysis guidebook, Sage.

Neumayer, E., 2003. Sustainability and well-being indicators, Working Paper; UNU-WIDER.

Newman, P. \& Kenworthy, J., 1989. Cities and automobile dependence: a sourcebook, Gower Technical.

Newman, P.G. \& Kenworthy, J.R., 1989. Cities and automobile dependence: an international sourcebook, Available at: http://trid.trb.org/view.aspx?id=351194 [Accessed November 7, 2013]. 
Newton, K., 1976. Second city politics: democratic processes and decision-making in Birmingham. Available at: http://eprints.soton.ac.uk/34417/ [Accessed January 17, 2012].

Nickson, R.A., 2011. Where is Local Government going in Latin America? A comparative perspective. International Centre for Local Democracy, (Working Paper No. 6), pp.1-36.

Norcliffe, G., Bassett, K. \& Hoare, T., 1996. The emergence of postmodernism on the urban waterfront: geographical perspectives on changing relationships. Journal of Transport Geography, 4(2), pp.123-134.

North, D.C., 1990. Institutions, Institutional Change and Economic Performance, Cambridge University Press.

OECD, 2002. OECD Guidelines towards Environmentally Sustainable Transport, Paris.

OECD, 2000. The Reform of Metropolitan Governance, Paris.

OECD/IEA, 2008. World Energy Outlook, Paris: International Energy Agency, OECD Publications.

Ohmae, K., 1996. The end of the nation state: the rise of regional economies, Free Press Paperbacks.

Osborne, D.E., 1992. Reinventing Government: How the Entrepreneurial Spirit Is Transforming the Public Sector, Addison-Wesley Publishing Company, Incorporated.

Owen, D., 2010. Green Metropolis: Why Living Smaller, Living Closer, and Driving Less Are theKeys to Sustainability Reprint ed., Riverhead Trade.

O' Meara Sheehan, M., 2001. City Limits: Putting the Brakes on Sprawl, Washington, DC: Worldwatch paper 156.

Paiva, A., 2003. Relevance of Metropolitan Government in Latin American Cities: Inter-institutional Coordination in Caracas, Venezuela and Monterrey, Mexico, Delft: Eburon Delft.

Pardo, C., 2005. Salida de Emergencia: Reflexiones Sociales sobre las Políticas del Transporte. Universitas Psychologica, 4(3), pp.271-284. 
Parlow, E., 2011. Chapter 1.2: Urban Climate. In Urban Ecology. Oxford University Press, pp. 31-43. Available at:

http://books.google.com/books?id=0_qtm_GsQt4C.

Parra, F.R. \& Garcias, C.M., 2005. El transporte público colectivo en Curitiba y Bogotá. Revista de ingeniería-Facultad de Ingeniería Universidad de Los Andes, p.106-15.

Peñalosa, E., 2013. Buses: not sexy but the only solution. In R. Burdett, ed. City Transformations. London: London School of Economics.

Peñalosa, E., 2003. La Ciudad y la Igualdad. El Malpensante, (Bogotá).

Pflieger, G. et al., 2009. How Does Urban Public Transport Change Cities? Correlations between Past and Present Transport and Urban Planning Policies. Urban Stud, 46(7), pp.1421-1437.

Pierson, P., 2000. Increasing Returns, Path Dependence, and the Study of Politics. The American Political Science Review, 94(2), pp.251-267.

Popper, K.R., 2002. The Logic of Scientific Discovery, Routledge.

Portes, A. \& Hoffman, K., 2003. La estructura de clases en América Latina: composición y cambios durante la era neoliberal. Desarrollo Económico, pp.355-387.

Portes, A. \& Roberts, B.R., 2005. The free-market city: Latin American urbanization in the years of the neoliberal experiment. Studies in Comparative International Development, 40(1), pp.43-82.

Procopiuck, M., 2011. Governança Multinível E Inovações Em Trajetórias De Sistemas Sociotécnicos: O Caso Dos Transportes Coletivos De Curitiba. Curitiba: Pontificia Universidade Católica do Paraná.

Przeworski, A., Stokes, Susan C \& Manin, B., 1999. Democracy, accountability, and representation, Cambridge University Press. Available at: http://books.google.com/books?hl=es\&lr=\&id=aid080pvF5gC\&oi=fnd\&pg $=$ PR9\&dq=political+accountability\&ots=W07qb0StTL\&sig=0ThVHoxWMQa NTpoZiwbEbdOhmug [Accessed March 16, 2014].

Rabinovitch, J., 1996. Innovative land use and public transport policy: The case of Curitiba, Brazil. Land Use Policy, 13(1), pp.51-67. 
Rabinovitch, J. \& Leitman, J., 1996. Urban planning in Curitiba. Scientific American, 274(3). Available at: http://trid.trb.org/view.aspx?id=458138 [Accessed December 19, 2013].

Ragin, C.C., 1987. The Comparative Method: Moving Beyond Qualitative and Quantitative Strategies, University of California Press.

Ramírez Ríos, J., 2011. Historia Críticas de la Planeación Urbana en Colombia. Una aproximación Interpretativa desde los Estudios Sociales de la Ciencia. Universidad Nacional de Colombia Facultad de Artes, Área Curricular: Territorio, Hábitat y Sociedad.

Rees, W. \& Wackernagel, M., 2012. Urban ecological footprints: why cities cannot be sustainable-and why they are a key to sustainability. The Urban Sociology Reader, p.157.

De Ridder, W. \& Petersen, A., 2008. Types of impact assessment and tool overview, Bilthoven, The Netherlands.: Netherlands Envionmental Assessment Agency.

Roberts, N., 2004. Public deliberation in an age of direct citizen participation. The American Review of Public Administration, 34(4), pp.315-353.

Rojas, E, Cuadrado-Roura, J. \& Fernández Guell, J. eds., 2005. Gobernar las Metropolis, Washington D.C.: Universidad Alcalá de Henares, InterAmerican Development Bank (IADB).

Rojas, Eduardo, 2005. Las regiones metropolitanas de América Latina. Problemas de gobierno y desarrollo. In Gobernar las Metrópolis. Washington D.C.: Universidad Alcalá de Henares, Inter-American Development Bank (IADB), pp. 35-59.

SAUTU, R. et al., 2005. Manual de Metodología: construcción del marco teórico, formulación de los objectivos y elección de la metodología. In Buenos Aires: CLACSO, p. 187 p.

SUTP, 2010. Financing Sustainable Urban Transport. In Sustainable Transport: A Sourcebook for Policy-makers in Developing Cities.

Sager, F., 2005. Metropolitan institutions and policy coordination: The integration of land use and transport policies in Swiss urban areas. Governance, 18(2), pp.227-256. 
Salinas, V. \& Wormald, G., 2003. Informalidad en Chile durante la década de los años 90. In Conference on Latin American Urbanization in the Late Twentieth Century, Institute for Social and Economic Development (IDES), Buenos Aires.

Santos, G., Behrendt, H. \& Teytelboym, A., 2010. Part II: Policy instruments for sustainable road transport. Research in Transportation Economics, 28(1), pp.46-91.

Sassen, S., 2001. The Global City: New York, London, Tokyo, Princeton University Press.

Schafer, A., 2011. The future of energy for urban transport. In Urban Transport in the Developing World: A Handbook of Policy and Practice. Edward Elgar Publishing.

Schafer, A. \& Victor, D.G., 2000. The future mobility of the world population. Transportation Research Part A: Policy and Practice, 34(3), pp.171-205.

Scharpf, F.W., 1997. Games Real Actors Play: Actor-Centered Institutionalism in Policy Research, Boulder, CO: Westview.

Schumpeter, J.A., 1934. The Theory of Economic Development: An Inquiry Into Profits, Capital, Credit, Interest, and the Business Cycle, Transaction Publishers.

Seawright, J., 2008. Case Selection Techniques in Case Study Research. Political Research Quarterly, 61(2), pp.294-308.

Sharpe, L.J., 1995. The Government of World Cities: The Future of the Metro Model, Wiley.

Sheller, M., 2004. Automotive emotions feeling the car. Theory, culture \& society, 21(4-5), pp.221-242.

Simon, D., 1993. The World City Hypothesis: Reflections from the Periphery, University of London : Centre for developing Areas.

Smith, H. \& Raemaekers, J., 1998. Land use pattern and transport in Curitiba. Land Use Policy, 15(3), pp.233-251. 
Steg, L., 2005. Car use: lust and must. Instrumental, symbolic and affective motives for car use. Transportation Research Part A: Policy and Practice, 39(2), pp.147-162.

Steinberg, F., 2005. Strategic urban planning in Latin America: Experiences of building and managing the future. Habitat International, 29(1), pp.69-93.

Thelen, K., 1999. Historical Institutionalism in Comparative Politics. Annual Review of Political Science, 2(1), pp.369-404.

Thompson, J.D. \& Tuden, A., 1959. Strategies, Structures, and Processes of Organizational Decision, Bobbs-Merrill.

Tiebout, C.M., 1956. A Pure Theory of Local Expenditures. Journal of Political Economy, 64(5), pp.416-424.

Torfing, J., 2001. Path-Dependent Danish Welfare Reforms: The Contribution of the New Institutionalisms to Understanding Evolutionary Change. Scandinavian Political Studies, 24(4), pp.277-309.

UITP, 2011. Public transport: the smart green solution. In 59th UITP World Congress and Mobility \& City Transport Exhibition Boosting public transport: Action! Dubai.

UN-ESCAP, 2005. What is Good Governance?, Social Commission for Asia and the Pacific (ESCAP).

UN-HABITAT, 2013. Planning and Design for Sustainable Urban Mobility - Global Report Human Settlements 2013, Nairobi.

UN-HABITAT, 2012. State of the World's Cities 2012/2013: Prosperity of Cities, Nairobi.

UN-HABITAT, 2011. State of the World's Cities 2010/2011: Bridging the Urban Divide. Nairobi.

UN-HABITAT, 2010. Annual Report 2010. Nairobi: United Nations Human Settlements Programme.

UN-HABITAT, 2009. Planning sustainable cities-Global report on human settlements 2009, Nairobi.

UN-HABITAT, 2002. Sustainable Urbanization Achieving Agenda 21, Nairobi. 
UNAL, 2012. Procesos de Ordenamiento en América Latina y Colombia, Bogotá: Instituto Hábitat, Ciudad y Territorio.

UNDESA, 2013. Population density and urbanization, New York: Last Accesses on March 2014 from

http://unstats.un.org/unsd/demographic/sconcerns/densurb/densurbme thods.htm.

UNDP, 2013. Citizen Security with a Human Face: evidence and proposals for Latin America, New York: UNDP, Regional Human Development Report.

UNEP, 1972. Declaration of the United Nations Conference on the Human Environment. Available at:

http://www.unep.org/Documents.multilingual/Default.asp?DocumentID= 97\&ArticlelD=1503 [Accessed October 29, 2013].

UNEP, 2011. Towards a Green Economy - Transport: Investing in energy and resource efficiency, Nairoboi.

UNFPA, 2007. State of world population 2007: unleashing the potential of urban growth,

Urry, J., 2004. The "system" of automobility. Theory, Culture \& Society, 21(4-5), pp.25-39.

VNG uitgeverij, 2000. The Economic Significance of Cycling A study to illustrate the costs and benefits of cycling policy, The Hague.

WBCSD, 2004. Mobility 2030: Meeting the Challenges to Sustainability W. B. C. for S. Development, ed., World Business Council for Sustainable Development.

WWF, 2010. Reinventing the City: Three prerequisites for greening urban infrastructure, Available at: http://www.wwf.se/source.php/1285816/Reinventing\%20the\%20City_FI NAL_WWF-rapport_2010.pdf [Accessed January 29, 2012].

Walker, D., 1987. Snow White and the 17 Dwarfs: From Metro Cooperation to Governance. National Civic Review, 76, pp.14-28.

Weisbrod, G. \& Reno, A., 2009. Economic impact of public transportation investment, American Public Transportation Association. 
Whitelegg, J., 2007. Integrating sustainability into transport. In National Transport Conference. London. Available at: www.eco-

logica.co.uk/pdf/Integrating_Sustainability_Transport.pdf.

Willis, E., da CB Garman, C. \& Haggard, S., 1999. The politics of decentralization in Latin America. Latin American Research Review, pp.7-56.

Wittneben, B. et al., 2009. Integrating Sustainable Transport Measures into the Clean Development Mechanism. Transport Reviews, 29(1), pp.91-113.

World Bank, 1996. Sustainable Transport: Priorities for Policy Reform, Washington D.C.

World Commission on Environment and Development (WCED). 1987. Our common future. Oxford: Oxford University Press.

Wright, L., 2011. Bus rapid transit:a review of recent advances. In Urban Transport in the Developing World: A Handbook of Policy and Practice. Edward Elgar Publishing, pp. 421-455.

Wright, L., 2004. The limits of technology: achieving transport efficiency in developing nations. Available at: http://eprints.ucl.ac.uk/108/ [Accessed January 17, 2012].

Yin, R.K., 2009. Case Study Research: Design and Methods, SAGE.

Zegras, C. et al., 2004. Indicators for Sustainable Urban Development. Chapter 7 in From Understanding to Action: Sustainable Urban Development in Medium-Sized Cities in Africa and Latin America (M. Keiner, C. Zegras, W. Schmid, D. Salmerón, Eds.). In Medium-Sized Cities in Africa and Latin America (M. Keiner, C. Zegras, W. Schmid, D. Salmerón, Eds.). Dordrecht, The Netherlands: Springer.

Zegras, C., 2005a. Sustainable urban mobility: exploring the role of the built environment, (Doctoral dissertation, Massachusetts Institute of Technology).

Zegras, C., 2005b. Sustainable urban mobility: exploring the role of the built environment, (Doctoral dissertation, Massachusetts Institute of Technology). 


\section{Samenvatting in het Nederlands}

Dit proefschrift bestudeert de relatie tussen politieke en institutionele factoren in Latijns-Amerikaanse steden, en het duurzaamheidsniveau van hun openbare transport systemen. Dit onderzoek contribueert met een unieke en diepgaande analyse van de duurzame transport in de context van Curitiba (Brazilië), Guadalajara (Mexico), en Medellín (Colombia).

De stedelijke populatie in onze wereld groeit hard. Het tempo van de stedelijke bevolkingsgroei in ontwikkelingslanden vindt vaak plaats in een chaotisch een ongestructureerde manier. De exponentiële groei van de stedelijke bevolking gaat gepaard met een uitzonderlijke vernietiging van stedelijke ecosystemen en het ongenuanceerd gebruik van eindige natuurlijke hulpbronnen, wat resulteert in milieurampen in stedelijke gebieden. Een specifiek onderdeel om verder te onderzoeken bij het bestuderen van stedelijke verduurzaming zijn de transportsystemen. Deze zijn niet alleen inherent verbonden met de stedelijke hoeveelheid milieuvervuiling en congestie, maar ook hebben ook te maken met de vitale structuur die het mogelijk maakt de burgers te mobiliseren, en om hen te laten voldoen aan hun sociale en economische behoeften.

De afhankelijkheid van het gebruik van auto's is een van de belangrijkste verschijnselen om te overwegen. Het impliceert dat steden waar auto's het belangrijkste vervoersmiddel zijn, de burgers niet de keuzevrijheid wordt geboden over de manier waarop ze willen leven en bewegen in en rond de stad. Helaas, heeft deze auto afhankelijkheid ernstige sociale, ecologische en economische gevolgen. Dit proefschrift behandelt dit probleem, en pocht de pogingen te meten die het duurzame transport systemen in LatijnsAmerikaanse steden bevorderen.

'Duurzaam vervoer' heeft in dit proefschrift betrekking op een stedelijk systeem dat (1) ecologische duurzaamheid steunt door de bescherming van het mondiale klimaat, ecosystemen, de volksgezondheid en de natuurlijke bronnen; (2) economische duurzaamheid door middel van een betaalbare, eerlijke en efficiënt transport middel dat een duurzame competitieve economie bevordert, evenals een evenwichtige regionale ontwikkeling en het scheppen van aanzienlijke werkgelegenheid, en; (3) sociale duurzaamheid, door de toegang en ontwikkelingsbehoeften van individuen, bedrijven en de maatschappij die voldoet aan de veiligheidseisen en die in overeenstemming is met de menselijke en ecologische gezondheid, terwijl 
het de armoedebestrijding en het eigen vermogen tussen de opeenvolgende generaties bevordert, en dit alles volgens het milieu programma van de Verenigde Naties.

Met het oog op de institutionele en politieke factoren te identificeren die de verschillen in duurzaam transport uitkomsten in grootstedelijke gebieden in Latijns-Amerika te bepalen, wordt dit project begeleid door de volgende onderzoeksvraag: "Onder welke politieke en institutionele omstandigheden is de duurzaamheid van het stedelijk vervoer gefaciliteerd in LatijnsAmerikaanse grootstedelijke gebieden?". De afhankelijke variabele (de duurzaamheid van het stedelijk vervoer) wordt geoperationaliseerd door middel van een "Green Transport Index" (GTI), gemaakt door de auteur, die drie afzonderlijke dimensies van duurzaamheid onderhoudt: ecologisch, economisch en sociaal.

Het plan van aanpak voor dit onderzoek bestaat uit een tweedelig onderzoek analyse die onderverdeeld is in een initiële empirische karakterisering van het stedelijk vervoer in zestien Latijns-Amerikaanse steden, en een vergelijkende studie analyse die betrekking heeft op de drie bovengenoemde steden. De initiële karakterisering wordt uitgedrukt als 'Green Transport Index' en wordt gebruikt om de steden te selecteren die een rol spelen in de tweede fase van het onderzoek, waar beperkte generalisaties over de rol van de politieke en institutionele voorwaarden over het duurzame transport worden gegenereerd. De studie is zo ontworpen dat beide delen elkaar complimenteren.

Dit proefschrift toont een verklarende essentie geworteld in een bewijs voerend onderzoek aanpak. Zowel de index als de studie resultaten bewijzen zeer beleidsbepalend te zijn voor partijen in de regio. Als eerste is dit proefschrift gericht op de totstandkoming van een steeds terugkerende oefening, uiteindelijk kan deze dienen als 'benchmark', en tegelijkertijd politieke partijen stimuleren om duurzaam transport in hun beleidsvorming na te streven in de regio. Als tweede zal dit proefschrift bijdragen aan het identificeren van duurzame voorwaarden die geldt voor het stedelijk vervoer van de onderzochte steden.

De afgelopen twee decennia zijn de discussies, over wat duurzaam vervoer inhoudt, sterk toegenomen. Vandaag de dag hebben we voldoende wetenschappelijke overeenstemming over de kernpunten op dit gebied, maar de werkelijke vooruitgang op de grond blijft zeer beperkt; in het bijzonder de duurzame ontwikkeling van wereldsteden. Dit proefschrift laat zich niet uit over de verantwoordelijkheid van de politiek in de ontbrekende 
koppeling tussen theorie en praktijk. In veel Latijns-Amerikaanse steden is het bijvoorbeeld beleidsvorming dat vaak wordt gekenmerkt door een scheiding van politieke retoriek en beleidsbepalingen; terwijl de overheid over meerdere geografische schalen functioneert. Hoewel bepaalde planning kwesties coördinatie vereisen op grootstedelijke schaal, het uiteindelijke resultaat is een direct gevolg van de traditionele politieke dynamiek van de regio.

Deze trends vormen zorgwekkende vooruitzichten voor de stedelijke duurzaamheid van Latijns-Amerika, zoals de regio worstelt met extra uitdagingen op het gebied van armoede, de overheidsfinanciën, en geweld, onder andere. Voor deze en andere redenen is dit gedetailleerd omschreven in dit proefschrift, daarnaast zijn alle onderzoeksinspanningen gericht op deze regio, met de bedoeling om een debat te initiëren over de benodigde maatregelen vanuit de regering, in een sector en regio, die vaak niet meegenomen worden in globale scenario studies.

Dit onderzoek geeft een vernieuwde kijk op de vooruitzichten van de duurzaamheid van het vervoer in de Latijns-Amerikaanse steden. Terwijl de 'Green Transport Index' de prestaties van zestien grote steden rangschikt over de economische, sociale en milieu aspecten, en dit heeft de macht om te worden gebruikt als maatstaf door politieke partijen en andere belanghebbenden in de regio. Aan de andere kant, de studie fase legt de fundering voor een grondige vergelijking van de drie gekozen steden, die was gebaseerd op een unieke dataset opgebouwd uit primaire gegevens rechtstreeks overgenomen door de auteur, via vooraanstaande expert interviews. De conclusies van deze fase beschrijven de voorwaarden die zijn toegestaan om Curitiba hoog te rangschikken in de GTI, Medellín te rangschikken met een gemiddelde, en Guadalajara laag te rangschikken, in vergelijking met elkaar.

Daarnaast worden er een aantal strategische uitgangspunten aangeboden, waaronder het verstrekken van beperkte generalisaties van de bevindingen die vervolgens kunnen worden toegepast op andere steden in de regio. Dit markeert de verbinding tussen de afhankelijke en de onafhankelijke variabelen in deze studie. Ten eerste worden er betere grootstedelijke overheidsovereenkomsten afgesloten wat resulteert in hogere niveaus van duurzaamheid in transport in de desbetreffende onderzochte steden. Ten tweede, zijn de politieke omstandigheden belangrijker dan de financiële omstandigheden waardoor re een toenemende mate van de stedelijke duurzaamheid van het vervoer in de hedendaagse Latijns-Amerika ontstaat. 
Ten derde, eerder genomen overheidsbeslissingen bepalen de doorvoering van het belangrijkste stedelijk vervoer, en daarmee kunnen de niveaus van duurzaamheid worden verhoogd. 


\section{Curriculum Vitae}

Carlos Cadena Gaitán was born in 1983, in Medellín, Colombia, where he studied at the local Montessori school. He obtained a B.A (Summa Cum Laude) in Business from the McCamish School of Business at Reinhardt University, where he was chosen to offer the valedictory address. He also holds an MPA from the Andrew Young School of Policy Studies at Georgia State University.

Prior to joining the $\mathrm{PhD}$ programme at the Maastricht University - United Nations University in Maastricht, Mr. Cadena Gaitán accumulated experience in public, private, and not-for-profit organizations in Medellín, Atlanta, New York and Washington D.C. He is a weekly op-ed contributor to media outlets such as El Mundo, Las 2 Orillas, and TeleMedellín; an activity which he combines with his work for La Ciudad Verde, a think tank advocating for urban sustainability in Colombia, and for the Yoga|Art|Innovation gallery Humanese in Envigado, Colombia. 


\section{MGSoG Dissertation Series}

Katie Kuschminder

Female Return Migration and Reintegration Strategies in Ethiopia

MGSoG Dissertation Series, nr 42 (2014)

Metka Hercog

Highly-Skilled Migration and New Destination Countries

MGSoG Dissertation Series, nr 41 (2014)

Margaret Agaba Rugadya

Can Remittances Influence the Tenure and Quality of Housing in Uganda?

MGSoG Dissertation Series, nr 40 (2014)

Ilire Agimi

New Governance Under Limited Statehood

The Case of Local Government Reform in Kosovo

MGSoG Dissertation Series, nr 39 (2014)

Kristine Farla

Empirical Studies on Institutions, Policies and Economic Development

MGSoG Dissertation Series, nr 38 (2013)

Marina Petrovic

Social Assistance and Activation in the Pursuit of Happiness:

Shedding New Light on Old Policy Solutions to Social Exclusion

MGSoG Dissertation Series, nr 37 (2013)

Laura Torvinen

Assessing Governance Assessments; The Case of Mozambique

Governance Assessments in the Context of Aid Effectiveness Discourse

MGSoG Dissertation Series, nr 36 (2013)

Biniam Egu Bedasso

Institutional Change in the Long Shadow of Elites

Essays on Institutions, Human Capital and Ethnicity in Developing Countries 
MGSoG Dissertation Series, nr 35 (2013)

Sepideh Yousefzadeh Faal Deghati

Childhoods Embargoed

Constructing and Reconstructing Multidimensional Child Poverty in Iran 1984-2009

MGSoG Dissertation Series, nr 34 (2013)

Robert Bauchmüller

Investing in Early Childhood Care and Education:

The Impact of Quality on Inequality

MGSoG Dissertation Series, nr 33 (2013)

Martin Rehm

Unified Yet Separated

Empirical Study on the Impact of Hierarchical Positions within Communities of Learning

MGSoG Dissertation Series, nr 32 (2013)

Dorcas Mbuvi

Utility Reforms and Performance of the Urban Water Sector in Africa

MGSoG Dissertation Series, nr 31 (2012)

Lina Salanauskaite

Distributional Impacts of Public Policies:

Essays in Ex-Ante and Ex-Post Evaluation

MGSoG Dissertation Series, nr 30 (2012)

Esther Schüring

To Condition or not - is that the Question?

An Analysis of the Effectiveness of Ex-Ante and Ex-Post Conditionality in Social

Cash Transfer Programs

MGSoG Dissertation Series, nr 29 (2012)

Joe Abah

Strong Organisations in Weak States

Atypical Public Sector Performance in Dysfunctional Environments 
MGSoG Dissertation Series, nr 28 (2012)

Zina Samih Nimeh

Social Citizenship Rights: Inequality and Exclusion

MGSoG Dissertation Series, nr 27 (2012)

Lenka Eisenhamerová

Legitimacy of 'Humanitarian Military Intervention'

MGSoG Dissertation Series, nr 26 (2011)

Sonila Tomini

Informal Payments for Health Care Services in Albania

MGSoG Dissertation Series, nr 25 (2011)

Jinjing Li

Dynamic Microsimulation in Public Policy Evaluation

MGSoG Dissertation Series, nr 24 (2011)

Aziz Atamanov

Rural Nonfarm Employment and International Migration as Alternatives to

Agricultural Employment:

The Case of Kyrgyztan

MGSoG Dissertation Series, nr 23 (2011)

Frieda Vandeninden

Poverty Alleviation: Aid and Social Pensions

MGSoG Dissertation Series, nr 22 (2011)

Juliana Nyasha Tirivayi

The Welfare Effects of Integrating AIDS Treatment with Food Transfers:

Evidence from Zambia

MGSoG Dissertation Series, nr 21 (2011)

Agnieska Ewa Sowa

Who's Left Behind? Social Dimensions of Health Transition and Utilization of Medical Care in Poland 
MGSoG Dissertation Series, nr 20 (2011)

Emmanaouil Sfakianakis

The Role of Private Actors in the Provision of Public Goods with Applications to Infrastructure and Financial Stability

MGSoG Dissertation Series, nr 19 (2011)

Siu Hing Lo

White Collars Green Sleeves

An Interonganizational Compariso of Deteminants of Energie-Related Behaviors among Office Workers

MGSoG Dissertation Series, nr 18 (2011)

Treena Wu

Constraints to Human Capital Investment in Developing Countries:

Using the Asian Financial Crisis in Indonesia as a Natural Experiment

MGSoG Dissertation Series, nr 17 (2011)

Henry Espinoza Peña

Impact Evaluation of a Job-Training Programme for Disadvantaged Youths:

The Case of Projoven

MGSoG Dissertation Series, nr 16 (2011)

Florian Tomini

Between Family and Friends

Understanding the Interdependency of Private Transfers

MGSoG Dissertation Series, nr 15 (2010)

Michał Polalowski

The Institutional Transformation of Social Policy in East Central Europe:

Poland and Hungary in comparative and historical perspective

MGSoG Dissertation Series, nr 14 (2010)

Maha Ahmed

Defining, Measuring and Adressing Vulnerability:

The Case of Post Conflict Environments 
MGSoG Dissertation Series, nr 13 (2010)

Pascal Beckers

Local Space and Economic Success

The role of spatial segregation of migrants in the Netherlands

MGSoG Dissertation Series, $\mathrm{nr} 12$ (2010)

Victor Cebotari

Complicting Demands in Ethnically Diverse Societies

Ethnopolitical Contention and Identity Values in Europe

MGSoG Dissertation Series, nr 11 (2010)

Dennis Gyllensporre

Competing and Complementary Perspectives on the EU as a Crisis Management

Actor:

An Examination of the Common Security and Defence Policy through the Lenses of Idealism and Realism

MGSoG Dissertation Series, $\mathrm{nr} 10$ (2010)

Judit Vall Castello

Business Cycle and Policy Effects on Labour Market Transitions of Older and

Disabled Workers in Spain

MGSoG Dissertation Series, nr. 9 (2010)

Keetie Roelen

False Positives or Hidden Dimentions: the definition and measurement of child poverty

MGSoG Dissertation Series, nr. 8 (2010)

Denisa Maria Sologon

Earning Dynamics in Europe

MGSoG Dissertation Series, nr. 7 (2010)

Melissa Siegel

Money and Mobility: Migration and Remittances

MGSoG Dissertation Series, nr. 6 (2010) 
Jessica S. Hagen-Zanker

Modest Expectations: Causes and effects of migration on migrant households in source countries

MGSoG Dissertation Series, nr. 5 (2010)

Mirtha R. Muniz Castillo

Human Development and Autonomy in Project Aid: Experiences from four bilateral projects in Nigaragua and El Salvador MGSoG Dissertation Series, nr. 4 (2009)

Christiane Arndt

Governance Indicators

MGSoG Dissertation Series, nr. 3 (2009)

Britta Augsburg

Microfinance - Greater Good or Lesser Evil?

MGSoG Dissertation Series, nr. 2 (2009)

Geranda Notten

Measuring and Managing Poverty Risks

MGSoG Dissertation Series, nr. 1 (2008) 